[Insert ANU logo and running head]

Contact: Dr Liz Curran

Senior Lecturer, ANU Legal Workshop (Australia-wide Professional Legal Training) \& Assoc. Director International Centre for the Profession, Education and Regulation in Law (PEARL), Australian National University, College of Law.

Mobile 0404106614

Email Liz.Curran@anu.edu.au

Canberra ACT 0200 Australia (Melbourne based)

www.anu.edu.au

CRICOS Provider No. 00120C. ORCID ID 0000-0002-6371-2975

\title{
Draft Working Paper for a Research and Evaluation Report for the Bendigo Health- Justice Partnership: A partnership between ARC Justice Ltd and Bendigo Community Health Services
}

\section{December 2016}

\section{by Dr Liz Curran, Australian National University ${ }^{1}$}

Full Final \& Abridged Reports to be released in 2017.

'I sleep better at night.' (Interview with Client)

\footnotetext{
${ }^{1}$ Thanks for the assistance of Dr Robert Southgate, Project Research Assistant, clients, external agencies and staff of LCCLC and BCHS for their participation and facilitation of the research for this research evaluation report.
} 
[Insert ANU logo and running head]

Contact: Dr Liz Curran

Senior Lecturer, ANU Legal Workshop (Australia-wide Professional Legal Training) \& Assoc. Director International Centre for the Profession, Education and Regulation in Law (PEARL), Australian National University, College of Law.

Mobile 0404106614

Email Liz.Curran@anu.edu.au

Canberra ACT 0200 Australia (Melbourne based)

www.anu.edu.au

CRICOS Provider No. 00120C. ORCID ID 0000-0002-6371-2975

\section{Acknowledgements}

Mr Peter Noble, former Executive Officer (EO) of Advocacy and Rights Centre Ltd (t/a ARC Justice) Bendigo and Ms Chris Sedgman, Acting EO, ARC Justice

Ms Kim Sykes, CEO, Bendigo Community Health Services

Dr Robert Southgate, Project Research Assistant

BCH Staff and Management, and Project Participants

ARC Justice Staff and Management, and Project Participants

Clients and Community Focus Group Participants for their insights

Advisers to the Project: Professor Mary Anne Noone, School of Law, La Trobe University, and Dr Alex Philips, Quality Control Co-coordinator, Research Evaluation \& Development, Banyule Community Health (advice on social determinants of health)

Clayton Utz Foundation

RE Ross Trust

Research Support Unit \& Finance Division, ANU College of Law

ANU, Human Ethics Support Unit

Professor Liz Tobin-Tyler, Assistant Professor of Family Medicine and Health Services, Policy and Practice, The Warren Alpert Medical School of Brown University, Brown University School of Public Health

Ellen Lawton, JD, National Centre for Medical-Legal Partnerships, the Milken Institute School of Public Health, George Washington University

Thanks to my Directors at ANU, my close family and friends for their support during the sometimes challenging moments over the three years of this project.

In memory of my brother Nick who passed away during the final stages of this project. May these findings go some way to bringing justice, health, peace and wellbeing to others who suffer as you did. 
[Insert ANU logo and running head]

Contact: Dr Liz Curran

Senior Lecturer, ANU Legal Workshop (Australia-wide Professional Legal Training) \& Assoc. Director International Centre for the Profession, Education and Regulation in Law (PEARL), Australian National University, College of Law.

Mobile 0404106614

Email Liz.Curran@anu.edu.au

Canberra ACT 0200 Australia (Melbourne based)

www.anu.edu.au

CRICOS Provider No. 00120C. ORCID ID 0000-0002-6371-2975

[Designer: Please insert page numbers where indicated by ' XXX'. Please vertically align these numbers.]

\section{Contents}

Executive Summary $\quad X X X$ (To be included in Full Final Report in 2017)

Definitions $\quad X X X$

Glossary XXX

PART ONE - Service Context and Background XXX

Chapter One - Service Context: Community Legal Centres and Community Health Centres in Australia XXX

Chapter Two - Background to the Health-Justice Partnership Research and Evaluation (HJPRAE) XXX

Chapter Three - The Literature Review XXX

Chapter Four - Methodology XXX

PART TWO - Field Research XXX

Chapter Five - Phase One: The Community Focus Group (February 2015) XXX

Chapter Six - Phase Two: Snapshot One (Trial of Research Methodology and Mine for Recurrent Themes, 20 April - 1 May 2015) XXX

Chapter Seven - Phase Three: Snapshot Two (9-13 November 2015) XXX

Chapter Eight - Phase Four: Snapshot Three (6-10 June 2016) XXX

PART THREE - Aggregated Data XXX

Chapter Nine - Aggregated Quantitative Data for the HJPRAE XXX

Chapter Ten - Aggregated Qualitative Data, Analysis and Discussion XXX

Chapter Eleven - Professional Cultures, Ethics, Collaborative Measurement

Tool's Application and Need for Economic Modelling/Costings on Impact XXX

PART FOUR - Overall Findings, Learnings, Conclusions and Recommendations XXX

Chapter Twelve - Overall Findings $\quad$ XXX 
[Insert ANU logo and running head]

Contact: Dr Liz Curran

Senior Lecturer, ANU Legal Workshop (Australia-wide Professional Legal Training) \& Assoc. Director International Centre for the Profession, Education and Regulation in Law (PEARL), Australian National University, College of Law.

Mobile 0404106614

Email Liz.Curran@anu.edu.au

Canberra ACT 0200 Australia (Melbourne based)

www.anu.edu.au

CRICOS Provider No. 00120C. ORCID ID 0000-0002-6371-2975

Chapter Thirteen - Lessons Emerging for other HJP and MDP More Broadly: 'Informing Replicable Models' XXX

Chapter Fourteen - Conclusions and Recommendations XXX

References $\quad X X X$

Appendix A - Bendigo Community Health Services $\quad X X X$

Appendix $B-A R C$ Justice $\quad X X X$

Appendix C-Community Focus Group Summary $\quad X X X$

Appendix D-Curran Collaborative Measurement Tool $\quad X X X$

Appendix E-Tools and Questions $\quad X X X$ 
[Insert ANU logo and running head]

Contact: Dr Liz Curran

Senior Lecturer, ANU Legal Workshop (Australia-wide Professional Legal Training)

$\&$ Assoc. Director International Centre for the Profession, Education and Regulation in Law (PEARL), Australian National University, College of Law.

Mobile 0404106614

Email Liz.Curran@anu.edu.au

Canberra ACT 0200 Australia (Melbourne based)

www.anu.edu.au

CRICOS Provider No. 00120C. ORCID ID 0000-0002-6371-2975 
[Insert ANU logo and running head]

\section{Contact: Dr Liz Curran}

Senior Lecturer, ANU Legal Workshop (Australia-wide Professional Legal Training) \& Assoc. Director International Centre for the Profession, Education and Regulation in Law (PEARL), Australian National University, College of Law.

Mobile 0404106614

Email Liz.Curran@anu.edu.au

Canberra ACT 0200 Australia (Melbourne based)

www.anu.edu.au

CRICOS Provider No. 00120C. ORCID ID 0000-0002-6371-2975

\section{[Designer: Footnotes to be renumbered from '1' for each new section/chapter.]}

\section{Definitions}

Health-Justice Partnership - HJPs see lawyers working alongside health and allied health professionals in a multi-disciplinary practice so as to reach clients with a range of problems capable of legal solutions who are more likely to turn to a health or allied health professional with problems which may have a legal solution (e.g., debt, family violence, poor housing, consumer issues, care and protection, human rights, access to services).

Advocacy - In this report, advocacy has a broad meaning. It is not limited to representation of a client in a court of law or tribunal. It also includes advocacy that may involve negotiating, mediation, conflict conferencing, facilitation and/or putting an argument, or explaining a client's situation or the legal position to decision-makers, authorities, government personnel or companies.

'Mixed Model of Legal Aid' - Unlike the predominantly private practitioner ('judicare') models of legal aid service delivery in Britain and New Zealand, Australia has a 'mixed model' where LAS are concerned. This means legal assistance services are provided by a blend of salaried and private practitioners. The mixed model resulted from a 'market failure' by private law firms to take on more time-intensive and lessprofitable legal assistance work. It was considered critical that service delivery be combined with responsiveness to systemic issues to solve causes of problems and to deliver substantive legal equality. ${ }^{2}$

National Legal Aid - This is an informal association formed of all the Directors of legal aid commissions around Australia to work strategically on issues to do with quality legal services and access to justice.

Early Intervention and Prevention - Early intervention is defined in the National Partnership Agreement (NPA) as legal services provided by LAS to help people resolve their legal problems before they escalate. This includes providing legal advice, minor assistance and advocacy other than that provided under a grant of legal assistance. Early intervention, as it is used in this report, applies more broadly than how it has been defined in the NPA and some other government documents such as the 'Strategic

\footnotetext{
${ }^{2}$ Noone, M \& Tomsen, S. (2006), Lawyers in Conflict: Australian Lawyers and Legal Aid, The Federation Press, New South Wales, p. 228.
} 
[Insert ANU logo and running head]

\section{Contact: Dr Liz Curran}

Senior Lecturer, ANU Legal Workshop (Australia-wide Professional Legal Training) \& Assoc. Director International Centre for the Profession, Education and Regulation in Law (PEARL), Australian National University, College of Law.

Mobile 0404106614

Email Liz.Curran@anu.edu.au

Canberra ACT 0200 Australia (Melbourne based)

www.anu.edu.au

CRICOS Provider No. 00120C. ORCID ID 0000-0002-6371-2975

Framework on Access to Justice in the Federal Civil Justice'. ${ }^{3}$ In this report, 'early intervention and prevention' are defined to encompass the original wider meaning. It may include legal mechanisms but also includes problem-solving at early stages to prevent escalation or the problem arising at all. It sits within a context of health promotion (noting that the author has been trained for over a decade in health promotion approaches by Banyule Community Health). ${ }^{4}$ At the local level, health promotion involves community development as a commonly used strategy. This involves informing the process of community needs assessment, and is one of the starting points for most local programs. Public consultation is also routine in the development of health promotion policy. It is predicated on comprehensive, sustained programs that address determinants of major public health problems and can succeed in improving the health status of the population. Emphasis is on policy, advocacy, intersectional action and action at a local level to assist, inform and support communities. ${ }^{5}$ If a service is engaging, then people are likely to seek the help they need at the times they need it. For example, consider a 'Men's Shed' program in a community health centre (CHC). Men with mental illness, such as agoraphobia, gather together to work on a task such as fixing bikes. This sees them feel safe out of home, socialising with other people, and then services can better engage with them in their treatment. However, the term 'early intervention and prevention' is commonly used by justice officials to imply an action that reduces people's use of the court system. This report maintains that early intervention and prevention operates more broadly than this.

Multi-Disciplinary Practice - As referred to in this report, this is where a range of professionals work together in one practice to holistically work on a range of problems using their different professional skills and approaches to resolve problems in an integrated and effective way. It sees the client as a person with a range of issues that may be interconnected, overlap and need a range of professionals to resolve them working in collaboration.

Proxies - These are acknowledged in social, public health and economic research as a measurement tool. Proxies are indicators or benchmarks, and if present in this data are suggestive of the existence of a positive outcome. These indicators in this research

\footnotetext{
${ }^{3}$ See Attorney-General, 'Strategic Framework on Access to Justice in the Federal Civil Justice System', available at:

https://www.ag.gov.au/LegalSystem/Documents/A\%20Strategic\%20Framework\%20for\%20Access $\% 2$ 0to\%20Justice\%20in\%20the\%20Federal\%20Civil\%20Justice\%20System.pdf

${ }^{4}$ Thanks to Victoria Smith, Health Promotion Project, formerly Banyule Community Health.

${ }^{5}$ Wise, M \& Signal, L (2000), 'Health promotion development in Australia and New Zealand', vol. 15, no. 3, Health Promotion International, Oxford University Press, pp. 242-6.
} 
[Insert ANU logo and running head]

Contact: Dr Liz Curran

Senior Lecturer, ANU Legal Workshop (Australia-wide Professional Legal Training) \& Assoc. Director International Centre for the Profession, Education and Regulation in Law (PEARL), Australian National University, College of Law.

Mobile 0404106614

Email Liz.Curran@anu.edu.au

Canberra ACT 0200 Australia (Melbourne based)

www.anu.edu.au

CRICOS Provider No. 00120C. ORCID ID 0000-0002-6371-2975

consist of four proxies which if present are indicative of a possible positive impact they may have had on client social determinants of health and a positive standard of service. They denote the elements required for an effective, quality service and are derived in this research from studies and literature in humanitarian, therapeutic and public health spheres (namely engagement, capacity, collaboration and empowerment). (See Chapter Four, on methodology, for further detail.)

Legal Assistance Services in Australia - This refers to the full range of services provided by legal aid commissions, community legal centres, Aboriginal and Torres Strait Islander legal services and family violence prevention services.

Pro Bono - Free or voluntary services.

Snapshots - This is where data is collected in a short time period with a view to having insights in such periods. This can then be extrapolated in order to learn about what might be occurring during the life of a project, during the periods when the snapshot is not occurring. Snapshots tend to be less resource intensive than onerous ongoing data collection can be, especially where there are limited staff resources and where the funding for the actual research and evaluation is limited. 
[Insert ANU logo and running head]

Contact: Dr Liz Curran

Senior Lecturer, ANU Legal Workshop (Australia-wide Professional Legal Training) \& Assoc. Director International Centre for the Profession, Education and Regulation in Law (PEARL), Australian National University, College of Law.

Mobile 0404106614

Email Liz.Curran@anu.edu.au

Canberra ACT 0200 Australia (Melbourne based)

www.anu.edu.au

CRICOS Provider No. 00120C. ORCID ID 0000-0002-6371-2975

\section{Glossary}

\section{[Designer: Please vertically align all the glossary term definitions.]}

AOD Alcohol and Drug

ARC Justice Advocacy and Rights Centre Ltd (t/a ARC Justice) Bendigo

BCH Banyule Community Health

BCHS Bendigo Community Health Services

CHC Community Health Centre

CiP Changes in Practice

CLC Community Legal Centre

CLE Community Legal Education

CLSISCommunity Legal Services Information System

CSDH Commission on Social Determinants of Health

DHHS Child protection within the Department of Health and Human Services, Victoria; formerly known as the Department of Human Services (DHS)

ECD Early Childhood Development

EI\&P Early Intervention and Prevention

HJP Health-Justice Partnership

HJPRAE Health-Justice Partnership Research and Evaluation

ILEC International Legal Ethics Conference

ILAG International Legal Aid Conference

KF Kangaroo Flat

LAS Legal Assistance Services

LCCLC Loddon Campaspe Community Legal Centre

LSC Legal Secondary Consultations

MDP Multi-Disciplinary Practice

MLP Medical-Legal Partnerships (what HJPs are called in the USA)

NACLC National Association of Community Legal Centres

NCMLP National Center for Medical-Legal Partnership, USA (Washington, DC)

NLA National Legal Aid

PD Professional Development 
[Insert ANU logo and running head]

Contact: Dr Liz Curran

Senior Lecturer, ANU Legal Workshop (Australia-wide Professional Legal Training) \& Assoc. Director International Centre for the Profession, Education and Regulation in Law (PEARL), Australian National University, College of Law.

Mobile 0404106614

Email Liz.Curran@anu.edu.au

Canberra ACT 0200 Australia (Melbourne based)

www.anu.edu.au

CRICOS Provider No. 00120C. ORCID ID 0000-0002-6371-2975

SDH Social Determinants of Health

UK United Kingdom

USA United States of America

WHO World Health Organization 
[Insert ANU logo and running head]

\section{Contact: Dr Liz Curran}

Senior Lecturer, ANU Legal Workshop (Australia-wide Professional Legal Training) \& Assoc. Director International Centre for the Profession, Education and Regulation in Law (PEARL), Australian National University, College of Law.

Mobile 0404106614

Email Liz.Curran@anu.edu.au

Canberra ACT 0200 Australia (Melbourne based)

www.anu.edu.au

CRICOS Provider No. 00120C. ORCID ID 0000-0002-6371-2975

'I now know that sometimes when the department says it's a "No" to my client, that they may be wrong and I feel better able to question it, as the legal advice shows me a "No" is often a "Maybe". ' (In-depth interview with Community Health Nurse, April 2015)

'Poverty and low living standards are powerful determinants of ill health and health inequity. They have significant consequences for ECD and lifelong trajectories, among others, through crowded living conditions, lack of basic amenities, unsafe neighbourhoods, parental stress and lack of food security. Child poverty and transmission of poverty from generation to generation are major obstacles to improving population health and reducing health inequity.' (Commission on Social Determinants of Health, 2007, 84) 
[Insert ANU logo and running head]

\section{Contact: Dr Liz Curran}

Senior Lecturer, ANU Legal Workshop (Australia-wide Professional Legal Training) \& Assoc. Director International Centre for the Profession, Education and Regulation in Law (PEARL), Australian National University, College of Law.

Mobile 0404106614

Email Liz.Curran@anu.edu.au

Canberra ACT 0200 Australia (Melbourne based)

www.anu.edu.au

CRICOS Provider No. 00120C. ORCID ID 0000-0002-6371-2975

\section{PART ONE - Service Context and Background}

\section{[Designer: Footnotes to be renumbered from '1' for each new chapter.] \\ Chapter One - Service Context: Community Legal Centres and Community Health Centres in Australia}

Research by the Legal Services Research Centre (UK) ${ }^{6}$ and the Legal Australia-Wide (LAW) Survey ${ }^{7}$ demonstrates that unresolved legal problems are likely to have a deleterious impact on stress and health outcomes. For 15 years the author has researched, written and worked as a practitioner in integrated and collaborative contexts of legal service delivery. This experience suggested multi-disciplinary practice (MDP) as effective in reaching vulnerable and disadvantaged people and for collaborative work for systemic change that improves outcomes in terms of access to justice for community. This view was informed by both her academic research and her own work as a practitioner for a decade in a legal service that was co-located with a health service in one of the poorest postcodes in Australia: the first Health-Justice Partnership (HJP) in Australia, established in 1975. The author (and Noone) had written about this approach to service delivery and other overseas research for many years. ${ }^{8}$ There was, however, a

\footnotetext{
${ }^{6}$ Balmer, NJ, Pleasence, P, Buck, A \& Walker, HC (2006), 'Worried sick: The experience of debt problems and their relationship with health, illness and disability', Social Policy and Society, vol. 5, no. 1, pp. 39-51; Pleasence, P \& Balmer, NJ (2009), 'Mental health and the experience of social problems involving rights: Findings from the United Kingdom and New Zealand', Psychiatry, Psychology and Law, vol. 16, no. 1, pp. 123-40; Pleasence, P, Balmer, NJ \& Buck, A (2008), 'The health cost of civillaw problems: Further evidence of links between civil-law problems and morbidity, and the consequential use of health services', Journal of Empirical Legal Studies, vol. 5, no. 2, pp. 351-73; and Pleasence, P, Balmer, NJ, Buck, A, O’Grady, A \& Genn, H (2004a), 'Civil law problems and morbidity', Journal of Epidemiology and Community Health, vol. 58, no. 7, pp. 552-7.

${ }^{7}$ Coumarelos, C, MacCourt, D, People, J, McDonald, HM, Wei, Z, Iriana, R \& Ramsey, S (2012), 'Access to Justice and Legal Needs: Legal Australia-Wide Survey Legal Need in Australia', Law and Justice Foundation of New South Wales, Sydney, p. 27, available at: http://www.lawfoundation.net.au/ljf/site/templates/LAW_AUS/\$file/LAW_Survey_Australia.pdf. ${ }^{8}$ Curran, L (2007a), 'Ensuring Justice and Enhancing Human Rights: A Report on Improving Legal Aid Service Delivery to Reach Vulnerable and Disadvantaged People', La Trobe University, Melbourne, available at: http://libertyvictoria.org/sites/default/files/Report\%20-\%20Ensuring\%20Justice\%20and\%20Enhancing \%20Human\%20Rights.pdf; Curran, L (2007b), 'Making the Legal System More Responsive to Community: A Report on the Impact of Victorian Community Legal Centre (CLC) Law Reform Initiatives', West Heidelberg Community Legal Service, West Heidelberg, Vic.; Curran, L (2008), 'Relieving some of the legal burdens on clients: Legal aid services working alongside psychologists
} 
[Insert ANU logo and running head]

\section{Contact: Dr Liz Curran}

Senior Lecturer, ANU Legal Workshop (Australia-wide Professional Legal Training) \& Assoc. Director International Centre for the Profession, Education and Regulation in Law (PEARL), Australian National University, College of Law.

Mobile 0404106614

Email Liz.Curran@anu.edu.au

Canberra ACT 0200 Australia (Melbourne based)

www.anu.edu.au

CRICOS Provider No. 00120C. ORCID ID 0000-0002-6371-2975

gap in the empirical evidence base that might exist to confirm this view. There was a critical need to determine whether there is an empirical basis for whether HJP and MDP are effective and the impact of MDP such as HJP on clients, community and service providers, and to determine what works well or not so well and why not. The Bendigo HJP Research and Evaluation (HJPRAE) presented an opportunity for the author and the Advocacy and Rights Centre Ltd (trading as ARC Justice and hereinafter referred to as ARC Justice), to build the evidence base to discover whether HJP and MDP are an effective model of service delivery.

Noone has written extensively on the value of integrated service delivery and conducted research on the topic in 2008-10. ${ }^{9}$ In the UK, other research has examined and suggested that 'one-stop shops', co-located and integrated legal services are effective ways of reaching clients. ${ }^{10}$

In the past two years, the seminal evidence-based LAW Survey commissioned by National Legal Aid (NLA) (August 2012), ${ }^{11}$ The Allen's Review of the Legal

and other health and social service professionals', The Australian Community Psychologist, vol. 20, no. 1, pp. 47-56; Curran, L \& Noone, M (2007), 'The challenge of defining unmet legal need', Journal of Law and Social Policy, vol. 21, no. 1, pp. 63-89; and Noone, MA, \& Digney, K (2010), “'It's Hard to Open up to Strangers" - Improving Access to Justice: The Key Features of an Integrated Legal Services Delivery Model', La Trobe University Rights and Justice Program Research Report, available at SSRN: http://ssrn.com/abstract=1799648

${ }^{9}$ Noone, MA, \& Digney, K (2010), “It's Hard to Open up to Strangers" - Improving Access to Justice: The Key Features of an Integrated Legal Services Delivery Model', La Trobe University Rights and Justice Program Research Report, available at SSRN: http://ssrn.com/abstract=1799648; Noone, MA (2009), 'Towards an integrated service response to the link between legal and health issues', Australian Journal of Primary Health, vol. 15, pp. 203-11; and Noone, MA (2012), 'Integrated legal services: Lessons from West Heidelberg Community Legal Service', Alternative Law Journal, vol. 37, no. 1, p. 26, available at SSRN: http://ssrn.com/abstract=2030556 or http://dx.doi.org/10.2139/ssrn.2030556

${ }^{10}$ Buck, A, Smith, M, Sidaway, J \& Scanlon, L (2010), 'Piecing It Together: Exploring One-stop Shop Legal Service Delivery on Community Legal Advice Centres', Legal Services Commission, London; and Moorhead, R, Robinson, M \& Matrix Research and Consultancy (2006), 'A Trouble Shared: Legal Problems Clusters in Solicitors' and Advice Agencies', DCA research series, no. 8/2006, Department of Constitutional Affairs, London.

${ }^{11}$ Coumarelos, C, MacCourt, D, People, J, McDonald, HM, Wei, Z, Iriana, R \& Ramsey, S (2012), 'Access to Justice and Legal Needs: Legal Australia-Wide Survey Legal Need in Australia', Law and Justice Foundation of New South Wales, Sydney, p. 27, available at: http://www.lawfoundation.net.au/ljf/site/templates/LAW_AUS/\$file/LAW_Survey_Australia.pdf 
[Insert ANU logo and running head]

\section{Contact: Dr Liz Curran}

Senior Lecturer, ANU Legal Workshop (Australia-wide Professional Legal Training) \& Assoc. Director International Centre for the Profession, Education and Regulation in Law (PEARL), Australian National University, College of Law.

Mobile 0404106614

Email Liz.Curran@anu.edu.au

Canberra ACT 0200 Australia (Melbourne based)

www.anu.edu.au

CRICOS Provider No. 00120C. ORCID ID 0000-0002-6371-2975

Assistance Services' National Partnership Agreement (July 2014) ${ }^{12}$ and the Productivity Commission's inquiry into 'Access to Justice Arrangements' (December 2014) ${ }^{13}$ have all affirmed the virtues of co-location, integrated legal service with nonlegal service delivery and effective outreach as valuable and instrumental if access of justice and improved outcomes are to be attained for the most disadvantaged of clients. ${ }^{14}$

It is important to note that, unlike the UK and Canada, there has been little significant funding for research on advice-seeking behaviour and the legal assistance sector in Australia. This lack of funding in Australia for legal services research has been identified as an issue by the Australian Productivity Commission. ${ }^{15}$ The New South Wales Law and Justice Foundation did some work in the 2000s but this was largely specific to New South Wales. It was not until the work was commissioned by NLA, through a cobbling together of various funding sources (after repeated requests for over a decade for government to fund such research were declined), that such evidencebased national research has been conducted on any scale in Australia. This has been complemented by further recent research by Cunneen et al. in 2012 on Aboriginal and Torres Strait Islander legal needs. ${ }^{16}$

Since August 2014 and alongside this Bendigo HJPREA, the author has been advising the Victorian Legal Services Board (LSB) and Commissioners in the development of

\footnotetext{
${ }^{12}$ Allen Consulting Group (2014), 'Review of the National Partnership Agreement on Legal Assistance Services, Final Report', June, Allen Consulting Group, Melbourne, Australia, available at: http://www.acilallen.com.au/cms_files/NPA\%20Review_LAS\%20report_final.pdf

${ }^{13}$ Australian Government Productivity Commission (2014), 'Access to Justice Arrangements, Final Report', no. 72, September, Australian Government Productivity Commission, Canberra, available at http://www.pc.gov.au/inquiries/completed/access-justice/report

${ }^{14}$ See Australian Government Productivity Commission (2014), 'Access to Justice Arrangements' (draft report - overview), Australian Government Productivity Commission, Canberra, p. 2, available at: http://www.pc.gov.au/projects/inquiry/access-justice/draft; and Allen Consulting Group (2014), 'Review of the National Partnership Agreement on Legal Assistance Services, Final Report', June, Allen Consulting Group, Melbourne, Australia, available at: http://www.acilallen.com.au/cms_files/NPA\%20Review_LAS\%20report_final.pdf ${ }_{15}$ Australian Government Productivity Commission (2014), 'Access to Justice Arrangements, Final Report', no. 72, September, Australian Government Productivity Commission, Canberra, vol. 2, chapter 23, available at http://www.pc.gov.au/inquiries/completed/access-justice/report

${ }^{16}$ Schwarz, M, Allison, F \& Cunneen, C (2013a), 'A Report of the Australian Indigenous Legal Needs Project', James Cook University, Cairns, available at: http://www.jcu.edu.au/ilnp/public/groups/everyone/documents/technical_report/jcu_131180.pdf; and Schwarz, M, Allison, F \& Cunneen, C (2013b), 'The Civil and Family Law Needs of Indigenous People in Victoria', James Cook University, Cairns.
} 
[Insert ANU logo and running head]

\section{Contact: Dr Liz Curran}

Senior Lecturer, ANU Legal Workshop (Australia-wide Professional Legal Training) \& Assoc. Director International Centre for the Profession, Education and Regulation in Law (PEARL), Australian National University, College of Law.

Mobile 0404106614

Email Liz.Curran@anu.edu.au

Canberra ACT 0200 Australia (Melbourne based)

www.anu.edu.au

CRICOS Provider No. 00120C. ORCID ID 0000-0002-6371-2975

common measures of outcomes in HJP settings. The LSB is a statutory authority which regulates the legal profession and uses the interest accrued on solicitors' trust accounts for grants. These grants are assessed upon application of a model for funding of service innovations. ${ }^{17}$ The LSB funds eight HJPs (not including the Bendigo HJP). The author and LSB have recently published a report which also draws upon the findings of the Bendigo HJPREA and on the authors' other HJP evaluations (many still in progress). ${ }^{18}$ For international readers of this report, the Victorian LSB is not a 'tender board' for private lawyers providing legal aid but is more akin to a philanthropy with a grants program and is a regulator for the legal profession. It is not a procurer of legal aid services and so is not comparable to the English Legal Services Agencies or the Legal Services Corporation in the USA.

Unlike the United States, where historically the health system has been provided by private providers (noting the recent ObamaCare model is in development), the main health provision in Australia is publicly funded through a universal healthcare system called Medicare. There are some private health providers, but these are mainly for services where people want a choice of hospital provider or a private room. Therefore, given the universal public access to health care in Australia, there are not the same problems with accessing health care as experienced in the United States. As a consequence, this has often been a focus of many Medical-Legal Partnerships (MLPs) historically in the USA ${ }^{19}$ although this has been changing due to ObamaCare. In Australia, the focus of HJPs is on broader legal problems that patients/clients face, such as income security, debt, housing conditions, discrimination, family violence and so on, rather than on access to health care or the inability to pay for private health care. The HJPs in Australia do not take on medical negligence cases due to the conflict of interest ${ }^{20}$ that this would present to the HJP model, compromising the relationships on which HJPs are reliant. Such matters are referred out.

\footnotetext{
${ }^{17}$ The author discloses that she is also a grants assessor from time to time for the LSB.

${ }^{18}$ Curran, L \& the Victorian Legal Services Board and Commissioner (2016), 'Health-Justice Partnership Development Report', available at: http://www.lsbc.vic.gov.au/documents/ReportHealth_Justice_Partnership_Development-2016.PDF; and the Redfern Legal Centre, 'Aboriginal Health-Justice Partnership, Redfern Legal Centre and Sydney Area Health District, Six Month Evaluation', December 2015, available at: www.redfern legalcentre.org.au

${ }^{19}$ Discussions between the National Centre for Medical Legal Partnerships, Washington, DC and the author on 21 July 2016.

${ }^{20}$ Gyorki, L (2013), 'Breaking Down the Silos: Overcoming the Practical and Ethical Barriers of Integrating Legal Assistance into a Healthcare Setting', Inner Melbourne Community Legal Centre and The Churchill Trust Fellowship, available at: https://www.churchilltrust.com.au/media/fellows/Breaking_down_the_silos_L_Gyorki_2013.pdf
} 
[Insert ANU logo and running head]

\section{Contact: Dr Liz Curran}

Senior Lecturer, ANU Legal Workshop (Australia-wide Professional Legal Training) \& Assoc. Director International Centre for the Profession, Education and Regulation in Law (PEARL), Australian National University, College of Law.

Mobile 0404106614

Email Liz.Curran@anu.edu.au

Canberra ACT 0200 Australia (Melbourne based)

www.anu.edu.au

CRICOS Provider No. 00120C. ORCID ID 0000-0002-6371-2975

In Australia, there is not a government-set procurement contractual basis for Legal Assistance Services (LAS) as there is in other jurisdictions such as the UK, USA and New Zealand. In Australia, similarly to Canada, there is what is termed a 'mixed model' of LAS, with the private profession gaining grants for legal aid administered by statutory legal aid commissions in each Australian state or territory which also undertakes its own legal work, legal education and law reform and so on, itself engaging in direct service delivery rather than being solely a 'tender board'.

Alongside legal aid, and as a complement, there are community legal centres (CLCs) which are publicly funded, with a legal assistance sector required as part of their 'core services' under a National Partnership Agreement (negotiated between the services, states and Commonwealth Government) to provide information, advice, casework representation, community and professional legal education, law reform and policy work. Again, this is to be distinguished from the UK model where law centres are contracted for specific service or service types as determined by government agencies. In Australia, services are guided and responsive to client and community needs and are led and informed by this rather than by content in a procurement contract as in the UK. CLC funding is shared between the Commonwealth and state governments, and with some philanthropic funding. So it is not analogous to systems of legal aid funding in the USA, the UK and New Zealand. Australia is more akin to the law clinics in Canada. For this reason, it sees less fragmentation as casework can inform legal education and policy responses in a more cohesive and connected way than procurement contracts administered by agencies isolated from direct service delivery. This enables the building up of expertise and strategic responses in assisting the disadvantaged, and also enables casework-informed policy and legal education as they are all undertaken simultaneously in the one setting rather than fragmented through different service providers conducting this work in isolation. ${ }^{21}$ As Australia has a different legal assistance delivery model, it is important to note the different contexts, but there are still many learnings that can be shared across jurisdictions from this report. Still, it is important to be mindful and cautious as different jurisdictions have different settings, cultures and histories in relation to service delivery and so innovations need to be in the contexts of each jurisdiction. The purpose of this Full Final Report is to share the results and findings of the research and evaluation of the Bendigo HJP and developments both nationally across Australia and internationally. As research is ongoing and occurring

\footnotetext{
${ }^{21}$ Curran, L (2013f), 'The Strategic Approach to Legal Problem Solving - Examples, Processes \& Strategies', Legal Workshop, Australian National University College of Law, available at: http://www.plelearningexchange.ca/database/solving-problems-strategic-approach-examplesprocesses-strategies/
} 
[Insert ANU logo and running head]

\section{Contact: Dr Liz Curran}

Senior Lecturer, ANU Legal Workshop (Australia-wide Professional Legal Training) \& Assoc. Director International Centre for the Profession, Education and Regulation in Law (PEARL), Australian National University, College of Law.

Mobile 0404106614

Email Liz.Curran@anu.edu.au

Canberra ACT 0200 Australia (Melbourne based)

www.anu.edu.au

CRICOS Provider No. 00120C. ORCID ID 0000-0002-6371-2975

across a range of HJPs worldwide, and given some of the measurement challenges, it is a work in progress but it is hoped this research will assist other programs. It is hoped this Final Research and Evaluation Report will add to the body of work around effective legal and health and social service delivery that assists in bringing about positive outcomes in the social determinants of health (SDH) for clients and community.

To provide further context, this HJP model sits in a community health centre (CHC) context and is provided by a CLC by a publicly funded, salaried community lawyer.

\section{Community Legal Centres}

The peak body of CLCs, the National Association of Community Legal Centres (NACLC), described CLCs as:

'Independently operating, not-for-profit, community-based organisations that provide free legal and related services to the public, focusing on the disadvantaged and people with special needs. There are some generalist CLCs that provide services on a range of legal issues to people within their geographic area. There are some CLCs that offer specialist legal services. The clients of CLCs are those who face economic, social or cultural disadvantage, are often experiencing multiple interrelated problems, and frequently their legal problem may affect their and their family's entire life circumstances. CLCs are located throughout Australia in metropolitan, regional, rural and remote locations. They are part of their communities and respond flexibly to the changing needs of those communities, offering creative, effective and targeted solutions to legal problems ... While providing legal services to individuals, CLCs also work beyond the individual. CLCs undertake community development, community legal education, capacity building and law and policy reform projects that are based on people's needs, are preventative in outcome, and strengthen and empower the community they serve.' ${ }^{22}$

\section{Community Health Services (CHS) in Australia}

Community Health Services (CHS) also emerged in the 1970s during the Labor Whitlam government after recommendations from the Henderson Poverty Inquiry commissioned by the previous Liberal McMahon government in 1972. The 'BetterHealth' website describes CHS as follows:

'CHS sit alongside general practice and privately funded services, and other health and support services, to make up the majority of the primary health sector

\footnotetext{
${ }^{22}$ Source: http://www.naclc.org.au/cb_pages/clcs.php
} 
[Insert ANU logo and running head]

\section{Contact: Dr Liz Curran}

Senior Lecturer, ANU Legal Workshop (Australia-wide Professional Legal Training) \& Assoc. Director International Centre for the Profession, Education and Regulation in Law (PEARL), Australian National University, College of Law.

Mobile 0404106614

Email Liz.Curran@anu.edu.au

Canberra ACT 0200 Australia (Melbourne based)

www.anu.edu.au

CRICOS Provider No. 00120C. ORCID ID 0000-0002-6371-2975

in Victoria. State-funded primary health care predominantly refers to dental, allied health, counselling, nursing services and health promotion ... Most community health program funding supports flexibility in the delivery of services, and enables them to develop models of care that meet the needs of their local communities. However, specific initiatives deliver particular services to vulnerable population groups. Community health services focus on health promotion, and disease prevention and management, which are designed to improve the health and wellbeing of local residents, as well as take pressure off the acute care health system. ${ }^{, 23}$

Despite the common history between the two sectors, in meeting local community needs and solving systemic causes of problems, by and large, they have operated apart and often in silos - the exception being the West Heidelberg arrangements. Given the recent research discussed above, some CLCs and CHCs in Australia are considering or partnering to form HJPs to address unmet need and support of and for clients/patients. ${ }^{24}$ They are also mindful of the research that suggests disadvantaged people, while often having multiple and complex problems, are the least likely to find legal help but may be seeing other health, allied health and social services. ${ }^{25}$

The NACLC National Census of CLCs 2015 Report $^{26}$ based on CLC service data that is required to be kept by various funders) reveals that CLCs provide free legal help to the most vulnerable and disadvantaged communities in Australia. The average proportion of Aboriginal and Torres Strait Islander clients was $15.3 \%$, clients with a disability was $26.6 \%$ and clients from a culturally and linguistically diverse background was $20.6 \%$. The top three areas of specialist advice or client groups was family violence (46\%), homelessness (41\%) and family law (40.3\%). The report notes the risks to communities associated with the 30\% cut to Commonwealth funding from 1 July 2017. CLCs reported that they are already having to turn away a high number of people due to insufficient resources. Ninety-two CLCs reported turning away 159,220 people, and

\footnotetext{
${ }^{23}$ Source:

http://www.betterhealth.vic.gov.au/bhcv2/bhcarticles.nsf/pages/Community_health_centres?open

${ }^{24}$ Coumarelos, C \& Wei, Z (2009), 'The legal needs of people with different types of chronic illness or disability', Justice Issues, no. 11, Law and Justice Foundation of NSW, Sydney.

${ }^{25}$ Coumarelos, C, MacCourt, D, People, J, McDonald, HM, Wei, Z, Iriana, R \& Ramsey, S (2012), 'Access to Justice and Legal Needs: Legal Australia-Wide Survey Legal Need in Australia', Law and Justice Foundation of New South Wales, Sydney, available at: http://www.lawfoundation.net.au/ljf/site/templates/LAW_AUS/\$file/LAW_Survey_Australia.pdf ${ }^{26}$ National Association of Community Legal Centres (2015), 'National Census Report', available at: http://www.naclc.org.au/resources/NACLC\%20Census\%20-\%20National\%20Report\%202015\%20-\%2 OFINAL.pdf
} 
[Insert ANU logo and running head]

\section{Contact: Dr Liz Curran}

Senior Lecturer, ANU Legal Workshop (Australia-wide Professional Legal Training) \& Assoc. Director International Centre for the Profession, Education and Regulation in Law (PEARL), Australian National University, College of Law.

Mobile 0404106614

Email Liz.Curran@anu.edu.au

Canberra ACT 0200 Australia (Melbourne based)

www.anu.edu.au

CRICOS Provider No. 00120C. ORCID ID 0000-0002-6371-2975

$64.4 \%$ of people turned away could not be given an appropriate, accessible and affordable referral. HJP presents an innovative way of working as a complement to these other services aimed at reaching those currently excluded.

The Bendigo Community Health Services (BCHS) provides a wide range of regional and rural community-based health and allied health services in Bendigo and the surrounding area. Appendix A sets out the service philosophy and services they provide in detail. Appendix B provides further information on the philosophy and services of ARC Justice. The two agencies that formed the HJP in Bendigo share common aims around client autonomy and empowerment, and the broader aims of alleviating poverty and systemic change. These philosophies arose from the origins of both community legal centres and community health unique to Australia emerging out of the Henderson Poverty Inquiry of the 1970s. ${ }^{27}$ The research methodology reflects and embraces the nature of the agencies' philosophies and also the nature and aims of the services.

Different services may adopt different approaches given resources and settings. In this case, this research and evaluation may be different to the research in a large hospital setting with large numbers of clients and more resources for both service provision and evaluation. Often in hospital settings there are shorter engagements and higher numbers. This project is not situated in a hospital setting where some work on developing social indicators of determinants of health has been done looking at hospital admission reductions as indicators. ${ }^{28}$ The Bendigo HJP setting is a community health setting, a very different setting. In community health settings, as in the Bendigo HJP, there is a longer engagement, an underpinning philosophy of empowerment and changes to make an equitable and just system, less client/patients than in hospitals and a longer engagement by the centre in view of the complex and often multiple issues of clients and patients.

Health centres ordinarily engage in MDP with social workers, paediatricians, psychologists and so on. What is unique here is that the HJP models bring a lawyer into the team. This report also shares findings and methods that may be used and are being used now in Australia and Canada to build common measures to build the evidence base and tell the HJP story - with a view to its sustainability. Assistance and advice from the community health sector has been critical to this research and evaluation.

\footnotetext{
${ }^{27}$ For a discussion, see Noone, M (1992), 'Imperatives for Community Legal Centres', Alternative Law Journal, vol. 17 , no. 3, pp. 120-4.

${ }^{28}$ Centers for Disease Control and Prevention, 'Social Determinants of Health', available at: http://www.cdc.gov/socialdeterminants/faq.html\#b; and Healthy People 2020 Leading Health Indicators Progress Update, available at: http://healthypeople.gov/2020/LHI/LHI-ProgressReportExecSum.pdf
} 
[Insert ANU logo and running head]

\section{Contact: Dr Liz Curran}

Senior Lecturer, ANU Legal Workshop (Australia-wide Professional Legal Training) \& Assoc. Director International Centre for the Profession, Education and Regulation in Law (PEARL), Australian National University, College of Law.

Mobile 0404106614

Email Liz.Curran@anu.edu.au

Canberra ACT 0200 Australia (Melbourne based)

www.anu.edu.au

CRICOS Provider No. 00120C. ORCID ID 0000-0002-6371-2975

\section{Chapter Two - Background to the Health-Justice Partnership Research and Evaluation (HJPRAE)}

ARC Justice, more specifically one of its programs, the Loddon Campaspe Community Legal Centre (LCCLC), and BCHS formed a partnership in 2013 with the view of starting a HJP in January 2014. The partnership was fostered to better reach those clients experiencing vulnerability and disadvantage. The aim is to assist clients who are unlikely to gain legal help and to try, through a community health setting, to influence their SDH in a positive way by resolving legal problems that can directly affect health and wellbeing. A decision was made at the management level of each partner agency to target a group of clients with specific vulnerability and whom they suspected were currently not accessing legal services. This decision was informed by the recent findings of the LAW Survey in $2012 .{ }^{29}$ This noted that the most disadvantaged were likely to have multiple legal issues but were not accessing legal services. The site at Kangaroo Flat (KF) was determined to be a place that would host the pilot HJP. The 2011 Australian Census found this area to have a significantly high proportion of low incomes in the City of Greater Bendigo. ${ }^{30}$

Three teams were identified as providing the catchment of clients for the HJP model:

1. Counselling and Family Services: comprising of social workers, general counsellors and family counsellors working with children and families to strengthen their capacity and resilience, outside of the formal child protection system

2. Child Health Invest: including child counsellors, Alcohol and Drug (AOD) workers, paediatricians, social workers and nurses. Runs a specialist Autism Assessment Program. Also provides a supported play group and the services of a child advocate

3. The Early Years team: operates the Bendigo Family Day Care scheme and supports families of children with a disability aged less than six years.

Project Description - The Bendigo Health-Justice Partnership

\footnotetext{
${ }^{29}$ Coumarelos, C, MacCourt, D, People, J, McDonald, HM, Wei, Z, Iriana, R \& Ramsey, S (2012), 'Access to Justice and Legal Needs: Legal Australia-Wide Survey Legal Need in Australia', Law and Justice Foundation of New South Wales, Sydney, available at: http://www.lawfoundation.net.au/ljf/site/templates/LAW_AUS/\$file/LAW_Survey_Australia.pdf ${ }^{30}$ See Australian Bureau of Statistics, Atlas ID, http://atlas.id.com.au/bendigo\#MapNo=10039\&SexKey=4\&datatype=1\&themtype=1\&topicAlias=low -income-households\&year $=2011$
} 
[Insert ANU logo and running head]

\section{Contact: Dr Liz Curran}

Senior Lecturer, ANU Legal Workshop (Australia-wide Professional Legal Training) \& Assoc. Director International Centre for the Profession, Education and Regulation in Law (PEARL), Australian National University, College of Law.

Mobile 0404106614

Email Liz.Curran@anu.edu.au

Canberra ACT 0200 Australia (Melbourne based)

www.anu.edu.au

CRICOS Provider No. 00120C. ORCID ID 0000-0002-6371-2975

The Bendigo HJP (called an 'Advocacy-Health Alliance' (AHA) in January 2014, then changed its name in February 2015 to a 'Health-Justice Partnership') is a partnership between ARC Justice (through its program the LCCLC) and BCHS. The Bendigo HJP project aims to address the SDH capable of legal redress. As noted above, the partnership is based on the understanding that many vulnerable and disadvantaged people do not consult lawyers for problems that may be capable of a legal resolution; instead, they see their trusted health worker. The idea was that having a lawyer working alongside health workers would provide preventative and strategic advocacy to holistically address barriers to client health and wellbeing. The project was informed and supported by a related project at LCCLC focusing on the legal needs of women who experience family violence. The author evaluated this family violence project in May 2015 as part of the same contractual arrangement with ARC Justice as this HJPRAE. ${ }^{31}$

The Bendigo HJPRAE was undertaken over three years with an evaluative process embedded in the service from start-up. The author provided pro-bono advice over the summer of 2013-14 in anticipation of service start-up in January 2014, as ARC Justice had not been able to source any project funding for an evaluation at the time. In July 2014 ARC Justice was able to find philanthropic funding towards funding research and an evaluation, and the contract with the Australian National University (ANU) was signed on 28 July 2014. It is noted the project had to fit into the limited available funding for such research and evaluation rather than the available funding being adequate to support the project requirements. The Productivity Commission ${ }^{32}$ has noted the constant struggle in Australia where there is a historical reticence to fund legal services research even though government and funders often require an evidence base for proof of service project worth.

The ANU was commissioned with the author to conduct the research and develop the methodology on 28 July 2014 when ARC Justice was able to source some limited funds for the evaluation. Project advisers were appointed as consultants to the project by ARC Justice in October 2014. Dr Robert Southgate was employed by ARC Justice in late December 2014 as a research assistant.

\footnotetext{
${ }^{31}$ Curran, L (2015a), 'Family Violence Project Evaluation Report', available at: http://lcclc.org.au/wpcontent/uploads/2015/05/Final-Evaluation-Report-LSB-Family-Violence-Curran-14-May-2015.pdf

${ }^{32}$ Australian Government Productivity Commission (2014), 'Access to Justice Arrangements, Final Report', no. 72, September, Australian Government Productivity Commission, Canberra, vol. 2, chapter 23, available at http://www.pc.gov.au/inquiries/completed/access-justice/report
} 
[Insert ANU logo and running head]

\section{Contact: Dr Liz Curran}

Senior Lecturer, ANU Legal Workshop (Australia-wide Professional Legal Training) \& Assoc. Director International Centre for the Profession, Education and Regulation in Law (PEARL), Australian National University, College of Law.

Mobile 0404106614

Email Liz.Curran@anu.edu.au

Canberra ACT 0200 Australia (Melbourne based)

www.anu.edu.au

CRICOS Provider No. 00120C. ORCID ID 0000-0002-6371-2975

The Bendigo project required the author to not only measure the impact of the service, but in 'groundbreaking' research to establish measures for positive outcomes for the SDH. The stated purpose and aims of the HJPRAE are to:

1. identify how legal interventions through the Bendigo HJP Pilot make a difference to clients' legal and health outcomes with consideration of the qualitative and quantitative data that can be captured and measured within the two-year time frame

2. document the processes and relationships developed in the Bendigo HJP Pilot and evaluate them for appropriateness, effectiveness and efficiency

3. inform future HJP pilots and projects on the pilot's critical learning relating to establishing and maintaining a HJP in an Australian context and abroad

4. determine the value, efficiency and effectiveness of an innovative approach to legal services to disadvantaged populations.

At the time of the research being commissioned in 2013, many other jurisdictions, including the USA, lamented a lack of any concrete measurement for the $\mathrm{SDH} .{ }^{33}$ The author stresses that her brief was to not merely measure service transaction or 'tick a box' of things done. The brief went further. She was asked to actually examine the impact of the HJP on client outcomes and their SDH and delve deeper into the practices that could make a difference to clients' lives and reach and resolve their issues effectively and humanely. To be able to do this, it was essential to gather significant qualitative data in addition to the more traditional quantitative data. This was a challenge given the small amount of funding for the evaluation. Accordingly, the author's time and that of the research assistant has been mainly pro bono, especially once disbursements for the field trips were costed. The challenges of the research are discussed in Chapter Four.

In addition, the further brief for the author of the HJPRAE included specific objectives which, it was reconfirmed in a meeting in August 2016, were to do the following for ARC Justice:

1. create a range of monitoring and evaluation tools, methodologies and processes drawing on the author's existing Background Intellectual Property and practice and research experience which would be developed further in line with the project brief

\footnotetext{
${ }^{33}$ Beeson, T, McCallister, BD, \& Regenstein, M (2013), 'Making the Case for Medical-Legal Partnerships: A Review of Evidence', The National Center for Medical-Legal Partnership, School of Public Health and Health Services, The George Washington University, pp. 2-13.
} 
[Insert ANU logo and running head]

\section{Contact: Dr Liz Curran}

Senior Lecturer, ANU Legal Workshop (Australia-wide Professional Legal Training) \& Assoc. Director International Centre for the Profession, Education and Regulation in Law (PEARL), Australian National University, College of Law.

Mobile 0404106614

Email Liz.Curran@anu.edu.au

Canberra ACT 0200 Australia (Melbourne based)

www.anu.edu.au

CRICOS Provider No. 00120C. ORCID ID 0000-0002-6371-2975

2. review the draft evaluation framework and methodology, incorporating qualitative and quantitative data with performance indicators and outcomes in partnership with the Bendigo HJP project partners at the commencement of 2014

3. in partnership with key stakeholders, design a data collection and assessment process, including a health and wellbeing measurement, and build on and further establish a baseline set of data

4. establish a monitoring process and interim reporting time frame for use throughout the two-year monitoring phase (the contract period)

5. develop, test and implement the research methodology with the ultimate goal of generating a replicable operating model to support the burgeoning HJP movement within Australia

6. provide the project team and funding bodies with a detailed impact assessment/empirical study that examines the appropriateness, effectiveness and efficiency of the pilot, with lessons, findings, conclusions and recommendations emerging

7. determine if the HJP project has met its objectives and reached its key priority client groups

8. present a detailed impact assessment through a Final Report (and Interim Reports at two project intervals) that examine the appropriateness, effectiveness and efficiency of the Bendigo HJP Pilot project, and measure the effects on the $\mathrm{SDH}$ and the impact on the lives of clients who are serviced by the project.

The contract also requested the following:

'The evaluation framework will need to incorporate the outcomes, objectives and outputs associated with all four elements of the project, including direct service provision, education and training, policy change and stakeholder engagement. This will require incorporating the requirements of both the health and allied health and legal sectors within the specified data collection process. It is envisaged that a proportion of clients will be asked to participate in an intensive monitoring and evaluation process that will follow their journey and document the activities and outcomes to use as case studies and to supplement the quantitative data. This will require ANU ethics approval.'

Over Christmas 2013 the author had already provided ARC Justice with preliminary advice only on the collection of baseline data and frameworks for service to administer at start-up in January 2014. This included some questions (1, 2 \& 7-21) which were to be asked in a service survey (via the online Survey Monkey software) in March 2014 
[Insert ANU logo and running head]

\section{Contact: Dr Liz Curran}

Senior Lecturer, ANU Legal Workshop (Australia-wide Professional Legal Training) \& Assoc. Director International Centre for the Profession, Education and Regulation in Law (PEARL), Australian National University, College of Law.

Mobile 0404106614

Email Liz.Curran@anu.edu.au

Canberra ACT 0200 Australia (Melbourne based)

www.anu.edu.au

CRICOS Provider No. 00120C. ORCID ID 0000-0002-6371-2975

and form a start for the baseline data for later comparisons. This in effect has meant that the author has been involved in the evaluation and project start-up for a period of three years. This longer period of time, compared with that for the usual 'pilot' projects which is often yearly or two-yearly, has enabled a longitudinal examination of the Bendigo HJP. Issues of start-up, establishment, settling in and movement, from working in silos to networks, partnerships and assessment of ingredients of each, has been enabled and is discussed in Chapters Eleven and Thirteen of this Full Final Report. (See Appendix D for the Collaborative Measurement Tool.)

In mid-August the author developed a research and evaluation framework, project logic and project plan with time lines, protocols, task and tools for measurements. This was reworked in mid- October 2014 after discussions with the project advisers.

There were two ethics body requirements. One was the BCHS (the Bendigo HJP project partner) Board and another the ANU Human Ethics Committee. Ethics approval was granted in October 2014 and March 2015 respectively, with variations in April 2015, October 2015 and April 2016. The ANU Ethics Committee asked that each component of the research be done in stages and a report be made to the committee after each phase so that they could monitor the progress before the next phase was approved. This was due to the specific vulnerability of some of the project participants and enabled opportunities for continuous reflection and improvement on the methodology while retaining consistency of measures throughout the evaluation. The limited research and evaluation funding for this project was never going to cover the time needed but it was all that was available. The author has spent over three times the contracted time on the project pro bono. It is noted that this highlights the problems in Australia, as noted above in findings of the Productivity Commission, where very little funding is available for research or evaluation of legal services. Without a commitment of pro-bono time in its absence, it becomes hard to build an empirical evidence-based framework to inform good practice. This will be discussed in the recommendations, in Chapter Fourteen. 
[Insert ANU logo and running head]

\section{Contact: Dr Liz Curran}

Senior Lecturer, ANU Legal Workshop (Australia-wide Professional Legal Training) \& Assoc. Director International Centre for the Profession, Education and Regulation in Law (PEARL), Australian National University, College of Law.

Mobile 0404106614

Email Liz.Curran@anu.edu.au

Canberra ACT 0200 Australia (Melbourne based)

www.anu.edu.au

CRICOS Provider No. 00120C. ORCID ID 0000-0002-6371-2975

\section{Chapter Three - The Literature Review}

An initial literature review was conducted by the author during late July, August and September 2014 on measuring SDH and other areas pertinent to the HJPRAE in line with the project brief (Aim 1, Objective viii). Much of the discussion in the literature was around how it might be measured rather than anyone having actually taken steps to measure it other than via a 'tick a box' approach or with very broad parameters (e.g., 'better health', 'better housing'), which would not reveal the depth or concrete impacts being sought. In 2013 and 2014 there was little literature to guide the author on how to measure the SDH.

Now, in 2016, the literature and methodologies to measure the SDH in more concrete terms are emerging, although on analysis of recent studies these are still problematic, with gaps in approach and empirical rigour, narrow exclusion criteria ${ }^{34}$ (UK) and limited responsiveness to client complexity and diversity ('Chart-IT'), all of which are conceded by their authors. Those developing these measures have all noted the challenges in measuring impact and the SDH, and have endeavoured to grapple with it and find systems to attempt to collect some common data. ${ }^{35}$ Most of the approaches are still in their infancy or trial phase whereas the HJPRAE that this report documents have been trialled, tested, conducted and concluded with a methodology in the community health and community legal centres sphere. The LSB report, mentioned earlier, has also made some headway in finding and identifying ways to find common measures for HJP impact, effectiveness and the SDH in Australia. It is, however, important to place in context that, at the time the project was being developed in 2013-14, little of the current suggestions were available. On the author's recent study tour in the USA and Canada in July 2016, she was informed that the approach undertaken in the HJPRE and by the LSB is influencing the development of measures elsewhere. ${ }^{36}$

\footnotetext{
${ }^{34}$ Low Commission (2015), 'The Role of Advice Services in Health Outcomes', June, Consilium Research and Consultancy, London, available at: http://asauk.org.uk/wpcontent/uploads/2015/06/ASA-report_Web.pdf

${ }^{35}$ See recent reports as follows: Low Commission (2015), 'The Role of Advice Services in Health Outcomes', June, Consilium Research and Consultancy, London, available at: http://asauk.org.uk/wpcontent/uploads/2015/06/ASA-report_Web.pdf; 'CHART-IT or, Capturing Health - An Attorney Reporting Tool for Impact Tracking: A Framework for Systematically Documenting the Impact of Legal Assistance on the Health of Low Income Individuals and Families', Medical Legal Partnership Illinois, hard copy handed to the author in Canada on 7 July 2016; and National Center for MedicalLegal Partnership (2015), Performance Measures Handbook, August, available at: http://medicallegalpartnership.org/resources/

${ }^{36}$ For example, see http://www.plelearningexchange.ca/resources/needs_evaluations/; http://canadianepc.org/files/CBA-Access-to-Justice-Metrics.pdf;
} 
[Insert ANU logo and running head]

\section{Contact: Dr Liz Curran}

Senior Lecturer, ANU Legal Workshop (Australia-wide Professional Legal Training) \& Assoc. Director International Centre for the Profession, Education and Regulation in Law (PEARL), Australian National University, College of Law.

Mobile 0404106614

Email Liz.Curran@anu.edu.au

Canberra ACT 0200 Australia (Melbourne based)

www.anu.edu.au

CRICOS Provider No. 00120C. ORCID ID 0000-0002-6371-2975

The author had experience in measuring the outcomes and effectiveness of the service and service quality ${ }^{37}$ - measuring the impact of the service on the SDH for the clients of the service was new. The extension of the project scope to include the examination and measurement of the impact of the HJP on the SDH (Aim 1, Objective viii) was seen as challenging in the literature reviewed in 2014.

\section{Why Is a Health-Justice Partnership Necessary?}

1. Individuals only consult lawyers for about $16 \%$ of their legal problems and a key access point for disadvantaged individuals is the health profession. ${ }^{38}$

2. Legal problems have a detrimental impact on the health and wellbeing of individuals. ${ }^{39}$

3. A collaborative, multi-disciplinary approach to problem-solving can be effective in improving health outcomes for vulnerable individuals. ${ }^{40}$

http://internationallegalaidgroup.org/index.php/papers-publications/conference-papers-

reports/category/5-edinburgh-2015-conference-papers; and http://ohrh.law.ox.ac.uk/realizing-the-rightto-health-for-the-most-disadvantaged/

The author presented a conference paper at the International Legal Aid Conference in Edinburgh in June 2015 on preliminary findings from the HJPRAE. As a result, the Executive Director, Community Advocacy and Legal Centre, Ontario, Canada, who was in attendance at the conference, was 'inspired' to start up four HJPs. The author has been providing them with pro-bono advice on start-up and evaluation.

${ }^{37}$ Curran, L (2012b), "We Can See There's Light at the End of the Tunnel Now": Demonstrating and Ensuring Quality Service to Clients', Legal Aid ACT, Canberra, available at: http://www.legalaidact.org.au/pdf/Light_at_the_end_of_the_Tunnel_Legal_Aid_Services_Quality_and _Outcomes.pdf

${ }^{38}$ Coumarelos, C, MacCourt, D, People, J, McDonald, HM, Wei, Z, Iriana, R \& Ramsey, S (2012), 'Access to Justice and Legal Needs: Legal Australia-Wide Survey Legal Need in Australia', Law and Justice Foundation of New South Wales, Sydney, available at: http://www.lawfoundation.net.au/ljf/site/templates/LAW_AUS/\$file/LAW_Survey_Australia.pdf

${ }^{39}$ Pleasence, P \& Balmer, NJ (2009), 'Mental health and the experience of social problems involving rights: Findings from the United Kingdom and New Zealand', Psychiatry, Psychology and Law, vol. 16, no. 1, pp. 123-40; Pleasence, P, Balmer, NJ \& Buck, A (2008), 'The health cost of civil-law problems: Further evidence of links between civil-law problems and morbidity, and the consequential use of health services', Journal of Empirical Legal Studies, vol. 5, no. 2, pp. 351-73; and Pleasence, P, Balmer, NJ, Buck, A, O’Grady, A \& Genn, H (2004a), 'Civil law problems and morbidity', Journal of Epidemiology and Community Health, vol. 58, no. 7, pp. 552-7.

${ }^{40}$ Noone, MA, \& Digney, K (2010), “It's Hard to Open up to Strangers” - Improving Access to Justice: The Key Features of an Integrated Legal Services Delivery Model', La Trobe University Rights and Justice Program Research Report, available at SSRN: http://ssrn.com/abstract=1799648 
[Insert ANU logo and running head]

\section{Contact: Dr Liz Curran}

Senior Lecturer, ANU Legal Workshop (Australia-wide Professional Legal Training) \& Assoc. Director International Centre for the Profession, Education and Regulation in Law (PEARL), Australian National University, College of Law.

Mobile 0404106614

Email Liz.Curran@anu.edu.au

Canberra ACT 0200 Australia (Melbourne based)

www.anu.edu.au

CRICOS Provider No. 00120C. ORCID ID 0000-0002-6371-2975

A key access point for individuals seeking assistance with their problems are the health and allied health professions. Having a lawyer/legal service providing advice and casework alongside and integrated with health services can be effective in improving health outcomes for vulnerable individuals. ${ }^{41}$ As noted earlier in Chapter One, findings of the former Legal Services Research Centre in London (Balmer and Pleasence et al.) support the view that resolving people's legal problems can reduce stress factors and help health outcomes.

The Bendigo HJP is modelled on the US MLP movement ${ }^{42}$ which has been operating successfully since the mid-1990s. Peter Noble, the former Executive Officer at ARC Justice, was funded by the Clayton Utz Foundation in 2012 to research MLPs. The research report by Noble underpins the philosophy and practice of the project ${ }^{43}$ and has catalysed many similar pilots throughout Australia; it was the reason for embedding this evaluation.

MLPs broadly encompass three aims:

1. the provision of a legal service integrated into a health care setting

2. the education and training of healthcare staff to enable the effective screening and referral of clients with legal issues

3. collaboration and partnership with the healthcare team to advocate and champion systemic issues. ${ }^{44}$

As noted, the limited literature on measuring the SDH revealed one of the key challenges for the project - that there is sparse detail on how to actually measure the SDH. Even so, the existing research informed the design of the HJPRAE. ${ }^{45}$ The World

\footnotetext{
${ }^{41}$ Buck, A \& Curran, L (2009), 'Delivery of advice to marginalised and vulnerable groups: The need for innovative approaches', Public Space: The Journal of Law and Social Justice, vol. 3, pp. 1-29.

$42 \mathrm{http}: / /$ medical-legalpartnership.org/

${ }^{43}$ Noble, P (2012), 'Advocacy-Health Alliances - Better Health through Medical-legal Partnership', Loddon Campaspe Community Legal Centre \& The Clayton Utz Foundation, available at: https://advocacyhealthalliances.files.wordpress.com/2012/08/aha-report_general1.pdf

${ }^{44}$ Noble, P (2012), 'Advocacy-Health Alliances - Better Health through Medical-legal Partnership', Loddon Campaspe Community Legal Centre \& The Clayton Utz Foundation, available at: https://advocacyhealthalliances.files.wordpress.com/2012/08/aha-report_general1.pdf

${ }^{45}$ Pope, J (2012), 'Making Bendigo a Child Friendly City: A Set of Indicators of Child and Young People's Well-Being to Galvanise Action', Department of Planning and Community, St Luke's, Bendigo, Vic., available at: https://www.stlukes.org.au/File.axd?id=9bea31a7-a4bc-4a03-86e7b28dc69c5a94; Victorian Health Care Association (2014), Health Matters, Issue 1, May, p. 5, available at: http://www.vha.org.au; Loddon Campaspe Community Profile, available at: http://www.communityprofile.com.au/loddonmallee; and World Health Organization (WHO) and Commission on Social Determinants of Health (2008), 'Closing the Gap in a Generation: Health Equity
} 
[Insert ANU logo and running head]

\section{Contact: Dr Liz Curran}

Senior Lecturer, ANU Legal Workshop (Australia-wide Professional Legal Training) \& Assoc. Director International Centre for the Profession, Education and Regulation in Law (PEARL), Australian National University, College of Law.

Mobile 0404106614

Email Liz.Curran@anu.edu.au

Canberra ACT 0200 Australia (Melbourne based)

www.anu.edu.au

CRICOS Provider No. 00120C. ORCID ID 0000-0002-6371-2975

Health Organization (WHO) stresses through its Commission on Social Determinants of Health (CSDH) that outcomes can only occur when systemic issues such as poverty, inequity, access and resourcing of services and government policies are also addressed. For this reason, and in line with the contract brief to examine policy change, the project examined collaborations which involve systemic responses. ${ }^{46} \mathrm{WHO}$ note that much of the literature discusses the conceptual frameworks necessary for measurement and gaps in existing evidence-based approaches, but does not tackle the concrete 'how to's in measurement of SDH at a micro level that can inform services and programs more broadly. This HJP evaluation tackles this gap.

In the USA, HJP are called Medical-Legal Partnerships. The National Center for Medical-Legal Partnership (NCMLP) in April 2014 put out for exposure a draft on measurement of SDH and sought comment on some outcomes. Broad measures like 'better health outcomes, better housing' and 'better income' identified as SDH measures in the literature did not provide enough information about what these things mean or constitute for the HJPRAE. ${ }^{47}$ The HJPRAE sought to identify specific outcomes which are both more specific, broken down and hence more meaningful. ${ }^{48}$ It did this by seeking the views of the community. This grounded the research. Such an approach was taken in consultation with the project's adviser in public health to ensure measures are not too remote from the lived experiences of the clients to whom the service is seeking to assist and could be identified with more precision, concreteness and relevance as to client impacts.

through Action on Social Determinants of Health', pp. 28, 33, 36, available at: http://whqlibdoc.who.int/publications/2008/9789241563703_eng.pdf?ua=1.

${ }^{46}$ World Health Organization (WHO) and Commission on Social Determinants of Health (2008),

'Closing the Gap in a Generation: Health Equity through Action on Social Determinants of Health', pp. 37, 39, available at: http://whqlibdoc.who.int/publications/2008/9789241563703_eng.pdf?ua=1; and

Commission on Social Determinants of Health, 'Frequently Asked Questions - What Are Social Determinants of Health?', available at: http://www.cdc.gov/socialdeterminants/faq.html\#h

${ }^{47}$ National Center for Medical-Legal Partnership and Milken Institute School of Public Health, George Washington University (2014), 'Background and Related Information about the MLP Measures Development Process', 9 July, copy provided to the author; see also http://medicallegalpartnership.org/wp-content/uploads/2014/07/MLP-Metrics-background-memo-FINAL.pdf ${ }^{48}$ Beeson, T, McCallister, BD, \& Regenstein, M (2013), 'Making the Case for Medical-Legal Partnerships: A Review of Evidence', The National Center for Medical-Legal Partnership, School of Public Health and Health Services, The George Washington University, pp. 7-8; and Medical-Legal Partnership Literature Matrix, Department of Health Policy, School of Health and Health Policy, George Washington University, February 2013 (copies provided to the author on 28 July 2014). 
[Insert ANU logo and running head]

\section{Contact: Dr Liz Curran}

Senior Lecturer, ANU Legal Workshop (Australia-wide Professional Legal Training) \& Assoc. Director International Centre for the Profession, Education and Regulation in Law (PEARL), Australian National University, College of Law.

Mobile 0404106614

Email Liz.Curran@anu.edu.au

Canberra ACT 0200 Australia (Melbourne based)

www.anu.edu.au

CRICOS Provider No. 00120C. ORCID ID 0000-0002-6371-2975

Further, often what was suggested to measure the SDH was whether something was done; i.e., transactional. ${ }^{49}$ This does not reveal what is actually happening for the clients in terms of their SDH as a result of service intervention, as is required by the HJPRAE project brief (See Item 1 of the HJPRAE Project Aims discussed in Chapter Two).

The public health literature is helpful in that it indicates that there can be proxy measures which, if present, suggest a positive impact is being achieved in respect of the SDH. ${ }^{50}$ As a consequence, this project included the use of proxies in its design. An example of this is that if an isolated person starts to be engaged in a community-based program such as a 'Men's Shed' and has regular attendance, this demonstrates he is less socially isolated, less likely to be depressed, and is an indicator that his mental health and wellbeing are improved.

'Poverty and low living standards are powerful determinants of ill health and health inequity. They have significant consequences for ECD and lifelong trajectories, among others, through crowded living conditions, lack of basic amenities, unsafe neighbourhoods, parental stress, and lack of food security. Child poverty and transmission of poverty from generation to generation are major obstacles to improving population health and reducing health inequity. ${ }^{, 51}$

Noone $^{52}$ conducted a research evaluation of a co-located legal and health service, producing a significant report that heavily informed the HJPRAE. ${ }^{53}$ The purpose of the research was different to the aims of this project but it was a useful study.

\footnotetext{
${ }^{49}$ For an example, see Healthy People 2020 Leading Health Indicators Progress Update, available at: http://healthypeople.gov/2020/LHI/LHI-ProgressReport-ExecSum.pdf

${ }^{50}$ World Health Organization (WHO) and Commission on Social Determinants of Health (2008), 'Closing the Gap in a Generation: Health Equity through Action on Social Determinants of Health', available at: http://whqlibdoc.who.int/publications/2008/9789241563703_eng.pdf?ua=1; and Healthy People 2020 Leading Health Indicators Progress Update, available at: http://healthypeople.gov/2020/LHI/LHI-ProgressReport-ExecSum.pdf

${ }^{51}$ World Health Organization (WHO) and Commission on Social Determinants of Health (2008), 'Closing the Gap in a Generation: Health Equity through Action on Social Determinants of Health', available at: http://whqlibdoc.who.int/publications/2008/9789241563703_eng.pdf?ua=1, p. 84.

${ }^{52}$ Noone, MA, \& Digney, K (2010), “It's Hard to Open up to Strangers”- Improving Access to Justice: The Key Features of an Integrated Legal Services Delivery Model', La Trobe University Rights and Justice Program Research Report, available at SSRN: http://ssrn.com/abstract=1799648

${ }^{53}$ The author discloses that she was Director of the legal service at the time of the 2010 research.
} 
[Insert ANU logo and running head]

\section{Contact: Dr Liz Curran}

Senior Lecturer, ANU Legal Workshop (Australia-wide Professional Legal Training) \& Assoc. Director International Centre for the Profession, Education and Regulation in Law (PEARL), Australian National University, College of Law.

Mobile 0404106614

Email Liz.Curran@anu.edu.au

Canberra ACT 0200 Australia (Melbourne based)

www.anu.edu.au

CRICOS Provider No. 00120C. ORCID ID 0000-0002-6371-2975

Also, Dr Marsha Regenstein's ${ }^{54}$ suggestions informed the project's design, namely the development of measures for MLPs as follows:

\section{Stages of Measures Development}

1. Understand the landscape.

2. Review the relevant literature.

3. Collect tools and measures currently used in the field.

4. Identify a framework for measuring the impact of MLP activities.

5. Develop the measures.

6. Assess the draft measures.

7. Broader review of measures.

8. Field test the measures.

9. Go live with the measures.

\section{Identifying a Framework}

Social Determinants Theory:

- complex, integrated structures, health inequities

- $\quad$ perception of health must be cross-disciplinary

- $\quad$ supports primary health care and promotes prevention

- framework leads to questions about health and social welfare impacts.

Regenstein, Beeson et al. ${ }^{55}$ have conducted a literature review in the area of evaluating MLPs and conclude that the measurement of the SDH, which this research evaluation is seeking to explore, are complex and that there is a dearth of concrete measures available to determine these in the setting in which the HJP sits. And so often these are expressed broadly as they have been in the table below, described as 'Outcomes'.

\section{TABLE 3.1}

\footnotetext{
${ }^{54}$ Regenstein, M (2014), 'Developing Measures for Medical-Legal Partnership', 10 April, National Center for Medical-Legal Partnership, Milken Institute of Public Health, The George Washington University (PDF provided to the author in April 2014).

${ }^{55}$ Beeson, T, McCallister, BD, \& Regenstein, M (2013), 'Making the Case for Medical-Legal Partnerships: A Review of Evidence', The National Center for Medical-Legal Partnership, School of Public Health and Health Services, The George Washington University, pp. 2-13.
} 
[Insert ANU logo and running head]

\section{Contact: Dr Liz Curran}

Senior Lecturer, ANU Legal Workshop (Australia-wide Professional Legal Training) \& Assoc. Director International Centre for the Profession, Education and Regulation in Law (PEARL), Australian National University, College of Law.

Mobile 0404106614

Email Liz.Curran@anu.edu.au

Canberra ACT 0200 Australia (Melbourne based)

www.anu.edu.au

CRICOS Provider No. 00120C. ORCID ID 0000-0002-6371-2975

\begin{tabular}{|c|c|c|}
\hline Process Measures & $\begin{array}{l}\text { Legal/Service } \\
\text { Measures }\end{array}$ & $\begin{array}{c}\text { Intermediate Health } \\
\text { Measures }\end{array}$ \\
\hline $\begin{array}{l}\text { Client was appropriately } \\
\text { screened for legal needs }\end{array}$ & $\begin{array}{l}\text { Client's legal issue is } \\
\text { resolved/unresolved }\end{array}$ & $\begin{array}{l}\text { Client increased access to } \\
\text { health services }\end{array}$ \\
\hline $\begin{array}{l}\text { Legal needs were } \\
\text { appropriately identified }\end{array}$ & $\begin{array}{l}\text { Client obtained or } \\
\text { maintained household } \\
\text { income }\end{array}$ & $\begin{array}{l}\text { Client reduced emergency } \\
\text { room use }\end{array}$ \\
\hline $\begin{array}{l}\text { Appropriate referral was } \\
\text { provided }\end{array}$ & $\begin{array}{l}\text { Client received retroactive } \\
\text { benefits }\end{array}$ & $\begin{array}{l}\text { Increase in number of } \\
\text { clients with regular } \\
\text { provider }\end{array}$ \\
\hline Client obtained legal help & $\begin{array}{l}\text { Client completed/received } \\
\text { legal documentation }\end{array}$ & $\begin{array}{l}\text { Client reduced overnight } \\
\text { hospital stay }\end{array}$ \\
\hline $\begin{array}{l}\text { Client increased } \\
\text { understanding of legal } \\
\text { rights }\end{array}$ & $\begin{array}{l}\text { Client increased access to } \\
\text { services }\end{array}$ & $\begin{array}{l}\text { Client perceived stress } \\
\text { reduced }\end{array}$ \\
\hline $\begin{array}{l}\text { Client was connected with } \\
\text { another resource }\end{array}$ & & $\begin{array}{l}\text { Client self-reported health } \\
\text { status }\end{array}$ \\
\hline $\begin{array}{l}\text { Client was satisfied with } \\
\text { services }\end{array}$ & & Client self-efficacy \\
\hline $\begin{array}{l}\text { Residents or Providers } \\
\text { received legal training }\end{array}$ & & \\
\hline $\begin{array}{l}\text { Residents or Providers } \\
\text { increased their legal } \\
\text { knowledge/understanding }\end{array}$ & & \\
\hline $\begin{array}{l}\text { Residents or Providers } \\
\text { increased confidence in } \\
\text { working with legal } \\
\text { services }\end{array}$ & & \\
\hline
\end{tabular}

Source: Regenstein (2014).

\section{FIGURE 3.1}

[Designer: Please insert a high-res version of the figure shown in the file titled Figure 3.1.] 
[Insert ANU logo and running head]

\section{Contact: Dr Liz Curran}

Senior Lecturer, ANU Legal Workshop (Australia-wide Professional Legal Training) \& Assoc. Director International Centre for the Profession, Education and Regulation in Law (PEARL), Australian National University, College of Law.

Mobile 0404106614

Email Liz.Curran@anu.edu.au

Canberra ACT 0200 Australia (Melbourne based)

www.anu.edu.au

CRICOS Provider No. 00120C. ORCID ID 0000-0002-6371-2975

The following chart from the public health sphere, provided by a senior manager at BCHS to the author, also informed the HJPRAE. It suggests that the frameworks for measuring the SDH are not isolated from each other but rather there is an interconnection between social and health and an overlap that cuts into and can affect different areas such as work, living conditions, education - and that the spheres all relevant to examination are not limited to the individual but apply also to social and community networks and the systemic environment, including socioeconomic, cultural and environmental conditions. Accordingly, the project sought to use proxies across the client, community, service provider and systemic contexts, and used the Regenstein suggestions in the MLP Logic Model above about the importance of skills training of the professional staff.

\section{FIGURE 3.2}

\section{[Designer: Please insert a high-res version of the figure shown in the file titled Figure 3.2.]}

Source: Dahlgren and Whitehead (1991).

The author has written elsewhere ${ }^{56}$ about the dangers in a legal practice sense of using the term 'client satisfaction' from a legal professional and ethical obligation and role perspective. Much of the literature examined used 'client satisfaction' as a measure, which is problematic. 'Client feedback' on the experience of the service was be used in this HJPRAE based on the author's previous research experience. ${ }^{57}$

\section{Literature Influencing the Methodology and Tools Undertaken in the HJPRAE}

Buck et al. ${ }^{58}$ in the UK informed the HJPRAE design and also informed the author's previous research evaluations for Legal Aid ACT, Consumer Action and Footscray Community Legal Service. Buck uses a triangulated methodology and has quantitative data alongside qualitative data (which explains the quantitative data) gathered through:

\footnotetext{
${ }^{56}$ Crockett, A \& Curran, L (2013a), 'A Practical Methodology for Measuring the Quality and Outcomes and Legal Assistance Services', University of Tasmania Law Review, vol. 32, no. 1, October; and Curran, L (2013c), 'Legal Review: Not All in the Statistics', Law Institute Journal, vol. 87, no. 7, July, pp. 36-9.

${ }^{57}$ Curran, L (2012b), "We Can See There's Light at the End of the Tunnel Now": Demonstrating and Ensuring Quality Service to Clients', Legal Aid ACT, Canberra, available at: http://www.legalaidact.org.au/pdf/Light_at_the_end_of_the_Tunnel_Legal_Aid_Services_Quality_and _Outcomes.pdf

${ }^{58}$ Buck, A, Smith, M, Sidaway, J \& Scanlon, L (2010), 'Piecing It Together: Exploring One-stop Shop Legal Service Delivery on Community Legal Advice Centres', Legal Services Commission, London.
} 
[Insert ANU logo and running head]

\section{Contact: Dr Liz Curran}

Senior Lecturer, ANU Legal Workshop (Australia-wide Professional Legal Training) \& Assoc. Director International Centre for the Profession, Education and Regulation in Law (PEARL), Australian National University, College of Law.

Mobile 0404106614

Email Liz.Curran@anu.edu.au

Canberra ACT 0200 Australia (Melbourne based)

www.anu.edu.au

CRICOS Provider No. 00120C. ORCID ID 0000-0002-6371-2975

observations of advice sessions; interviews with both clients and advisers immediately following the advice sessions; and follow-up, in-depth interviews with clients and advisers. Their first client interview was to examine: motivations for attending on the day and preparation for the advice session; perceptions of interacting and communicating with the adviser; perceptions of the extent to which the session went as expected; and views on the extent to which the session met advice needs.

The author notes that Buck's methodology was informed by the work of Moorhead and Robinson, ${ }^{59}$ as was the author's research for Legal Aid ACT in 2011 mentioned above. Buck and the author had also previously co-authored an article about a need for integrated legal and other services reaching out to other services and advice-seeking behaviours which informed the HJPRAE. ${ }^{60}$ The methodology was also informed and influenced by the work of Sen ${ }^{61}$ on the importance of community capability in achieving empowerment and outcomes.

Noone and Digney gathered both quantitative and qualitative data on the integrated (holistic) legal practice based at the West Heidelberg Community Legal Service (WHCLS) and Banyule Community Health (BCH). ${ }^{62}$ Their aims were:

- $\quad$ to identify key features of an integrated legal service delivery model that delivers appropriate and timely legal services to clients in an ethical and efficient manner

- to assess what facilitates and impedes the provision of an integrated legal service to clients with multiple problems.

Noone's study confirmed the importance of joint casework, Legal Secondary Consultations (LSC) between WHCLS and BCH staff, and joint community projects by WHCLS and BCH as facilitators to a holistic approach. These assist a community member with multiple and connected problems to gain help with prevalent problems. For this reason and as a result of the author's work for a decade in this West Heidelberg HJP, the HJPRAE examines the role of LSC.

In her study, Noone's methodology included the following features:

\footnotetext{
${ }^{59}$ Moorhead, R, Robinson, M \& Matrix Research and Consultancy (2006), 'A Trouble Shared: Legal Problems Clusters in Solicitors' and Advice Agencies', DCA research series, no. 8/2006, Department of Constitutional Affairs, London.

${ }^{60}$ Buck, A \& Curran, L (2009), 'Delivery of advice to marginalised and vulnerable groups: The need for innovative approaches', Public Space: The Journal of Law and Social Justice, vol. 3, pp. 1-29.

${ }^{61}$ Sen, A (2000), Development as Freedom, Anchor Books, New York.

${ }^{62}$ The author discloses that she was a Director of the legal service at the time and as such was involved in the project design and a participant in the research.
} 
[Insert ANU logo and running head]

\section{Contact: Dr Liz Curran}

Senior Lecturer, ANU Legal Workshop (Australia-wide Professional Legal Training) \& Assoc. Director International Centre for the Profession, Education and Regulation in Law (PEARL), Australian National University, College of Law.

Mobile 0404106614

Email Liz.Curran@anu.edu.au

Canberra ACT 0200 Australia (Melbourne based)

www.anu.edu.au

CRICOS Provider No. 00120C. ORCID ID 0000-0002-6371-2975

- multiple methods to collect the data, which included:

- an Advisory Group - two WHCLS solicitors, the BCH CEO, BCH community staff and Primary Care Partnership EO

- $\quad$ collection of existing data - the six-month period January-June 2009

- $\quad$ identification of referral practices

- $\quad$ formal policies and practices:

- $\quad$ staff online survey -62 responses (150 staff approx.)

- $\quad$ staff diaries - three WHCLS and six BCH

- client interviews/lawyer interviews - 30

- $\quad$ staff interviews - 12 (approx. 1 hour)

- $\quad$ staff workshop.

Her methodology and findings have also informed the formulation of the HJPRAE design by the inclusion of referral information and LSC data.

In summary, there was help from literature in the legal, health, humanitarian and community sector. These were not specific enough to concretely measure the SDH beyond those which had a tendency to focus on processes being in place, often through a 'tick a box' approach to the processes or transaction being undertaken. Such approaches were limited and were not what the author's project brief required (Aim 1, Objectives vi-viii). The HJPRAE has examined what concrete measures of SDH looked like by building on the work of those in the public community health sphere in Australia. ${ }^{63}$ ARC Justice's brief was to go beyond a process approach to also include actual outcomes and changes in the wealth and wellbeing of patients/clients, worker practices that facilitate these, and steps towards systemic reform through qualitative data as well as ensuring processes facilitate the outcomes.

The guidance from the advisory panel for this HJPRAE was that one way of ensuring that the SDH were realistic, concrete and grounded in reality, rather than remote, vague or imprecise, was by directly asking the affected community what a SDH was for them, what an outcome might look like, and what things for them would have an impact on $\mathrm{SDH}$. With this advice, the author undertook the first phase of the project which was to

\footnotetext{
${ }^{63}$ Triado, T, White, J \& Brown, A (2013), 'Community Health Quality Health Improvement Initiatives', Department of Health, available at: http://www.healthcaregovernance.org.au/docs/forum-1quality-in-vic.pdf; see also Healthy Living Network (2012), 'Healthy Communities Initiative Quality Framework Guide', Australian Government Department of Health and Aging, available at: http://www.healthylivingnetwork.com.au
} 
[Insert ANU logo and running head]

Contact: Dr Liz Curran

Senior Lecturer, ANU Legal Workshop (Australia-wide Professional Legal Training) \& Assoc. Director International Centre for the Profession, Education and Regulation in Law (PEARL), Australian National University, College of Law.

Mobile 0404106614

Email Liz.Curran@anu.edu.au

Canberra ACT 0200 Australia (Melbourne based)

www.anu.edu.au

CRICOS Provider No. 00120C. ORCID ID 0000-0002-6371-2975

inform the development of the proxies and indicators with a 'Focus Group with Community'. So this task was added to the initial Evaluation Framework as a first step to ask the community affected what they thought the SDH were and what made them engage with a service to resolve their problems, and for this to inform the project design and measurement of the SDH. 
[Insert ANU logo and running head]

\section{Contact: Dr Liz Curran}

Senior Lecturer, ANU Legal Workshop (Australia-wide Professional Legal Training) \& Assoc. Director International Centre for the Profession, Education and Regulation in Law (PEARL), Australian National University, College of Law.

Mobile 0404106614

Email Liz.Curran@anu.edu.au

Canberra ACT 0200 Australia (Melbourne based)

www.anu.edu.au

CRICOS Provider No. 00120C. ORCID ID 0000-0002-6371-2975

\section{Chapter Four - Methodology}

As noted in Chapter Three of this Full Final Report, a literature review was conducted as the first step. In discussions with the services that formed the HJP, it became important to ensure that the actual process and manner in which the HJPRAE was conducted also reflects the proxies to be measured - namely, that the process of the evaluation itself engaged, built capacity, was collaborative and empowered the project participants. Accordingly, a 'participatory action research' approach was used. Using a participatory action research approach means literature informing collaboration in design; research participation uses a 360-degree inclusion of community, clients'/patients' professionals and staff delivering the service, management and identified stakeholders in both design and as research participants. This can also verify and test results of different tools of measurement. Participatory action research has been described as a reflective process of progressive problem-solving led by individuals working as part of a 'community of practice' to improve the way they address issues and solve problems. ${ }^{64}$

Feedback on the process of the evaluation and its findings along the way, so as to enable the participants to own the project, feel able to be frank and honest and also to foster a climate of continuous reflection, learning and development, was seen as critical by the author. This meant that along the way, preliminary findings were used and shared through project debriefs and interim reports by the HJP to adjust their service model so as to improve their practice to better assist clients and professional staff.

The methodology for this HJPRAE started with detailed discussions by the author with clients, community, service providers and the agency itself from 29 July - 1 August 2014. The author presented to a number of potential stakeholders, middle management and possible research participants using PowerPoint presentations detailing the available international and national research, and aims and questions around what the HJPRAE might look like. The author sought input from those engaged in service delivery about what, in their informed view, might be some measures of an impact on the SDH.

Through three $\times$ two-hour focus groups with BCHS and ARC Justice staff and management, service materials and intake procedures and other materials were gathered and input was sought so as to inform the methodology (Project Objectives ii, iii). The discussions focused on the nature of service, the complexities of casework for lawyers and health/allied health professionals, what they thought ought to be measured, what

\footnotetext{
${ }^{64}$ See Bob Dick's Action Research and Action Learning for Community and Organisational Change website at http://www.aral.com.au
} 
[Insert ANU logo and running head]

\section{Contact: Dr Liz Curran}

Senior Lecturer, ANU Legal Workshop (Australia-wide Professional Legal Training) \& Assoc. Director International Centre for the Profession, Education and Regulation in Law (PEARL), Australian National University, College of Law.

Mobile 0404106614

Email Liz.Curran@anu.edu.au

Canberra ACT 0200 Australia (Melbourne based)

www.anu.edu.au

CRICOS Provider No. 00120C. ORCID ID 0000-0002-6371-2975

leads to an outcome in SDH and what that looks like on the ground, and finally the approach they wished to take. The research was inclusive so that the partners could also identify what would work to enable collaboration and project aims. An action research and continuous reflection and development framework was favoured. In this way the partners and participants in the research became co-designers in the methodology and approach, thereby having ownership and a voice in the process of the HJPRAE and outcomes, as the process was inclusive. They were also asked their views as to what would be relevant and concrete elements in measuring SDH based on their service experience, and their advice was sought on what tools they thought would work and would be the least burdensome of potential research participants. This process of engaging those delivering services to the community being targeted by the HJP in the how the project might be designed was very valuable and underscored the collaborative nature of the project's design.

The author decided against observational research and file reviews for a range of reasons, including the limited nature of information a file may reveal, ethical concerns in view of the vulnerability of many clients/patients, and the limitations of file review based on her practice experience in revealing the true complexity and nature of legal and community health work. This is often not captured in documents (hence the professional journal and client interview after lawyer interview approach) due to client legal privilege issues and significant cost. It may be revisited as a method in further research, especially in hospital settings where qualitative research of the kind undertaken for the HJPRAE may be too onerous.

At these meetings and focus groups, it was thought to be less burdensome for service providers (with their heavy workloads) to conduct the research in week-long snapshots at decent intervals rather than an expectation that they gather data through the whole HJPRAE. Snapshots are where data is collected in a short time period with a view to having insights in short time periods. This data can also be extrapolated in order to learn about what might be occurring during the life of a project, during the periods when the snapshot is not occurring. Snapshots tend to be less resource intensive than onerous ongoing data collection can be, especially where, like the Bendigo HJP, there are limited staff resources and where the funding for the actual research and evaluation is limited. It tends to also be less burdensome on staff than ongoing data collection, especially when qualitative data collection is entailed.

The snapshots are replicated over time; in this case, in eight-month intervals. This enables short-, medium- and longer-term comparisons in the data collected in that week. This is provided in more detail in the aggregated data in Chapters Six, Seven and Eight. There was also a firm request from those consulted for the gathering of not just quantitative data but also qualitative data to explain the former and to explain client 
[Insert ANU logo and running head]

\section{Contact: Dr Liz Curran}

Senior Lecturer, ANU Legal Workshop (Australia-wide Professional Legal Training) \& Assoc. Director International Centre for the Profession, Education and Regulation in Law (PEARL), Australian National University, College of Law.

Mobile 0404106614

Email Liz.Curran@anu.edu.au

Canberra ACT 0200 Australia (Melbourne based)

www.anu.edu.au

CRICOS Provider No. 00120C. ORCID ID 0000-0002-6371-2975

complexity. In addition, de-identified overall aggregated data from the service on numbers of clients seen, nature of matter/s and demographics from Community Legal Services Information System (CLSIS) was to be provided by ARC Justice to the author as well as referrals to and from, and numbers of LSCs undertaken by the HJP lawyer would be collected as part of the research. These initial consultations identified the actual complexities of the client groups in the different service teams and the complex nature of the HJPRAE that the author was being asked to undertake. In addition, the vulnerable nature of the client group would ensure that a complicated, careful human ethics approval process would be needed.

Critical to note is that this research evaluation does not aim to measure the impact on clients only. It was clear in the public health literature, and from the guidance of advisers, that critical in affecting positive client outcomes in general and in terms of their SDH was the engagement and capacity of their professional staff. This is also reflected in the Regenstein chart (see Chapter Three). The more professional staff are able and empowered to assist the clients/patients, the more effective the service will be. The public health advice noted that in SDH research in the public health sphere, 'intentions to change practice of professional staff' or 'changes in practice' were critical to be measured to ascertain if there is an impact on the SDH. These were incorporated into the benchmarks for the project, as were engagement, capacity and empowerment of the professional staff and collaboration. Given the complex and challenging nature of the work with vulnerable communities with complex and multiple needs, it was stressed that staff capacity, engagement and empowerment also be critical measures of service success and effectiveness. This was consistent with the literature at the time from the CSDH and UN Development Agency discussed in Chapter Three. For this reason, the professional staff - legal and non-legal - were added as a critical element in the measurement of the proxies as they too are critical in effecting change and impacting on the SDH.

\section{Snapshots}

CHCs and CLCs have few resources and already have a burdensome accounting and reporting regime. The author had used snapshots in previous evaluations to reduce the burden on already stretched front-line service providers with similar funding constraints on evaluation. The staff at BCHS and ARC Justice asked that this research be done by way of snapshots so as to minimise the burden and so as to not distract them from their casework commitments. Before each snapshot there was a lead time with training and information and consent processes to fully inform participants. Three snapshots, each of a week, over two years were designed to minimise the toll that regular data collection entails. The service's aggregated data that is already deidentified and collected is used as a complement to the snapshot data; e.g. numbers of 
[Insert ANU logo and running head]

\section{Contact: Dr Liz Curran}

Senior Lecturer, ANU Legal Workshop (Australia-wide Professional Legal Training) \& Assoc. Director International Centre for the Profession, Education and Regulation in Law (PEARL), Australian National University, College of Law.

Mobile 0404106614

Email Liz.Curran@anu.edu.au

Canberra ACT 0200 Australia (Melbourne based)

www.anu.edu.au

CRICOS Provider No. 00120C. ORCID ID 0000-0002-6371-2975

clients and referrals between the services BCHS and LCCLC. ${ }^{65}$ There were three snapshots at eight-month intervals. The project team was measuring engagement, capacity and collaboration over the life of the project as well as in the short, medium and longer term. The project team wanted to gauge shifts in the professionals engaged in the HJP and their movement from largely working in silos to see if the experience of the HJP led to changes in these areas and in their approaches to how they practise. Therefore, many of the same professionals were interviewed for each snapshot and others were interviewed for only some snapshots either because there were changes in staff or as they further engaged with the HJP. For this reason, the aggregated data over the life of the project may include data taken from the same participants. This was unavoidable given the need to measure these shifts over the life of the project. In addition, on occasion the data extracted does not mention the specific snapshot from which it is extracted. This was sometimes needed to further ensure de-identification of participants as required by the ethics approval.

\section{Process for the Conduct of the HJPRAE}

The research team (the author and research assistant) and participants in the HJPRAE were routinely asked to test the methodology after each snapshot and especially after the first trial snapshot, to ensure it was:

- $\quad$ relevant
- $\quad$ realistic
- $\quad$ supable of informing and improving practice
- $\quad$ enabling comparisons and contrasts
- $\quad$ useful

\footnotetext{
${ }^{65}$ Curran, L (2013b), 'Encouraging Good Practice in Measuring Effectiveness in the Legal Service Sector', Legal Workshop, Australian National University College of Law, 21 May, available at: http://www.plelearningexchange.ca/database/solving-problems-strategic-approach-examplesprocesses-strategies/; Curran, L (2012b), "We Can See There's Light at the End of the Tunnel Now": Demonstrating and Ensuring Quality Service to Clients', Legal Aid ACT, Canberra, available at: http://www.legalaidact.org.au/pdf/Light_at_the_end_of_the_Tunnel_Legal_Aid_Services_Quality_and _Outcomes.pdf; Crockett, A \& Curran, L (2013a), 'A Practical Methodology for Measuring the Quality and Outcomes and Legal Assistance Services', University of Tasmania Law Review, vol. 32, no. 1, October; Curran, L (2013c), 'Legal Review: Not All in the Statistics', Law Institute Journal, vol. 87, no. 7, July, pp. 36-9; Crockett, A \& Curran, L (2013b), 'A Practical Model for Measuring Effectiveness', Conference Paper, International Legal Aid Group Conference, The Hague, June, available at: http://papers.ssrn.com/sol3/cf_dev/AbsByAuth.cfm?per_id=2030109
} 
[Insert ANU logo and running head]

\section{Contact: Dr Liz Curran}

Senior Lecturer, ANU Legal Workshop (Australia-wide Professional Legal Training) \& Assoc. Director International Centre for the Profession, Education and Regulation in Law (PEARL), Australian National University, College of Law.

Mobile 0404106614

Email Liz.Curran@anu.edu.au

Canberra ACT 0200 Australia (Melbourne based)

www.anu.edu.au

CRICOS Provider No. 00120C. ORCID ID 0000-0002-6371-2975

- $\quad$ measuring what is measurable

- measuring what is in the service's ability to control

- $\quad$ a low burden and not expensive - limited funding. of sector evaluation and heavy caseloads (input from staff).

Quantitative and qualitative data were collected during the snapshots. The HJPRAE brief required significant qualitative data to examine impacts on the lives of clients. Some studies categorise qualitative data as 'anecdotal' and not worthy of inclusion or not 'rigorous' enough. ${ }^{66}$ Although time-consuming, in the author's view and that of some of BCHS health/allied health professionals, data such as this is essential in studies like this one to seek to understand complexity, human effects and explain behaviours and responses. Dismissing the lived experiences of people who rely on human services delivery as 'anecdotal' and not seeing them as direct experiential observations that have value (especially in a context of working out if services provide better health outcomes) misses a significant part of the information that underpins quantitative data and can explain patterns and the reasons for those patterns. This is especially important, as evaluations seek to find out what works and why or why not in a human services context. Accordingly, if research is to be relevant, meaningful and informative, neither approach should be dismissed to the exclusion of the other. It also risks lacking a resonance with those who actually use or deliver the service, and ensures findings and policy responses are connected to the reality of service delivery and are not remote and/or likely to be poorly targeted or tailored.

\section{Methodology for Data Analysis}

Multiple tools for measurement (i.e. triangulated tools) with a 360-degree aspect (which means the inclusion of clients, professional workers, administration staff, managers and external agencies, all interfacing with the Bendigo HJP) were used. In research, the use of multiple tools is critical to reducing bias and testing and verifying data across the tools. The three snapshots were taken eight months apart to capture short-, mediumand long-term impacts of the HJP.

As well as aggregated service data, the following occurred to enable data collection:

A. Community Focus Group (CFG) (February 2015) - to inform SDH data and the proxy development

\footnotetext{
${ }^{66}$ Low Commission (2015), 'The Role of Advice Services in Health Outcomes', June, Consilium Research and Consultancy, London, available at: http://asauk.org.uk/wpcontent/uploads/2015/06/ASA-report_Web.pdf
} 
[Insert ANU logo and running head]

\section{Contact: Dr Liz Curran}

Senior Lecturer, ANU Legal Workshop (Australia-wide Professional Legal Training) \& Assoc. Director International Centre for the Profession, Education and Regulation in Law (PEARL), Australian National University, College of Law.

Mobile 0404106614

Email Liz.Curran@anu.edu.au

Canberra ACT 0200 Australia (Melbourne based)

www.anu.edu.au

CRICOS Provider No. 00120C. ORCID ID 0000-0002-6371-2975

B. Snapshot One (a two-week trial of the methodology as well as data collection, April-May 2015) - to gather short-term project data over eight months preceding the snapshot. This phase also was designed to mine for recurrent and consistent themes across the tools and test the resonance of the proxies formulated in the CFG, from the literature and consultations with the partners discussed earlier in this chapter and in Chapter Three. Once these were identified, they were then formalised in the measurements and used as benchmark baseline data to make comparisons in and across the snapshots in both the themes examined and the proxies. Levels of stress, anxiety and hope were also identified as important factors in the measurement of the SDH and were factored into the tools and their questions (see Appendix E).

C. Staff debrief for BCHS and ARC Justice and management as an Interim Report

D. Data analysis

E. Snapshot Two (one week in November 2015: medium-term project data over eight months preceding the snapshot) - this used the proxies, themes and SDH measurements from the Snapshot One trial.

F. Data analysis

G. Interim Report

H. Snapshot Three (one week in June 2016) - this was the longer term-project data over eight months preceding the snapshot). Using the themes and proxies and the same tools but after ethics approval, some of the questions (namely question 23 of the in-depth interview with health/allied health professional staff) were developed so as to address their reflections over the life of the project using the same questions in the pre-existing tools from Snapshot One.

I. Data analysis

J. Final Report.

The tools (see Appendix E for further details) included:

- $\quad$ Client feedback questionnaires at reception after lawyer interviews

- Interviews with clients

- Interviews with reception (front of office staff are the first port of call for clients in need)

- $\quad$ Focus groups (community at project commencement and staff as an interim report back after trial to seek feedback on measures)

- $\quad$ Professional Development (PD) Evaluations (pre and post training) 
[Insert ANU logo and running head]

\section{Contact: Dr Liz Curran}

Senior Lecturer, ANU Legal Workshop (Australia-wide Professional Legal Training) \& Assoc. Director International Centre for the Profession, Education and Regulation in Law (PEARL), Australian National University, College of Law.

Mobile 0404106614

Email Liz.Curran@anu.edu.au

Canberra ACT 0200 Australia (Melbourne based)

www.anu.edu.au

CRICOS Provider No. 00120C. ORCID ID 0000-0002-6371-2975

- $\quad$ Guided professional journal - this has key questions as prompts to enable relevant data and reflection consistent with the proxies and themes (see Appendix E)

- In-depth interviews (of 2.5 hours including ethics form completion) with professional workers (with case studies of the same clients tracked in each snapshot to enable some longitudinal measure of SDH with client consent)

- $\quad$ Interviews with key relationship holders (external and managers)

- $\quad$ After files were closed, a client call-back survey

- $\quad$ Online survey professionals - at the Bendigo HJP service start-up (administered by ARC Justice) and then in the research snapshots for the short, medium, long term, focusing on professional referral patterns and capacity. Note the initial instrument was administered not by the research project team but by ARC Justice to capture service baseline data across the BCHS sites and not just at the KF site. Questions were added by ARC Justice that are not pertinent to this HJPRAE and that are in addition to those suggested by the author in December 2013 - January 2014.

- $\quad$ Collaborative Measurement Tool (developed by the author in November 2015 - January 2016, loosely based on Vic Health's Tool and other tools; see Appendix D) - this was used in August 2016 as a benchmark to see if the data aligned against the measures in it identified as stages towards or demonstrative of collaboration as a way to gauge the Bendigo HJP's progress to collaboration

- $\quad$ Aggregated service data from 7 January 2014 - 30 June 2016

- $\quad$ Case studies from qualitative tools.

\section{Overall Achievements/Outcomes}

As noted above and in the definition section of this Full Final Report, proxies were developed, and if these are demonstrated as present in the data collected they form information around any impacts the Bendigo HJP possibly may have had on the SDH and positive outcomes for clients and their health /allied health professionals. As noted, these were assessed (based on the literature and tested through participant co-design and in the CFG and Snapshot One trial of the methodology and the data that emerged). The proxies for the HJPRAE are:

- $\quad$ Proxy One - Engagement (including responsiveness of service, learning and life skills development) with clients, worker of BCHS and the Legal Services lawyer/s.

- $\quad$ Proxy Two - Capacity of clients, worker of BCHS and the Legal Services lawyer/s. 
[Insert ANU logo and running head]

\section{Contact: Dr Liz Curran}

Senior Lecturer, ANU Legal Workshop (Australia-wide Professional Legal Training) \& Assoc. Director International Centre for the Profession, Education and Regulation in Law (PEARL), Australian National University, College of Law.

Mobile 0404106614

Email Liz.Curran@anu.edu.au

Canberra ACT 0200 Australia (Melbourne based) www.anu.edu.au

CRICOS Provider No. 00120C. ORCID ID 0000-0002-6371-2975

- $\quad$ Proxy Three - Collaboration between clients, worker of BCHS and the Legal Services lawyer/s and other relevant partners. This includes integration and partnership as a shift from services previously largely working in isolation (silos) beyond mere networking (loose connections from time to time) to changes in practice and seamless, holistic practice in response to client need.

- $\quad$ Proxy Four - Empowerment, Advocacy and Voice clients, worker of BCHS and the Legal Services lawyer/s, and involvement in systemic work for change informed by on-the-ground experience. ${ }^{67}$

Other things being measured through questions in each of the tools included (not exhaustive) stress and anxiety, but for the intervention, early intervention, prevention, hope, de-escalation, holistic service, responsiveness, respect and voice.

- Qualitative and quantitative instruments with questions designed to elicit relevant data (see Appendix E) for each snapshot (with the informed consent of participants) were undertaken. A triangulated approach is being used to test and verify results between the tools and reduce bias.

- Methods for the snapshot include the 360-degree involvement of clients and professional staff, management and stakeholders.

- Interviews were conducted with clients, relationship holders, lawyers, health/allied health professionals, reception staff, managers and external agencies (the latter were identified as likely to interact with the Bendigo HJP clients by initial consultations with ARC Justice and BCHS).

The author used a scenario for the CFG based on general studies with vulnerable groups, casework experience and also on reading several BCHS annual reports. Using a scenario elicits powerful responses and reduces the risk of personal disclosure, thus minimising the risk of participants sharing confidential or embarrassing material. The author has used this approach in previous research and studies to effect. This was to allay ethics concerns. (See Appendix $\mathrm{C}$ for the detail and scenario used.)

\footnotetext{
${ }^{67}$ The author notes that on sharing these proxies at the International Legal Ethics Conference at Fordham University Law School in New York City on 16 July 2016, in a session entitled 'Interdisciplinary and Collaborative Approaches to Addressing Ethical Challenges of Vulnerable Populations', Dr Andrew P. Levin, Assistant Clinical Professor of Psychiatry Columbia University, and Dr Anthony Roberson, Associate Professor at the University of Miami, School of Nursing and Health Studies of the University of North Carolina School of Nursing and Health Studies, affirmed the author's proxy methodology as consistent and pertinent to the principles of therapeutic jurisprudence around family violence, mental health, trauma and critical for especially the notion of voice and respect in coordinated community responses.
} 
[Insert ANU logo and running head]

\section{Contact: Dr Liz Curran}

Senior Lecturer, ANU Legal Workshop (Australia-wide Professional Legal Training) \& Assoc. Director International Centre for the Profession, Education and Regulation in Law (PEARL), Australian National University, College of Law.

Mobile 0404106614

Email Liz.Curran@anu.edu.au

Canberra ACT 0200 Australia (Melbourne based)

www.anu.edu.au

CRICOS Provider No. 00120C. ORCID ID 0000-0002-6371-2975

A Staff De-Brief Focus Group by way of interim reporting on preliminary findings was also added to the methodology so the collaboration with BCHS was nurtured and they were kept informed of the results of their ongoing participation consistent with a participatory action research process.

Aggregated data on clients coming to the HJP, referrals to and from the HJP and numbers of LSCs, PD of non- legal professional (pre and post PD) with questions to determine 'practice' and 'intentions to change practice' as well as Community Legal Education (CLE) Feedback Surveys were provided by the author to the LCCLC to be administered during PD and CLE, but to the author's knowledge, none were administered.

As noted above, thematic analysis occurred after the first snapshot during data analysis by the research project team where themes were mined for recurrence across all the tools. A grid and colour code of recurrent themes was determined based on recurrence being significant in Snapshot One. In each snapshot these have been colour-coded or connected to the grid, collected. If they were demonstrated in data across the tools, six times each and then across four of the tools, in the first snapshot, they were then used as a focus for data analysis in the subsequent two snapshots. They are discussed in detail in Chapters Six through Ten. If they were evidenced, they were then each included in the 'Overall Data Shell' document. In later snapshots, if the theme was noted consistently, again, across four of the tools more than six times in each, then it was also considered significant and included in the 'Overall Data Shell' for data analysis, and some of it was used in this Full Final Report.

As noted, as the project funding was limited there was not scope in the budget for data analysis to be undertaken using a computer software program, which would have had to be purchased, staff trained and so on. Accordingly, data was captured in computer notes and handwritten notes of each researcher and these were then analysed on hard copy - with the use of Excel software, different coloured highlight pens and a grid, they were developed and used to identify themes and proxies, and recurrence and contrasts and comparisons. These were then extracted under these categories and numbered for recurrence. The Excel spreadsheet was developed by the research team - the quantitative data was dropped and quantified both in each snapshot and aggregated over the life of the project at the end.

\section{Data Capture Issues}

Data was collected, analysed and then placed in an 'Overall Data Shell' document to enable later comparison and contrast for use in future snapshots in November 2015 and June 2016. All the data from subsequent snapshots (relevant to the themes and proxies identified in the trial in Snapshot One) was later dropped into a 'Master Shell' for the 
[Insert ANU logo and running head]

\section{Contact: Dr Liz Curran}

Senior Lecturer, ANU Legal Workshop (Australia-wide Professional Legal Training) \& Assoc. Director International Centre for the Profession, Education and Regulation in Law (PEARL), Australian National University, College of Law.

Mobile 0404106614

Email Liz.Curran@anu.edu.au

Canberra ACT 0200 Australia (Melbourne based)

www.anu.edu.au

CRICOS Provider No. 00120C. ORCID ID 0000-0002-6371-2975

HJPRAE over the life of the project. It is too substantial to replicate in this Final Report as it runs to over 320 pages.

For the purpose of this Full Final Report, the author has selected the quotes, case studies and extracts from the data that are either most informative and recurrent in unpacking what works well and why or why not, or which represent the substantive views expressed. Some of the data and extracts were pertinent to more than one theme. For example, participants' extensive use and reliance on LSCs went to proxies of engagement and capacity and to comparative data analysis on movement from an 'intention to change practice' in Snapshot One to an 'actual change in practice' by Snapshot Three.

In Snapshot One, the author found that the material captured in the notes taken on the computer were summaries only and missed critical information in relation to the indicators being used to measure the SDH, quality and impact of the HJP intervention. The computer notes were supplemented and complemented by the author's contemporaneous handwritten notes and the research assistant's summary computer notes.

To ensure comprehensive data collection for Snapshots Two and Three, the author applied for an ANU Ethics Variation to enable audio recordings of the in-depth and relationship holder interviews for comprehensive data capture and cross-checking. She took detailed contemporaneous handwritten notes in the interviews in Snapshots Two and Three. These and the digital recordings have been used to supplement the summaries done on the computer taken at the time of interview.

Where quotations are used in the extracts taken from the data for this report, they are actual quotes and have either been verified against the digital recordings as correct or were noted verbatim in contemporaneous notes. This means some extracts do not have quotations, but these are reflective of the comments made rather than verbatim extracts. It was time-consuming but worthwhile to verify against the digital recordings as there was not sufficient funding for the research evaluation to fund transcription. For future HJP evaluations, funding for transcription ought to be included in the funding budget. In addition, in the Ethics Variation question 23 and reflection, responses to questions on both clients and professional staff over the life of the project were added for Snapshot Three, and for Snapshots Two and Three on stress levels. This enabled the researchers to drill down to discover the impact of stress and anxiety mentioned in Snapshot One, not just after legal advice, but for the effect of their legal problems and having the HJP intervention, personally and more broadly for example, on their family relationships. Prior to Snapshot Three, the author also sought a further Ethics Variation to enable the administration of the Collaborative Measurement Tool (see Appendix D). This will be discussed in Part Three. 
[Insert ANU logo and running head]

\section{Contact: Dr Liz Curran}

Senior Lecturer, ANU Legal Workshop (Australia-wide Professional Legal Training) \& Assoc. Director International Centre for the Profession, Education and Regulation in Law (PEARL), Australian National University, College of Law.

Mobile 0404106614

Email Liz.Curran@anu.edu.au

Canberra ACT 0200 Australia (Melbourne based)

www.anu.edu.au

CRICOS Provider No. 00120C. ORCID ID 0000-0002-6371-2975

\section{Sample Size - Clients Have Multiple, Complex Problems; Less Clients Seen}

The National Partnership Agreement (NPA) Review ${ }^{68}$ states:

'Legal Assistance Service providers are providing services to disadvantaged Australians that are relevant to the needs of this diverse and complex population. However, there are significant levels of unmet demand for LAS, particularly by the most disadvantaged, across a wide range of areas of law and service categories ... Services are, in the main, of appropriate quality. Some quality concerns were attributed to high caseloads, inexperienced staff, ability to attract and retain staff in regional and remote areas and gaps in quality assurance processes ... Constraints identified in achieving the NPA objectives related generally to costs of providing LAS, with areas of stress including staffing, changes in demand linked to government policy and provision of services to complex high-need clients, and servicing regional and remote locations ... This impacts on the provision and management of an integrated LAS sector that is well equipped to meet the legal needs of the most disadvantaged in our community.'

It is noted that only a small number of clients have been interviewed for the HJPRAE and the reason for this is adequately described in the extract above from the NPA Review. Each snapshot, as it was in the main only a week long, meant that the service had only seen a small number of clients in the snapshot period. In three cases, the clients were in such a state of distress or in crisis that, appropriately, it was decided that they were not appropriate for research interviews. This low number of clients seen is consistent with some of the studies in the USA which reveal that many HJPs target a specific vulnerable group (as with the HJP at KF which targets at-risk families with children with a disability) and low-income people with a variety of needs and barriers to be overcome. Such work is of itself time-intensive and each individual client has multiple legal issues, and previously to the HJP they had not been able to gain legal help. Such legal interviews and casework is thus bound to take more time and require intensive work to unravel and problem-solve.

'However when a family is both poor and affected by another problem such as terminal illness of a parent, substance abuse or domestic abuse the risk of instability increases. Families in this situation face many legal issues ... The

\footnotetext{
${ }^{68}$ Allen Consulting Group (2014), 'Review of the National Partnership Agreement on Legal Assistance Services, Final Report', June, Allen Consulting Group, Melbourne, Australia, pp. viii, ix, available at: http://www.acilallen.com.au/cms_files/NPA\%20Review_LAS\%20report_final.pdf
} 
[Insert ANU logo and running head]

\section{Contact: Dr Liz Curran}

Senior Lecturer, ANU Legal Workshop (Australia-wide Professional Legal Training) \& Assoc. Director International Centre for the Profession, Education and Regulation in Law (PEARL), Australian National University, College of Law.

Mobile 0404106614

Email Liz.Curran@anu.edu.au

Canberra ACT 0200 Australia (Melbourne based)

www.anu.edu.au

CRICOS Provider No. 00120C. ORCID ID 0000-0002-6371-2975

process of deciding who takes responsibility for a child in an unstable situation is complex ... at risk families have other legal issues as well ... discrimination, housing, judgement letters ... ${ }^{69}$

Where problems are complex and often intertwined with systemic issues and non-legal issues, MDP requires an investment in time and case planning and different discussions and collaboration between the different professionals working with a client. Such collaboration is also time-intensive but critical to build capacity and understanding to be able to adequately reach, engage and holistically assist clients. ${ }^{70}$ For this reason, a HJP model is likely to see fewer clients given these are often clients otherwise excluded and who, as the Bendigo HJP research shows, have not necessarily previously identified an issue as a legal problem and would not readily go to a lawyer without the support of a 'trusted intermediary'.

Even though the numbers of clients interviewed in the snapshot periods are small, and so represent a small sample, what is valuable is their explanation of the impact of the service on their health and circumstances. They also provided input on advice-seeking behaviour and what works and does not work in terms of them seeking help. This is revealed in the 10 client interviews from snapshots and in the seven longitudinal clients tracked over the life of the HJPRAE by the health/allied health professionals. There is also overall aggregated service data on the number of clients and the nature of their legal problems since service start-up, from 7 January 2015 to end June 2016, discussed in Chapter Nine.

\section{Some Conclusions about the Methodology and Cautions for Others Embarking on Such Research}

- When the client group has any possibility of vulnerability or is perceived as having risks, university ethics committees will often require 'step-by-step' ethics processes rather than granting overall approval until they are reassured about the harm. This may delay a project and will entail significant additional

\footnotetext{
${ }^{69}$ Trubek, L \& Farnham, J (2000), 'Social Justice Collaboratives: multi-disciplinary practices for people', Clinical Law Review, vol. 7, pp. 227-8.

${ }^{70}$ Tobin-Tyler, E (2008), 'Allies Not Adversaries: Teaching Collaboration to the Next Generation of Doctors and Lawyers to Address Social Inequality', Roger Williams University, School of Law Faculty Papers, Paper 17, p. 249, available at:

http://lsr.nellco.org/cgi/viewcontent.cgi?article=1017\&context=rwu_fp; and Noone, MA, \& Digney, K (2010), "It's Hard to Open up to Strangers" - Improving Access to Justice: The Key Features of an Integrated Legal Services Delivery Model', La Trobe University Rights and Justice Program Research Report, available at SSRN: http://ssrn.com/abstract=1799648
} 
[Insert ANU logo and running head]

\section{Contact: Dr Liz Curran}

Senior Lecturer, ANU Legal Workshop (Australia-wide Professional Legal Training) \& Assoc. Director International Centre for the Profession, Education and Regulation in Law (PEARL), Australian National University, College of Law.

Mobile 0404106614

Email Liz.Curran@anu.edu.au

Canberra ACT 0200 Australia (Melbourne based)

www.anu.edu.au

CRICOS Provider No. 00120C. ORCID ID 0000-0002-6371-2975

work as often the tools, information sheets and consent forms will require modification at each phase.

- $\quad$ SDH are hard to measure but it is not impossible to measure them. By and large, most of the conclusions in the report from client and professional feedback on SDH impacts are drawn on a 'it is possible that' rather than a 'if this is there, then this the conclusion'. Stating what the client identified as a consequence compared to what is a likely consequence is a common trap in qualitative analysis, and to mix what the client/participant actually said with our assumptions of what the consequences are is not necessarily correct.

- $\quad$ This project is about finding out what works and why, and what impacts on the $\mathrm{SDH}$. To have a deeper understanding, qualitative data is needed. Much universal research does not collect qualitative data as it is time-consuming to collect, identify themes and analyse, and yet it is this that uncovers the complexities and layers which are so important in research around social exclusion and what works. Quantitative data is often favoured as it is often about adding and aggregating and can utilise computer programs. It is easier and not as time-consuming to analyse as qualitative data, but the two, when combined, can go deep and find the reasons why.

- Quantitative data does little to explain why the patterns exist and this has been the challenge of this project. The qualitative data is critical in understanding the 'push and pull' factors behind what makes people engage in getting legal help and understanding advice-seeking behaviour.

- When seeking funding for future evaluation, agencies should incorporate in the budget monies for a data analysis software program and training in that software. There was significant qualitative data collected in this project. The qualitative and quantitative data fills 320 pages in a 'Shell' that houses all the data that the author provided to ARC Justice on Friday 20 August 2016. In addition, it is wise to seek funding for transcription of the digital recordings as this consumed many pro-bono author hours (approximately 120 hours). 
[Insert ANU logo and running head]

\section{Contact: Dr Liz Curran}

Senior Lecturer, ANU Legal Workshop (Australia-wide Professional Legal Training) \& Assoc. Director International Centre for the Profession, Education and Regulation in Law (PEARL), Australian National University, College of Law.

Mobile 0404106614

Email Liz.Curran@anu.edu.au

Canberra ACT 0200 Australia (Melbourne based)

www.anu.edu.au

CRICOS Provider No. 00120C. ORCID ID 0000-0002-6371-2975

\section{PART TWO - Field Research}

\section{Chapter Five - Phase One: The Community Focus Group (February 2015)}

As noted above, the purpose of the CFG was to help determine the elements that contribute to positive impacts on SDH to inform the project design. The CFG was facilitated by the author using the scenario and questions in Appendix $\mathrm{C}$ with the research assistant in attendance. Each took notes. It took place in the early childhood development room of the BCHS KF site. Participants were recruited by a poster (approved by the ANU Ethics Committee) which was placed in the reception area at the BCHS KF site and on the noticeboard in the reception area. It was in the afternoon before school pick-up. The CFG went for two hours. Fifteen people were expected but 26 people attended. Some (17 people) voluntarily indicated the money was attractive, but now having done the CFG it would have been worthwhile even without the money. Seven people indicated they would have attended even without the contribution for their time.

The community stated in the CFG that they never felt heard and that they wanted to have a voice as many decisions affected them but they were never asked. They advised that they often did not know their legal rights and how to speak to decision-makers. They also observed that they had lived experience of policies but that they felt they had no voice. They identified a need for training that might give them information and confidence so they could be 'empowered'. Some suggestions of participants included: simple things help with engagement, relationships, trust, support, and step-by-step solutions; concrete timely interventions 'under one roof' around housing, information about debt and solutions; accessible services and dignity and respect. Disconnections of utilities have huge flow-on effects on SDH and could be part of the areas for SDH to be measured (no heating, no heated food for children and no light to do school work), more community education, and that poor health impacts are caused by debt, illness, depression and not knowing solutions.

Using the responses to the scenario and questions, the research team (the author and the research assistant) examined these to see if they correlated with the draft proxies and whether any additions or tweaking needed to be made. This led to the inclusion of 'community' in all of the proxies. (See Chapter Four.) The CFG affirmed the four proxies be used as indicators of positive outcomes on the SDH, namely engagement, capacity, collaboration and empowerment, in addition to other things that ought to be measured such as stress, anxiety, early intervention and prevention, hope, de-escalation, holistic service, responsiveness, respect and voice. These informed the project design 
[Insert ANU logo and running head]

Contact: Dr Liz Curran

Senior Lecturer, ANU Legal Workshop (Australia-wide Professional Legal Training) \& Assoc. Director International Centre for the Profession, Education and Regulation in Law (PEARL), Australian National University, College of Law.

Mobile 0404106614

Email Liz.Curran@anu.edu.au

Canberra ACT 0200 Australia (Melbourne based)

www.anu.edu.au

CRICOS Provider No. 00120C. ORCID ID 0000-0002-6371-2975

as to what would be used as indicators of outcomes, questions asked of participants, impacts and effectiveness.

In early August 2016, the author prepared a draft one-page poster by way of a report back to the CFG Participants to be displayed at BCHS, which has been provided by the author to ARC Justice for this purpose. This is because the CFG participants asked to be simply informed of the project outcomes. 
[Insert ANU logo and running head]

\section{Contact: Dr Liz Curran}

Senior Lecturer, ANU Legal Workshop (Australia-wide Professional Legal Training) \& Assoc. Director International Centre for the Profession, Education and Regulation in Law (PEARL), Australian National University, College of Law.

Mobile 0404106614

Email Liz.Curran@anu.edu.au

Canberra ACT 0200 Australia (Melbourne based)

www.anu.edu.au

CRICOS Provider No. 00120C. ORCID ID 0000-0002-6371-2975

\section{Chapter Six - Phase Two: Snapshot One (Trial of Research Methodology and Mine for Recurrent Themes, 20 April - 1 May 2015)}

The first snapshot ran for two weeks as it was a trial of the method. As a trial it also aimed to test the tools, mine for the recurring themes and gain staff feedback on any adjustments needed. By mining themes in the trial (as suggested by one of the project advisers), its focus was on the emerging themes and seeing if trends were consistent across the tools, and then whether they were consistent or changed in the two further snapshots.

The data emerging from each tool was cross-referenced across the other tools and, if verified as consistent across the tools, checked for the recurrent themes emerging and consistent across all tools. This cross-verification was to reduce bias and test the conclusions.

The following summarises the participation rates in Snapshot One:

- $\quad$ Professional journals kept by BCH professionals and lawyer (5 Participants) Verdict - Rich/Useful Data Emerging. Staff at a debrief focus group facilitated by the author in late May 2015 asked that the method be tweaked and done over a month rather than a week for the second and third snapshot.

- In-depth interviews with non-legal professional staff, 2.5 hours (health/allied health professionals). Part A on DVD on an 'opt-in basis' for participants (5 Participants) (most felt uncomfortable about being in a DVD); and Part B discussing two de-identified clients. These would become longitudinal case studies over the three snapshots, aiming to gather some longitudinal information about the impacts on clients and their SDH of the HJP interventions. (Clients identified for tracking by health/allied health professionals over three snapshots × 6) - Verdict - Very Rich/Useful Data Emerging.

- In-depth interview with lawyers $\times 2$ - Rich/Useful Data Emerging.

- $\quad$ Client follow-up, by phone, after file closure; $\mathbf{0}-\mathrm{A}$ number of attempts were made to contact clients but there were no responses or there were phone disconnections (not surprising given issues with debt and poverty in the demographic). Not a rich data source. This might be different in a different research setting. For example, the author has used this method with good response rates in her other research. The clients in the Bendigo HJP identified an issue of understandable reticence to revisit legal issues as clients wanted to move on. The author in this HJPRAE was hesitant about this as a data source for future snapshots. However, BCHS staff were keen to see it retried over a 
[Insert ANU logo and running head]

\section{Contact: Dr Liz Curran}

Senior Lecturer, ANU Legal Workshop (Australia-wide Professional Legal Training) \& Assoc. Director International Centre for the Profession, Education and Regulation in Law (PEARL), Australian National University, College of Law.

Mobile 0404106614

Email Liz.Curran@anu.edu.au

Canberra ACT 0200 Australia (Melbourne based)

www.anu.edu.au

CRICOS Provider No. 00120C. ORCID ID 0000-0002-6371-2975

month with SMS requests before phone contact. If this did not work in Snapshot Two, it was decided it would not be done for Snapshot Three. The attempt in Snapshot Two to recruit participants was again problematic and the tool was dropped for Snapshot Three.

- $\quad$ HJP client feedback questionnaire; 1 - Rich/Useful Data emerging but limited in terms of response rate. The author suspected this tool would be limited, given her previous experience using it in a community health setting and for legal aid. Clients of community services often cannot read and write. Also, the client numbers seen by the HJP are small, and so are even smaller over the snapshot periods. Most were actually interviewed face-to face in the snapshot weeks by the researchers and so the client feedback questionnaire was not sought for these clients to avert duplication. The idea of the questionnaire was to have a separate source of client data to the lawyer-referred client to ensure bias was reduced. In initial discussion with BCHS about the administration of the questionnaire, it was decided there would be a 'concierge' in place who would be independent of the service and who could also support people who might not be able to read or write. This did not occur. For these reasons, throughout the three snapshots there were very few questionnaires completed by clients. Efforts were made by BCHS reception staff, but most clients who attended the HJP during the snapshot weeks were either interviewed directly by the researchers or were deemed not appropriate for the questionnaire due to their state of crisis. Accordingly, there was a low response rate over the life of the HJPRAE for this tool.

- $\quad$ Online survey of BCHS professional staff on awareness of impact of legal on health - the survey was done at service start-up in March 2014 (administered by ARC Justice) and again in Snapshot One - Response rate - 22 (out of 120 BCHS staff at the time employed, administered across the whole of BCHS, not just Kangaroo Flat) - Rich/Useful Data Emerging.

- Interview with client after lawyer interview $\times 3-$ Very Rich/Useful Data Emerging.

- Community Legal Education/Prof. Development Evaluation Sheets (to be administered throughout the service operations as they occurred between snapshots). Feedback in interviews was not to label training for professional staff as 'community legal education' as this was specifically relevant for community. It was noted that professional staff training should be called 'professional development' (PD) as it would engage staff in the training, because this was the customary terminology. The term 'community legal education' (CLE) was considered disrespectful of professionals - CLE for 
[Insert ANU logo and running head]

\section{Contact: Dr Liz Curran}

Senior Lecturer, ANU Legal Workshop (Australia-wide Professional Legal Training) \& Assoc. Director International Centre for the Profession, Education and Regulation in Law (PEARL), Australian National University, College of Law.

Mobile 0404106614

Email Liz.Curran@anu.edu.au

Canberra ACT 0200 Australia (Melbourne based)

www.anu.edu.au

CRICOS Provider No. 00120C. ORCID ID 0000-0002-6371-2975

community and PD were identified as a significant need by all participants in all interviews. This might be useful information more broadly for other legal services engaging in HJP. This is discussed further in Chapter Fourteen in line with the author's project brief to provide lessons and recommendations (Project Objective vi).

- $\quad$ Short interview with front-line reception staff of BCHS $\times \mathbf{2}-$ Very Rich/Useful Data Emerging.

- Interview with relationship holders (incl. management $\times 3$ and 2 external agencies) (identified by BCHS + ARC Justice) $=\mathbf{5}$ Total - Rich/Useful Data Emerging.

- $\quad$ Case studies (de-identified) emerging from open questions asked in the above tools - Rich/Useful Data.

- $\quad$ Aggregated data collected and de-identified during snapshot on the numbers of legal LSCs by lawyers with BCHS staff ( $\times 10$ in the trial snapshot) and crossreferrals between the two agencies $-\times 4$ referrals to HJP and $\times 2$ referrals to BCHS - Rich Data Emerging/test verifying qualitative data.

\section{Concrete Factors That It Is Possible Determine SDH Emerging from the CFG and Snapshot One Client Interviews}

- When utilities are cut off (a legal issue) it is possible there is no electricity or gas for heating - it is possible that without warmth children get sick, it is possible without light children cannot do homework, and it is possible they fall behind in school. This affects income security.

- Debt collectors or fines (a legal issue) - it is possible these mean there is less money to live on to buy food and essentials for kids, possibly including medications, clothes, shoes and school equipment. This affects income security.

- $\quad$ Poor, substandard, unstable or no housing (a legal issue) - it is possible this leads to: a lack of security, poor health due to damp and mould or living outside, increased risk to safety if homeless as sleep in unsafe areas. It is possible this affects health through, for example asthma and cold and flu. It is possible this affects housing security and can lead to poor health.

- $\quad$ Family violence (a legal issue) - it is possible this can lead to: lack of housing, safety, security, fear, anxiety, stress leading to poor health and poor decisionmaking, flow-on effects to children on schooling, relocations (often to escape). It is possible this affects health by physical, emotional and psychological harm.

- $\quad$ Lack of access to a car (can be a legal issue) - it is possible in a rural area poorly served by public transport: this means missed medical and other appointments 
[Insert ANU logo and running head]

\section{Contact: Dr Liz Curran}

Senior Lecturer, ANU Legal Workshop (Australia-wide Professional Legal Training) \& Assoc. Director International Centre for the Profession, Education and Regulation in Law (PEARL), Australian National University, College of Law.

Mobile 0404106614

Email Liz.Curran@anu.edu.au

Canberra ACT 0200 Australia (Melbourne based)

www.anu.edu.au

CRICOS Provider No. 00120C. ORCID ID 0000-0002-6371-2975

for parents and children. It is possible it also can increase social exclusion and hinder social connection, leading to depression and/or withdrawal and affects children's ability to undertake school activities. It is possible this affects social inclusion and ability to attend and keep appointments critical to gaining support.

- $\quad$ Family disputes (legal issues) - it is possible these lead to tensions and to violence if left unresolved or heightened. It is possible this affects health by physical, emotional and psychological harm.

- $\quad$ Safety (may be a legal issue) - it is possible this is compromised by drug addiction and unstable housing as they were exposed to the violence of others, or it is possible there are other forms of violation causing a state of fear, anxiety and resulting stress. This affects health as it can lead to physical harm or becoming mentally unwell.

- $\quad$ The involvement of child protection (a legal issue) agencies - it is possible this places stress on parents and children. It is possible that not knowing their legal rights or obligations and being unsupported can lead to mistakes and place further tension and stress on families that lead to problems in parenting and child feelings of rejection. It is possible this can lead to poor mental health in children and parents. Threats of child removal were identified as a cause of concern and panicked parenting was possible, leading to poor decision-making based on poor information provided or fear. Threats of removal of a child, loss of contact or removal of a child it is possible led to: loss of hope and a sense of powerlessness identified as causing susceptibility to drug or alcohol relapse or self-harm, both of parents and children alike, through losing the family connection. It is possible this affects health regarding physical, emotional and psychological wellbeing.

- $\quad$ Loss of employment and no employment (can be a legal issue) - it is possible this leads to: loss of income to support the family, or a feeling of hopelessness and powerlessness that leads to depression and social exclusion. The participants noted loss of 'dignity' also led them to feel unable to function in terms of doing daily activities such as shopping and leaving the house. It is possible this affects mental health and income support.

- $\quad$ Due to no food, not enough money to buy decent food, having to eat cold food rather than heated food and/or limited money to pay for utilities, poor nutrition is a possibility.

- Unresolved legal issues mount as often there are many and people are embarrassed or don't know how to get help as they are overwhelmed. It is possible this causes a range of negative impacts (increased stress and anxiety 
[Insert ANU logo and running head]

\section{Contact: Dr Liz Curran}

Senior Lecturer, ANU Legal Workshop (Australia-wide Professional Legal Training) \& Assoc. Director International Centre for the Profession, Education and Regulation in Law (PEARL), Australian National University, College of Law.

Mobile 0404106614

Email Liz.Curran@anu.edu.au

Canberra ACT 0200 Australia (Melbourne based)

www.anu.edu.au

CRICOS Provider No. 00120C. ORCID ID 0000-0002-6371-2975

leading to poorer physical (e.g., lack of sleep) and mental health (e.g., panic attacks). It is possible this affects health regarding physical, emotional and psychological wellbeing.

- $\quad$ Not knowing your legal rights or responsibilities (legal issue) - it is possible this could lead to: rash or poor responses which were identified by participants as likely to lead to problem escalation, loss of control and uncertainty. It is possible this was identified as making a 'bad situation worse' or increasing a loss of hope or increasing stress and anxiety.

- $\quad$ Numerous problems and a lack of information and or confidence - it is possible these create an inability to make informed decisions or focus on health, drug and alcohol consumption, and/or relapse suicidal ideation. It is possible this affects health regarding physical, emotional and psychological wellbeing and harm.

- Increases in stress and anxiety - it is possible these lead to anger and temper, which flows on to children and partners and grandparents. This affects health regarding physical, emotional and psychological wellbeing and harm.

\section{Client Demographics and Feedback on SDH}

Client One is aged between 55 and 64 years of age, female and a pensioner. The client has health issues, fines and a physical disability. Their educational attainment was a Certificate in Business Management. They were referred to HJP by a financial counsellor. Client Two is a female aged between 25 and 34 years of age. Their issues were criminal law and child contact. They were referred to HJP by a family counsellor. The client noted a lack of contact with their child led to suicidal ideation and increased their stress and anxiety (SDH). They had issues with fines, housing, health, mental health income difficulties, debt and credit. The client noted these circumstances of poor income or lack of stable housing impacted negatively on mental health and exacerbated it. (SDH). Their educational level was 'not stated'. Client Three was aged between 45 and 54 years and a male. They were referred to the HJP by q financial counsellor. Their issues include health, employment, bipolar and income. They were living in a shed (pertinent to SDH). They were on a pension, namely the Newstart Allowance. Their educational attainment was Year Nine or the equivalent of 15 years of age. Client noted these circumstances of poor income and a lack of skill and housing impacted negatively on his mental health, exacerbating it. (impact on SDH).

\section{Key Themes Recurring and Emerging in Snapshot One}

The quantitative data was mined and colour-coded or given a grid reference (symbol) when it was evident that there were recurring and consistent themes (these themes are 
[Insert ANU logo and running head]

\section{Contact: Dr Liz Curran}

Senior Lecturer, ANU Legal Workshop (Australia-wide Professional Legal Training) \& Assoc. Director International Centre for the Profession, Education and Regulation in Law (PEARL), Australian National University, College of Law.

Mobile 0404106614

Email Liz.Curran@anu.edu.au

Canberra ACT 0200 Australia (Melbourne based)

www.anu.edu.au

CRICOS Provider No. 00120C. ORCID ID 0000-0002-6371-2975

listed below) in evidence in the various tools on six occasions across at least four of the tools. The same approach was used against the qualitative data that was being gathered.

\section{Colour-coding and Grids Developed from the CFG and Snapshot One and then Used through the Project}

These codes and grids were developed using the methodology detailed in Chapter Four.

\section{Proxies (also Themes)}

- $\quad$ Engagement (also proxy one for SDH))

- $\quad$ Capacity Enhancement (also proxy two for SDH)

- $\quad$ Collaboration - Integration - smooth processes (also proxy three for SDH)

- $\quad$ Empowerment (advocacy and voice) (also proxy four for SDH).

Other themes from the data include:

- $\quad$ Complexity

- Clients have multiple legal and non-legal problems

- Clients reaching service when otherwise would not have done so.

Comparative Themes to See if Progress/Frequency over Time

- $\quad$ Reductions in Anxiety and Stress (SDH)

- $\quad$ Changes in Practice of professional staff (SDH)

- $\quad$ Value of LSCs

- $\quad$ Risk of Worker overload

- Hope (SDH)

- $\quad$ Early Intervention (SDH) \& Prevention (SDH)

- Impact and Effectiveness.

A 'But for the intervention of HJP' test was used to elicit case studies on the impact of HJP. This also unravelled some complexities in the clients' lives often due to their legal problems not having been identified or assisted until the HJP intervention.

Consistent with the literature (in Chapter Three) and participant feedback, these themes were also relevant to issues of effectiveness, targeting, efficiency, impact and outcomes for SDH.

In Snapshot One's trial of the methodology the theme of engagement was repeatedly noted. Due to client complexity and their range of issues, appointment 'no-shows' were frequent. The 'opportunism' of the co-located model was repeatedly identified by all participants as critical for engagement. The themes emerging from Snapshot One were 
[Insert ANU logo and running head]

\section{Contact: Dr Liz Curran}

Senior Lecturer, ANU Legal Workshop (Australia-wide Professional Legal Training) \& Assoc. Director International Centre for the Profession, Education and Regulation in Law (PEARL), Australian National University, College of Law.

Mobile 0404106614

Email Liz.Curran@anu.edu.au

Canberra ACT 0200 Australia (Melbourne based)

www.anu.edu.au

CRICOS Provider No. 00120C. ORCID ID 0000-0002-6371-2975

also consistent with the participants in the CFG in February 2015 around engagement and the need to build capacity - they also noted that not only did community and individuals need capacity but so too did their support people such as counsellors and doctors, to be able to provide pathways and enable 'service all under one roof' (integration and collaboration). They identified a need to have information at the right times and to support them 'to act' (empowerment) and have a 'say' (voice).

The Snapshot One trial saw participants agree to using the following as indicators engagement: capacity, collaboration and empowerment ('the proxies'), in addition to other things that ought be measures such as stress, anxiety, but for the intervention, early intervention, prevention, hope, de-escalation, holistic service, responsiveness, respect and voice. There was significant overlap and consistency from client, health/allied health professionals, legal professionals and relationships holder participants on the relevance of these elements as concrete determinants towards a positive outcome. These all went to inform the project design as to what would be used as indicators of outcomes, impacts and effectiveness in Snapshots Two and Three.

The professional and administrative participants kept reiterating the value of having the lawyer available so as to 'opportunistically' respond when clients presented. After the staff debrief and their input on the trial in late May 2015, the proxies were tweaked for future use by deleting the reference to 'workers' in the proxies and replacing it with the word 'professionals'.

Some clear and concrete elements as to what hindered positive SDH outcomes or assisted them also emerged across the research tools. All client participants and health/allied health profession participants noted that the ability to understand their legal position (even if not ideal) made them less anxious. Some identified ways a legal intervention could positively impact on the SDH, including:

- a lawyer explaining their legal rights and responsibilities and negotiating or advocating (see the Definition section of this Full Final Report)

- $\quad$ the lawyer advocating for a reduction in debts or hardship waiver or presenting materials that no debt is in fact owed by the client

- the lawyer not necessarily securing housing but delaying an eviction until alternative housing can be found, or delaying foreclosure until other arrangements can be put in place

- the lawyer or the allied/health professional, 'skilled up' in knowing the legal options, enabling a hardship application to secure utilities or gain concessions available for utilities to enable ongoing connection 
[Insert ANU logo and running head]

\section{Contact: Dr Liz Curran}

Senior Lecturer, ANU Legal Workshop (Australia-wide Professional Legal Training) \& Assoc. Director International Centre for the Profession, Education and Regulation in Law (PEARL), Australian National University, College of Law.

Mobile 0404106614

Email Liz.Curran@anu.edu.au

Canberra ACT 0200 Australia (Melbourne based)

www.anu.edu.au

CRICOS Provider No. 00120C. ORCID ID 0000-0002-6371-2975

- the lawyer having a fine or debt waived or using special circumstances provisions available at law, leaving the client with a greater income to spend on necessities or pharmaceuticals and other life expenses

- $\quad$ the lawyer providing legal support to a client where otherwise their legal rights are compromised by overzealous departmental imperatives

- $\quad$ the lawyer linking the client or their children up with supported accommodation and family violence or other forms of protection to better protect the safety of the client, children and or extended family members from a violent or otherwise harmful person

- $\quad$ the lawyer negotiating with a telecommunications company to ensure contact by phone is made possible to enable social and health support for a client in crisis

- $\quad$ the lawyer negotiating with a company where the client has been a victim of predatory conduct that is a breach of the law and leads to faulty products or loss of income

- $\quad$ the lawyer explaining the client's legal position simply and clearly and in terms the client and health/allied health professional can understand, and acting on this advice so as to enable better choices and decision-making, leading to either a de-escalation of the problem or prevention of ill-advised action either on the part of the client, a decision-maker or a support person.

All the interventions above were identified in the data as possibly having a positive affect on client SDH and improving outcomes. 
[Insert ANU logo and running head]

\section{Contact: Dr Liz Curran}

Senior Lecturer, ANU Legal Workshop (Australia-wide Professional Legal Training) \& Assoc. Director International Centre for the Profession, Education and Regulation in Law (PEARL), Australian National University, College of Law.

Mobile 0404106614

Email Liz.Curran@anu.edu.au

Canberra ACT 0200 Australia (Melbourne based)

www.anu.edu.au

CRICOS Provider No. 00120C. ORCID ID 0000-0002-6371-2975

\section{Chapter Seven - Phase Three: Snapshot Two (9-13 November 2015)}

The same themes emerging from Snapshot One's mining of themes recurred in Snapshot Two (save for the 'risk of worker overload').

The qualitative data in Snapshot Two consisted of:

- $\quad$ Eight external interviews (3 more than Snapshot One) with relationship holders (4) and management of the partner agencies (4)

- $\quad$ Four in-depth interviews with non-legal professional staff (1 less than Snapshot One) (includes some staff doing longitudinal case studies of two clients over the project life)

- $\quad$ Two in-depth interviews with the lawyers (same as Snapshot One)

- $\quad$ Three client interviews (same as Snapshot One)

- Two interviews with reception staff (same as Snapshot One)

- One 'Guided professional journal' (4 less than Snapshot One)

- $\quad$ Survey Monkey of professionals (7 participants - 15 less than Snapshot One).

Snapshot Two - Context: Staff Transition Period

As noted earlier, the Bendigo Project has one full-time lawyer who is based at KF for three days per week. The author has been advised by ARC Justice and BCHS that at the time of Snapshot Two, a new lawyer had been incumbent in her role for five weeks after relocating from rural Victoria. The previous lawyer was still employed by ARC Justice but was to focus on a care and protection position. Given the significant amount of care and protection work emerging from the HJP and other service work, having a specialist care and protection lawyer was seen as a need to respond to the client work. ARC Justice proactively sought funding for such a position so as to enable the Bendigo HJP to focus on other client problems.

This is reflected in the data from Snapshot One where the lawyer indicated that in care and protection work, significant time was needed to do quite detailed and complex court documentation for such matters. Rather than hire a new lawyer, given the relationships built up with BCHS at KF, it was decided to retain Lawyer One in the care and protection specialism at the KF site one day a week and recruit a further lawyer to work in the HJP. A new lawyer was hired coming from a CLC from a different region of Victoria. In the transition period there were some initial start-up IT issues and the new lawyer tended to work out of the legal centre in Bendigo on most days. 
[Insert ANU logo and running head]

\section{Contact: Dr Liz Curran}

Senior Lecturer, ANU Legal Workshop (Australia-wide Professional Legal Training) \& Assoc. Director International Centre for the Profession, Education and Regulation in Law (PEARL), Australian National University, College of Law.

Mobile 0404106614

Email Liz.Curran@anu.edu.au

Canberra ACT 0200 Australia (Melbourne based)

www.anu.edu.au

CRICOS Provider No. 00120C. ORCID ID 0000-0002-6371-2975

New staff require time to settle into a service which has a multitude of staff. The LCCLC program of ARC Justice, although in central Bendigo, was still able to take referrals and LSC for BCHS KF staff. The data below, however, serves to highlight that for busy professionals with heavy caseloads, co-location and visibility are key to prompting and 'opportunistic' client help, as is repeatedly noted in the data in this Full Final Report (see Chapters Nine and Ten).

\section{Client Demographics and Feedback on SDH}

Client One is a male between the ages of 35 and 44 years of age. He is a single parent and was referred by a support worker from the BCHS KF site to the HJP lawyer. The client lives 35 kilometres from KF. The matter related to a legal issue with a car repossession and impost financially and impact of loss of car. The client noted these compounded his mobility and mental health and capacity to support his daughter's medical appointments (SDH impact). The client in the interview with the researcher also identified that he had issues with a family relationship, money, income and debt. Client Two is a female between 25 and 34 years of age. She was referred by a BCHS KF nurse to the HJP. She had been receiving assistance from the HJP for some time. She had an array of legal issues for which she was seeking help, including care and protection, family violence and debt. She noted a significant impact of HJP involvement on her levels of stress, where previously there was uncertainty and a lack of knowledge of her legal position which made her at risk of returning to drug use and depression (impact on SDH). Client Three is aged between 25 and 34 years of age, is female and a single parent. She was referred by a doctor from BCHS KF. She was gaining assistance from the HJP lawyer in matters related to family violence and the interview was conducted by phone as she could not come into the site. Her highest qualification was a Certificate IV. The client had an intervention order matter in court the following day. She also had family law matters in addition to the family violence. She noted that the two legal issues were connected and that she had heightened stress as the ex-partner was threatening to take the children which was affecting her psychologically and physically (impact on SDH).

\section{Qualitative Data Collected}

Nineteen interviews were conducted. Nine interviews were conducted by the author alone and 10 with the author and the research assistant present.

\section{Methodologies for Comparison and Contrast Short Term to Medium Term of the Snapshot Data}

In Snapshot Two there was a noticeable shift in the quantitative data. The qualitative data revealed the reductions in use of LSC by health/allied health professionals and a drop in referrals. On then looking at the qualitative data, the reason for this decline 
[Insert ANU logo and running head]

\section{Contact: Dr Liz Curran}

Senior Lecturer, ANU Legal Workshop (Australia-wide Professional Legal Training) \& Assoc. Director International Centre for the Profession, Education and Regulation in Law (PEARL), Australian National University, College of Law.

Mobile 0404106614

Email Liz.Curran@anu.edu.au

Canberra ACT 0200 Australia (Melbourne based)

www.anu.edu.au

CRICOS Provider No. 00120C. ORCID ID 0000-0002-6371-2975

became clear. It stemmed from a period of transition of lawyers and in BCHS staff, specifically where the lawyer was not on-site and was basing themselves largely at the legal service in Bendigo. This contrasted with Snapshot One where the HJP model involved the regular presence of the lawyer in line with the multi-disciplinary HJP practice. The transition from the previous lawyer to a new lawyer correlated with the decline in LSCs and referrals. The author is advised by the Bendigo HJP managers (from the health and legal sides of the partnership) that were also some staff changes at BCHS KF which may have also impacted on referrals. This highlights the need for continuous updating from both sides of a HJP partnership to ensure new staff and transitions are managed.

The qualitative data explained the reasons behind the quantitative data and highlights the positive nature of collecting both data types. Collecting only quantitative data might otherwise suggest a failure of the HJP model when in fact the converse is true. The evidence revealed a transition of staff resulted in a return to a more traditional legal service model (by not being based on-site and visible as much). This was a reduction in on-site presence and the innovation of co-located service delivery of the HJP (which was designed to improve client reach in the first place), and led to the reduction in referrals and LSC in the lead-up to Snapshot Two, which was commented on by many participants in Snapshot Two.

One professional journal was provided for Snapshot Two. This was a decline in participation from Snapshot One where five guided professional journals were provided. During some of the in-depth interviews (3) participants flagged that they did not feel they were able to provide a journal due to a staff transition in the HJP. It is noted that there was also a staff changeover at BCHS as well which may have impacted on the number of journals.

This meant that in Snapshot Two data, staff reported that during the month leading up to the second snapshot, they had not really utilised the HJP as much as previously, and leading up to and during the snapshot period they felt they had nothing to write. Similarly, in a significant number of responses (6) to questions in a number of interviews and in-depth interviews, the health/allied health professionals and staff indicated that they could not comment as they had not really utilised the HJP, noting that the lawyer was 'out of sight, out of mind'. They noted that as the lawyer was less visible and not on-site, this reduced the 'opportunistic' nature for referrals and their inclination to have LSCs. This is a 'two-way street' - BCHS have had staff turnover too. This also explains why the research team could not always consistently interview professional staff across all three snapshots.

Importantly, the participants in Snapshot Two were concerned about a reducing of the 'transferral of trust' in the transition. 
[Insert ANU logo and running head]

\section{Contact: Dr Liz Curran}

Senior Lecturer, ANU Legal Workshop (Australia-wide Professional Legal Training) \& Assoc. Director International Centre for the Profession, Education and Regulation in Law (PEARL), Australian National University, College of Law.

Mobile 0404106614

Email Liz.Curran@anu.edu.au

Canberra ACT 0200 Australia (Melbourne based)

www.anu.edu.au

CRICOS Provider No. 00120C. ORCID ID 0000-0002-6371-2975

'When the CLC was short-staffed and the lawyer was not here so much I noticed the difference with not having the lawyer here.' (Interview with BCHS reception)

'[Bendigo HJP] Not as much impact in my practice recently.' (In-depth interview with health/allied health professional)

'Knowing the person [lawyer], seeing them in the staff room or in their office, will mean more referrals. No point if sitting there in their legal office in Bendigo [6.5 km distance].' (In-depth interview with health/allied health professional)

This highlights the difficulties where there is under-resourcing and a small legal centre core staff, which means that one absence or resignation can have an impact across the programs. The lawyer, consistently with Snapshot One, did note that when she was regularly on-site at the KF health centre, the following occurred:

'You get an appreciation of the breadth of support and different perspectives from health service professionals, it makes you think more broadly as a lawyer ... the HJP project has enabled us to build and get traction for other new projects. Knowing these workers means you can have frank conversations and you can have them because of the relationships. You can pick up early warning signs where clients might slip, and be more targeted and effective early on with a head-start and aware of the issues and focus more on the client ... reward is being part of the team ... so much value in being there but it can be hard with court cases, part heard, to get back to KF ... it's a nice space in community health, not so judgemental as compared to law practice, not so adversarial as it's more collaborative. It's a different perspective and so you have different dialogues and you focus more on client health and wellbeing.' (In-depth interview with lawyer)

'Email and responsiveness, seeing person in their office is the prompt, if the lawyer is approachable. Trust is really important for me to be prepared to refer as you want the engagement with both me as professional and my client to be meaningful. If you don't get on with the person or know them, you are less likely to refer ...' (In-depth interview with health/allied health professional)

'Diminished if the lawyer off-site. Harder for clients and staff - it's all about relationships and networks.' (Interview with relationship holder)

'Ease of lawyer being here in the office - the initial contact with the client is here via the person with the service connection. My adult client would have lost loads of sleep and been terrified to otherwise go off to see a lawyer, benefits of lawyer being here ... hopefully we can get the connections happening again 
[Insert ANU logo and running head]

\section{Contact: Dr Liz Curran}

Senior Lecturer, ANU Legal Workshop (Australia-wide Professional Legal Training) \& Assoc. Director International Centre for the Profession, Education and Regulation in Law (PEARL), Australian National University, College of Law.

Mobile 0404106614

Email Liz.Curran@anu.edu.au

Canberra ACT 0200 Australia (Melbourne based)

www.anu.edu.au

CRICOS Provider No. 00120C. ORCID ID 0000-0002-6371-2975

from when you last interview us for the next snapshot.' (In-depth interview with health/allied health professional)

'In first weeks, I had to work remotely as there were IT issues and so now restructured will be easier to be on-site. Had to take files back to Bendigo office. Still learning about services and trying to get know the people. Going to try to get to Kangaroo Flat more. Starting to realise little things make a difference, like going to their [BCHS] Annual General Meeting [Wednesday mid Snapshot Two week] which I was not originally going to go to. Got to meet the early development team and some others there. Giving my card out to some people who didn't know had already come to that centre. Will be on-site more in the future, need to - didn't know me so not on a roundabout of services for client. I intend to get to on-site meetings in future. I realise I need to get to know the people and that knowledge is about the best person. I get that showing a desire to be at these events to increase trust and they will be more likely to attend training. I've got to build relationships and trust. All about trust, which leads to referrals, and got to gain trust and as professionals care and they will to refer to a place.' (In-depth interview with lawyer)

This data is suggestive of the fact that regarding the HJP model, when being implemented through the co-location, visibility and availability of a lawyer being onsite, there were more referrals, and as a direct contrast less LSCs when the lawyer was off-site. This transition period has not only provided learnings but also has reinforced the value of the HJP model in having lawyers embedded in health settings when it is more effective than the traditional model of lawyering with the lawyer off-site.

\section{Discussion}

The key finding for Snapshot Two is that it is key 'being on-site', 'visible' and 'opportunistic' when clients arrive or are emotionally ready to see a lawyer or reveal information to a worker, so that they can get a speedy LSC.

The transition saw a reversion, for a range of reasons, to a more traditional model of lawyering where the lawyer was back in their legal office some distance away rather than regularly on-site, and clients and their health/allied health professionals were expected to identify legal problems or navigate their way to the lawyer. It also saw reticence to refer from most of the health/allied health professionals interviewed, some noting a concern about clients being back on the legal roundabout.

Most interview participants noted that during the first snapshot period the HJP was reaching clients experiencing vulnerability and multiple disadvantage who they submitted were gaining access to legal help because the lawyer was visible, known, and there were relationships built up in 'corridors', 'by the photocopy machine' and in the 
[Insert ANU logo and running head]

Contact: Dr Liz Curran

Senior Lecturer, ANU Legal Workshop (Australia-wide Professional Legal Training) \& Assoc. Director International Centre for the Profession, Education and Regulation in Law (PEARL), Australian National University, College of Law.

Mobile 0404106614

Email Liz.Curran@anu.edu.au

Canberra ACT 0200 Australia (Melbourne based)

www.anu.edu.au

CRICOS Provider No. 00120C. ORCID ID 0000-0002-6371-2975

'lunch room' - they were seen and 'about'. They noted relationships take time, and ground and trust can be easily lost. As the extracts above reveal, there was, nonetheless, goodwill on both sides to work through the transition for the benefit of clients.

In some ways, Snapshot Two was like a control group (although this was not intentional) where a reversion to traditional lawyering with a reduced co-location as the Bendigo HJP is predicated on, saw a drop in engagement, capacity, responsiveness, client reach and collaboration according to many participants interviewed, and a drop in referrals and LSC. This is by contrast to Snapshots One and Three when the lawyer was often on-site and co-located. This, as noted earlier, was also due to staff transitions on both sides of the partnership in that time.

The author suggests that what is enlightening is that the transition has shown that the innovative nature of an HJP where what is effective is having the lawyer on-site, working in an integrated and holistic way with health and allied health providers, seen as a part of the community health team, thus being visible, building up trust and mutual respect, is critical to MDPs and reaching clients. 
[Insert ANU logo and running head]

\section{Contact: Dr Liz Curran}

Senior Lecturer, ANU Legal Workshop (Australia-wide Professional Legal Training) \& Assoc. Director International Centre for the Profession, Education and Regulation in Law (PEARL), Australian National University, College of Law.

Mobile 0404106614

Email Liz.Curran@anu.edu.au

Canberra ACT 0200 Australia (Melbourne based)

www.anu.edu.au

CRICOS Provider No. 00120C. ORCID ID 0000-0002-6371-2975

\section{Chapter Eight - Phase Four: Snapshot Three (6-10 June 2016)}

For Snapshot Three, the instruments and numbers of participants were as follows:

- $\quad$ Client Interviews $\times 4$ (an increase of 1 from Snapshots 1 and 2).

- Client Feedback Questionnaire $\times 1$. On scrutiny, the feedback questionnaire was handed to the client by the lawyer inadvertently. As explained in Chapter Four, one of the key reasons for this tool was to test and verify it against the client interviews to reduce the bias of the lawyer being the referrer for the latter tool. It also appeared that the same client has been interviewed and so it was a duplication. For these reasons it had been discounted. (See Chapter Four.)

- $\quad$ In-depth interviews with health/allied health professionals $\times 7$ (increase of 7 from Snapshot Two and 6 from Snapshot Two). There was an increase by the Final Snapshot, suggesting increased engagement over the life of the project of the health/allied health professionals in the HJP.

- In-depth interview with lawyers $\times \mathbf{2}$.

- Interview with reception $\times 2$ (same number of responses as Snapshots One and Two). This data given the small number of participants is discussed in the Qualitative Chapter on Snapshot Three.

- Interview with relationship holders $\times 5$ (includes 3 managers and 2 external agencies). This is a reduction of one manager from Snapshot Two and Snapshot One. A decision was made by the author of this report, in discussion with ARC Justice, that given the data from externals was consistent from Snapshots One and Two and unlikely to change, limited time for the week-long snapshot might be better spent focusing on the health/allied health professionals (given the interviews were 2.5 hours duration, and they were larger in number). In view of the additional in-depth interviews scheduled, it was deemed more important resource-wise and in terms of data significance to interview less external agencies in Snapshot Three. The two external relationship holders interviewed in Snapshot Three reinforced the same message, as suspected, namely that HJP was a great and effective model and that they would like an HJP at their respective services given the complexity of clients and their often multi-natured legal problems and barriers of access.

- $\quad$ Online survey of professionals $\times 24$.

- $\quad$ Aggregated data for Snapshot Three of lawyers was that there were three LSC per week and up to five referrals a week. It is noted that the interviews with 
[Insert ANU logo and running head]

\section{Contact: Dr Liz Curran}

Senior Lecturer, ANU Legal Workshop (Australia-wide Professional Legal Training) \& Assoc. Director International Centre for the Profession, Education and Regulation in Law (PEARL), Australian National University, College of Law.

Mobile 0404106614

Email Liz.Curran@anu.edu.au

Canberra ACT 0200 Australia (Melbourne based)

www.anu.edu.au

CRICOS Provider No. 00120C. ORCID ID 0000-0002-6371-2975

health/allied health professionals suggests that there are more LSC occurring than have been noted.

\section{Client Demographics and Feedlback on SDH}

Of the four clients interviewed, two were male and two were female. One male was aged between 45 and 54 years of age; another male was between 55 and 64 years of age. Both females were aged between 25 and 34 years of age. Three had children who were minors. Referrals were by a BCHS social worker, a pharmacotherapy nurse, family counsellor and by a doctor. Of the clients interviewed in Snapshot Three, $100 \%$ had more than one legal problem, with 50\% having more than three legal problems for which they were seeking help from the HJP lawyer. This highlights the complex nature of the HJP legal work, suggesting that while the clients are seen in smaller numbers, they have complex and multiple legal issues, some of which, due to the infancy of the HJP project, they had never believed they could gain help for, for a range of reasons which will be discussed in Part Three. The nature of problems included issues around guardianship and administration, housing and debt (featuring for one-third of the clients in this snapshot), family violence, and family law, mental health status, fines and care and protection.

All these clients noted these problems has reduced their social involvement, income for food, heating and children's clothes, and had impacted in three cases on child school excursions. They had less money for clothes and pharmaceuticals (impact on SDH). All four clients noted their legal problems had until the HJP interventions caused stress and anxiety and impacted on families (impact on SDH).

\section{Themes}

The overall increase in participation of participants represented in the increase in health/allied health professionals in Snapshot Three, is suggestive that the transition phase issues of Snapshot Two had been overcome. It also suggests the HJP had engaged with more health/allied health professional staff over the life of the project. This was verified in the evidence from the qualitative data where all health/allied health professionals in Snapshot Three, who had been interviewed for Snapshot Two, noted the improvement since Snapshot Two.

In Snapshot Three the proxies of engagement, capacity, collaboration and engagement were all evidenced as positive. They were deemed as effective and as increasing over the life of the project in the data. There were reductions in stress and anxiety reported by clients and professional staff. There have also been significant changes in practice over the life of the project in comparison to the baseline data collected in Snapshot One, which suggests not only an intention to change practice but that actual changes in practice have occurred as evidenced by professional staff, legal and health/allied health 
[Insert ANU logo and running head]

\section{Contact: Dr Liz Curran}

Senior Lecturer, ANU Legal Workshop (Australia-wide Professional Legal Training) \& Assoc. Director International Centre for the Profession, Education and Regulation in Law (PEARL), Australian National University, College of Law.

Mobile 0404106614

Email Liz.Curran@anu.edu.au

Canberra ACT 0200 Australia (Melbourne based)

www.anu.edu.au

CRICOS Provider No. 00120C. ORCID ID 0000-0002-6371-2975

professionals in both the qualitative and quantitative data in Snapshot Three. This is also suggestive of a positive impact on the SDH.

Some other themes also emerged in Snapshot Three reflecting the longitudinal nature of this research evaluation. These will now be discussed.

\section{Discussion}

\section{Poor Experiences of Lawyers as a Barrier to Referral and Reach}

The research into advice-seeking behaviour of clients discussed in Chapter Three notes the barriers to client access as including an inability to identify the legal nature of a problem, lack of information, lack of access to a lawyer, and cost.

The qualitative data from Snapshot Three not only suggests that the issues to do with transition have been overcome, but also, as result of the experience, it has made the relationships between the services and the individual health/allied health professionals even stronger.

Snapshot Three also saw the language of participants in the qualitative data move beyond descriptions of the relationship as 'co-located' to references to the lawyer now 'being part of the team', 'seamless client work' and 'smooth integration', 'it's now a no-brainer as the lawyer is one of us all working for the client together', 'any professional differences, if there were any, have been overcome with clear communication and transparency', 'I now don't hesitate to ask the lawyer for help as she is so approachable and reliable ... responsive', 'even if she does not know the answer I know she will always get back to me. This is essential as so many of our clients are in crisis or could so easily be with worry over their legal issues'.

This shift, as four participants noted, is as a result of the pilot project being over three years, 'unlike so many programs which are funded for 12 months'.

Participants continuously stressed in interviews that projects such as this one rely heavily on trust and relationships and these can take time to foster and sustain. They stressed that one of the strengths of the HJP has been it was not a short-term funding project: 'It would be a great shame if it were to end as it's so critical to our clients getting the help they have always needed but could not reach'. The comments are detailed in Part Three.

Participants noted that the HJP lawyers were 'responsive, 'approachable' and 'part of the team', 'easy to work with seamlessly over time'. It was noted as a significant deterrent in seeking legal help if lawyers were 'stuffy' and 'too technical'. 'Our clients want to see a human being and not be judged or dismissed. These lawyers in the HJP are great. No question is silly and they make time even though I know they don't have it.' 
[Insert ANU logo and running head]

\section{Contact: Dr Liz Curran}

Senior Lecturer, ANU Legal Workshop (Australia-wide Professional Legal Training) \& Assoc. Director International Centre for the Profession, Education and Regulation in Law (PEARL), Australian National University, College of Law.

Mobile 0404106614

Email Liz.Curran@anu.edu.au

Canberra ACT 0200 Australia (Melbourne based)

www.anu.edu.au

CRICOS Provider No. 00120C. ORCID ID 0000-0002-6371-2975

What emerges from the qualitative data and across four tools - namely the client interviews, health/allied health professional interviews, interviews with relationship holders, namely the non-lawyers - in Snapshot Three is that previous experiences of lawyers had been poor and that this is a factor which influences client engagement, professional engagement and the health/allied health professionals' preparedness to refer to a lawyer; it was either previous poor experiences of lawyers or their poor perceptions of lawyers. (See Chapter Eleven for further discussion.)

'YES. I'm just glad that the lawyer has helped me. Lawyers can leave you in limbo and they say in terms that make your issues unclear. You don't pay for it so that makes life easier and the lawyer is a lovely person. If I have not got an appointment she will find time to speak to me.' (Interview with Client, Snapshot Three)

At least seven health/allied health professionals in their interviews for Snapshot Three noted that they once would have been reticent to hand a vulnerable client over to a lawyer for this reason, in line with their 'duty of client care' for fear of 'further retraumatising' their client. Four participants speculated that it is possibly a result of an adversarial system which can be 'harsh' and 'unsympathetic' and 'judgemental of clients' who experience disadvantage.

'There are lots of clients historically who have been in the criminal system or who are still in it who have had drug problems. The drugs have been used sometimes because of that involvement in the criminal justice system as it is so traumatic. This use has an impact on the health and so the legal system is not disconnected from their health. Here at the HJP my clients have had a better experience of lawyers than they have ever had before. I have to be frank: most have not had a really great experience of lawyers. One client told me his lawyer suggested he plead and he had not done anything but it was just easier, yet the ramifications for the client were ongoing.' (In-depth interview with health/allied health professional, Snapshot Three)

All research participants in this HJPRAE noted that the lawyer in the Bendigo HJP was different in their approach and so they had overcome their concerns and referred or sought LSC as a matter of course. Some noted that their experience of community lawyers at CLCs was different to private lawyers and some legal aid lawyers. This comment is consistent with some of the results of the LCCLC Family Violence 
[Insert ANU logo and running head]

\section{Contact: Dr Liz Curran}

Senior Lecturer, ANU Legal Workshop (Australia-wide Professional Legal Training) \& Assoc. Director International Centre for the Profession, Education and Regulation in Law (PEARL), Australian National University, College of Law.

Mobile 0404106614

Email Liz.Curran@anu.edu.au

Canberra ACT 0200 Australia (Melbourne based)

www.anu.edu.au

CRICOS Provider No. 00120C. ORCID ID 0000-0002-6371-2975

Collaborative Survey Tool that the author analysed and commented on in her 2015 evaluation of the LCCLC Family Violence Project. ${ }^{71}$

Also emerging from Snapshot Three (which was not such a focus in the previous snapshots) was the suggestion of many participants, and a specified area in need for future action at the Bendigo HJP but also for others doing HJP and HJP evaluations, to also incorporate and measure organisational benchmarks of the proxies of engagement, capacity, collaboration and empowerment so as 'to include executive and board level of the partner agencies' beyond the existing framework of 'client, community and professionals'. This is also noted by Noone and Digney as important. ${ }^{72}$ This will be discussed in Chapters Ten and Fourteen.

The Snapshot Three results overall suggest that the project has strengthened and, over time, become engrained as people have overcome transitions and built relationships, trust and understanding.

The results reflect the fact that the HJP, after its almost three years of operations since January 2014 until and culminating in Snapshot Three results, had been successful and effective in meeting all of the proxies for health/allied health professional staff. The responses are overwhelmingly positive in assessing the value of the service and its impact both on staff and the clients they support.

\section{Engagement with Doctors}

Of the nine health/allied health professionals interviewed in Snapshot Three, two were doctors. In previous snapshots, the researchers struggled to get participation by doctors in the research. This is considered to be a breakthrough. It emerged in the in-depth interviews with both doctors that time is a huge constraint for them. Short 10-minute patient consultations and huge client numbers booked in and Medicare billing systems mean they have little time for training and little time to ask clients more detailed questions around their other problems even though they may well be connected to their health.

Such issues are a challenge for the Bendigo HJP but are also challenges for other HJPs in Australia and abroad. ${ }^{73}$ One of the doctors interviewed admitted that they engaged

\footnotetext{
${ }^{71}$ Curran, L (2015a), 'Family Violence Project Evaluation Report', available at: http://lcclc.org.au/wpcontent/uploads/2015/05/Final-Evaluation-Report-LSB-Family-Violence-Curran-14-May-2015.pdf

${ }^{72}$ Noone, MA, \& Digney, K (2010), “'It's Hard to Open up to Strangers" - Improving Access to Justice: The Key Features of an Integrated Legal Services Delivery Model', La Trobe University Rights and Justice Program Research Report, available at SSRN: http://ssrn.com/abstract=1799648

73 The author in her meetings with Sick Kids at the Toronto Hospital and at the Center for MedicalLegal Partnership in Washington, DC in July 2016 was advised that these issues also resonate in other
} 
[Insert ANU logo and running head]

\section{Contact: Dr Liz Curran}

Senior Lecturer, ANU Legal Workshop (Australia-wide Professional Legal Training) \& Assoc. Director International Centre for the Profession, Education and Regulation in Law (PEARL), Australian National University, College of Law.

Mobile 0404106614

Email Liz.Curran@anu.edu.au

Canberra ACT 0200 Australia (Melbourne based)

www.anu.edu.au

CRICOS Provider No. 00120C. ORCID ID 0000-0002-6371-2975

with the HJP at the urging of their team leader and would otherwise not have done so. The doctor also indicated that although being at BCHS for two years, they had not attended any training by the HJP when offered and noted she was reticent to explore other problems patients might have for fear of 'opening a Pandora's box'. The doctor noted that they would like to do more but felt constrained and given time unable to utilise the offerings of the HJP. This highlights some of the challenges around capacity for some professions.

In addition there was, in Snapshot Three, a strong link made between the value of LSC and engaging by a client, as health/allied health professionals often use the LSC to 'test out a lawyer' and how it is done therefore becomes critical to enable a 'transferral of trust' from the professional to the client that comes through LSC. It is also noted, given the doctors are concerned about time, that feedback from participants in the data collected has been that LSCs actually save time and can impact positively on client health outcomes. This came through repeatedly and recurrently in the qualitative data in snapshots.

In Snapshot Three, ${ }^{74}$ as this was the final and longer-term view of the HJP, more of a focus was on reflecting over the life of the project what the HJP had meant to staff and clients in terms of the SDH and the level of collaboration for the professionals (both lawyers and health/allied health professionals). The 11 professionals were asked in their in-depth interviews their views on the impact of the HJP on their clients and themselves through question 23. (See Appendix E.) This asks the health/allied health professional about the levels of stress, anxiety, responsiveness and resilience of themselves, and perceptions of these levels on their clients of the HJP. This is discussed in Chapter Nine where the data is presented and Chapter Eleven in the discussion of the Collaborative Measurement Tool.

\section{Part Four - Overall Data}

For reasons of not identifying participants in the research (consistent with the ANU Ethics Approval), Part Four and Chapter Ten will only identify the specific professional's role where it is pertinent and unlikely to identify the personnel.

\section{Aggregated Participants for Data over the Three Snapshots}

After the trial of methodology in April 2015, the client call-backs were disbanded as a methodology. (See Chapter Six for a full discussion of the reasons in the Full Final

jurisdictions, as doctors have a combination of barriers which affect their buy-in and also their ability to engage. Many barriers are systemic and are not of their choosing.

${ }^{74}$ In line with the final Ethics Variation. 
[Insert ANU logo and running head]

\section{Contact: Dr Liz Curran}

Senior Lecturer, ANU Legal Workshop (Australia-wide Professional Legal Training) \& Assoc. Director International Centre for the Profession, Education and Regulation in Law (PEARL), Australian National University, College of Law.

Mobile 0404106614

Email Liz.Curran@anu.edu.au

Canberra ACT 0200 Australia (Melbourne based)

www.anu.edu.au

CRICOS Provider No. 00120C. ORCID ID 0000-0002-6371-2975

Report.) The instruments and number of participants over the life of the project were as follows:

- $\quad$ CFG (26)

- $\quad$ Client interviews $\times \mathbf{1 0}$

- $\quad$ Longitudinal client case studies (7)

- $\quad$ Client Feedback Questionnaire $\times 1$ (See, for full discussion of the reasons for this small number, Chapter Six, Full Final Report.)

- In-depth interviews with health/allied health professionals $\times 18$ (approximately six health and allied health professionals were reinterviewed in each snapshot to enable short-, medium- and long-term comparisons through the project snapshots). There was an increase in health/allied health professionals by the Final Snapshot, suggesting increased engagement over the life of the project of the health/allied health professionals in the HJP.

- $\quad$ In-depth interview with lawyers $\times \mathbf{6}$. (The lawyer staff were consistent and they were reinterviewed in snapshots to enable short-, medium- and long-term comparisons through the project snapshots.)

- Interview with reception $\times \mathbf{6}$. (The reception staff were consistent and they were reinterviewed in each snapshot to enable short-, medium- and long-term comparisons through the project snapshots.)

- Interview with relationship holders $\times \mathbf{1 8}$ (includes 10 Managers and 8 external agencies). Three of the managers were reinterviewed in each snapshot to enable short-, medium- and long-term comparisons through the project snapshots. Similarly, two external agencies were reinterviewed in each snapshot. For the Final Snapshot a decision was made by the author in discussion with ARC Justice that, given the data from externals was consistent from Snapshots One and Two (and unlikely to change given they had reiterated similar points in each snapshot), and due to the increased number of in-depth interviews with health/allied health professional staff, resource and time wise and in terms of data significance, it was best to interview less external agencies in Snapshot Three. The two external relationship holders interviewed in Snapshot Three confirmed this by reinforcing the same message, as suspected, namely that HJP was a great and effective model. They each noted that they would like an HJP at their respective services given the complexity and often multi-natured legal problems and barriers of access facing their clients.

- $\quad$ Online survey of BCHS staff (53) across all Bendigo Community Health sites (not just KF where the Bendigo HJP was conducted). 
[Insert ANU logo and running head]

Contact: Dr Liz Curran

Senior Lecturer, ANU Legal Workshop (Australia-wide Professional Legal Training) \& Assoc. Director International Centre for the Profession, Education and Regulation in Law (PEARL), Australian National University, College of Law.

Mobile 0404106614

Email Liz.Curran@anu.edu.au

Canberra ACT 0200 Australia (Melbourne based)

www.anu.edu.au

CRICOS Provider No. 00120C. ORCID ID 0000-0002-6371-2975

- $\quad$ Case studies from the qualitative data (23).

- $\quad$ Aggregated service data provided to the author by ARC Justice from 7 January to 30 June 2016. 
[Insert ANU logo and running head]

\section{Contact: Dr Liz Curran}

Senior Lecturer, ANU Legal Workshop (Australia-wide Professional Legal Training) \& Assoc. Director International Centre for the Profession, Education and Regulation in Law (PEARL), Australian National University, College of Law.

Mobile 0404106614

Email Liz.Curran@anu.edu.au

Canberra ACT 0200 Australia (Melbourne based)

www.anu.edu.au

CRICOS Provider No. 00120C. ORCID ID 0000-0002-6371-2975

\section{PART THREE - Aggregated Data}

\section{Chapter Nine - Aggregated Quantitative Data for the HJPRAE}

\section{CLSIS Service Data from 7 January 2014 until 30 June 2016}

Aggregated CLSIS data is difficult and time-consuming to extract. Duplications in results are problematic and the categories do not adapt easily to integrated settings such as the Bendigo HJP. This has been discussed previously as a difficulty for evaluators in finding service data that is relevant and useable. ${ }^{75}$ Nevertheless, LCCLC (the program of ARC Justice) provided the following service data after the significant time it took to extract. It is helpful in gaining a view of clients seen by the HJP since startup and the nature of their legal problems.

\section{Totals}

- $\quad$ Casework and Advices combined where clients are only counted once (106 + 141) $=247$

- $\quad$ Casework and Advices combined where duplicates are included but only if the open date and close date is different between those duplicates $(122+161)=$ 283.

Both numbers are reported as the program aims to address a client's multifaceted legal issue. This may require additional casework or advice for a particular client, therefore those instances where the client has come back are counted.

The author has also been advised by ARC Justice that all client matters from the HJP come from referrals from BCHS, and so the number of total casework and advices is also the same as the number of referrals from BCHS to the HJP.

On this basis:

- $\quad$ Total referrals to the HJP by BCHS from 7 January 2014 to 30 June $2016=247$.

Summary

\footnotetext{
${ }^{75}$ See Noone, MA, \& Digney, K (2010), “It's Hard to Open up to Strangers" - Improving Access to Justice: The Key Features of an Integrated Legal Services Delivery Model', La Trobe University Rights and Justice Program Research Report, available at SSRN: http://ssrn.com/abstract=1799648; and Curran, L (2013c), 'Legal Review: Not All in the Statistics', Law Institute Journal, vol. 87, no. 7, July, pp. 36-9.
} 
[Insert ANU logo and running head]

\section{Contact: Dr Liz Curran}

Senior Lecturer, ANU Legal Workshop (Australia-wide Professional Legal Training) \& Assoc. Director International Centre for the Profession, Education and Regulation in Law (PEARL), Australian National University, College of Law.

Mobile 0404106614

Email Liz.Curran@anu.edu.au

Canberra ACT 0200 Australia (Melbourne based) www.anu.edu.au

CRICOS Provider No. 00120C. ORCID ID 0000-0002-6371-2975

- $\quad$ Casework - 159 instances of casework over 47 problem types

- $\quad$ Advice - 160 instances of advice over 50 problem types.

Casework (detailed)

- $\quad 159$ legal casework files over 47 different legal problems.

Table 9.1 below explains the relationship.

\section{TABLE 9.1}

\begin{tabular}{|c|c|c|c|}
\hline $\begin{array}{l}\text { Number of } \\
\text { differing } \\
\text { legal issues }\end{array}$ & $\begin{array}{c}\text { CLSIS } \\
\text { code }\end{array}$ & $\begin{array}{c}\text { Number of clients } \\
\text { experiencing type of } \\
\text { legal issue }\end{array}$ & Description of legal issue \\
\hline 1 & 1130 & 1 & Child Support Appeal \\
\hline 2 & 1290 & 1 & Child Support (Other) \\
\hline 3 & 1420 & 3 & Child Residency \\
\hline 4 & 1430 & 10 & Parenting Plan \\
\hline 5 & 1440 & 1 & Parenting Abduction \\
\hline 6 & 1450 & 6 & $\begin{array}{l}\text { Specific Child Contact and } \\
\text { Residency }\end{array}$ \\
\hline 7 & 1480 & 6 & $\begin{array}{l}\text { Child Contact or Contact } \\
\text { Orders }\end{array}$ \\
\hline 8 & 1610 & 1 & Family or Domestic Violence \\
\hline 9 & 1620 & 3 & $\begin{array}{l}\text { Family or Domestic Violence } \\
\text { Order }\end{array}$ \\
\hline 10 & 1710 & 5 & Property in Marriage \\
\hline 11 & 1720 & 2 & Property De Facto \\
\hline 12 & 1790 & 2 & Property (Other) \\
\hline 13 & 1810 & 34 & $\begin{array}{l}\text { Child Protection } \\
\text { Application/Orders }\end{array}$ \\
\hline 14 & 1820 & 14 & Child Protection (Other) \\
\hline 15 & 1990 & 1 & Family Law (Other) \\
\hline 16 & 3160 & 1 & $\begin{array}{l}\text { Tenancy Fees and Other } \\
\text { Charges }\end{array}$ \\
\hline 17 & 3250 & 1 & Tenancy Ending Tenancy \\
\hline
\end{tabular}


[Insert ANU logo and running head]

\section{Contact: Dr Liz Curran}

Senior Lecturer, ANU Legal Workshop (Australia-wide Professional Legal Training) \& Assoc. Director International Centre for the Profession, Education and Regulation in Law (PEARL), Australian National University, College of Law.

Mobile 0404106614

Email Liz.Curran@anu.edu.au

Canberra ACT 0200 Australia (Melbourne based)

www.anu.edu.au

CRICOS Provider No. 00120C. ORCID ID 0000-0002-6371-2975

\begin{tabular}{|c|c|c|c|}
\hline 18 & 3430 & 1 & $\begin{array}{l}\text { Credit and Debt Owed to } \\
\text { Client }\end{array}$ \\
\hline 19 & 3440 & 7 & $\begin{array}{l}\text { Credit and Debt Owed by } \\
\text { Client }\end{array}$ \\
\hline 20 & 3470 & 1 & $\begin{array}{l}\text { Credit and Debt Recovery } \\
\text { (Court) }\end{array}$ \\
\hline 21 & 3490 & 1 & Credit and Debt (Other) \\
\hline 22 & 3680 & 1 & Immigration Miscellaneous \\
\hline 23 & 3720 & 1 & $\begin{array}{l}\text { Government (Govt)/Admin } \\
\text { FOI/Privacy }\end{array}$ \\
\hline 24 & 3740 & 4 & Govt/Admin Mental Health \\
\hline 25 & 3770 & 2 & $\begin{array}{l}\text { Govt/Admin Complaints } \\
\text { against Government } \\
\text { Processes or Procedures (e.g., } \\
\text { taxation assessment) }\end{array}$ \\
\hline 26 & 3780 & 7 & $\begin{array}{l}\text { Govt/Admin Issues Relating } \\
\text { to Fines }\end{array}$ \\
\hline 27 & 3890 & 1 & $\begin{array}{l}\text { Govt Complaints Issues } \\
\text { Relating to Govt }\end{array}$ \\
\hline 28 & 3940 & 1 & $\begin{array}{l}\text { Govt Pension Review of } \\
\text { Allowance Benefit }\end{array}$ \\
\hline 29 & 5330 & 1 & Consumer Complaints Health \\
\hline 30 & 5370 & 1 & $\begin{array}{l}\text { Consumer Complaints } \\
\text { Services }\end{array}$ \\
\hline 31 & 5380 & 2 & $\begin{array}{l}\text { Consumer Complaints Fair } \\
\text { Trading/Trading/Selling } \\
\text { Practices }\end{array}$ \\
\hline 32 & 5390 & 1 & $\begin{array}{l}\text { Consumer Complaints } \\
\text { (Other) }\end{array}$ \\
\hline 33 & 5510 & 1 & MVA \\
\hline 34 & 5520 & 1 & MV Property Damage \\
\hline 35 & 5720 & 2 & $\begin{array}{l}\text { Wills/Probate } \\
\text { Guardianship/Trusteeship }\end{array}$ \\
\hline
\end{tabular}


[Insert ANU logo and running head]

\section{Contact: Dr Liz Curran}

Senior Lecturer, ANU Legal Workshop (Australia-wide Professional Legal Training) \& Assoc. Director International Centre for the Profession, Education and Regulation in Law (PEARL), Australian National University, College of Law.

Mobile 0404106614

Email Liz.Curran@anu.edu.au

Canberra ACT 0200 Australia (Melbourne based)

www.anu.edu.au

CRICOS Provider No. 00120C. ORCID ID 0000-0002-6371-2975

\begin{tabular}{|c|c|c|l|}
\hline 36 & 5730 & 1 & $\begin{array}{l}\text { Wills/Probate } \\
\text { Making/Contesting/Obtaining } \\
\text { Benefit under }\end{array}$ \\
\hline 37 & 6920 & 2 & Other Civil Contracts \\
\hline 38 & 6970 & 5 & $\begin{array}{l}\text { Other Civil Violence } \\
\text { Restraining Order }\end{array}$ \\
\hline 39 & 6990 & 4 & Other Civil \\
\hline 40 & 7200 & 3 & Acts Intended to Cause Injury \\
\hline 41 & 7500 & 1 & $\begin{array}{l}\text { Robbery Extortion (related) } \\
\text { Offences }\end{array}$ \\
\hline 42 & 8200 & 2 & Theft and Related Offences \\
\hline 43 & 8500 & 1 & Illicit Drug Offences \\
\hline 44 & 8600 & 1 & $\begin{array}{l}\text { Property Damage and } \\
\text { Environmental Offences }\end{array}$ \\
\hline 45 & 8700 & 9 & $\begin{array}{l}\text { Road Traffic and Motor } \\
\text { Vehicle Regulatory Offences }\end{array}$ \\
\hline 46 & 8900 & 1 & $\begin{array}{l}\text { Other and Miscellaneous } \\
\text { Offences Weapons/Explosive }\end{array}$ \\
\hline TOTAL & & 159 & \\
\hline
\end{tabular}

Advice (detailed)

- $\quad 160$ Client legal advices files, over 50 different legal problems.

Table 2 below explains the relationship.

\section{TABLE 9.2}

\begin{tabular}{|c|c|c|l|}
\hline $\begin{array}{c}\text { Number of } \\
\text { differing } \\
\text { legal issues }\end{array}$ & $\begin{array}{c}\text { CLSIS } \\
\text { code }\end{array}$ & $\begin{array}{c}\text { Number of clients } \\
\text { experiencing type of } \\
\text { legal issue }\end{array}$ & Description of legal issue \\
\hline 1 & 1130 & 1 & Child Support Appeal \\
\hline 2 & 1170 & 1 & DNA Testing \\
\hline 3 & 1290 & 2 & Child Support (Other) \\
\hline 4 & 1420 & 6 & Child Residency \\
\hline 5 & 1430 & 19 & Parenting Plan \\
\hline
\end{tabular}


[Insert ANU logo and running head]

\section{Contact: Dr Liz Curran}

Senior Lecturer, ANU Legal Workshop (Australia-wide Professional Legal Training) \& Assoc. Director International Centre for the Profession, Education and Regulation in Law (PEARL), Australian National University, College of Law.

Mobile 0404106614

Email Liz.Curran@anu.edu.au

Canberra ACT 0200 Australia (Melbourne based)

www.anu.edu.au

CRICOS Provider No. 00120C. ORCID ID 0000-0002-6371-2975

\begin{tabular}{|c|c|c|c|}
\hline 6 & 1450 & 3 & $\begin{array}{l}\text { Specific Child Contact and } \\
\text { Residency }\end{array}$ \\
\hline 7 & 1460 & 1 & Taking Child Overseas \\
\hline 8 & 1480 & 12 & $\begin{array}{l}\text { Child Contact or Contact } \\
\text { Orders }\end{array}$ \\
\hline 9 & 1510 & 1 & Divorce \\
\hline 10 & 1610 & 3 & Family or Domestic Violence \\
\hline 11 & 1620 & 10 & $\begin{array}{l}\text { Family or Domestic Violence } \\
\text { Order }\end{array}$ \\
\hline 12 & 1710 & 4 & Property in Marriage \\
\hline 13 & 1720 & 1 & Property De Facto \\
\hline 14 & 1790 & 1 & Property (Other) \\
\hline 15 & 1810 & 22 & $\begin{array}{l}\text { Child Protection } \\
\text { Application/Orders }\end{array}$ \\
\hline 16 & 1820 & 5 & Child Protection (Other) \\
\hline 17 & 1990 & 1 & Family Law (Other) \\
\hline 18 & 3210 & 1 & Tenancy Repairs \\
\hline 19 & 3240 & 1 & $\begin{array}{l}\text { Tenancy Termination by } \\
\text { Lessor }\end{array}$ \\
\hline 20 & 3250 & 1 & Tenancy Ending Tenancy \\
\hline 21 & 3290 & 1 & Tenancy (Other) \\
\hline 22 & 3430 & 2 & $\begin{array}{l}\text { Credit and Debt Owed to } \\
\text { Client }\end{array}$ \\
\hline 23 & 3440 & 6 & $\begin{array}{l}\text { Credit and Debt Owed by } \\
\text { Client }\end{array}$ \\
\hline 24 & 3680 & 1 & Immigration Miscellaneous \\
\hline 25 & 3720 & 2 & Govt/Admin FOI/Privacy \\
\hline 26 & 3740 & 4 & Govt/Admin Mental Health \\
\hline 27 & 3750 & 1 & Complaints against Police \\
\hline 28 & 3770 & 2 & $\begin{array}{l}\text { Govt/Admin Complaints } \\
\text { against Government }\end{array}$ \\
\hline
\end{tabular}


[Insert ANU logo and running head]

\section{Contact: Dr Liz Curran}

Senior Lecturer, ANU Legal Workshop (Australia-wide Professional Legal Training) \& Assoc. Director International Centre for the Profession, Education and Regulation in Law (PEARL), Australian National University, College of Law.

Mobile 0404106614

Email Liz.Curran@anu.edu.au

Canberra ACT 0200 Australia (Melbourne based)

www.anu.edu.au

CRICOS Provider No. 00120C. ORCID ID 0000-0002-6371-2975

\begin{tabular}{|c|c|c|c|}
\hline & & & $\begin{array}{l}\text { processes or Procedures (e.g., } \\
\text { taxation assessment) }\end{array}$ \\
\hline 29 & 3780 & 5 & $\begin{array}{l}\text { Govt/Admin Issues Relating } \\
\text { to Fines }\end{array}$ \\
\hline 30 & 3890 & 2 & $\begin{array}{l}\text { Govt Complaints, Issues } \\
\text { Relating to Govt }\end{array}$ \\
\hline 31 & 5370 & 1 & $\begin{array}{l}\text { Consumer Complaints } \\
\text { Services }\end{array}$ \\
\hline 32 & 5380 & 1 & $\begin{array}{l}\text { Consumer Complaints Fair } \\
\text { Trading/Trading/Selling } \\
\text { Practices }\end{array}$ \\
\hline 33 & 5390 & 1 & $\begin{array}{l}\text { Consumer Complaints } \\
\text { (Other) }\end{array}$ \\
\hline 34 & 5510 & 2 & MVA \\
\hline 35 & 5520 & 1 & MV Property Damage \\
\hline 36 & 5710 & 1 & $\begin{array}{l}\text { Wills/Probate - Powers of } \\
\text { Attorney }\end{array}$ \\
\hline 37 & 5720 & 2 & $\begin{array}{l}\text { Wills/Probate } \\
\text { Guardianship/Trusteeship }\end{array}$ \\
\hline 38 & 5730 & 1 & $\begin{array}{l}\text { Wills/Probate } \\
\text { Making/Contesting/Obtaining } \\
\text { Benefit under }\end{array}$ \\
\hline 39 & 5790 & 1 & Wills/Probate (Other) \\
\hline 40 & 6110 & 2 & Injuries Assaults \\
\hline 41 & 6710 & 1 & $\begin{array}{l}\text { Neighbourhood Disputes } \\
\text { Complaints }\end{array}$ \\
\hline 42 & 6970 & 5 & $\begin{array}{l}\text { Other Civil violence. } \\
\text { Restraining orders }\end{array}$ \\
\hline 43 & 6990 & 3 & Other Civil \\
\hline 44 & 7200 & 1 & Acts Intended to Cause Injury \\
\hline 45 & 7500 & 1 & $\begin{array}{l}\text { Robbery Extortion and } \\
\text { Related Offences }\end{array}$ \\
\hline 46 & 8200 & 1 & Theft and Related Offences \\
\hline
\end{tabular}


[Insert ANU logo and running head]

\section{Contact: Dr Liz Curran}

Senior Lecturer, ANU Legal Workshop (Australia-wide Professional Legal Training) \& Assoc. Director International Centre for the Profession, Education and Regulation in Law (PEARL), Australian National University, College of Law.

Mobile 0404106614

Email Liz.Curran@anu.edu.au

Canberra ACT 0200 Australia (Melbourne based)

www.anu.edu.au

CRICOS Provider No. 00120C. ORCID ID 0000-0002-6371-2975

\begin{tabular}{|c|c|c|l|}
\hline 47 & 8500 & 1 & Illicit Drug Offences \\
\hline 48 & 8600 & 1 & $\begin{array}{l}\text { Property Damage and } \\
\text { Environmental Offences }\end{array}$ \\
\hline 49 & 8700 & 9 & $\begin{array}{l}\text { Road Traffic and Motor } \\
\text { Vehicle Regulatory Offences }\end{array}$ \\
\hline 50 & 8900 & 1 & $\begin{array}{l}\text { Other and Miscellaneous } \\
\text { Offences Weapons/Explosive }\end{array}$ \\
\hline TOTAL & & $\mathbf{1 6 0}$ & \\
\hline
\end{tabular}

This data verifies the other qualitative data and quantitative data emerging from the client interviews on the numbers of multiple legal, health and social issues for each client. Issues which dominate are those relating to parenting (including care and protection), family violence, financial problems and fines. These are all matters which participants in the research have identified as impacting on their SDH, namely on their safety, income security, levels of stress and anxiety and health (see discussion in Chapter Six).

The data provides evidence that in reaching individual clients, the Bendigo HJP has been able to assist with a significant number of legal issues that may have either been ignored or escalated. In addition, without the help of the health or allied health professionals in referral, it is likely a client's problems will escalate and they would not seek help, then by the health/allied health professionals through identifying the legal issue at all or earlier and through referrals and LSC, help being obtained through the HJP which would otherwise not have been the case. It is suggestive that such earlier interventions prior to problems becoming acute and causing later harm to health and court action are being averted. This is significant as it highlights the very nature of the intervention as an early intervention and prevention tool (see discussion of a need for economic modelling and costing in Chapters Eleven and Fourteen, which is beyond this project's brief).

\section{Aggregated LSCs with a Lawyer and Secondary Consultations with a Health/Allied Health Professional}

Lawyer 1 (88 weeks)

- $\quad$ BCHS LSC with lawyer 3 per week $=264$

- $\quad$ SC with BCHS professional 1 per week $=88$.

Lawyer 2 (47 weeks)

- $\quad$ LSC with lawyer 3 per week $=141$

- $\quad \mathrm{SC}$ BCHS professional 1 per week $=47$. 
[Insert ANU logo and running head]

\section{Contact: Dr Liz Curran}

Senior Lecturer, ANU Legal Workshop (Australia-wide Professional Legal Training) \& Assoc. Director International Centre for the Profession, Education and Regulation in Law (PEARL), Australian National University, College of Law.

Mobile 0404106614

Email Liz.Curran@anu.edu.au

Canberra ACT 0200 Australia (Melbourne based)

www.anu.edu.au

CRICOS Provider No. 00120C. ORCID ID 0000-0002-6371-2975

\section{Summary Total}

- $\quad$ LSC $264+141=405$

- $\quad$ SC with BCHS professional $88+47=135$.

Total secondary consultations

- 540

\section{Discussion}

With an aggregated number of 247 clients (without duplicates included) and 540 LSC, it suggests that a number of clients are being assisted beyond 'one-on-one' face-to-face advice through the LSC process being offered by the Bendigo HJP to health and allied professionals at the KF site. The qualitative data reveals that LSC, because it can be quick, responsive and at a time and place as and when needed (for example, when a client presents to the health/allied health worker in crisis), it can be an effective complement to one-on-one, face-to-face advice to clients and extend the reach of people gaining help with their legal problems. (See Chapter Fourteen for further discussion.)

\section{Aggregated Client Data}

\section{Discussion and Data}

Over the three Snapshots, which occurred at eight-monthly intervals, 10 clients were interviewed by the researchers. Although a small sample (see Chapter Four for an explanation of factors relevant to the small sample size), the author has used percentages to enable consistency in how the data was gathered and to enable consistency with other data from the other research participants. All $(100 \%)$ have/had more than one legal problem; $80 \%$ of clients interviewed had/have between five and eight legal problems; $100 \%$ had/have more than one legal problem; $90 \%$ of clients interviewed noted that they would have not seen a lawyer if it had not been from the HJP either through a referral or a LSC with a health/allied health professional from the HJP. This demonstrates that, if the clients interviewed are a representative sample of clients (in the short snapshot week periods) seen by the service since service start-up (7 January 2014) to 30 June 2016, the HJP is meeting its primary goal of reaching clients/patients otherwise not gaining legal help to solve their legal problems.

The data below suggests that having legal support beyond merely resolving a legal problem can have flow-on effects in reducing stress and anxiety, increasing a 'sense of security' even if the client's legal situation 'may not be ideal'. In other words, the access to legal help through the HJP is having a positive and demonstrable impact on the SDH. 
[Insert ANU logo and running head]

\section{Contact: Dr Liz Curran}

Senior Lecturer, ANU Legal Workshop (Australia-wide Professional Legal Training) \& Assoc. Director International Centre for the Profession, Education and Regulation in Law (PEARL), Australian National University, College of Law.

Mobile 0404106614

Email Liz.Curran@anu.edu.au

Canberra ACT 0200 Australia (Melbourne based)

www.anu.edu.au

CRICOS Provider No. 00120C. ORCID ID 0000-0002-6371-2975

Interestingly, in terms of the SDH, $100 \%$ of clients interviewed (a sample size of 10) reported that their stress had been reduced as a result of the intervention by the Bendigo HJP. Comments like 'I now know that I am not alone' or 'my voice is being heard by staff' were volunteered in response to the interview questions which were designed to elicit the quantitative data.

Figure 9.1 below charts the impact on client stress levels of the HJP intervention.

\section{FIGURE 9.1}

[Designer: Please insert a high-res version of the graph shown in the file titled Figure 9.1. Note the correction requested in this file.]

Overall, $60 \%$ of clients stated their stress had been reduced a lot as a result of the intervention, while $40 \%$ noted their stress had been reduced 'a bit'. None reported stress increasing or remaining the same - even though when you examine the qualitative data taken from clients in each of the three snapshots, their situations and circumstances were often far from ideal and often they had complex legal issues and complicated factors at play in their day-to-day lives.

Of the clients interviewed, $100 \%$ reported that their voice was being heard, which goes positively to indicate the proxy around empowerment with client 'voice' was in evidence. Similarly, in terms of the capacity proxy, $100 \%$ of clients reported that they 'knew more about the legal rights and where they sit in the legal process'.

All clients (100\%) also stated they 'feel they had options they did not know they had'. The response to this question is concerning when placed alongside the statistics from clients that reflected that, were it not for the HJP, they would not have known or sought legal assistance. This suggests that many clients who might not be currently being helped with legal support ( $86 \%$ of people experiencing some form of disadvantage or vulnerability according to the LAW Survey) are not able to avail themselves of legal rights as they did not know they had them.

The HJP has reached clients who would not otherwise have sought help. The use of trusted health/allied health professionals linking them in, a service that is co-located and 'visible', accessible, 'responsive' and the 'opportunistic' service at times when clients are there and ready, combine to not merely enable clients to have access to legal information and knowledge but to know about options they otherwise would not have known that they had. One might speculate that knowing of other options might lead to better and informed decision-making. 
[Insert ANU logo and running head]

\section{Contact: Dr Liz Curran}

Senior Lecturer, ANU Legal Workshop (Australia-wide Professional Legal Training) \& Assoc. Director International Centre for the Profession, Education and Regulation in Law (PEARL), Australian National University, College of Law.

Mobile 0404106614

Email Liz.Curran@anu.edu.au

Canberra ACT 0200 Australia (Melbourne based)

www.anu.edu.au

CRICOS Provider No. 00120C. ORCID ID 0000-0002-6371-2975

Anxiety and stress are exacerbated when there is a lack of a sense of security and experiences of disadvantage $;^{76} 90 \%$ of clients reported that they 'have a better sense of security now they know their legal rights'. This response is suggestive of the connection between knowing one's legal position, even if it may not be ideal, and feeling supported $(100 \%)$ and the sense of security that this provides, and a link between gaining legal support and a better sense of security. This goes directly to issues around having a positive impact through the HJP on the SDH.

The graphs and data tables (Figures 9.2 and 9.3) below demonstrate these responses:

\section{FIGURE 9.2}

[Designer: Please insert a high-res version of the graph shown in the file titled Figure 9.2.]

\section{FIGURE 9.3}

[Designer: Please insert a high-res version of the graph shown in the file titled Figure 9.3. Note the corrections requested in this file.]

\section{Aggregated Reach of Clients of HJP and Previous Lawyer Contact - Discussion}

The HJP has met one of the key aims, namely reaching people experiencing some form of disadvantage or vulnerability (which all clients report existed), with $90 \%$ of all clients interviewed noting that were it not for the referral from BCHS they would not have accessed a lawyer (see Figure 9.4 below).

\section{FIGURE 9.4}

[Designer: Please insert a high-res version of the graph shown in the file titled Figure 9.4. Note the correction requested in this file.]

\section{Aggregated Client Data, Early Intervention and Prevention - Discussion}

With $90 \%$ of clients saying they would not have accessed a lawyer without the HJP, $100 \%$ now say that they would seek help earlier in the future. This is suggestive of an effective and quality experience of the HJP and early intervention and prevention, where previously they would not have sought help, but now with the HJP they feel they are able to (see Figure 9.5 below). Early intervention and prevention was one of the key themes identified at the project outset to benchmark against and its presence in this data also goes to the effectiveness of the project.

\footnotetext{
76 Thoits, PA (2010), 'Stress and health: Major findings and policy implications', vol. 51(S), Journal of Health and Behaviour, pp. 41-53.
} 
[Insert ANU logo and running head]

\section{Contact: Dr Liz Curran}

Senior Lecturer, ANU Legal Workshop (Australia-wide Professional Legal Training) \& Assoc. Director International Centre for the Profession, Education and Regulation in Law (PEARL), Australian National University, College of Law.

Mobile 0404106614

Email Liz.Curran@anu.edu.au

Canberra ACT 0200 Australia (Melbourne based)

www.anu.edu.au

CRICOS Provider No. 00120C. ORCID ID 0000-0002-6371-2975

\section{FIGURE 9.5}

[Designer: Please insert a high-res version of the graph shown in the file titled Figure 9.5. Note the correction requested in this file.]

Of the clients interviewed, $100 \%$ would seek assistance again from the service and come back earlier for intervention. This suggests that by being more inclined to present earlier at the HJP, there might also be possible prevention of problems in future for these clients if they operationalise this inclination.

\section{Aggregated Client Data, Empowerment - Discussion}

$100 \%$ knew the steps being taken by their HJP lawyer on their behalf and felt better able to plan and organise their affairs as a result of their HJP legal help. This suggests the capacity proxy has been met and also that they are empowered to move forward. See Figures 9.6 and 9.7 below.

\section{FIGURE 9.6}

[Designer: Please insert a high-res version of the graph shown in the file titled Figure 9.6. Note the correction requested in this file.]

\section{FIGURE 9.7}

[Designer: Please insert a high-res version of the graph shown in the file titled Figure 9.7. Note the correction requested in this file.]

\section{Aggregated Client Data, Holistic Service - Discussion}

Given the clients interviewed all identified a range of complex problems and needs (which was also supported by the aggregated service data on the problems people presented with), the result that only $60 \%$ found their lawyers discussed other services may be an area for further consideration of holistic care. Just as the health partner is referring legal clients to the service, it makes sense if there is to be holistic care for the referrals to flow the other way. However, it may be no referral has occurred and these issues have not been followed up by the lawyer as they are already being dealt with through BCHS. See Figure 9.8 below.

\section{FIGURE 9.8}

[Designer: Please insert a high-res version of the graph shown in the file titled Figure 9.8. Note the correction requested in this file.]

\section{Overall Discussion of Figures 9.4-9.8}

As noted earlier, the client snapshot data was collected due to the burden of ongoing data collection for those delivering services (See discussion in Chapter Four, Full Final Report). This data in Figures 9.4-9.8 were consistent across all three snapshots and it 
[Insert ANU logo and running head]

\section{Contact: Dr Liz Curran}

Senior Lecturer, ANU Legal Workshop (Australia-wide Professional Legal Training) \& Assoc. Director International Centre for the Profession, Education and Regulation in Law (PEARL), Australian National University, College of Law.

Mobile 0404106614

Email Liz.Curran@anu.edu.au

Canberra ACT 0200 Australia (Melbourne based)

www.anu.edu.au

CRICOS Provider No. 00120C. ORCID ID 0000-0002-6371-2975

might be cautiously extrapolated that across other clients outside the snapshot periods, similar feedback might be provided.

\section{Aggregated Professional Data, Snapshots One, Two and Three - Discussion}

As noted earlier, two doctors provided feedback on the HJP in the final snapshot. It was clear from the qualitative responses detailed below that they had only just started to have a relationship with the HJP. In the case of each, this is likely to change with time and strategic effort by the HJP (see Chapter Fourteen, Recommendations). This is not inconsistent with issues in other jurisdictions where engaging doctors has been noted as a significant hurdle. ${ }^{77}$ The HJP experience in the USA and in this study both suggest doctor inclusion takes time and concerted effort and that once this occurs buy-in can be immense. ${ }^{78}$ Of all the feedback from professional staff, the most neutral came from these two doctors who are effectively latecomers to the project. It may be useful in future, with more time to tailor to the doctors' needs identified above, for ACR Justice and BCHS to check in again and see if, as with other professionals, the doctors' responses and practices in terms of responding to social and legal issues change over time with such support and targeted LSC. (See Chapter Fourteen, Recommendations.)

In the aggregated data (noting that some professionals were interviewed more than once across the snapshots; see discussion in Chapter Four), 90.9\% 'Strongly Agree' that they can confidently refer; $45.5 \%$ 'Agree' that the referral process to and from is clearly understood; and 36.4\% 'Strongly Agree' that the referral process is clearly understood (see Figure 9.9 below). These results are higher than they were when the initial baseline capture occurred in the online survey at service start-up and in Snapshot One.

\section{FIGURE 9.9}

[Designer: Please insert a high-res version of the graph shown in the file titled Figure 9.9. Note the corrections requested in this file.]

In relation to the responses ' $a$ '-'d' and ' $f$ ' \& ' $h$ ', the responses reflect HJP responsiveness and effectiveness.

\footnotetext{
${ }^{77}$ See Low Commission (2015), 'The Role of Advice Services in Health Outcomes', June, Consilium Research and Consultancy, London, available at: http://asauk.org.uk/wpcontent/uploads/2015/06/ASA-report_Web.pdf

${ }^{78}$ Tobin-Tyler, E (2012), 'Aligning public health, health care, law and policy: Medical-legal partnership as a multilevel response to the social determinants of health', Journal of Health \& Biomedical Law, no. 8, pp. 211-47.
} 
[Insert ANU logo and running head]

\section{Contact: Dr Liz Curran}

Senior Lecturer, ANU Legal Workshop (Australia-wide Professional Legal Training) \& Assoc. Director International Centre for the Profession, Education and Regulation in Law (PEARL), Australian National University, College of Law.

Mobile 0404106614

Email Liz.Curran@anu.edu.au

Canberra ACT 0200 Australia (Melbourne based)

www.anu.edu.au

CRICOS Provider No. 00120C. ORCID ID 0000-0002-6371-2975

The response to question ' $\mathrm{e}$ ' is lower than the other responses. This, when examined in light of the qualitative data, reflects the substantial work that needs to go into building relationships of trust and reciprocity across the different professionals, not just the health/allied health professionals but also the lawyers in their respect and referrals to BCHS as well.

In Snapshot Three, all managers interviewed highlighted that projects (which rely on the development of partnerships and work across different disciplines) require time and longer-term funding, and that with time the ease and sorting out of systems (IT and Intake), training, confidence and trust can all occur to a point where the work seems seamless. The physical layout of the lawyer's office, being 'visible' but 'confidential', were noted as important across all snapshots. In addition, corridor conversations, taking lunch together in the lunchroom and chats by the photocopier all were reminders to staff of the lawyer and a prompt or 'trigger' for them to explore with patients/clients the possibility of legal issues being promoted. Such informal connections were important for relationships being built that facilitated trust and ease. These aspects of building a relationship cannot be ignored and cannot be imposed from the top down; they need to occur naturally and organically. This was a strong point made by Noone in her 2010 study referred to earlier in the Full Final Report. Such relationships cannot occur overnight or be imposed from the 'top down', and they need support from senior management and sufficient resources, funding and understanding by funders of the value of such things to make effective work.

This trust and relationship importance was stressed by participants throughout the field research and is discussed in Chapters Ten and Eleven (the Collaborative Measurement Tool). The latter tool was applied in examining the progress over the life of the project. Given the author's brief for this HJPRAE includes making replications and other replicable models (Project Objectives v and vi) that may emerge in the future, the author notes that the results underscore that the challenge of HJPs and MDPs, in general, is building professional relationships across the different disciplines is not automatic or easy. These take time, effort and need constant nurturing, sustaining and building. This is discussed in more detail in Chapters Seven, Ten and Eleven, in the discussion of the qualitative data and also explains the quantitative data. This time to build relationships and break down problematic stereotypes that participants had experienced prior to their involvement with the Bendigo HJP needs to be factored into to any funding and appraisal of future HJPs and MDPs, if they too are to be as effective, efficient and targeted as the Bendigo HJP. Funders need to also take note of this. (See Chapter Fourteen, Recommendations.)

Similarly, across the project, the responses to the statement in ' $\mathrm{g}$ ' on examining 'systemic causes of problems' (Project Objective as per contract, see Chapter Two) 
[Insert ANU logo and running head]

\section{Contact: Dr Liz Curran}

Senior Lecturer, ANU Legal Workshop (Australia-wide Professional Legal Training) \& Assoc. Director International Centre for the Profession, Education and Regulation in Law (PEARL), Australian National University, College of Law.

Mobile 0404106614

Email Liz.Curran@anu.edu.au

Canberra ACT 0200 Australia (Melbourne based)

www.anu.edu.au

CRICOS Provider No. 00120C. ORCID ID 0000-0002-6371-2975

were lower. What was revealed by the qualitative data as a complement to understanding these results, is that responses to ' $\mathrm{g}$ ' can go to personal attitude and values and also can relate to confidence in advocacy and skills at identifying trends and seeing the pattern and link of the health to the legal settings, and this takes time to develop. As noted in Chapter Fourteen in the recommendations, over time it is likely that more joint work on systemic issues will continue. There was a shift from Snapshot One where not many staff were contemplating the possibility of joint HJP systemic responses. By Snapshot Two and Three there was more awareness and a letter was drafted in collaboration to a department about a problem with the department's administration. By Snapshot Three, some joint systemic work was emerging; e.g., submissions to the Royal Commission on Family Violence, to OPA, and on Care and Protection issues etc., and with intentions in the future to do more work on systemic issues in partnerships.

\section{Reflections on SDH and Capacity of Clients and Professional Staff over the Life of the Project}

In Snapshot Three, using question 23, the professionals were asked to reflect over the life of the project firstly on a series of conditions (e.g., 'stress', 'resilience') and what was the impact on clients of the HJP in relation to those conditions. In this case, the questions were not put to the professionals more than once and so there is no repetition across the other snapshots of participants.

This means the aggregated responses for question 23 can be taken as true aggregates (as they do not have the repetition of participants as some of the other aggregated data has, as some professionals may have answered the questions through different snapshots, as noted in Chapter Four). The results from the professional participants in terms of the perceived effect or impact of the HJP over the life of the project are summarised in the graph and data table below (see Figure 9.10.).

\section{FIGURE 9.10}

\section{[Designer: Please insert a high-res version of the graph shown in the file} titled Figure 9.10. Note the corrections requested in this file.]

\section{Discussion}

The response to question 23 by professionals, although only their perception/view on clients and so second-hand, should still be considered. Community health settings, such as the Bendigo HJP, place health/allied health professionals in the lives of the families and their children for a much longer time, due to complex needs including child and parent disabilities. Accordingly, as professionals, they have a sense of the effect on the patients'/clients' lives because of this routine and often regular contact with their clients 
[Insert ANU logo and running head]

\section{Contact: Dr Liz Curran}

Senior Lecturer, ANU Legal Workshop (Australia-wide Professional Legal Training) \& Assoc. Director International Centre for the Profession, Education and Regulation in Law (PEARL), Australian National University, College of Law.

Mobile 0404106614

Email Liz.Curran@anu.edu.au

Canberra ACT 0200 Australia (Melbourne based)

www.anu.edu.au

CRICOS Provider No. 00120C. ORCID ID 0000-0002-6371-2975

over time. This is illustrated in the in-depth interviews with the professionals (although small in number) who were able to track their patients/clients over the life of the research evaluation project. By contrast, as noted in Chapter Three, in hospital settings there is high patient turnover with admissions and discharges and where the exchanges can be more short term and one-off (e.g., in accident or emergency).

At the end of the research evaluation period and reflecting on the clients over the life of the HJP, professionals reported a positive impact of the Bendigo HJP on clients on their SDH in that:

- $\quad$ stress in clients was reported to have decreased by $90.9 \%$

- $\quad$ anxiety in clients was reported to have decreased by $90.9 \%$

- $\quad$ resilience in clients was reported to have increased by $90.9 \%$

- $\quad$ engagement in clients was reported to have increased by $90.9 \%$

- $\quad$ responsiveness in clients was reported to have increased by $90.9 \%$

- $\quad$ confidence in engaging with services in clients was reported to have increased by $90.9 \%$

- $\quad$ sense of hope in clients was reported to have increased by $81.8 \%$

- $\quad$ flow-on effects of the above to family members was reported to have increased by $81.8 \%$.

The latter response is suggestive that the impact of the intervention by the HJP may have also improved or positively assisted family members and so had a flow-on effect on their SDH. This is supported by the qualitative evidence collected in the data across all snapshots and discussed in Chapter Ten.

In terms of the effectiveness and quality of the HJP service and impact delivered, the following responses was reported by health/allied health professionals and are relevant:

- $\quad$ confidence in engaging with services in clients to have increased by $90.9 \%$

- $\quad$ knowledge of rights and responsibilities in clients to have increased by $72.7 \%$

- $\quad$ knowledge of options and more skilled over time in clients to have increased by $90.9 \%$.

These quantitative results suggest all the proxies are in evidence with an increase in engagement, capacity, collaboration and empowerment through the Bendigo HJP of non-professional staff involved in the Bendigo HJP at the BCHS KF site. These suggest that the Bendigo HJP project has had a positive impact on the SDH of clients as the proxies have been demonstrated to be present. They also indicate a significant change in practice when identifying and dealing with a client with legal problems. These go to providing evidence of the HJP improving responsiveness by building the professional 
[Insert ANU logo and running head]

\section{Contact: Dr Liz Curran}

Senior Lecturer, ANU Legal Workshop (Australia-wide Professional Legal Training) \& Assoc. Director International Centre for the Profession, Education and Regulation in Law (PEARL), Australian National University, College of Law.

Mobile 0404106614

Email Liz.Curran@anu.edu.au

Canberra ACT 0200 Australia (Melbourne based)

www.anu.edu.au

CRICOS Provider No. 00120C. ORCID ID 0000-0002-6371-2975

capacity of the health/allied health professional to assist clients who would otherwise not seek legal help, and 'changes in practice' which are associated with affecting positive SDH as discussed earlier in Chapter Three. The qualitative data discussed in Chapter Ten will also add flesh to how this has in fact been achieved, its impact and outcomes on the clients' SDH as well as on staff and client empowerment.

In a similar way, the longitudinal question 23 was posited at the research conclusion (nearing the end of the HJP pilot) to professional staff. They were also asked to reflect on their own experiences both in their 'professional capacity' and 'personally' in Snapshot Three on the impact of the HJP for them. They were asked to respond, reflecting over the life of the project, on a series of conditions (e.g., 'stress', 'resilience'). ${ }^{79}$ This also informed the proxy of capacity and themes of the SDH, including 'changes in practice' and the application of the Collaborative Measurement Tool. These are summarised in the graph and data table below (see Figure 9.11).

\section{FIGURE 9.11}

[Designer: Please insert a high-res version of the graph shown in the file titled Figure 9.11.]

This question enabled each professional participant to reflect longitudinally on the impact of the project and what it meant to their capacity and practice, and whether it had led to changes. The responses indicate that the HJP has had an impact, not just on clients but also on the professionals. Changes in practice are enabled through their capacity to better support and respond holistically to clients' legal problems, not just their social and health needs. The emergence of the lawyer as part of their team meant that it not only prompted a change in clients' SDH but that they as professionals feel enabled, empowered, more confident, capable and engaged in dealing and responding to client problems that are capable of a legal solution.

Professionals reported the personal and professional changes in themselves over the time of the Bendigo HJP as follows:

- $\quad$ Stress decreased by $75 \%$.

- $\quad$ Anxiety decreased by $75 \%$.

- $\quad$ Resilience increased by $75 \%$

- Trust increased by $87.5 \%$.

- Responsiveness increased by $87.5 \%$.

\footnotetext{
${ }^{79}$ In line with an ANU Ethics Variation in April 2016.
} 
[Insert ANU logo and running head]

\section{Contact: Dr Liz Curran}

Senior Lecturer, ANU Legal Workshop (Australia-wide Professional Legal Training) \& Assoc. Director International Centre for the Profession, Education and Regulation in Law (PEARL), Australian National University, College of Law.

Mobile 0404106614

Email Liz.Curran@anu.edu.au

Canberra ACT 0200 Australia (Melbourne based)

www.anu.edu.au

CRICOS Provider No. 00120C. ORCID ID 0000-0002-6371-2975

- $\quad$ Engagement increased over time by $87.5 \%$.

- Confidence increased by $75 \%$.

- Knowledge of rights and responsibilities increased by $62.5 \%$.

All of these responses again suggest that the four proxies of engagement, capacity, collaboration and empowerment of professional staff have been met to a significant degree over the life of the HJP project. This data is also relevant to the discussion of the Collaborative Tool in Chapter Ten.

\section{A Summary of the Survey Comparisons with Baseline Data of Service Taken of Health/Allied Health Professional BCHS Staff: Comparisons between Snapshot One, Two and Three}

As discussed in Chapter Nine, there were different participants in the surveys in Snapshots One, Two and Three. There were also variations in the response rates across the fours surveys administered from March 2014 which were directed across all BCHS sites, not just KF, so as to be consistent with the baseline data of the first survey undertaken by LCCLC on behalf of ARC Justice. Accordingly, changes in awareness levels and practice are likely to vary from across the whole agency to those staff where the HJP is situated. KF is where the relationships have been built and where the clients are assisted by the pilot project.

The survey was implemented to establish the baseline data and also had other questions the service wished to include, such as whether the professional was required to mandatorily report child abuse under Victorian legislation. It also set out to ascertain levels of awareness around legal issues of all of BCHS as of March 2014. The author was not involved in the initial administration of the survey as it was before ANU was commissioned to conduct the HJPRAE. The survey's utility is limited and it mainly serves to indicate that there may be a shift in awareness due to the pilot HJP at KF to other parts of the BCHS agency. For this reason, this HJPRAE Report and its findings will not give the results significant prominence as illustrative of the impact of the HJP on KF specifically and as the data is problematic for the reasons noted above and in Chapter Four, Methodology.

In Snapshot One there were 22 participants out of approximately 100 staff, with 15 actually responding to some questions. In Snapshot Two there were seven participants to the HJPRAE specific questions. In Snapshot Three there were 24 participants for the questions relevant to the HJP discussed in this Full Final Report. It is noted that questions 1-4 and 6-10 related to issues that ARC Justice wanted for data and these are unrelated to the HJPRAE. Also, many of those questions were unanswered. Although the author had some input into the questions for the online BCHS Staff Survey tool, the legal service also added its own questions to inform the service and some practice and 
[Insert ANU logo and running head]

\section{Contact: Dr Liz Curran}

Senior Lecturer, ANU Legal Workshop (Australia-wide Professional Legal Training) \& Assoc. Director International Centre for the Profession, Education and Regulation in Law (PEARL), Australian National University, College of Law.

Mobile 0404106614

Email Liz.Curran@anu.edu.au

Canberra ACT 0200 Australia (Melbourne based)

www.anu.edu.au

CRICOS Provider No. 00120C. ORCID ID 0000-0002-6371-2975

referral behaviours. Relevant to this research and this report were questions 5, 11-21 and later 22-24 in Snapshot Three. All participants responded to these questions.

Despite the variations in responses between the snapshots and the possible different personnel participating in the Survey Monkey, there are nonetheless consistent messages from the Survey Monkey about an increase in awareness in the wider BCHS agency. Awareness of a broader range of legal issues rather than just crime and family law occurred, extending to consumer law, debt, family violence, involvement with child and fines. Also, the awareness of and referrals for legal issues appear to have increased in their consciousness than previous to the Bendigo HJP. These appear to be more resonant when the responses are cross-referenced with the other research tool results. This therefore gives the online BCHS staff survey some limited utility as they may confirm, test and verify responses from across the other triangulated and different HJPRAE tools. It is also suggested that the lower participation rate in Snapshot Two for the online survey can be explained by the qualitative data as it correlates with the issues of the transition period. (See the discussion in Chapter Ten of the Full Final Report.)

Question Eleven of the online survey revealed similar responses from Snapshots One, Two and Three in that the key issues for which the professionals wanted assistance include family violence, involvement with child protection, debt, fines and consumer issues, in addition to discrimination, problems with Centrelink, crime, tenancy (this was higher for Snapshot One), disability and mental health. This is not surprising given the nature of the service where the Bendigo HJP is based (namely parents of children with disabilities in a low-socioeconomic demographic (see Chapter One, Full Final Report), the clients coming to the BCHS at KF. Interestingly, this is also consistent with the sorts of issues the community identified in the CFG as impacting on their SDH, discussed in Chapter Five on the CFG. The community participants discussed debt, child protection, fines, housing and consumer issues etc. as all possible issues that impact on their SDH as they increased their stress levels and led to utility cut-offs, reduced income, impacted on learning and left little money if there was a reduction in household income for food, heating, medical and educational necessities. When the CLSIS aggregated data (discussed in Chapter Seven) is examined, the HJP has been assisting clients with these same issues identified in the CFG and the online survey. This also suggests that clients are now receiving help from the HJP with the very issues that they identify as impacting on their SDH.

In Snapshot Three, $100 \%$ of all participants 'Strongly Agree' that the issues facing clients identified in the previous questions (and noted in the above paragraph of this report) adversely impacted on client health. This was an increase from $66 \%$ in Snapshot Two, which is suggestive of an increase in awareness as to how legal and social issues 
[Insert ANU logo and running head]

\section{Contact: Dr Liz Curran}

Senior Lecturer, ANU Legal Workshop (Australia-wide Professional Legal Training) \& Assoc. Director International Centre for the Profession, Education and Regulation in Law (PEARL), Australian National University, College of Law.

Mobile 0404106614

Email Liz.Curran@anu.edu.au

Canberra ACT 0200 Australia (Melbourne based)

www.anu.edu.au

CRICOS Provider No. 00120C. ORCID ID 0000-0002-6371-2975

can affect their clients and the connection of these as impacting 'adversely' on their clients' SDH.

It is noted that all staff in the online survey wanted more information on the issue of 'cyberbullying and sexting'.

Snapshot Two saw an increase, albeit slight in the frequency and numbers of referrals to lawyers, for BCHS participants from all sites. This contrasts with Snapshot One which had seen an increase from start-up. Snapshot Three saw an increase in referrals or providing legal information once a week again to levels higher (namely 75\%, making referrals to a lawyer and referrals once a week 41.6\%) than in Snapshots One (making referrals to a lawyer and referrals once a week or two - making referrals to a lawyer $85.7 \%$ and once a week $71.3 \%$ noting there were only seven participants).

In response to the question as to whether the health/allied health professionals routinely ask clients if they need legal advice/help, in Snapshot Three 20.83\% stated they 'Strongly Agree', 37.50\% stated they 'Agree', 33.3\% 'Disagreed' and 8.3\% 'Strongly Disagree'. This is higher than for Snapshot One ('Strongly Agree' 6.67\%; 'Agree' 53.33\%; 'Strongly Disagree' 33.33\%) but lower than for Snapshot Two ('Strongly Agree' 0\%, 'Agree' 100\%; 'Strongly Disagree' 0\%). Overall, it is suggestive of an increase in the practice of health/allied health professionals at all BCHS sites (not just $\mathrm{KF}$ ) who now routinely ask clients if they need legal advice/help from Snapshot One to Snapshot Three.

There was a shift in the response over three snapshots to the question 'I routinely ask clients if they need legal assistance'. In Snapshot One (22 Participants) 6.67\% 'Strongly Agree', 53.33\% 'Agree', 6.67\% 'Disagree' and 33.33\% 'Strongly Disagree'. In Snapshot Two (7 Participants) 0\% 'Strongly Agree' and 100\% 'Agree'. In Snapshot Three (24 Participants), in response to the same question, 20.83\% 'Strongly Agree', 37.50\% 'Agree', 33.33\% 'Disagree' and 8.33\% 'Strongly Disagree'. The movement upwards in professionals asking clients if they need legal assistance tends to be at the 'Strongly Agree' or 'Agree' level.

In Snapshot Three, as noted in Chapter Eight, some additional questions were also asked to assist in the application of the Collaborative Measurement Tool (discussed in Chapter Ten). In response to the question, 'A community lawyer on my team at BCHS will ensure that client legal problems do not escalate and client overall health is improved', 75\% 'Strongly Agree', 16.67\% 'Agree' and 8.33\% were 'Not Sure'. In response to the question, 'Collaborative, client-focused practice at BCHS can successfully involve a lawyer', 70.83\% 'Strongly Agree', 20.83\% 'Agree' and '8.33\%' were unsure. These responses are encouraging and suggestive of the overcoming of the initial professional barriers and resistance that emerged in responses to some of the survey questions in the first two snapshots, as noted above. It suggests that over time, 
[Insert ANU logo and running head]

\section{Contact: Dr Liz Curran}

Senior Lecturer, ANU Legal Workshop (Australia-wide Professional Legal Training) \& Assoc. Director International Centre for the Profession, Education and Regulation in Law (PEARL), Australian National University, College of Law.

Mobile 0404106614

Email Liz.Curran@anu.edu.au

Canberra ACT 0200 Australia (Melbourne based)

www.anu.edu.au

CRICOS Provider No. 00120C. ORCID ID 0000-0002-6371-2975

if there was any ambivalence across the $\mathrm{BCH}$ three sites in Bendigo about having a lawyer, this has dissipated and has shifted to a sense that having them as part of a team can enhance the clients' health.

In Snapshot Three, participants of the online survey considered if collaborative, clientfocused practice at BCHS can successfully involve a lawyer: $70.83 \%$ 'Strongly Agree', 20.83\% 'Agree' and $8.3 \%$ were 'Not Sure'.

In aggregated data from all of the snapshots, $50 \%$ of the participants were asked if a 'Legal Health Check Tool' would assist them in their current work. In all of the snapshots, the majority answered in the affirmative. Reception staff in their interviews also asked for one and said it would be helpful. In Chapter Fourteen's recommendations, it is suggested that a very simple 'Legal Health Check Tool' be available to all BCHS staff at all sites. Based on both the survey response and qualitative data, it ought to be one that can be easily integrated with existing health tools so as to not make more work for staff but also to enable it to be a routine part of the assessment and intake process for all BCH staff.

Relevant to the online survey tool with the whole $\mathrm{BCH}$ staff were comments from reception staff and some other health/allied health professional staff who noted in their interviews that they were of the view that the experience of KF had seeped through into other parts of BCHS, and that through word of mouth from clients and colleagues there was a better understanding of the value of an HJP over time. Some noted that other BCHS site staff were 'jealous of the fact that KF had an HJP'. (Interview with reception, Snapshot Three)

As noted, this online survey data is problematic for a range of reasons, but other data from the other tools is more relevant, informative and precise. Caution is needed in extrapolating from the Survey Monkey data alone given the variation in response rates and types of professionals responding to each snapshot survey. The survey results should be read merely in the context of all the other data. It is also reiterated that there was consistency in the personnel interviewed from Snapshots One, Two and Three and that they were all at the KF site where the HJP is based.

In conclusion, there was an observable increase in health/allied health professionals asking if clients need legal help (47\% in the short to medium term and $58.3 \%$ in the longer term, respectively). This seems significant in terms of the theme of client reach and a 'change in practice' by non-legal professional staff. 
[Insert ANU logo and running head]

\section{Contact: Dr Liz Curran}

Senior Lecturer, ANU Legal Workshop (Australia-wide Professional Legal Training) \& Assoc. Director International Centre for the Profession, Education and Regulation in Law (PEARL), Australian National University, College of Law.

Mobile 0404106614

Email Liz.Curran@anu.edu.au

Canberra ACT 0200 Australia (Melbourne based)

www.anu.edu.au

CRICOS Provider No. 00120C. ORCID ID 0000-0002-6371-2975

\section{Chapter Ten - Aggregated Qualitative Data, Analysis and Discussion}

As noted, quantitative data helps explain the qualitative data and the reasons for what works well and why or why not. These questions are critical for a research evaluation that aims to gauge the impact of the service on client and professional lives, and inform the possible replication of other HJP models and future practice and funding considerations.

Qualitative data, although cumbersome, also uncovers the complexities of the HJP work and client circumstances and the barriers at the client, service and systemic levels. As noted in Chapter Two, there is a document which contains the data from the three snapshots that is over 320 pages in length. Many studies do not gather qualitative data to the same extent as this project as it is time-intensive to analyse and reproduce. The author and ARC Justice were concerned that if largely quantitative data was collected then it would possibly miss the layers of complexity and difficulty that the client group encounter. As the author's brief was to find out the actual impact on clients' lives and their SDH that went beyond transactions to measure what had occurred in their lives, qualitative data collection was an essential tool. It forms a complement to large quantitative data also collected in this HJPRAE in going deeper to understand the impact on the service on clients' lives. The two combined help explain service patterns and responsiveness and give a more complete picture to enable reflection and improvement in line with the action research model the author is taking for this research evaluation.

As noted earlier, SDH are hard to measure but it is not impossible to measure them. By and large, most of the conclusions in the report from client and professional feedback on SDH impacts are drawn on a 'it is possible that' rather than a 'if this is there then this the conclusion'. Stating what the client identified as a consequence compared to what is a likely consequence is a common trap in qualitative analysis, and to mix what the client/participant actually said with our assumptions of what the consequences are is not necessarily correct and can overstate things or supplant interpretations too strongly. The author asks therefore that the data presented below all be considered with this qualification/constraint in mind.

\section{Longitudinal Case Studies from April 2015 - 10 June 2016}

Health/allied health professionals were asked to track two clients (with the clients' informed consent) over the three snapshots as there are difficulties in tracking clients by other means (as discussed earlier in this report) and ethics issues around recontacting clients in this vulnerable group. Although only four health/allied health professionals 
[Insert ANU logo and running head]

\section{Contact: Dr Liz Curran}

Senior Lecturer, ANU Legal Workshop (Australia-wide Professional Legal Training) \& Assoc. Director International Centre for the Profession, Education and Regulation in Law (PEARL), Australian National University, College of Law.

Mobile 0404106614

Email Liz.Curran@anu.edu.au

Canberra ACT 0200 Australia (Melbourne based)

www.anu.edu.au

CRICOS Provider No. 00120C. ORCID ID 0000-0002-6371-2975

in the in-depth interviews (and one who did so for Snapshots 1 and 3) collected this client information over time, it gives insights into seven clients over the course of the HJPRAE. This complements the 10 individual client interviews undertaken by the project team.

The longitudinal case studies reinforced the other findings: that clients presenting at BCHS and in the Bendigo HJP have complex problems that take time to resolve, as well as the multiple and cascading nature of the issues for this client group.

Each of the longitudinal case studies presented by the health/allied health professionals in the in-depth interviews reiterated that engagement, capacity of and collaboration between professionals, and empowerment all had an impact in enabling improvements in client SDH. This included reductions in their stress and anxiety, an 'ability to get on with their lives', and a 'help' to the professionals in getting the clients to focus on their health needs as their legal matters 'were being taken care of'. This is illustrated in some of the extracts below from the in-depth interviews with health/allied health professionals. Each longitudinal case study highlights that the problems experienced are interconnected, and where there is a holistic approach such as the Bendigo HJP, inroads have been made not just in resolving the legal problems but in giving the client space to now work on their other health issues.

Key feedback on these longitudinal clients summarised from the qualitative data collected is as follows.

Client One (longitudinal) - still engaged with AOD and still engaged with the HJP lawyer. Conflicts make it difficult to know, as well as confidentiality of client, so hard to keep abreast of where it's at from the health/allied health professional's point of view. Client has been engaged and responsive over the project with the HJP. Client was overwhelmed and confused before referral and work undertaken by the HJP on their behalf, but is no longer. Legal involvement has led to reunification with child, hope and educational attainment. Lawyer tries but not exactly sure where legal matter is now with this client. Client engaged with the last two snapshots with the HJP, whereas previously they had a bad experience with lawyers, so kept away.

Client Two (longitudinal) - matter resolved. After getting assistance, the client was better able to manage the issues so that she was in line with the legislation. She came in again in relation to a different matter. She is well supported and had moved along. Client is empowered and resourced. Co-location and responsiveness have been key for this client. Lawyer always approachable noted by client in feedback to their allied health professional.

Client Three (longitudinal) - still gets legal and health/allied health professional help. She is less stressed now she is slowly having multiple legal issues solved and with 
[Insert ANU logo and running head]

\section{Contact: Dr Liz Curran}

Senior Lecturer, ANU Legal Workshop (Australia-wide Professional Legal Training) \& Assoc. Director International Centre for the Profession, Education and Regulation in Law (PEARL), Australian National University, College of Law.

Mobile 0404106614

Email Liz.Curran@anu.edu.au

Canberra ACT 0200 Australia (Melbourne based)

www.anu.edu.au

CRICOS Provider No. 00120C. ORCID ID 0000-0002-6371-2975

lawyer helping. As a result, her health/allied health professionals have been able to engage better with her on her other health and social stuff as she is less worried, as some of the legal issues have gone away and others are in the lawyer's hands. She has more capacity and is empowered. Intervention by the lawyer 'absolutely useful' in assisting with the client's problem: 'There is greater support in terms of me referring to the legal service. The client gets support for mental health and wellbeing that in combination with the legal issues being resolved has a positive impact on her daily wellbeing and health. By being assisted by two practitioners, the client gets a better picture of the way forward. This also allows the client to check in. "Choice is important for our clients." Seems to be a holistic approach - we can look at a range of the client's problems as you are seeing the client holistically.' 'She is functioning well. She wasn't when she came to BCHS and Bendigo HJP. In terms of counselling, our service does not stop as a result of a negative legal outcome. The client can come and talk about that outcome. This is a benefit of the HJP. There is obviously a limit as to how long the lawyer can remain engaged, so we pick the client up with the wraparound service and holistic service. There would have been an outcome but the outcome was enhanced by the inclusion of the lawyer. Lawyer does things in timely manner ... and has never said she does not have capacity. She takes the work on.'

Client Four (longitudinal) - has disengaged from BCHS and Bendigo HJP. She was hugely positive and doing really well as a result of the lawyer sorting out a large number of her issues. Was back in training and getting her life together with re-establishment of contact with her child. As a result of changes to Children Youth and Families Act 2005 (Victoria) legislation, she decided 'what was the point' as she could no longer have hope due to laws saying she had to do certain things in 12 months. This is a client with significant trauma and even getting access to some services takes more than the 12 months. As BCHS has other community engagement programs, she is still connected to this and that is a positive thing. When she is ready she may re-engage as she trusted the lawyer and the workers, but the systemic changes in 2016 gave her little hope. BCHS and ARC Justice through the HJP are trying to reform the new laws to make them fairer and more humane.

Client Five (longitudinal) - 'I'd say because they were able to make contact that day I'd say the stress was reduced. They were either offered an appointment that day or the next day.' Health professional wished they had a longer-term case (the client from Snapshots One and Two no longer seen by health/allied health professional): 'yet to see the continuum ... those that have disengaged will eventually find their way back here. If I were looking for positive outcomes, I would not be working in AOD. What I have witnessed is the way the lawyer works - they work like us. They engage with the client and respect the client. The lawyers respect the client, give me confidence. I value the support from the lawyer.' 
[Insert ANU logo and running head]

\section{Contact: Dr Liz Curran}

Senior Lecturer, ANU Legal Workshop (Australia-wide Professional Legal Training) \& Assoc. Director International Centre for the Profession, Education and Regulation in Law (PEARL), Australian National University, College of Law.

Mobile 0404106614

Email Liz.Curran@anu.edu.au

Canberra ACT 0200 Australia (Melbourne based)

www.anu.edu.au

CRICOS Provider No. 00120C. ORCID ID 0000-0002-6371-2975

Client Six (longitudinal) - reported that they were doing well and had hope in Snapshots One and Two. Not seeing them now but think they are doing well. In this case the intervention has worked and so I don't think they need to engage. It can shift from client to client.

Client Seven (longitudinal) - the client has moved on via support from someone else. Resilience and faith in the world. 'Terrified rabbit most of the time' but lawyer made them realise they had legal rights, which was empowering. 'Positive outcome.'

\section{Data Extracted is Pertinent to the Identified Themes, SDH and Proxies}

The author has had to be ruthless as to what has been selected for this Full Final Report, given the data was plentiful, rich and compelling.

The author has selected the data most representative of all participant comments across all the tools. In extracting the qualitative data, it has been organised under the proxy headings and matters relevant to the SDH identified by clients, professionals and the literature and key themes (see Chapter Four, Methodology in the Full Final Report). The author has also endeavoured to take the extracts from each snapshot from an even spread of the different professionals participating rather than from the same professional.

The qualitative data that has been selected as consistent across the research participants is extracted below. In brackets after each extract are the relevant additional themes, proxies and SDH in addition to those under which they have been categorised in this report, so as to evidence the indicators as present have been provided. Chapter Twelve also discusses some issues that emerged in Snapshot Two and which emerged strongly in the data collected in Snapshot Three, namely issues in relation to professional cultures and ethics. In line with the project brief, the chapter will also apply the data emerging to a broader application than in the Bendigo HJP: to legal practice in general and other HJPs. It also covers the discussion of the Collaborative Measurement Tool and its application (also relevant to the discussion under the proxy of collaboration). These were not necessarily flagged in Snapshot One as it was the early days of the project. In addition, the chapter will examine a need for economic modelling and costing of HJP impact.

In the extracts there is a demonstrable difference between Snapshots One and Two. By Snapshot Three there is clear movement to positive achievement in all the proxies and significant feedback suggestive of possible positive impacts on client SDH, professional integration and collaboration. Transition issues in Snapshot Two had been remedied in Snapshot Three. The HJP, based on the snapshot data, is clearly very much on-site, with a building of the trust and relationships. Consequently, data shows benefits 
[Insert ANU logo and running head]

\section{Contact: Dr Liz Curran}

Senior Lecturer, ANU Legal Workshop (Australia-wide Professional Legal Training) \& Assoc. Director International Centre for the Profession, Education and Regulation in Law (PEARL), Australian National University, College of Law.

Mobile 0404106614

Email Liz.Curran@anu.edu.au

Canberra ACT 0200 Australia (Melbourne based)

www.anu.edu.au

CRICOS Provider No. 00120C. ORCID ID 0000-0002-6371-2975

flowing on to clients, lawyers and health/allied health professionals alike. After each extract, the indicators are identified as present and in brackets.

1. Proxy One - Engagement (including responsiveness, learning and life skills development) - clients, community \& professionals of BCHS and the Legal Services lawyer/s

\section{Client Engagement}

'Yes, BCH helping with all of my issues. Housing worker, drug and alcohol worker - great, very helpful. Been in services for a long time and this one is remarkable. We can come to the one place and everything is here. BCHS know the history, so I don't have to keep going over my history. If there is stuff I don't know how to answer, counsellor can help. Counsellor has been at every appointment with lawyer (I can't remember everything). Three months ago I was a mess. Counsellor helps me remember. Lawyer helped me meet with CASA and St Luke's and general help with getting psychology services. Linked in with services to help as my son is moving back home - counselling to assist me reengage with son. When first here I was a mess. I wouldn't make appointments with lawyer. Need to allow scope for setting up service. Drug addicts are expected to conform to normal person's life and time lines. Life is unmanageable as an addict. Need to have a service that takes into account the timing of an addict.' (Interview with Client, Snapshot One) (Engagement, also collaboration, reach, capacity, empowerment, integration)

'We have a client that has a chaotic life. She knows that lawyer is there and gets help with her matter which revolves around her child. Engages when she is organised enough to get here - by turning up she understands that the 'team' will help. If lawyer not here, reception will inform lawyer etc.' (Interview with BCHS reception, Snapshot One) (Engagement, also collaboration, integration)

'Lawyer demystifies the legal jargon and because lawyer is here clients don't have to go into a legal office. Some clients won't read legal letters, whereas lawyer will keep all correspondence on foot. When clients don't read legal correspondence this leads to myriad issues due to the addiction and apathy. By having lawyer here to deal with the legal issue and assist, this scenario is avoided. Simply having the intervention here in terms of interpreting the letters for the client may prevent escalation of a client's issue. I certainly could not provide this legal aspect to the service. Waiting two weeks for a reply is not going to assist my client. Having a lawyer working on-site - spontaneous, helps clients get help quickly, improvement in the client's ability to cope with their problem/s. Varies, particularly with the women. Had we not linked to lawyer, 
[Insert ANU logo and running head]

\section{Contact: Dr Liz Curran}

Senior Lecturer, ANU Legal Workshop (Australia-wide Professional Legal Training) \& Assoc. Director International Centre for the Profession, Education and Regulation in Law (PEARL), Australian National University, College of Law.

Mobile 0404106614

Email Liz.Curran@anu.edu.au

Canberra ACT 0200 Australia (Melbourne based)

www.anu.edu.au

CRICOS Provider No. 00120C. ORCID ID 0000-0002-6371-2975

the women would have been categorically in a worse position.' (Interview with health/allied health professional, Snapshot One) (Engagement, also complexity, capacity, early intervention \& prevention reach, empowerment, integration)

'If someone was acutely distressed. there was capacity to get someone else in the room (professional) to assist. A pre-existing relationship with workers here enables me to refer quickly. The referral professional is just down the corridor which makes the referral easy. I gain a sense of the professional over time and this creates a trusting relationship. The clients see this and understand the trusting relationship between workers. The service is integrated - many vulnerable clients would not otherwise engage with services.' (Interview with health/allied health professional, Snapshot One) (Engagement, also collaboration, reach, capacity, integration)

'Clients benefit - talk about how easy it is to walk around to the lawyer. Many clients say they would not have been able to get any legal advice without the lawyer. Most don't have the ability to pay for legal advice. The clients need this advice. The clients are so marginalised that without assistance the clients will fail. Lawyer gives people HOPE. The information lawyer gives is correct and assists. Without the service, people's suicidality increases - people cannot see a way out.' (Interview with health/allied health professional, Snapshot One) (Engagement, also reach, capacity, hope, SDH)

'When you have a rapport and service connection, it has value. It helps also if it's an Indigenous client to work with a community worker who is from an Indigenous agency or is Indigenous ... there is value to having cultural knowledge ... lately lawyers are getting better at explaining the law ... If the lawyer works alongside a social worker it will open their eyes. I saw a lawyer once rolling their eyes at the social worker. That's not a good thing. Clients are not stupid and can interpret body language and disrespect. If they have a relationship with their social worker it will put them off the lawyer. I reckon it reduces the stigma attached to lawyers if they are working in a social service or a health service; signs of permission, building trust and also if it's a mental health client with fines, bad housing, having the impacts of an IVO, then if services are disconnected they will not get help and go round in continuous circles. Our clients have many needs and so a support service that wraps professionals around each other so they can all work to help a client is a way, and as long as it engages it will change behaviours ... Perception that lawyers are higher up and they are the authority and intelligent ones. Most lawyers may be fantastic but if clients and workers don't know what they're saying, how can they be helping? ... plain English .... Our clients need a point of contact. They 
[Insert ANU logo and running head]

\section{Contact: Dr Liz Curran}

Senior Lecturer, ANU Legal Workshop (Australia-wide Professional Legal Training) \& Assoc. Director International Centre for the Profession, Education and Regulation in Law (PEARL), Australian National University, College of Law.

Mobile 0404106614

Email Liz.Curran@anu.edu.au

Canberra ACT 0200 Australia (Melbourne based)

www.anu.edu.au

CRICOS Provider No. 00120C. ORCID ID 0000-0002-6371-2975

will not go to services all over town. They will nod and say they understand when they do not or bow to authority as they do not want to make trouble ... Aboriginal community is complex and can be confronting. They tend to be better face to face when they trust and get to know the person. Unpacking their story over and over re-traumatises them and often they have enough trauma in their lives. Engagement paints a picture of who they are talking to. They may be uncertain of white people based on experiences ... they hear 'yes I understand' but then get no follow-up from services ... there are stereotypes about lateness but how can you get there if you have no clocks, no home and no car and transport-simple things ... Lawyers are outside our clients' experience unless sit in a court, and often they don't want to be there, so it takes effort and time to build the trust and connections. I reckon an HJP would be a good start ... Can we have one?' (Interview with relationship holder - external, Snapshot Two) (Engagement, also collaboration, reach, responsiveness, holistic service integration)

'If there is the wrong person in the lawyer role it could lead to not getting clients. Where there is an openness to clients and no judgement and where there is no arrogance, it works. Clients have their own ....*** detector. If the lawyer uses non-legal professionals as a resource and they can work together, then it's reciprocated and you are more likely to get a "transferral of trust", otherwise there are defences or barriers for worker and client alike. The value of this HJP to us has been the accessibility, the co-location and that it's free for clients.' (Interview with relationship holder - manager, Snapshot Two) (Engagement, also collaboration, capacity)

'Expecting clients to go elsewhere, to hold onto phones when they are poor and it's pre-paid, is not helpful. If there is a bill they will not be able to pay it, they get exasperated and so it's a deterrent, but when the lawyer is here day to day we can pick them up by a simple smile when they come to pharmacotherapy. That's the start of it. They come and go and slowly they feel there's no judgement as it's a community health setting. Some do activities here not related to service and all these things pick them up and then if we know how to identify their issues if the person is visible and nearby it triggers us to make a referral or have a chat to the lawyer ... they often distrust authority anyway and so they are unlikely to contact a legal service or not identify a remedy which might be critical in the sense of their broader health issues. You don't improve health by providing health services alone if you are serious about addressing health and welfare, so having many disciplines including lawyers, listening to others, having a presence when they need to be heard to support them and being able 
[Insert ANU logo and running head]

\section{Contact: Dr Liz Curran}

Senior Lecturer, ANU Legal Workshop (Australia-wide Professional Legal Training) \& Assoc. Director International Centre for the Profession, Education and Regulation in Law (PEARL), Australian National University, College of Law.

Mobile 0404106614

Email Liz.Curran@anu.edu.au

Canberra ACT 0200 Australia (Melbourne based)

www.anu.edu.au

CRICOS Provider No. 00120C. ORCID ID 0000-0002-6371-2975

to be there at crisis point, is the way to help. People want trust and respect and someone who is a highly qualified lawyer.' (Interview with receptionist, Snapshot Two) (Engagement, also SDH, complexity, negative previous experience of legal system, reach, capacity)

'DHS allegations were unsubstantiated. Lawyer assisted. Because you are broke you must have mental health issues. DHS are one organisation I am glad I no longer have to deal with. Lawyer did all the phone calls and all the mediation for me. She put over my point of view when I told what was right and what was not. DHS conditions were very onerous - they detailed who daughter should spend time with but she pushed back too and said "I'll decide who I'll spend time with".' (In-depth interview with health/allied health professional, Snapshot Two) (Engagement, also SDH)

'The lawyer has to work on trust and she does. We felt very respected and welcome.' (In-depth interview with health/allied health professional, Snapshot Two) (Engagement, also collaboration)

'She made me feel comfortable and at ease and respected.' (In-depth interview with health/allied health professional, Snapshot Two) (Engagement)

'Continuity is the big one. They feel like they can get the range of supports they need to get help. The less that they have to jump around and get support from specialist services, the better off the client. There is not only the black letter legal assistance, there is the value add by the service offered that seeks to support clients in a more empowering way.' (Interviews with relationship holders - managers, Snapshot Three) (Engagement, also, reach, integration \& collaboration, empowerment))

\section{Professional Staff Engagement}

'Feel like there's been a backward step. Once booked in a client with lawyer one, now client sent to another lawyer at the legal service. Three lots of us. I had to prepare him to turn up. Client had different issues and had to see different lawyers. These clients need greater antennae and to ensure greater outcomes for clients' needs to be seamless. This needs to be rebuilt as "out of sight, out of mind" in recent times. No training in recent times means low referrals and need professional development at the door, physical presence.' (In-depth interview with health/allied health professional, Snapshot Two) (Breaks in engagement, integration \& collaboration, transition)

'Email and responsiveness, seeing person in their office is the prompt - if the lawyer is approachable; trust is really important for me to be prepared to refer 
[Insert ANU logo and running head]

\section{Contact: Dr Liz Curran}

Senior Lecturer, ANU Legal Workshop (Australia-wide Professional Legal Training) \& Assoc. Director International Centre for the Profession, Education and Regulation in Law (PEARL), Australian National University, College of Law.

Mobile 0404106614

Email Liz.Curran@anu.edu.au

Canberra ACT 0200 Australia (Melbourne based)

www.anu.edu.au

CRICOS Provider No. 00120C. ORCID ID 0000-0002-6371-2975

as you want the engagement with both me as professional and my client to be meaningful. If you don't get on with the person or know them, you are less likely to refer ...' (In-depth interview with health/allied health professional, Snapshot Two) (Engagement, also, reach, integration \& collaboration, empowerment))

'The service provision of the HJP where clients know their rights, what they can do to stay safe, and service provision that gives them information in one place, at one time, when they feel safe in the environment of a health centre where they are not judged ... not going off here there and everywhere as they often do not have the wherewithal to do that and have child-care commitments and are scared ... so supports at court, information in a quick, timely way can help not just with the immediate issue but the other matters that are buried and often ignored that impact on wellbeing.' (Interview with relationship holder manager, Snapshot Two) (Engagement, also capacity, SDH)

'Opportunistic time and place is important. Often if the client is talking to staff they are in stress or crisis and being able to access someone has been invaluable. To be able to access advice or get help has been great [legal]. Being able to have someone in the building or via the telephone has been great. Has worked well for the client. Our staff try and have a little knowledge about legal issues but it is better that the lawyer can offer advice. Sometimes it is about being able to do things straight away, if you don't work in this space you don't always understand how important this is.' (Interviews with relationship holders managers, Snapshot Three) (Engagement, also responsiveness, reach, integration \& collaboration, SDH)

'The lawyer who has been on-site had been able to establish great relationships with BCHS workers. As you go up the levels of management the tiers seem to overlap more. The lawyers have built a great relationship between the workers on the ground and as you move up, the conversations tend to flow better. The work of the lawyers has forged the conversations. The subject matter of the conversations changes slightly but the overall strategy is about getting the HJP to remain on foot. A lot of the work of the HJP has identified that we need to work towards equity. Service for purpose is important. Because we have been able to build relationships and service, we don't want to lose the service. The conversation between upper level changes but does ID that the project needs to remain in place ... The experience of the HJP has opened up the possibilities for clients. In the past we have assisted our clients to access other services but having, for example, legal services here is important.' (Interviews with relationship holders - managers, Snapshot Three) (Engagement, also reach, $\mathrm{SDH}$, responsiveness, multilevel integration \& collaboration) 
[Insert ANU logo and running head]

\section{Contact: Dr Liz Curran}

Senior Lecturer, ANU Legal Workshop (Australia-wide Professional Legal Training) \& Assoc. Director International Centre for the Profession, Education and Regulation in Law (PEARL), Australian National University, College of Law.

Mobile 0404106614

Email Liz.Curran@anu.edu.au

Canberra ACT 0200 Australia (Melbourne based)

www.anu.edu.au

CRICOS Provider No. 00120C. ORCID ID 0000-0002-6371-2975

'Workers have the opportunity to talk about a client who has a number of issues etc. The week before last we had the lawyer talk about herself and her role but the staff who used the service talked about the benefits, they were able to talk about the positive outcomes. Clients were able to deal with fines. At least three staff talked about how they made a warm referral. Was easy to walk down the corridor or call. If worker was not sure of how they could help, they could make a warm referral.' (Interviews with relationship holders - managers, Snapshot Three) (Engagement, also capacity, responsiveness)

'Ease of referral. Less waiting for feedback. Clients have been able to see the lawyer on-site even without an appointment, which is important. Goodfeedback that is swift.' (In-depth Interview with health/allied health professional, Snapshot Three) (Engagement, also reach, integration \& collaboration, responsiveness)

'Worked with one of the clients. I had secondary consultation. Brief overview of what was going on to determine if lawyer could help - both clients went on to speak to the lawyer... client 1-was to do with client's wife. They had an argument. Police charged him. Wife didn't want that to happen. Police did it anyway. Lawyer spoke with him. He was supported. The outcome in the end is not what we'd hoped for unfortunately, the nature of the client group. I'd say because they were able to make contact that day, I'd say the stress was reduced. They were either offered an appointment that day or the next day. I wished that I had a longer-term case but I don't have a long case. I am yet to see the continuum ... those that have disengaged will eventually find their way back here. If I were looking for positive outcomes, I would not be working in AOD. My hope is that they will find their way back. What I have witnessed is the way the lawyer works - they work like us. They engage with the client and respect the client. The lawyer's respect for the client gives me confidence. I value the support from the lawyer.' (In-depth interview with health/allied health professional, Snapshot Three) (Engagement, also responsiveness, capacity, SDH reach, integration \& collaboration)

'The co-location helps a great deal, particularly with refugee clients. When I've asked the newer lawyer to come in, she does and helps. It helps their client's mental health when we respond immediately by getting a solicitor to talk. Quick secondary consultation occurs very fluidly. I've never had to demonstrate why I need the help to the lawyer; the lawyer trusts me and extends me the professional respect knowing that I have identified a real issue. I think that having a lawyer on-site is pivotal, is critical to our clients' wellbeing, particularly those clients that would not otherwise have access to legal 
[Insert ANU logo and running head]

\section{Contact: Dr Liz Curran}

Senior Lecturer, ANU Legal Workshop (Australia-wide Professional Legal Training) \& Assoc. Director International Centre for the Profession, Education and Regulation in Law (PEARL), Australian National University, College of Law.

Mobile 0404106614

Email Liz.Curran@anu.edu.au

Canberra ACT 0200 Australia (Melbourne based)

www.anu.edu.au

CRICOS Provider No. 00120C. ORCID ID 0000-0002-6371-2975

assistance. Very clear with refugee clients who don't really understand appointment timing etc. Having a lawyer here makes the process easier to navigate. We look at attendances and non-attendances. Do the lawyers get a higher attendance rate here than they do at the CLC ... I'd say because they were able to make contact that day, I'd say the stress was reduced. (In-depth interview with health/allied health professional, Snapshot Three) (Engagement, also responsiveness, capacity, SDH reach, integration \& collaboration, empowerment)

'Co-localised services de-escalate clients' issues. Clients being able to walk into a community health service takes away from the client's sense of being stigmatised. We are in a very middle-class setting. Our clients are judged by the outside world. The notion of a client being able to walk into a health service and get help, including legal issues which are often very pressing, is great. Not having this option, clients often won't be able to seek the information for themselves. By intervening you are assisting with health issues. Many of our clients in this service are intergenerational, they are used to being treated or not knowing that things can be different, that they don't have to put up with that. That they have legal rights. I've had to talk to child protection and they quote legislation at me and I find it difficult to understand and I'm an educated person. We ask a range of questions about our clients' psycho-social problems which includes legal questions, stock-standard questions plus ongoing assessment. There are often triggers for when a client is not travelling so well. Often parents slip back when their children have been taken to the cop shop, there is a negative impact all the way down the line. Workers have the opportunity to talk about a client who has a number of issues etc.' (Interviews with relationship holders - managers, Snapshot Three) (Engagement, also responsiveness, capacity, complexity, early intervention \& prevention, SDH reach, integration \& collaboration, empowerment)

2. Proxy Two - Capacity - of clients, community, professionals of BCHS and the Legal Services lawyer/s.

\section{Client Capacity}

'Why am I less stressed? Well with the lawyer, I know my options. I never knew I could fight and be heard. I didn't know my options after reunification and I never knew I could get half so far. Now I feel I have my life back. I am on the way to a certificate and feel like jumping in the air like the Toyota ad.' (Interview with Client, Snapshot Two) (Capacity, also SDH, hope, empowerment) 
[Insert ANU logo and running head]

\section{Contact: Dr Liz Curran}

Senior Lecturer, ANU Legal Workshop (Australia-wide Professional Legal Training) \& Assoc. Director International Centre for the Profession, Education and Regulation in Law (PEARL), Australian National University, College of Law.

Mobile 0404106614

Email Liz.Curran@anu.edu.au

Canberra ACT 0200 Australia (Melbourne based)

www.anu.edu.au

CRICOS Provider No. 00120C. ORCID ID 0000-0002-6371-2975

'People should be able to know their rights like I do. They should know they have choices, not just been told and threatened so they sign away their rights to their child. The lawyer also got DHS off my back which made me more stressed and likely to make more mistakes ... you need to get the word out there about your service, in fact I am going to post how good you are on my Facebook page as there are lots of people in KF who think they have to do what they are told and I want them to know their rights like I do. '(Interview with Client - Snapshot Two) (Capacity, also SDH, hope, empowerment)

\section{Professionals' Capacity}

'It has complemented my practice and added to it and enhanced it. It has helped me to reaffirm that I am on the right path. It refreshes my knowledge. It assists me to make sure that I make those referrals and helps me keep them at the forefront.' (Interview with health/allied health professional, Snapshot One) (Capacity, also SDH, empowerment)

'Given me another lens to look at the client's issues and options to respond to the client. Simple e.g. - colleague's client was on sexual offenders register, some limitations the client mentioned sounded iffy. Checked with lawyer if the limitations [legal] were real. Lawyer said yep, absolutely.' (Interview with health/allied health professional, Snapshot One) (Capacity, also reach)

'By holistically addressing issues including legal, the clients get a better sense of community and they can see we are gaining traction around their issue - this creates the "pull-up" for the issue. This is not a streamlined process per se but we are trying to make it more streamlined.' (Interview with health/allied health professional, Snapshot One) (Capacity, also movement to integration \& collaboration)

'One training on child protection and protection orders reaffirmed and put the "ducks in a row" for me. I used the information to advocate on behalf of the client with the DHHS. "DHHS misinformed me" and I was then able to identify that fact.' (Interview with health/allied health professional, Snapshot One) (Capacity, also reach, empowerment)

'I think being able to cross-refer like this has been a huge benefit of our HJP. It allows me to focus more on the legal issues, with the knowledge that the client has that additional emotional support that is also so vital for a positive outcome to be sustained in future.' (Guided professional journals - legal professionals, Snapshot One) (Capacity, also collaboration) 
[Insert ANU logo and running head]

\section{Contact: Dr Liz Curran}

Senior Lecturer, ANU Legal Workshop (Australia-wide Professional Legal Training) \& Assoc. Director International Centre for the Profession, Education and Regulation in Law (PEARL), Australian National University, College of Law.

Mobile 0404106614

Email Liz.Curran@anu.edu.au

Canberra ACT 0200 Australia (Melbourne based)

www.anu.edu.au

CRICOS Provider No. 00120C. ORCID ID 0000-0002-6371-2975

'Training is not just formal. Conversations are critical. Email just doesn't cut it unless it's a follow-up. I have come to realise it [training] happens by secondary consultation and it's all interrelated ... consistent access means that they can ask questions that are often pivotal to clients at important stages. They then often use that information again and again. Site meetings, chats by the photocopier are critical for the lawyer to be at. You mingle and there are opportunities to have conversations that you would never have if you are offsite and they are like training as and when it's needed and when it resonates.' (In-depth interview with lawyer, Snapshot Two) (Capacity, also engagement, integration \& collaboration)

'The training especially in the beginning has been very helpful; it's expanded my view of the legal process, it comes also through secondary consultations. I have learned there are no absolutes but there are also limitations in what can occur in that. I know the legal system is not easy but I can come and check in with the lawyer when not sure. That's invaluable - previously I would have been reticent to go there. I know that the process can be different in each individual's circumstances and so I am more cautious now and able to double-check. I haven't had much PD training as I am often off-site with my complex clients but that's where secondary consults come in and those corridor conversations. I am learning it's $O K$ to be patient and double-check and having exclusive lawyer access makes it easy. I don't think there's been a day in my practice when I have not used what I have learned from the HJP to help a client.' (In- depth interview with health/allied health professional, Snapshot Two) (Capacity, also engagement, LSC and empowerment)

'There are lots more clients out there who never get help. Training us professionals, if done well and in a way that helps us practically and is practical based on our actual work, means we can help you guys reach them. If we don't know what is legal, you are there and how you can help, well we cannot help you reach them ... you need to advertise more to make it work and amongst different professionals and agencies ... I know it's just a trial now and you don't want to bite off more than you can chew but there are lots of client still out there in dire need of help who are invisible ... model like your HJP is going to make inroads.' (Interview with relationship holder - external, Snapshot Two) (Capacity, also reach, engagement, empowerment)

'Training that's tailored and sequential like building blocks is key; combine this with secondary consultations and we get validations and it helps our confidence in helping clients ... it empowers us to do what we need to do, to front up to power when it's abused and arm our clients when they get tramped on ... so 
[Insert ANU logo and running head]

\section{Contact: Dr Liz Curran}

Senior Lecturer, ANU Legal Workshop (Australia-wide Professional Legal Training) \& Assoc. Director International Centre for the Profession, Education and Regulation in Law (PEARL), Australian National University, College of Law.

Mobile 0404106614

Email Liz.Curran@anu.edu.au

Canberra ACT 0200 Australia (Melbourne based)

www.anu.edu.au

CRICOS Provider No. 00120C. ORCID ID 0000-0002-6371-2975

often our clients expect the worse when that is not what they are entitled to under the laws. I realise now that laws govern everything and so, often there is a way. Did not know that before but so many other of my colleagues do not know this.' (In- depth interview with health/allied health professional, Snapshot Two) (Capacity, also SDH, reach, hope, engagement, empowerment)

'Training ... make sure it's not filled with legal jargon, its non-judgemental, acknowledges some of us do have experience and are professionals. '(Interview with relationship holder - manager, Snapshot Two) (Capacity, also collaboration, engagement)

'Not aware of any client or community of KF community legal education by the HJP yet but it is vital. They are often scared and rarely get an opportunity.' (Indepth interview with health/allied health professional, Snapshot Two) (Capacity, also empowerment.)

'More CLE for the community would be great.' (Interview with lawyer, Snapshot Two) (Capacity)

'You can build on a relationship by email and a phone call but the foundation for a professional relationship is confidence and personal knowledge of the casework; referrals need to come but they don't if you don't trust. Training plays a part as if poorly done you go backwards. It's all connected. You need to keep at it and not take relationships for granted and you also need to help us revisit knowledge, as once-off training does not all get retained - that's why it all works in together. Secondary consultations can reinforce training. If we have secondary consultations, we will want to do the training, but if it's not done in a way that respects us and what we have to do and heavy caseloads and in a sensible way, then we will just see it's a waste of time and that will then impact on your engagement proxy too. We want to help our clients too but we also don't and can't waste our time. Training and PD needs to be thought through not just in terms of content but effective delivery that is meaningful to us in practice.' (In-depth interview with health/allied health professional, Snapshot Two) (Capacity, also engagement, reach, LSC)

'Have done specific training. I've attended the staff development day. I try to embed myself as much as I can. I attend team meetings. I have been to a number of groups. Went to BCHS induction. Team meetings are good. The workers find it hard to identify at times problems that are legal. I've told workers to approach me and ask if they think there is a legal issue. I make myself available and approachable. The door is always open. In-situ learning via team meeting. Referrals come out of the team meeting exercise. I try to be as flexible as 
[Insert ANU logo and running head]

\section{Contact: Dr Liz Curran}

Senior Lecturer, ANU Legal Workshop (Australia-wide Professional Legal Training) \& Assoc. Director International Centre for the Profession, Education and Regulation in Law (PEARL), Australian National University, College of Law.

Mobile 0404106614

Email Liz.Curran@anu.edu.au

Canberra ACT 0200 Australia (Melbourne based)

www.anu.edu.au

CRICOS Provider No. 00120C. ORCID ID 0000-0002-6371-2975

possible. Some clients live closer to Bendigo so I book them in here at HQ on occasion. Got a lovely bunch of flowers from a client last week.' (In-depth interview with lawyer, Snapshot Three) (Capacity, also responsiveness, engagement)

'When I see the lawyer we debrief about where a client is at. The information is being exchanged between lawyer, client and worker. This helps me deal with the client more efficiently because it reinforces the message to the client, allows us to check if we are all on the same page and working in the same direction. If the client has misunderstood something, it allows us to clarify the issues.' (Indepth interview with health/allied health professional, Snapshot Three) (Capacity, also integration \& collaboration, holistic, responsiveness, engagement, empowerment)

3. Proxy Three - Collaboration - between clients, community, professionals of BCHS and the Legal Services lawyer/s and other relevant partners.

\section{Client and Professional Collaboration}

'If someone is acutely distressed there is the capacity to get someone else in the room [professional] to assist. A pre-existing relationship with workers here enables me to refer quickly. The referral professional is just down the corridor which makes the referral easy. I gain a sense of the professional over time and this creates a trusting relationship. The clients see this and understand the trusting relationship between workers. The service is integrated - many vulnerable clients would not otherwise engage with services.' (In-depth interview with lawyer, Snapshot One) (Collaboration, also SDH, reach, engagement)

'This is a new trial, forging new relationships and work in a new way for all of us. We are trying to break out of silos and traditional oppositions and adversarial settings, especially for lawyers, which is why the type of lawyer is key, as I said in Snapshot One. It's not always comfortable but we need to work through this as it is a better way of getting to the clients who need us.' (Interview with relationship holder - manager, Snapshot Two) (Collaboration, also SDH, reach, engagement, culture (see Chapter Eleven))

\section{Organisational Collaboration}

'I know the lawyer and a manager at BCH [de-identified], CEO of legal centre [de-identified], researcher and assistant [de-identified] have spoken at conferences. This also educates and informs about how we are reaching clients through this innovative model. This helps others know about it and is important 
[Insert ANU logo and running head]

\section{Contact: Dr Liz Curran}

Senior Lecturer, ANU Legal Workshop (Australia-wide Professional Legal Training) \& Assoc. Director International Centre for the Profession, Education and Regulation in Law (PEARL), Australian National University, College of Law.

Mobile 0404106614

Email Liz.Curran@anu.edu.au

Canberra ACT 0200 Australia (Melbourne based)

www.anu.edu.au

CRICOS Provider No. 00120C. ORCID ID 0000-0002-6371-2975

to give others the confidence to have a try at it.' (Interview with relationship holder - manager, Snapshot Two) (Collaboration, also engagement, capacity, culture (see Chapter Eleven))

'By working in a team, all perspectives can be looked at from different professional perspectives ... many of the problems have been there a long time and it was a matter of taking a different perspective to make solutions more sustainable and reduce the problems; the partnership enables us all to think differently and leads to solutions. If all professions are open to having a conversation, then there is more likely to be a holistic approach. Realise that if you want a response you need to build health rather than the traditional acute system. Simple things can get overlooked but if there is a conversation across professionals we will think about and hear and question and think of the context and situation and solutions.' (Interview with relationship holder - manager, Snapshot Two) (Collaboration, also early intervention \& prevention, SDH, capacity, culture (see Chapter Eleven))

'This model is about health and justice and making a difference to wellbeing ... though if legal issues could be identified earlier this might make a real difference. We as managers had a number of conversations before this about the location, the client group and different pathways to the vulnerable. Some issues have legal issues, yes, but this group is hidden and we thought how can we make a difference by making it safe to go to a lawyer when otherwise too scared. What made the difference was that the partners share the same values, that is a commitment to justice and having an impact where things are unfair. The manager of the legal service was prepared to put themself out there and we have trust and respect for him and the new lawyer who he bought in at start-up. We are all coming from an honourable place. It's all about relationships ... it's valid as it comes from an interdisciplinary team approach that works through the issues a client has ... sometimes people jump to a solution too fast. Here conversations can happen ... and do something that others might miss.' (Interview with relationship holder - manager, Snapshot Two) (Collaboration, also engagement, capacity, responsiveness, culture (see Chapter Eleven))

'The SDH are based around engagement and capacity, collaboration, and empowerment. If we had a lawyer who came in with traditional lawyer values, it would not have worked. The partners working together need to have a shared vision. Both organisations are trying to reach out to the vulnerable, and having a BCHS worker facilitate the relationship between lawyer and client is a really good thing. The approach of the professional staff has rubbed off on the lawyers. The two different languages between the workers creates positive role 
[Insert ANU logo and running head]

\section{Contact: Dr Liz Curran}

Senior Lecturer, ANU Legal Workshop (Australia-wide Professional Legal Training) \& Assoc. Director International Centre for the Profession, Education and Regulation in Law (PEARL), Australian National University, College of Law.

Mobile 0404106614

Email Liz.Curran@anu.edu.au

Canberra ACT 0200 Australia (Melbourne based)

www.anu.edu.au

CRICOS Provider No. 00120C. ORCID ID 0000-0002-6371-2975

modelling for both types of worker, shared learnings. The working of two professions together and having dialogue builds competence around each professional's expertise - if the lawyer speaks jargon the BCHS worker would feel confident to ask questions, and that in turn allows the client to ask questions which empowers the client. With confidence comes empowerment. This also demystifies and destigmatises a lawyer's role, creates familiarity between the worker and client. The client will invariably feel better able to cope when having to deal with other lawyers in the future. Secondary consultations are what provide the pathway of information and on processes. For example, what happens with the filing of documents. They are of immense value to me as otherwise I would be confused. I can check in. I know when I am not sure I can just ask. The beauty is that we are not the experts but it helps us navigate the system for our clients, especially as many clients may not be ready to see a lawyer right away. You need to understand that many of our clients, if they have even had a lawyer at all, it may not have been a good experience - it might have been a traumatic one. So we use secondary consultations to help clients who would otherwise never see a lawyer and help them ready themselves to see one if they need to by building up the trust. Most lawyers do not do a great job of respecting clients and to be honest I used the secondary consultation to test out the lawyer a number of times myself to see if I would be prepared to hand over my client. You see, if a client is likely to be further harmed, we have a duty of care. I have through the HJP come to see a different type of lawyering which is truly effective. It gives me confidence; I know I can check in quickly which helps me help other clients and it provides a pathway - who is going to refer cold with such vulnerable clients, so you need to know that secondary consultations are heavily linked into whether we will refer or not, and if we don't have a good sense of the lawyer and how they will engage with our client, we may not then refer.' (In-depth interview with relationship holder - manager, Snapshot Three) (Collaboration, also engagement, LSC, capacity, culture (see Chapter Eleven))

'Well, I know it's a collaboration. We have stopped using the terminology of co-location now. When we started it was all training and legal need identification that still needs to happen, especially with staff turnover and refreshing, but now it's a team approach. The staff are much less guarded, there is trust, relationships have been tested, especially during the transition around the second snapshot, but we have moved forward and are all stronger for it. There is less promoting, it's now more seamless and business as usual that we work together seamlessly. I reflect on when we first started this and really we had no idea we were in siloes, but now the clients are better off, we are better informed and we have changed our practice to a point where it's truly multi- 
[Insert ANU logo and running head]

\section{Contact: Dr Liz Curran}

Senior Lecturer, ANU Legal Workshop (Australia-wide Professional Legal Training) \& Assoc. Director International Centre for the Profession, Education and Regulation in Law (PEARL), Australian National University, College of Law.

Mobile 0404106614

Email Liz.Curran@anu.edu.au

Canberra ACT 0200 Australia (Melbourne based)

www.anu.edu.au

CRICOS Provider No. 00120C. ORCID ID 0000-0002-6371-2975

disciplinary, inclusive of law and the lawyers. It would not have worked if we had not had the right type of lawyers, as I have said previously, and good staff who are client-centred and who are working through issues for the SDH outcomes for clients. We share a vision and that has been key. I would like to see more reporting along the way.' (Interview with relationship holders managers, Snapshot Three) (Collaboration, also engagement, capacity, SDH, reach, culture (see Chapter Eleven))

'Boards and executive of both partners, and I guess that's been a learning, they need to also be included more in the reporting and dialogue about the HJP, and neither partner has probably done this enough. The reality for our clients is that without having the smaller things sorted, it means an escalation of stress and anxiety which has risks to their family. With the HJP here they now have had options and they come through the door, disclose to health and allied health and then they get help and then their stress and anxiety goes down. This is a direct effect on their HJP and often means we can work with them in a less anxious and heightened state to address their health and social wellbeing. It's been so great having the HJP, I want it to stay. It's become part of the way we do business.' (Interview with relationship holders - managers, Snapshot Three) (Collaboration, also engagement, capacity, SDH, reach, culture (see Chapter Eleven))

4. Proxy Four - Empowerment, advocacy and voice - clients, community, professionals of BCHS and the Legal Services lawyer/s, and involvement in systemic work for change informed by on-the-ground experience.

\section{Client Empowerment}

When I first started I did not have money to pay a lawyer. But having access to the services at BCHS assists because prior I would have paperwork coming in and not knowing what to do with it would make me anxious. The lawyer helps me in this respect. Been going so slow for so long that it takes time. The lawyer is very approachable and keeps me informed of the work she is doing. Informed me where there might be weaknesses and where there might be strengths. She informed me about process and where it was not being followed by the department, which could have affected the outcome of my matter. Prior to HJP, a private law practice and the lawyer did not listen and did not clarify instructions before sending out correspondence. Fair to say this is a contrast, how the lawyer operates and looks after me.' (Interview with Client, Snapshot One) (Empowerment, also SDH, capacity, engagement) 
[Insert ANU logo and running head]

\section{Contact: Dr Liz Curran}

Senior Lecturer, ANU Legal Workshop (Australia-wide Professional Legal Training) \& Assoc. Director International Centre for the Profession, Education and Regulation in Law (PEARL), Australian National University, College of Law.

Mobile 0404106614

Email Liz.Curran@anu.edu.au

Canberra ACT 0200 Australia (Melbourne based)

www.anu.edu.au

CRICOS Provider No. 00120C. ORCID ID 0000-0002-6371-2975

'People need information and advice on what they can do and can't do - if they get the information here at the BCHS it absolutely helps in de-escalating issues. It often gives a way for our clients in a space that's safe to them, and that's invaluable to have information available at the right times, when they are likely to disclose to their trusted health/allied health professional. We work from an empowerment model. We try to provide the best access points and this has helped us do that. They are actively involved in their own treatment. This has a direct positive benefit directly in their treatment.' (Interview with relationship holders - managers, Snapshot Three) (Empowerment, also SDH, capacity, early intervention \& prevention, integration \& collaboration, reach, impact \& effectiveness)

'Feel more confident about the law. I feel I have a better knowledge of the right of a mum and for the safety of my child [NB: family violence matter]. I'm better able to plan and organise my affairs. Because I am in control of them.' (Interview with Client, Snapshot Three) (Empowerment, also SDH, capacity, early intervention \& prevention, impact \& effectiveness)

'Out of all my history, DHHS would have been involved but not fair that they took all my kids away. Had I known the legal system back then I probably would have fought and won. No support for parents. I suffer from PTSD. Have started a Facebook page - Parenting and Venting with privacy settings to help others, now I know more about the law and what is right and not right.' (Interview with Client, Snapshot Three) (Empowerment, also SDH, capacity, early intervention $\&$ prevention, integration \& collaboration, reach, impact \& effectiveness)

\section{Professional Empowerment}

'The scenario of DHHS saying no but the lawyer saying well, it might actually be a maybe - the department sometimes uses scare tactics on parents; the lawyer can assist in dispelling these myths. "Hope produces better outcomes."

"Knowing your options create hope." When we have a lawyer to help, the client is assisted by feeling that there is more of a community assisting them. Discussing client's prior issues for e.g. sexual abuse with the lawyer opens up opportunity for further impact as one client was awarded a payout from the commission.' (Interview with health/allied health professional, Snapshot One) (Empowerment, also SDH - changes in practice, reach, capacity, early intervention \& prevention, integration \& collaboration, impact \& effectiveness)

'Systemic work to stop causes of client problems - two things come to mind. Professional was drafting a report to $C P$ and I assisted in the drafting of the letter to CP. Other thing comes to mind was our contribution to OPA report. 
[Insert ANU logo and running head]

\section{Contact: Dr Liz Curran}

Senior Lecturer, ANU Legal Workshop (Australia-wide Professional Legal Training) \& Assoc. Director International Centre for the Profession, Education and Regulation in Law (PEARL), Australian National University, College of Law.

Mobile 0404106614

Email Liz.Curran@anu.edu.au

Canberra ACT 0200 Australia (Melbourne based)

www.anu.edu.au

CRICOS Provider No. 00120C. ORCID ID 0000-0002-6371-2975

Provided the paper to BCHS staff to get their sense of the content.' (In-depth interview with lawyer, Snapshot Two) (Empowerment, also SDH, capacity, early intervention $\&$ prevention, integration \& collaboration, reach, impact \& effectiveness)

'Hey, what would be good is to get training where we rehearse how to use the law with the decision-makers. That is, put it into practice: how do we elevate and argue or negotiate to get an outcome for our client ... like using the human rights charter ... What to say and do when we get push-back ... give us more confidence to know how to ask the right questions. Yeah, like to also see us do more systemic stuff together. Identifying at-risk groups and things that are not helpful and work together to change them and get law reformed and administration improved. I am curious about all this but would not know how to go about it and you guys are good at the art of persuasive argument ... would be good to share it so we can advocate more and solve problems earlier or before they get large.' (In-depth interview with health/allied health professional, Snapshot Two) (Empowerment \& voice, also SDH, capacity, early intervention $\&$ prevention, reach, impact \& effectiveness)

'Joint public policy work is and has happened on ASD [autism]. We had a go. The lawyer brought our attention to an inquiry. It was for an under-represented group and potentially fragmented group. The lawyer asked us about it and we need to take some action. Lawyers work in a different realm. We don't often find out about these things but we could make the submission. Lawyer cannot access client group but we can so it is positive. Empowerment from a policy perspective - not unique to autism. People can have a lot of things that contribute towards their issues but often cannot contribute towards policy submissions. We can pass on information to allow the information to be used productively. You need a linkage to the client and service and the knowledge of where to input.' (In-depth interviews with health/allied health professionals, Snapshot Three) (Empowerment, also SDH - changes in practice, capacity, early intervention \& prevention, integration \& collaboration, reach, impact \& effectiveness)

\section{Reductions in anxiety and stress (SDH)}

\section{Client Stress/Anxiety}

'Client has come online with a change in medication. Addiction treatment has been improved along with assistance from lawyer; the two interventions combined have assisted the client. The client's addiction and substance abuse will always be present, but the mother's improved attitudeloutlook towards 
[Insert ANU logo and running head]

\section{Contact: Dr Liz Curran}

Senior Lecturer, ANU Legal Workshop (Australia-wide Professional Legal Training) \& Assoc. Director International Centre for the Profession, Education and Regulation in Law (PEARL), Australian National University, College of Law.

Mobile 0404106614

Email Liz.Curran@anu.edu.au

Canberra ACT 0200 Australia (Melbourne based)

www.anu.edu.au

CRICOS Provider No. 00120C. ORCID ID 0000-0002-6371-2975

being a mother via the lawyer's intervention has assisted the client. Stress is reduced, engages better and does not miss appointments. Self-care and outlook are better.' (Interview with health/allied health professional, Snapshot One) (Stress \& anxiety reduced also $=\mathrm{SDH}$, engagement)

'Once I got linked to the lawyer and she got involved, my anxiety got better. I am not on Xanax. Now I have help so my anxiety has reduced.' (Interview with Client, Snapshot Two) (Stress $\&$ anxiety reduced also $=$ SDH (drug dependence reduced), engagement)

'My stress has decreased, no drugs but I am on methadone. I have significantly reduced my reliance on medication.' (Interview with Client, Snapshot Two) (Stress $\&$ anxiety reduced also $=$ SDH (drug dependence reduced), engagement)

'The stress levels of clients go right down; for example, a client of mine had for 3-4 years been a quite dependent drug user. She was getting her life into order and I must say with these clients sometimes one setback can see them spiral backwards. The client had a minor accident and was devastated and the car couldn't be repaired. She had run into a gutter. The police charged her and she was very worried and ashamed. She really believed it would be on the front page of the paper and magnified the issue as she was not able to see through things. With the help of the lawyer in the HJP who was there and available, she was reassured. Later, the lawyer helped her in court and the magistrate noted that the police had been over-zealous and that she could keep her licence. Having the lawyer represent and the comments of the magistrate as a result made a real difference to her. The lawyer and non-legal health professionals worked alongside and managed the medical reports too. It was what you can do when you all work together as a team and the system works. By seeing how her case was managed, the client felt she was treated like an adult and supported. She had a sense she was not alone. If she had not been able to keep her licence, for this client it would have diminished her life options and her capacity to engage with services and community. There is no bus to get her to the key activity that keeps her going and so this was all pivotal to her health and wellbeing and averted in my view a recurrence and spiralling backwards.' (In-depth interview with health/allied health professional, Snapshot Three) (Stress \& anxiety reduced also $=\mathrm{SDH}$, capacity, engagement $)$

'I know I should not have worried quite so much about the criminal matter. We have seen the court bloke. Wanted to see if I have engaged with services. Getting a good doctor is important and lawyer has helped me to engage with services.' 
[Insert ANU logo and running head]

\section{Contact: Dr Liz Curran}

Senior Lecturer, ANU Legal Workshop (Australia-wide Professional Legal Training) \& Assoc. Director International Centre for the Profession, Education and Regulation in Law (PEARL), Australian National University, College of Law.

Mobile 0404106614

Email Liz.Curran@anu.edu.au

Canberra ACT 0200 Australia (Melbourne based)

www.anu.edu.au

CRICOS Provider No. 00120C. ORCID ID 0000-0002-6371-2975

(Interview with Client, Snapshot Three) (Stress \& anxiety reduced also $=\mathrm{SDH}$, capacity, engagement, collaboration)

'My fits are stressful for my daughter. HJP lawyer took stuff off my plate but lawyer has helped me to feel like things will be OK legally. My daughter is going to school.' (Interview with Client, Snapshot Three) (Stress \& anxiety reduced also $=\mathrm{SDH}$, capacity, engagement)

'I sleep better at night.' (Interview with Client, Snapshot Three) (SDH)

'There was a risk of losing my son and I had nowhere to live.' (Interview with Client, Snapshot Three) (SDH)

'Lawyer also explored what the options might be if we need to consider down the track. Made me not stress out as much.' (Interview with Client, Snapshot Three) (Stress \& anxiety reduced also $=\mathrm{SDH}$, capacity, engagement)

'She made sure that all the debt collectors communicated with her, not me, so one by one we got the issues dealt with.' (Interview with Client, Snapshot Three) $(\mathrm{SDH})$

'A young mother was stressed and had been provided misinformation about her rights in relation to her child. The lawyer was able to correct this misinformation and provide the mum with next steps in a concrete way. This meant for all of us the mum's decisions were informed and clearer and she was less stressed. She was an intervention order client and so she knew what to be wary of and not only could she be less stressed but safer.' (In-depth interview with non-legal professional, Snapshot Three) (Stress \& anxiety reduced also = $\mathrm{SDH}$, capacity, engagement)

\section{Professionals' Stress/Anxiety}

'Our job can be stressful too. Knowing we have somewhere to turn now when there are legal issues or something just doesn't seem right has significantly enhanced my ability to respond and help clients and accordingly reduces my own stress and anxiety, built my confidence and also made me more effective, so it's a win-win really.' (In-depth interview with non-legal professional, Snapshot Three) (Stress \& anxiety reduced, also capacity, engagement, empowerment)

'Access to a lawyer for my clients has made the job much easier and I make referrals. It's given the patients back their quality of life and I feel so much better when I know I have enabled that to happen.' (In-depth interview with 
[Insert ANU logo and running head]

\section{Contact: Dr Liz Curran}

Senior Lecturer, ANU Legal Workshop (Australia-wide Professional Legal Training) \& Assoc. Director International Centre for the Profession, Education and Regulation in Law (PEARL), Australian National University, College of Law.

Mobile 0404106614

Email Liz.Curran@anu.edu.au

Canberra ACT 0200 Australia (Melbourne based)

www.anu.edu.au

CRICOS Provider No. 00120C. ORCID ID 0000-0002-6371-2975

non-legal professional, Snapshot Three) (Stress \& anxiety reduced also $=$ SDH, capacity, engagement $\&$ responsiveness)

'Honestly, sometimes having gone to see the lawyer about a client has meant that I have been able to sleep better at night.' (In-depth interview with nonlegal professional, Snapshot Three) (Stress \& anxiety reduced also $=\mathrm{SDH}$, capacity)

\section{Changes in practice of professional staff (SDH)}

'It has complemented my practice and added to it and enhanced it. It has helped me to reaffirm that I am on the right path. It refreshes my knowledge. It assists me to make sure that I make those referrals and helps me keep them at the forefront.' (Interview with health/allied health professional, Snapshot One) (Changes in Practice (CiP), also capacity, engagement)

'Spontaneity of having the lawyer here. Previously there was more running around trying to get assistance from Legal Aid. Multiple and cascading issues. Because of dual diagnosis and co-morbidities, substance abuse and anxieties compound this client. (Interview with health/allied health professional, Snapshot One) (Changes in Practice (CiP), also capacity, complexity, multiple problems, engagement)

'Added knowledge imparted by lawyer and the lawyer lens. Helps to understand the full ambit of the client's issues. Lawyer corrects professional staff assumptions. Builds upon my practice - "more wholesome practice". Knowledge increases positive outcomes from lawyer ... my ongoing interaction with clients improves.' (Interview with health/allied health professional, Snapshot One) (CiP, also capacity, complexity, empowerment, multiple problems, engagement)

'It's changed my practice in terms of my competency and my confidence in what to question and the questions I can ask. I have more confidence to have the lawyer around whereas previously I would have been scared to ask. I am getting help for the client when I and the client needs it - it's made a clear difference in a positive way.' (In-depth interviews with health/allied health professionals, Snapshot Three) (CiP, also capacity, empowerment, engagement)

'Recently l have referred a few refugee clients to the lawyer through the HealthJustice Partnership. Having lawyer on-site has been so useful. On a number of occasions $l$ have been in a counselling session with a client with a phone interpreter and an issue arose that l needed to refer to the lawyer. At these times $l$ was able to go and see the lawyer in the middle of the appointment and ask if 
[Insert ANU logo and running head]

\section{Contact: Dr Liz Curran}

Senior Lecturer, ANU Legal Workshop (Australia-wide Professional Legal Training) \& Assoc. Director International Centre for the Profession, Education and Regulation in Law (PEARL), Australian National University, College of Law.

Mobile 0404106614

Email Liz.Curran@anu.edu.au

Canberra ACT 0200 Australia (Melbourne based)

www.anu.edu.au

CRICOS Provider No. 00120C. ORCID ID 0000-0002-6371-2975

she was available to attend my session. The lawyer was able to meet this need which had a direct positive impact on my client's wellbeing and mental health.' (Professional journals, Snapshot Three) (CiP, also SDH, capacity, empowerment, engagement, integration \& collaboration)

'Over the life of this project, professional differences, where there were any, have been overcome. It flows onto clients. They see the mutual respect between the professionals and the communication and mutual respect of the agencies, the workers for the lawyer and the lawyer for the worker, and this means a lot. It builds the trust for the client in knowing people are working together, when so often their experience is services working in contradiction to each other. The thing is, as professionals we have all been learning - we have learned about each other's roles, at times we have contested ideas, but that has led to better outcomes. We question and test each other in a good way and that leads to more nuanced and better responses. It's certainly changed my view of lawyers which was not so great before the HJP started. The process of sharing and learning and being clear with each other has been well managed and we have all learned. It's a great model.' In-depth Interview with health/allied health professional, Snapshot Three) (CiP also, SDH, capacity, empowerment, engagement, integration\& collaboration, culture (See Chapter Eleven)

'Changed how I practise big time. Your antenna goes up because you have had education about the issue. Many clients say they have not seen a lawyer. I say there is one around the corner so that is useful. In our assessment we ask if there are legal issues. Next question: Do you have a lawyer? Sometimes they say yes, sometime it is with DHHS. Sometimes very difficult to sit in and be aware that parent thinks kids are best with them because they get the money. Being told that you will get the first two kids back and then the other three is difficult.' (In-depth interview with legal professional, Snapshot Three) (CiP, also SDH, capacity, empowerment, engagement, early intervention \& prevention, integration \& collaboration)

'Secondary consultations, you just do it all the time. I can think of three or four clients in the building when I've approached the lawyer. But there is a lot of incidental stuff along the way the too. Other times I ring her, now I have her telephone number. The kitchen consultations and corridor consultations and photocopier consultations happen all the time. This is very fluid. We often talk about more than one situation in the conversation; e.g., one about clients around citizenship. Very much all about clients I've referred across. I just keep my fingers on the pulse of the client's issue. The secondary consultations are opportunistic and this leads to better outcomes for the client. If there is a 
[Insert ANU logo and running head]

\section{Contact: Dr Liz Curran}

Senior Lecturer, ANU Legal Workshop (Australia-wide Professional Legal Training) \& Assoc. Director International Centre for the Profession, Education and Regulation in Law (PEARL), Australian National University, College of Law.

Mobile 0404106614

Email Liz.Curran@anu.edu.au

Canberra ACT 0200 Australia (Melbourne based)

www.anu.edu.au

CRICOS Provider No. 00120C. ORCID ID 0000-0002-6371-2975

question she does not know the answer to, Jess will research the question and get back to me. It is a valid question and she will get back to me. Information from secondary consultation goes into my memory and I use it for other clients. Secondary consults are efficient. Regarding pivotal info garnered, we share it with the team. Sometimes we add it to our team meeting agenda or I'll send an email to the team and update them. Shared learning is really important.' (Indepth interview with legal professional, Snapshot Three) (CiP, also reach, LSC, SDH, capacity, empowerment, engagement, integration \& collaboration)

\section{Value of LSCs}

Secondary consultations are absolutely invaluable. Cheap way of gaining information. Cheaper and more efficient for the client. Prevents repetition for the client - they don't have to keep going back over the story. Great, there is ongoing education gained via secondary referral process. Valuable to have colocation. Valuable to build the secondary consultation relationship - staff feel they can ask ANY question of the lawyer ... They open up the door for referral and increased credibility - they build the credibility of the lawyer and build trust. Secondary consultations facilitate building confidence in the workforce which in turn positively impacts the client: safe place to disclose issues.' (Interview with health/allied health professional, Snapshot One) (LSC, also integration \& collaboration, engagement, reach, capacity, $\mathrm{CiP}-\mathrm{SDH}$ )

'Secondary consultations and open-door attitude helps me make effective referrals. If I'm unsure about a particular referral I ask the lawyer if a referral is appropriate etc. - lawyer then does conflict check. Open door is important as I already have a relationship with the client. When I refer to lawyer, the client feels confident that I'm referring to a lawyer of the service.' (Interview with health/allied health professional, Snapshot One) (LSC, also integration \& collaboration, engagement, reach, capacity, $\mathrm{CiP}-\mathrm{SDH}$ )

'So many times I've gone to the lawyer, one example being clients that I do secondary consultation with, we ask about the Family Law Act, multiple levels. It's not only client, its intra-organisational stuff. Ethical dilemmas I've talked to the lawyer about. Ethical and moral advice within the legal context in respect of personal experiences of the BCHS worker. Lawyer puts in the time and effort to research the issue and gets back to me.' (Interview with health/allied health professional, Snapshot One) (LSC, also integration \& collaboration, engagement, reach, capacity, $\mathrm{CiP}-\mathrm{SDH}$ )

'Secondary consultations, well I use them at least once a day, even if just a quick discussion regarding a person's rights in a particular setting. When a 
[Insert ANU logo and running head]

\section{Contact: Dr Liz Curran}

Senior Lecturer, ANU Legal Workshop (Australia-wide Professional Legal Training) \& Assoc. Director International Centre for the Profession, Education and Regulation in Law (PEARL), Australian National University, College of Law.

Mobile 0404106614

Email Liz.Curran@anu.edu.au

Canberra ACT 0200 Australia (Melbourne based)

www.anu.edu.au

CRICOS Provider No. 00120C. ORCID ID 0000-0002-6371-2975

professional for e.g. was talking to me about a client's matter, the professional thought there was already a grant of aid but there wasn't. The secondary consultation clarified the level of support that the client needed-may need extra support from the CLC. The client may think there is court support when there isn't and the CLC can step in to help in these circumstances. It is integral to the collaboration, me not being part of the team meetings. Secondary consultation builds capacity for myself and the service provider. For example, angst about a disposition report - not good for client to focus on the untruths, better to focus on how to move forward ... To be able to see someone straight away when a client is distressed is clearly very helpful, particularly when a person has catastrophised an issue. If I had not spoken with the client, the client would have read back over the untruths in the disposition report. The clarification I gave would have de-escalated the stress. I gave them an action plan with tasks for them to focus on. This assisted the relationship between mother and daughter and the grandchild who was the child under potential orders. The family have a strategy that will make the home life a little easier.' (Interview with health/allied health professional, Snapshot One) (LSC, also integration \& collaboration, engagement, reach, capacity, $\mathrm{CiP}-\mathrm{SDH}$, impact $\&$ effectiveness)

'Secondary consultations are key. They extend client service delivery beyond just one client, and when a lawyer does not have time or the client is not ready, we can assist having gotten clear information from the [HJP] lawyer. It builds capacity and overcomes when clients are resistant to lawyers.' (In-depth interview with health/allied health professional, Snapshot Two) (LSC, also integration \& collaboration, engagement, reach, capacity, CiP - SDH, impact $\&$ effectiveness)

'It is not unusual to have 1 to 2 requests per day for secondary consultations; e.g., medical consent for a teenager. This may come by way of email or a phone call etc. Often at the photocopier. It is a good spot to catch up with other workers ... They are not a significant part of your time, but they are significant to the project - in terms of creating relationships. E.g. had a lady who was so stressed that she missed a court date. She thought she might be locked up for days on end. I called the police and they said no problem, get her to contact police and we'll re-bail her. It is valuable asking the question and asking for assistance from the police. Secondary consultations are important.' (In-depth interview with lawyer, Snapshot Two) (LSC, also integration \& collaboration, engagement, reach, capacity, $\mathrm{CiP}-\mathrm{SDH}$, impact \& effectiveness) 
[Insert ANU logo and running head]

\title{
Contact: Dr Liz Curran
}

Senior Lecturer, ANU Legal Workshop (Australia-wide Professional Legal Training) \& Assoc. Director International Centre for the Profession, Education and Regulation in Law (PEARL), Australian National University, College of Law.

Mobile 0404106614

Email Liz.Curran@anu.edu.au

Canberra ACT 0200 Australia (Melbourne based)

www.anu.edu.au

CRICOS Provider No. 00120C. ORCID ID 0000-0002-6371-2975

\begin{abstract}
'Secondary consultations have helped me to be more confident in lawyers. These ones in the HJP have been timely and responsive - not my previous experience of lawyers - and they are also available and speak plain English. They help us become better at helping our clients with legal issues and also in general build our capacity to also see when perhaps we can be more forceful when we need to be, when we are told things by people that just don't feel right. Often I now know if it doesn 't feel right; it's often unlawful what they are trying to get us or the clients to do - especially DHS.' (In-depth interview with health/allied health professional, Snapshot Three) (LSC, also integration \& collaboration, engagement, reach, capacity, $\mathrm{CiP}-\mathrm{SDH}$, impact \& effectiveness, empowerment)
\end{abstract}

\section{Risk of worker overload}

This emerged in Snapshot One but has not resurfaced in later snapshots. It was noted as an emerging potential issue in the Interim Report in the staff and management debrief in May 2014 and proactive action was taken to be clearer in the role of the lawyer. Participant comments in the qualitative data for Snapshots Two and Three suggest it has been managed by each agency.

Participants noted that clear communication and transparency about the service and nature of the assistance can help. In addition, when it was identified that child protection cases were a significant number of the cases being referred, the ARC Justice partner applied for funding for dedicated caseworkers to do this work. This proactivity has also probably ameliorated the initial concerns about worker overload from Snapshot One which was identified early on in the research. This was a benefit of the 'participatory action research approach' in a model of 'continuous reflection, learning and development', as it has enabled the preliminary findings to inform the service which has been proactive in making necessary changes for effectiveness.

\section{Hope (SDH)}

'From the last month, my life being out of control, to it now being in more control and feeling as though I have hope. I feel better. (Interview with Client, Snapshot One) (Hope, also SDH)

'One of my clients has gone from hopeless before she saw us [HJP lawyer and health/allied health professional] to hopeful, and so this makes her easier for me to work with to get her to do what she needs for her health.' (In-depth interview with health/allied health professional, Snapshot Two) (Hope, also $\mathrm{SDH})$ 
[Insert ANU logo and running head]

\section{Contact: Dr Liz Curran}

Senior Lecturer, ANU Legal Workshop (Australia-wide Professional Legal Training) \& Assoc. Director International Centre for the Profession, Education and Regulation in Law (PEARL), Australian National University, College of Law.

Mobile 0404106614

Email Liz.Curran@anu.edu.au

Canberra ACT 0200 Australia (Melbourne based)

www.anu.edu.au

CRICOS Provider No. 00120C. ORCID ID 0000-0002-6371-2975

There were many extracts where hope was identified as important for health recovery and these appear under other proxy headings and below in the case studies, and so these are not replicated here.

\section{Early intervention (SDH) \& prevention (SDH)}

'To have a streamlined process; for e.g., those clients that need immediate, local advice. Early intervention/prevention stuff; for e.g., if one client had to go back to Melbourne for her matter she probably would have relapsed, but the lawyer got her matters listed in Bendigo!' (In-depth interview with lawyer, Snapshot One) (Hope, also complexity, SDH)

'Legal aid gets them often in a crisis. The HJP is more able to get them when it's earlier or when they might be motivated. If a lawyer can have a five-minute chat to the worker or the client, then because of the immediacy and relevance it can make a difference early on.' (In-depth interview with health/allied health professional, Snapshot Two) (EI\&P (early intervention and prevention), also reach, capacity, hope, complexity)

'You get an appreciation of the breadth of support and different perspectives from health service professionals; it makes you think more broadly as a lawyer ... the HJP project has enabled us to build and get traction for other new projects. Knowing these workers means you can have frank conversations and you can have them because of the relationships. You can pick up early warning signs where clients might slip and be more targeted and effective early on with a head-start, and be aware of the issues and focus more on the client ... reward is being part of the team ... so much value in being there but it can be hard with court cases, part-heard, to get back to KF ... it's a nice space in community health, not so judgemental as compared to law practice, not so adversarial as it's more collaborative. It's a different perspective and so you have different dialogues and you focus more on client health and wellbeing.' (In-depth interview with lawyer, Snapshot Two) (EI\&P, also SDH reach, capacity, professional culture (see Chapter Eleven), integration \& collaboration, empowerment)

'Instead of having to find a lawyer, this partnership allows referral to be quicker and more sensitive to the client's needs. They still may not have the outcome that they want but at least the client will feel supported through the journey. I think this has assisted the staff too. The relationship holistically is not as detached for the issue. This is empowering for our client group. The client gets support if/when they make mistakes in the process. There are situations where people have lashed out at each other and put their children in the way of harm, 
[Insert ANU logo and running head]

\section{Contact: Dr Liz Curran}

Senior Lecturer, ANU Legal Workshop (Australia-wide Professional Legal Training) \& Assoc. Director International Centre for the Profession, Education and Regulation in Law (PEARL), Australian National University, College of Law.

Mobile 0404106614

Email Liz.Curran@anu.edu.au

Canberra ACT 0200 Australia (Melbourne based)

www.anu.edu.au

CRICOS Provider No. 00120C. ORCID ID 0000-0002-6371-2975

but the assistance here supports those clients.' (Interview with relationship holder - external, Snapshot Three) (EI\&P, also SDH, reach, capacity, integration \& collaboration, empowerment)

\section{Social determinants of health general information (informed by 'lived experience')}

'The kids come first and what can you do when you don't know what to do and everything is so hard to work out. Kids are hard enough and then you add illness and I'm not well; Mum tries to help but she has not been well. Credit cards and owe lots to lots, tried to get help from one of those financial companies that said it could consolidate debt, now they charge and so in worse; no-one gets that when you are down you can't just shake yourself out of it mate. Kids, they are sick, and without the health centre I would not have been able to get the assessment I needed to get help for her; challenging kids' behaviours put on so much stress so to have workers there even to get ideas from is a godsend. Not enough to live on even for day to day costs, so you end up borrowing and then bugger you're in trouble.' (CFG participant, February 2015) (SDH, also reach, complexity, multiple problems)

'What happens if disconnected from gas, electricity, if they can't pay their bills? Other? No hot meals, kids get sick, can't do homework as no light, get behind in schools, get colds as no heater, get disconnected often. No money to pay. No, I didn't know about hardship cases - never have this sort of information and wouldn't know where to go to look for it.' (CFG participant, February 2015) (SDH, also reach, capacity, complexity, multiple problems)

'The co-location helps a great deal, particularly with refugee clients. When I've asked the newer lawyer to come in, she does and helps. It helps their client's mental health when we respond immediately by getting a solicitor to talk. Quick secondary consultation occurs very fluidly. I've never had to demonstrate why I need the help to the lawyer; the lawyer trusts me and extends me the professional respect knowing that I have identified a real issue.' (In-depth interviews with health/allied health professionals, Snapshot Three) (SDH, also reach, capacity, LSC, complexity, CiP, integration \& collaboration)

\section{Complexity}

'Me mental illness doesn't make it easy. So many rules and have no idea; noone to help when you need it, sometimes it's just someone as a sounding board. The health centre does this when I am desperate, it calms me down; yeah, like it seems like what's the point and they give you some ideas. Yeah, I would not have gotten my kid help if the worker hadn't talked to other workers who 
[Insert ANU logo and running head]

\section{Contact: Dr Liz Curran}

Senior Lecturer, ANU Legal Workshop (Australia-wide Professional Legal Training) \& Assoc. Director International Centre for the Profession, Education and Regulation in Law (PEARL), Australian National University, College of Law.

Mobile 0404106614

Email Liz.Curran@anu.edu.au

Canberra ACT 0200 Australia (Melbourne based)

www.anu.edu.au

CRICOS Provider No. 00120C. ORCID ID 0000-0002-6371-2975

advocated.' (CFG participant, February 2015) (Complexity, also reach, SDH, capacity, impact \& effectiveness)

'Through working with BCHS I feel I have a more nuanced view of child rights as opposed to just those of the parent. Note, sometimes it is difficult to get clients engaged. Has to be some agency from the client. It is not a legal practice here; it makes things a little challenging here. Clients are more likely to be involved in litigation here so paperwork accordingly increases. Here it tends to be a little amorphous. No admin to screen difficult clients. In essence I am trying to run a practice here by myself without much in the way of help. I can't debrief. People in the CLC debrief. It does not happen here. For example, conflict checks, I'm waiting for feedback. Barriers to the lawyer being effective. There is a reason legal services are grouped together. Location, often concentrated in areas that are difficult. Computer has been upgraded, IT and general internet etc. are general works in progress. I need some additional printing support. I bring my own lunch in the staff room. The very important thing of integrated service requires that you are available but it creates a tension because you still have to get the work done. I'd like a little more screening. I am so busy; for example, do not have IT expertise to think through inviting myself to her BCHS diary. Particular BCHS client needs to precipitate longer client interview times because of the cascade of legal needs, so we see less clients - the more complex their needs and the more legal issues they have: one client is many cases. As they have never reached lawyers before, it means it takes a long time to do the work. It's complex. The legal issue is not triaged into the legal issue alone. I have to work through all the other issues, be they psychological, physical etc. Lawyer is not a social worker. But it's learning different ways to deal and now we can also refer to BCH but it takes time to build relationships that will work for the client and I am realising I need to think differently than I used to holistically.' (In-depth interview with lawyer, Snapshot One) (Complexity, also $\mathrm{CiP}$, empowerment, integration \& collaboration, multiple problems, reach, SDH, capacity, impact \& effectiveness)

'Client has a generic anxiety disorder. Once legal issues are dealt with, other issues take hold, so the client is very complex. Mental health conditions psychosis. Earlier on in life, drug-induced psychosis - many complex issues. His former partner had a miscarriage, the child of which was the client's; this threw the client.' (Interview with health/allied health professional, Snapshot One) (Complexity, also CiP, empowerment, multiple problems, reach, SDH)

I had another lady, a new referral from AOD, booked in to see me at 3, however she too was a no-show. I called her and she was very apologetic, explaining 
[Insert ANU logo and running head]

\section{Contact: Dr Liz Curran}

Senior Lecturer, ANU Legal Workshop (Australia-wide Professional Legal Training) \& Assoc. Director International Centre for the Profession, Education and Regulation in Law (PEARL), Australian National University, College of Law.

Mobile 0404106614

Email Liz.Curran@anu.edu.au

Canberra ACT 0200 Australia (Melbourne based)

www.anu.edu.au

CRICOS Provider No. 00120C. ORCID ID 0000-0002-6371-2975

that she is very pregnant and has been up at the hospital and was feeling unwell. We rebooked for next week. I emphasised the importance of her coming to see me before her child is born as DHHS are hovering and her older child is not in her care.' (Guided professional journal, lawyer, Snapshot One) (Complexity, also multiple problems, reach, engagement)

I spent the morning with a client who was distressed by the removal of her young son from her care. The little boy has been retained by his father who, on my client's account, has had quite a limited relationship with the child. What was particularly distressing about this is that the child had been effectively kidnapped by his father while spending time with his paternal grandmother. The child also has only ever lived with the mother or his maternal grandmother and has a possible diagnosis of autism. This client was referred to the HJP by a DHHS worker, who knew the client from her previous involvement with them [her children had previously been removed and returned to her care].' (Guided professional journal, lawyer, Snapshot One) (Complexity, also multiple problems, reach, SDH)

'There is a lack of funding and a lack of identifying legal need in family violence. This complexity is not examined by courts or the care and protection system. The expectations that people can go home and recover ... time frames are not long enough, often people don't have the capacity or access and yet they have to meet unrealistic expectations of courts and departments. I go back to the collaborative model of an HJP, it might help with a woman's emotional health and stability and physical safety as you can work out a plan for safety. Law and safety are connected. If you leave to escape violence, you have debts, it impacts on your kids and their behaviour ... collaboration and professional training and planning make for more-effective and efficient targeting of actions, with responsibilities allocated and justice advocacy when needed. If you know the lawyer and they are in your office and taking your clients, it's bound to break down professional and other barriers.' (Interview with external relationship holder, Snapshot Two) (Complexity, also capacity, engagement, CiP, empowerment, integration \& collaboration, multiple problems, reach, SDH, capacity, impact \& effectiveness)

'As a worker I had to have a frank discussion with the non-lawyers about client professional privilege and the nature of a client interview. I explained that in the adversarial system the whole idea is that a client should be able to speak freely so that they get a full legal advice and that it is all premised on the importance of the client. The education has had to occur right through the project as it comes up again and again but it is so important that we all work 
[Insert ANU logo and running head]

\section{Contact: Dr Liz Curran}

Senior Lecturer, ANU Legal Workshop (Australia-wide Professional Legal Training) \& Assoc. Director International Centre for the Profession, Education and Regulation in Law (PEARL), Australian National University, College of Law.

Mobile 0404106614

Email Liz.Curran@anu.edu.au

Canberra ACT 0200 Australia (Melbourne based)

www.anu.edu.au

CRICOS Provider No. 00120C. ORCID ID 0000-0002-6371-2975

through the various roles that we have and we can all hear frank discussions and assessments, always mindful of ethics. There are clear understandings, and I guess once there is the explanation and as long as it's clear, we can all work through these sorts of issues. If they sit in on a lawyer interview they know about client confidentiality for legal purposes. We also work through what's appropriate and when and where and consent. We are aware, all of us, of not compromising our client's rights.' (In-depth interview with legal professional) (Complexity, also capacity, engagement, CiP, empowerment, integration \& collaboration, multiple problems, reach, $\mathrm{SDH}$, capacity, impact \& effectiveness)

\section{Clients have multiple legal and non-legal problems}

'Divorce papers were signed when not in good mental health which caused some legal problems. It's tough to spend life working only to have built yourself up again. I would have lost everything if I had not had access to this program.' (Interview with Client, Snapshot One) (Multiple problems, also impact \& effectiveness)

'Health problems I have which revolve around bipolar are compounded by financial issues associated with divorce proceedings, and social/economic issues are compounded by not now being financially secure and this feeds into my feelings of wellbeing.' (Interview with Client, Snapshot One) (Multiple problems, also impact \& effectiveness)

'Three children with medical issues - Mum and Dad both have anxiety/depression issues, private rentals, family don't have any space. Kids have autism issues as yet undiagnosed. Trying to empower the family to get what they are entitled to. Four children - need assistance because they are disempowered. Need some info about their rights-maybe need some education around empowerment.' (In-depth interview with health/allied health professional, Snapshot One) (Multiple problems, also $\mathrm{SDH}$, reach, empowerment)

'A client who I have worked with extensively is doing well on a poly-drug detox; she has made major improvements in her life and is now in stable housing and school. I asked if she has any legal issues. She said she had so many legal issues that dealing with them was too stressful to even start taking about. Hopefully I opened up a dialogue and she will eventually prioritise this. She was informed of the co-located legal service at Kangaroo Flat.' (In-depth interview with health/allied health professional, Snapshot One) (Multiple problems, also SDH, capacity, reach, impact \& effectiveness, integration) 
[Insert ANU logo and running head]

\section{Contact: Dr Liz Curran}

Senior Lecturer, ANU Legal Workshop (Australia-wide Professional Legal Training) \& Assoc. Director International Centre for the Profession, Education and Regulation in Law (PEARL), Australian National University, College of Law.

Mobile 0404106614

Email Liz.Curran@anu.edu.au

Canberra ACT 0200 Australia (Melbourne based)

www.anu.edu.au

CRICOS Provider No. 00120C. ORCID ID 0000-0002-6371-2975

'A client accepts he is likely to serve some jail time for repeated violent offences while intoxicated. He got quite stressed at different times over the last three days when trying to work out how he could sort out his many life issues and this caused him to become overwhelmed and he couldn't think straight and started requesting more medication. Presumably these would be the times when he would be at a high relapse risk. He did all he could do re: legal issues and arranging rehab on Friday, calling magistrate to ask for charges in multiple courts to be heard at the local court, and leaving messages for his barrister to call him back and assist. Nothing he tried was successful but at least he could be reassured that he had done everything he could do. It was apparent that the stress of the legal loose ends, insecure housing and unknown wait time for rehab will cause times where this client is at much higher risk of relapse in the community. He has poor emotional regulation abilities and an undiagnosed mental health issue, multiple other health issues, and this period of detox has probably been the first time in ages he has been organised or clear-minded enough to work through these arrangements, but paradoxically he can't attend legal appointments because he needs to be with staff at all times he is out of the unit, and we don't have enough staff to take him to all those things.' (In-depth interview with health/allied health professional, Snapshot One) (Multiple problems, also SDH, complexity, engagement, capacity, reach, integration \& collaboration)

\section{Clients reaching service when otherwise would not have done so}

'When I first started I did not have money to pay a lawyer. But having access to the services at BCHS assists because prior I would have paperwork coming in and not knowing what to do with it would make me anxious. The lawyer helps me in this respect. Been going so slow for so long that it takes time. The lawyer is very approachable and keeps me informed of the work she is doing. Informed me where there might be weaknesses and where there might be strengths. She informed me about process and where it was not being followed by the $O / P$, which could have affected the outcome of my matter. Prior to HJP, a private law practice and the lawyer did not listen and did not clarify instructions before sending out correspondence. Fair to say this is a contrast to how the lawyer operates and looks after me.' (Interview with Client, Snapshot One) (Reach, also engagement, responsiveness, professional culture (see Chapter Eleven), capacity)

'Over the snapshot period there have been multiple contacts with clients who have legal issues but have not yet found the bravery to face them. Clients have been made aware of the possibility of access to a lawyer and stated they will 
[Insert ANU logo and running head]

\section{Contact: Dr Liz Curran}

Senior Lecturer, ANU Legal Workshop (Australia-wide Professional Legal Training) \& Assoc. Director International Centre for the Profession, Education and Regulation in Law (PEARL), Australian National University, College of Law.

Mobile 0404106614

Email Liz.Curran@anu.edu.au

Canberra ACT 0200 Australia (Melbourne based)

www.anu.edu.au

CRICOS Provider No. 00120C. ORCID ID 0000-0002-6371-2975

consider this. I still see such huge value in having a lawyer on-site for the spontaneous meetings that would not be possible without having a lawyer physically here. Also, just having access to a lawyer allows me to do my job more holistically through secondary consult with the lawyer and really just more confident of opening legal issues as I can then get advice for the client which may lead to reduced stress for this client, ultimately leading to a better health outcome.' (Guided professional journals - non-legal professionals, Snapshot One) (Reach, also capacity, LSC, CiP, engagement, responsiveness, integration \& collaboration)

'Clients talk about how easy it is to walk around to the lawyer. Many clients say they would not have been able to get any legal advice without the lawyer. Most don't have an ability to pay for legal advice. The clients need this advice. The clients are so marginalised that without assistance the clients will fail. Lawyer gives people hope.' (In-depth interview with health/allied health professional, Snapshot One) (Reach, also engagement, responsiveness, integration \& collaboration, professional culture (see Chapter Eleven), complexity, capacity)

'Clients were used to not knowing what they did not have to put up with. It's been the same for workers. Now we all know our and the clients' rights better. The clients are learning they can push back a bit, but even more empowering is that the workers also know they can push back and that they can advocate and argue for the clients' rights. So having the HJP has meant a clearer idea of what is and not law and to argue for our and clients' rights not to be trodden on now. Even when you are well educated, sometimes when someone in authority says you have no rights you tend to believe them. Now with the HJP lawyer, we have been able to check in, and even if she has not got the answer she goes away and checks and always gets back to us. We know we can trust her and the advice and it makes us more effective as advocates. You cannot always have the lawyer do all the work, and by building and empowering us and our clients to know where they stand and to be able to speak up as appropriate, it means we can reach and help more clients to navigate the legal system and the HJP has and is helping us do this every day. Due to tenancy and financial circumstances our clients are more and more trapped, and so now we know more of the legal it is enhancing the help we can provide and our confidence and ability to be better at what we do ... secondary consultations have been invaluable - a short, sharp interaction goes a long way and helps clients further along the chain, thus extending our reach.' Interview with relationship holders - managers, Snapshot Three) (Reach, also engagement, multiple issues, complexity, capacity, $\mathrm{CiP}$, responsiveness, empowerment \& 
[Insert ANU logo and running head]

\section{Contact: Dr Liz Curran}

Senior Lecturer, ANU Legal Workshop (Australia-wide Professional Legal Training) \& Assoc. Director International Centre for the Profession, Education and Regulation in Law (PEARL), Australian National University, College of Law.

Mobile 0404106614

Email Liz.Curran@anu.edu.au

Canberra ACT 0200 Australia (Melbourne based)

www.anu.edu.au

CRICOS Provider No. 00120C. ORCID ID 0000-0002-6371-2975

advocacy, integration \& collaboration, professional culture (see Chapter Eleven))

'One thing starting to emerge is the five-minute secondary consultation; workers will use the advice for more than one client. The workers are given knowledge by the lawyer. In lots of cases staff will give a bit of info but they are not the experts, but they can say BTW if for e.g. you are getting your power cut off you can do this, that and the other, but we can link you up with someone who can assist ... I encourage my staff to have enough little snippets of info to allow them to tell the client to go and speak to the lawyer ... we have identified a number of issues, for example those things under criminal law, what you can keep private and confidential ... Again, it is doing the face-to-face that is important as our workers will have questions. I've been very clear to my staff what their role is. You seek to consult and get advice from others. Each worker has their individual specialist knowledge. You don't need to know it all but you do need to know where to go to get the information. Moreover, if you don't know, you will find out and relay that back to the client. Client-centric focus. What does the client want, not what you think they want!! Be clear about what it is the client wants! Really important - what is it that the client wants? Give them the information then let them make the decision to proceed. Secondary consultations, you just do it all the time. I can think of three or four clients in the building when I've approached the lawyer. But there is a lot of incidental stuff along the way too. Other times I ring her, now I have her telephone number. The kitchen consultations and corridor consultations and photocopier consultations happen all the time. This is very fluid. We often talk about more than one situation in the conversation, e.g. one about clients around citizenship. Very much all about clients I've referred across. I just keep my fingers on the pulse of the client's issue. The secondary consultations are opportunistic and this leads to better outcomes for the client. If there is a question she does not know the answer to, the lawyer will research the question and get back to me. It is a valid question and she will get back to me. Information from secondary consultation goes into my memory and I use it for other clients. Secondary consults are efficient. Regarding pivotal info garnered, we share it with the team. Sometimes we add it to our team meeting agenda or I'll send an email to the team and update them. Shared learning is really important.' (In-depth interview with legal professional, Snapshot Three) (Reach, also LSC, engagement, multiple issues, complexity, capacity, CiP, responsiveness, empowerment \& advocacy, integration \& collaboration, professional culture (see Chapter Eleven)) 
[Insert ANU logo and running head]

\section{Contact: Dr Liz Curran}

Senior Lecturer, ANU Legal Workshop (Australia-wide Professional Legal Training) \& Assoc. Director International Centre for the Profession, Education and Regulation in Law (PEARL), Australian National University, College of Law.

Mobile 0404106614

Email Liz.Curran@anu.edu.au

Canberra ACT 0200 Australia (Melbourne based)

www.anu.edu.au

CRICOS Provider No. 00120C. ORCID ID 0000-0002-6371-2975

'The HJP is reaching people who would not otherwise get help and the numbers are significant even based on my experience. It's either the clients getting direct help or me using the information from the legal consultations to help a number of other clients, all of whom would not know where to turn or that their problem could be helped in a legal way.' (In-depth interview with health/allied health professional, Snapshot Three) (Reach, also LSC, engagement, multiple issues, complexity, capacity, $\mathrm{CiP}$, responsiveness, integration \& collaboration, professional culture (see Chapter Eleven))

\section{Impact and effectiveness}

'I was doing the right thing and didn't realise I had signed everything away. It has been invaluable. The lawyer points out issues that I'm not aware of and explains them.' (Interview with Client, Snapshot One) (Impact \& effectiveness, also capacity)

'I had a massive fall from grace. I'm now making a new life. I have a fresh start. Something clicked, now I have less pressure, I feel like I can do it. I look at things differently. The counsellor is my family worker; she is my calming voice. When I get hectic, counsellor helps me calm down and take stock. When I got here I had a huge habit. I was working as an escort and flying between here and Melbourne and the Gold Coast. The only help I've had to get through this is through BCHS. ' (Interview with Client, Snapshot One) (Impact \& effectiveness, also capacity, $\mathrm{SDH}$, reach, engagement)

'There is no judgement - I've stood up the counsellor many times but there is never any shame here. I've told Worker 2 [drug nurse] that I use and he does not judge me; the lawyer is the same and is taking things off my plate I never thought could be sorted. I am so much better. The lawyer referred to the contract, how it related to the new matters that are coming up. The orders that are made need to be amended pursuant to changes to the original order and this what we were dealing with today. I walked out of the appointment feeling like I knew what was happening with my legal issue.' (Interview with Client, Snapshot One) (Impact \& effectiveness, also capacity, SDH, empowerment, complexity, engagement)

'If a private lawyer was involved in isolation, client would likely escalate and be aggressive - if bad news given at 5 clock on a Friday for e.g., the risk of selfharm would increase. In a co-located model this is avoided somewhat because of the "team" approach.' (Interview with health/allied health professional, Snapshot One) (Impact \& effectiveness, also capacity, SDH, empowerment, complexity, engagement, professional culture (see Chapter Eleven)) 
[Insert ANU logo and running head]

\section{Contact: Dr Liz Curran}

Senior Lecturer, ANU Legal Workshop (Australia-wide Professional Legal Training) \& Assoc. Director International Centre for the Profession, Education and Regulation in Law (PEARL), Australian National University, College of Law.

Mobile 0404106614

Email Liz.Curran@anu.edu.au

Canberra ACT 0200 Australia (Melbourne based)

www.anu.edu.au

CRICOS Provider No. 00120C. ORCID ID 0000-0002-6371-2975

'Client stated that she has been able to feel comfortable talking with the lawyer and that if she did not have access to the lawyer then she would not have any access to her child and would not have seen the child again during his childhood years. Invaluable for this client was understanding that she did have rights and that there is a process that can be followed, rather than just thinking that all is hopeless and that she started to believe what the child protection where telling her - that she is a really poor mother.' (In-depth interview with health/allied health professional, Snapshot One) (Impact \& effectiveness, also capacity, SDH, empowerment, complexity, engagement)

'Observable benefits include a sense of relief even if issue partly relieved-they know it has progressed, it is not just staying still. Been given information about different services for various other assistances; e.g., family counselling or financial service ... reciprocity across services.' (In-depth interview with health/allied health professional, Snapshot One) (Impact \& effectiveness, also capacity, SDH, empowerment, complexity, engagement, integration \& collaboration)

'The benefits of the combination of services on-site are critical for community as you get holistic knowledge and it contributes to a better identification of the clients' issues. You can have a united front and in future a cumulative effect.' (In-depth interview with professional, Snapshot Two) (Impact \& effectiveness, also capacity, SDH, empowerment, complexity, engagement, integration \& collaboration)

'The lawyer was able to respond to the client in crisis and reassured her she would not go to prison given the circumstances. This woman would have definitely reused drugs if she had not seen the lawyer there and then. It directly impacted on her health and her children and even the grandparents. Her problems were elevated because of previous drug use and it all impacted on the kids and at that point in time she needed immediate help or who knows what. She may not have gotten food on the table or the kids to school in her panic about going to prison. She definitely was at risk of going back to the drugs. She was about to drop, I would say, 60-80\%, but the intervention with the lawyer averted this and afterwards she [client] felt she could make sense of what was occurring and the lawyer would immediately put in train some actions and "get the pot off the boil".' ' (In-depth interview with health/allied health professional, Snapshot Two) (Impact \& effectiveness, also SDH, complexity, engagement)

'Gosh, if I had not got access to the [HJP] lawyer I would be a bad heroin addict, no way I would have done my certificate - no reunification with my child 
[Insert ANU logo and running head]

\section{Contact: Dr Liz Curran}

Senior Lecturer, ANU Legal Workshop (Australia-wide Professional Legal Training) \& Assoc. Director International Centre for the Profession, Education and Regulation in Law (PEARL), Australian National University, College of Law.

Mobile 0404106614

Email Liz.Curran@anu.edu.au

Canberra ACT 0200 Australia (Melbourne based)

www.anu.edu.au

CRICOS Provider No. 00120C. ORCID ID 0000-0002-6371-2975

and not a chance I might win against the department ... now, once a month I might get stressed - before I got help from the lawyer and my nurse it would have been three anxiety attacks a day. My stress has decreased, no drugs but I am on methadone. I have significantly reduced my reliance on medication.' (Interview with Client, Snapshot Two) (Impact \& effectiveness, also capacity, reach, SDH)

'Today she is doing much better in her life; the interaction with us all, although brief, has been effective. She feels safe and the dad is now in prison. The HJP lawyer and us working together eased client's mind on what she can do and helps her in her job of parenting her kids. The legal advice from the lawyer gave her validation and yet we could guide her to what was in the best interests of the children - all about trust and not being without true information, which the HJP lawyer can provide. Empathised with her and she is empowered to now do what's in the best interests of the children rather than being so powerless as she once was when she came to us.' (In-depth interview with health/allied health professional case study tracked over time, Snapshot Two) (Impact \& effectiveness, also capacity, SDH, empowerment, complexity, engagement, integration \& collaboration)

'A client had a significant history of family trauma, experiencing child abuse herself and running away as a child to avoid it. Extracts and quotes from the interview include: "This drove me to drugs." "You don't recover from that overnight." "DHS has so many witnesses and resources so it's great to have a lawyer that makes them accountable ... DHS told me to sign and agreed with what the form said and they told me if I did not sign, the matter would go to court. I did not want that so I signed and I did not know what it meant and it made me look slack ... as I had signed they just went ahead and got the orders. I became stressed and I cried a lot and got depressed ... now I have a lawyer I know my rights and I feel knowledge gives me power and they have backed off".' (Interview with Client, Snapshot Two) (Impact \& effectiveness, also capacity, reach, complexity, SDH, empowerment, complexity, engagement, integration $\&$ collaboration)

'Access to a free service where there are less barriers. There is an equity aspect to this. If we lessen barriers, people have more access. If we can promote this, it gives clients better outcomes. It is multifaceted - they have benefited from experience gained from their worker but also from the HJP lawyer. I get feedback second- or third-hand; the real value is multifaceted. The benefits have been across the board. If they don't know the answers, they know where to find the answers. Accurate information might not necessarily be good news but they 
[Insert ANU logo and running head]

\section{Contact: Dr Liz Curran}

Senior Lecturer, ANU Legal Workshop (Australia-wide Professional Legal Training) \& Assoc. Director International Centre for the Profession, Education and Regulation in Law (PEARL), Australian National University, College of Law.

Mobile 0404106614

Email Liz.Curran@anu.edu.au

Canberra ACT 0200 Australia (Melbourne based)

www.anu.edu.au

CRICOS Provider No. 00120C. ORCID ID 0000-0002-6371-2975

still know their position. Continuity of care concept.' (In-depth interview with health/allied health professional, Snapshot Three) (Impact \& effectiveness, also reach, capacity, SDH, empowerment, complexity, engagement, CiP, integration $\&$ collaboration)

'Everything is more and more centralised and people fall through the gaps because of this. The system is becoming less and less responsive, not more, and so a project like the HJP, where people who struggle with multiple needs and health issues that confound and debilitate are lost, so this face-to-face interaction between them, their health professional and a lawyer has a huge impact. Our clients can go into one site and get all their issues attended to. This is a relief not only to clients but has also been a huge relief to our staff who now have a better idea of how the system works and what they can do.' (Interview with relationship holders - managers, Snapshot Three) (Impact \& effectiveness, also capacity, reach, multiple problems, SDH, empowerment, complexity, engagement, integration \& collaboration)

'The client was required to have a regular drug screen as they had a primary relationship with a child. The legal professional raised concerns about the level of protein in the client's tests. We were able to use the screen details in court as we were able to easily get the screen explained by the nurse and it could have made a difference to the client outcome. So HJP works both ways - it's not just about us providing help to the health/allied health professionals but often they help us.' (In-depth interview with legal professional, Snapshot Three) (Impact $\&$ effectiveness, also capacity, SDH, CiP)

'Over the life of this project, professional differences, where there were any, have been overcome. It flows onto clients. They see the mutual respect between the professionals and the communication and mutual respect of the agencies, the workers for the lawyer and the lawyer for the worker, and this means a lot. It builds the trust for the client in knowing people are working together, when so often their experience is services working in contradiction to each other. The thing is, as professionals we have all been learning - we have learned about each other's roles, at times we have contested ideas, but that has led to better outcomes. We question and test each other in a good way and that leads to more-nuanced and better responses. It's certainly changed my view of lawyers which was not so great before the HJP started. The process of sharing and learning and being clear with each other has been well managed and we have all learned. It's a great model.' (In-depth interview with health/allied health professional, Snapshot Three) (Impact \& effectiveness, also capacity, SDH, 
[Insert ANU logo and running head]

\section{Contact: Dr Liz Curran}

Senior Lecturer, ANU Legal Workshop (Australia-wide Professional Legal Training) \& Assoc. Director International Centre for the Profession, Education and Regulation in Law (PEARL), Australian National University, College of Law.

Mobile 0404106614

Email Liz.Curran@anu.edu.au

Canberra ACT 0200 Australia (Melbourne based)

www.anu.edu.au

CRICOS Provider No. 00120C. ORCID ID 0000-0002-6371-2975

empowerment, engagement, integration \& collaboration, CiP, professional culture (see Chapter Eleven))

'If we were to lose the HJP, my concern would be back to inefficiency and clients being excluded. This model breaks down siloes - the lawyer does not wait for a client unlikely to ever get to them; they go to where the clients are, their trusted professional, often a doctor, nurse or counsellor. The concern is we go back to the old way of business. Worst case - we don't have additional funding to continue. How then might we resource the program? How do we realign resources? It may be that some internal design work needs to happen. Not all good ideas will be funded full term. There is some redesign work with health services. Are there big blue sky opportunities that will present themselves to reduce client accessibility problems? Funding applications that offer some mutual bonuses; for example, family violence in collaboration with BCHS.' (Interview with relationship holder - manager, Snapshot Three) (Impact \& effectiveness, also reach, capacity, SDH, empowerment, CiP, professional culture (see Chapter Eleven), engagement, integration \& collaboration)

'The lawyer gave me some good news that the car was going to be released from encumbrances with Motor Finance Wizard. I didn't have to pay the $\$ 140$ a week. I can afford to do more now. I can put $\$ 40$ in the car. I don't have to stress about going from supermarket to school. I can afford to see friends more often. Having PTSD, being stuck at home, can be very depressing. I have more money for the home, heating, my three-year-old. I can now better afford medication for my son.' (Interview with Client, Snapshot Three) (Impact \& effectiveness, also capacity, complexity, SDH, empowerment, engagement)

'Clients were used to not knowing what they did not have to put up with. It's been the same for workers. Now we all know our and the clients' rights better. The clients are learning they can push back a bit, but even more empowering is that the workers also know they can push back and that they can advocate and argue for the clients' rights. So having the HJP has meant a clearer idea of what is and not law and to argue for our and clients' rights not to be trodden on now. Even when you are well educated, sometimes when someone in authority says you have no rights you tend to believe them. Now with the HJP lawyer, we have been able to check in, and even if she has not got the answer she goes away and checks and always gets back to us. We know we can trust her and the advice and it makes us more effective as advocates. You cannot always have the lawyer do all the work, and by building and empowering us and our clients to know where they stand and to be able to speak up as appropriate, it means we can reach and help more clients to navigate the legal 
[Insert ANU logo and running head]

\section{Contact: Dr Liz Curran}

Senior Lecturer, ANU Legal Workshop (Australia-wide Professional Legal Training) \& Assoc. Director International Centre for the Profession, Education and Regulation in Law (PEARL), Australian National University, College of Law.

Mobile 0404106614

Email Liz.Curran@anu.edu.au

Canberra ACT 0200 Australia (Melbourne based)

www.anu.edu.au

CRICOS Provider No. 00120C. ORCID ID 0000-0002-6371-2975

system and the HJP has and is helping us do this every day. Due to tenancy and financial circumstances our clients are more and more trapped, and so now we know more of the legal it is enhancing the help we can provide and our confidence and ability to be better at what we do ... secondary consultations have been invaluable - a short, sharp interaction goes a long way and helps clients further along the chain, thus extending our reach.' Interview with relationship holders - managers, Snapshot Three) (Impact and Effectiveness, also capacity, SDH, empowerment, CiP, multiple problems, reach, complexity, engagement, integration \& collaboration)

'The client was required to have a regular drug screen as they had a primary relationship with a child. The legal professional raised concerns about the level of protein in the client's tests. We were able to use the screen details in court as we were able to easily get the screen explained by the nurse and it could have made a difference to the client outcome. So HJP works both ways - it's not just about us providing help to the health/allied health professionals but often they help us.' (In-depth interview with legal professional, Snapshot Three) (Impact \& effectiveness, also capacity, SDH, reach, empowerment, complexity, engagement, integration \& collaboration)

\section{Discussion}

Reach - Overwhelmingly, save for a period during staff transitions around the time of Snapshot Two, all qualitative tools reveal and cross-verified that clients reached legal services through the model of the HJP when otherwise they would not have done so. This is suggestive that the HJP model, when in action, is reaching clients who would otherwise not be seeking help with their legal problems through either direct referrals or indirectly through LSC. The LSC assist not only the initial client but other clients in similar circumstances, and the knowledge from the LSC is often used by other members of the team than the person who had the LSC, as they share learnings at team meetings. The extracts from the qualitative data demonstrate that the Bendigo HJP is reaching people not only through direct clients' advice but through the support of advice givers.

Legal Secondary Consultations - Health/allied health professional participants indicated a higher rate of LSC than in the aggregated data. LSC data reveals that more clients are being referred through LSC, which builds trust, tests the legal professional, checks that a matter is legal, and sees if a lawyer can see a client - or if the client is not emotionally ready to see a lawyer, the health/allied health professional through LSC can help guide the client as the trusted intermediary. In addition, the data shows that one short LSC can actually be used further downstream for other clients and so extends the reach of the HJP beyond clients it has the capacity to see. 
[Insert ANU logo and running head]

\section{Contact: Dr Liz Curran}

Senior Lecturer, ANU Legal Workshop (Australia-wide Professional Legal Training) \& Assoc. Director International Centre for the Profession, Education and Regulation in Law (PEARL), Australian National University, College of Law.

Mobile 0404106614

Email Liz.Curran@anu.edu.au

Canberra ACT 0200 Australia (Melbourne based)

www.anu.edu.au

CRICOS Provider No. 00120C. ORCID ID 0000-0002-6371-2975

Capacity and Empowerment - The Bendigo HJP has also started to build the capacity of health/allied health professionals to advocate and negotiate on behalf of clients through building their capacity. This enables the Bendigo HJP to reach many clients beyond what they may have capacity to do on a one-on-one basis given their limited resources - in other words, through building the capacity of health/allied health professionals to identify legal problems (either by training or LSC), facilitating increased referrals, enabling through access to quick legal information (LSC) such professionals to navigate the legal system (guiding their clients/patients or intervening themselves) and negotiate with decision-makers for clients/patients (by building advocacy capacity and knowledge of legal parameters and rights which the health/allied health professionals of BCHS note they then share with their team and others in the service), The data gathered indicates clearly that the Bendigo HJP has, as a result, been able to reach people with legal problems well beyond the immediate client that they assist.

Integration and Collaboration - There are changes in practice evident from the data where the consideration of legal issues in Snapshot One has shifted among participants to a factor to be 'reminded' of to becoming 'automatic' and 'seamless'.

SDH and Early Intervention \& Prevention - Health/allied health professionals also seem, based on the qualitative data, to trust the advice and feel confident checking with the Bendigo HJP personnel when uncertain. The evidence suggests it is possible that this feeling of being better able to support clients and gain early intervention and even prevent matters compounding, has the effect on clients of de-escalating their heightened sense of 'uncertainty', and leads to reductions in stress and anxiety (see quantitative data in Chapter Nine and qualitative data in this chapter). The evidence suggests it is possible that the Bendigo HJP has a positive impact on client SDH (e.g., social isolation, lack of income support, access to utilities and mobility). See the discussion on SDH in Chapters Five and Six, Full Final Report.

16. Case studies emerging from across the qualitative tools - note these case studies relate to the impact of the HJP on clients and on the work of the professional staff, given the impact of the HJP's success is connected to each.

The project brief also requires this HJPRAE to 'follow their [clients'] journey and document the activities and outcomes to use as case studies and to supplement data' (see Contract extract and Objective viii, Project Description, in Chapter Two, Full Final Report).

\section{Case Study One}

'Client had child eight years ago. Father estranged. Single mother for years. Second relationship is dysfunctional - child removed by department. Mother 
[Insert ANU logo and running head]

\section{Contact: Dr Liz Curran}

Senior Lecturer, ANU Legal Workshop (Australia-wide Professional Legal Training) \& Assoc. Director International Centre for the Profession, Education and Regulation in Law (PEARL), Australian National University, College of Law.

Mobile 0404106614

Email Liz.Curran@anu.edu.au

Canberra ACT 0200 Australia (Melbourne based)

www.anu.edu.au

CRICOS Provider No. 00120C. ORCID ID 0000-0002-6371-2975

has desperate behaviour and risky sexual activity. Six months ago, previous to lawyer's involvement, mother was told she would not have any contact with the child. Lawyer assisted with the appeal process. Child has re-engaged and reunited with the mother.' (In-depth interview with health/allied health professional, Snapshot One) (Complexity, also engagement, SDH, impact \& effectiveness)

\section{Case Study Two}

'When it first started I did not have money to pay a lawyer. But having access to the services at BCHS assists because prior I would have paperwork coming in and not knowing what to do with it would make me anxious. Lawyer helps me in this respect. Been going so slow for so long that it takes time. The lawyer is very approachable and keeps me informed of the work she is doing. Informed me where there might be weaknesses and where there might be strengths. She informed me about process and where it was not being followed by the department which could have affected the outcome of my matter. Prior to HJP, a private law practice and the lawyer did not listen and did not clarify instructions before sending out correspondence. Fair to say this is a contrast to how the lawyer operates and looks after me.' (Interview with Client, Snapshot One) (Complexity, also capacity, CiP, engagement, SDH, impact \& effectiveness, professional culture (see Chapter Eleven), empowerment, reduction in stress \& anxiety)

\section{Case Study Three}

'Client had a significant history of family trauma, experiencing child abuse herself and running away as a child to avoid it. This trauma "drove her to drugs". "You don't recover from that overnight." "DHS has so many witnesses and resources so it's great to have a lawyer that makes them accountable ... DHS told me to sign and agreed with what the form said and they told me if I did not sign the matter would go to court. I did not want that so I signed and I did not know what it meant and it made me look slack ... as I had signed they just went ahead and got the orders. I became stressed and I cried a lot and got depressed ... Once I got linked to the lawyer and she got involved, my anxiety got better. I am not on Xanax. Now I have help so my anxiety has reduced ... Why am I less stressed? Well, with the lawyer, I know my options. I never knew I could fight and be heard. I didn't know my options after reunification and I never knew I could get half so far. Now I feel I have my life back. I am on the way to a certificate and feel like jumping in the air like the Toyota ad".' (Interview with health/allied health professional, Snapshot Two) (Complexity, 
[Insert ANU logo and running head]

\section{Contact: Dr Liz Curran}

Senior Lecturer, ANU Legal Workshop (Australia-wide Professional Legal Training) \& Assoc. Director International Centre for the Profession, Education and Regulation in Law (PEARL), Australian National University, College of Law.

Mobile 0404106614

Email Liz.Curran@anu.edu.au

Canberra ACT 0200 Australia (Melbourne based)

www.anu.edu.au

CRICOS Provider No. 00120C. ORCID ID 0000-0002-6371-2975

also capacity, $\mathrm{CiP}$, engagement, $\mathrm{SDH}$, reach, hope, impact \& effectiveness, empowerment, reduction in stress \& anxiety)

\section{Case Study Four}

'It's a big issue for me as it's lots of money that I paid and as a single parent 35 kilometres out of town it's an issue, and I could have had a car and more money for us to live on ... it's about feeding my kids and the money lost was causing me stress and now [the lawyer] is sorting it out.' (Interview with Client, Snapshot Two) (Complexity, also capacity, SDH (increase income support, feeding children), impact \& effectiveness, professional culture (see Chapter Eleven), empowerment, reduction in stress \& anxiety)

\section{Case Study Five}

'The service provision of the HJP where clients know their rights, what they can do to stay safe, and service provision that gives them information in one place, at one time, when they feel safe in the environment of a health centre where they are not judged ... not going off here, there and everywhere as they often do not have the wherewithal to do that and have childcare commitments and are scared ... so supports at court, information in a quick timely way can help not just with the immediate issue but the other matters that are buried and often ignored that impact on wellbeing. The flow-on effects from fines is that you need to pay bills and it's harder when a partner comes out of prison if you don't know what to do and you are about to be unsafe, and how to get an IVO or you are afraid to get one. You want to protect your children from a toxic environment and stress levels go up. Anxiety and stress are caused by the unknown and there are flowon effects on the client's mental health. It impacts on the family's sense of security, not just the mums but the kids sense it too - they are often forgotten about. We see this here all the time and now we know where to send them and can identify issues as legal and send them to the lawyer.' (Interview with relationship holder - manager, Snapshot Two) (Complexity, also multiple problems, hope, capacity, engagement, SDH (improved mental health, increased income security for mum's children, reduction in fear), reach, impact $\&$ effectiveness, empowerment, reduction in stress \& anxiety)

\section{Case Study Six}

'This client was a complex client with so many issues. She was engaging well with the community health centre and the HJP lawyer but it's all changed. She has decided to sever contact and pulled out of the service. The client feels stripped of her parental persona as a mum. There are changes to the care and protection laws coming in, you see, and this has taken away all her hope. She 
[Insert ANU logo and running head]

\section{Contact: Dr Liz Curran}

Senior Lecturer, ANU Legal Workshop (Australia-wide Professional Legal Training) \& Assoc. Director International Centre for the Profession, Education and Regulation in Law (PEARL), Australian National University, College of Law.

Mobile 0404106614

Email Liz.Curran@anu.edu.au

Canberra ACT 0200 Australia (Melbourne based)

www.anu.edu.au

CRICOS Provider No. 00120C. ORCID ID 0000-0002-6371-2975

was doing so well. She feels she was doing everything the department [DHS] told her to but she could never achieve their benchmarks and in the time given, what with waiting lists and deep anxiety. She also felt the benchmarks were constantly shifting - she would try to make a stride and then they would raise the bar further and with little support, which is where we came in. She felt she was being blamed for things that were not her fault. DHS workers lied and pulled her up for really minor things and so she was struggling but was making ground when we [non-legal professionals and lawyers] were her advocates. The consequences of the law changes [around permanent care being fast-tracked in rigid time frames] mean that DHS is stripping her of her identity, which is as a parent ... was over-the-top. A tone conciliation, DHS had two security guards - this was unnecessary as her being upset was natural frustration and the HJP lawyer and I were there to support her, and without all guns blazing we could have and did relax her. This was the benefit of having three services to support her and highlights the importance of collaboration when up against a mighty force which is DHS. We are lucky that even though she has disengaged from the services at community health and the lawyer, that she is still coming to one of the BCHS groups where she gets peer support and perhaps when she is ready she will come back and re-engage. The nature of these groups for BCHS is that it gives a client space and a place especially for her when she feels let down, but it's not by us as you will recall from Snapshot One where she was doing so well.' (In-depth interview with health/allied health professional, Snapshot Three - case study tracked over time)

Comparison/contrast: Revisited Snapshot One in-depth interview Part B for tracking client. In Snapshot One comments for this Case Study, client knew her rights and had really made progress in her life skills, had a sense of hope, improved; although anxious from time to time, she had not relapsed and was tracking well for reunification if supported given previous impact of trauma to be overcome.

'We [HJP lawyer and health/allied health professionals $\times 2$ ) were able to validate her experience of being wronged in the context of her legal rights and this made her feel more empowered. Since recent changes in the law, client disengaged with services of BCHS and HJP except she is still involved in a peer BCHS Group for peer support. Interviewee notes not related to the service but changes in the law meant the client has lost hope. She may return as she is still in touch as at Snapshot Three.' (Interview with health/allied health professional, Snapshot Two) (Complexity, also capacity, CiP, engagement, SDH (peer support through BCHS still actioned - so still connected, no drug relapse), 
[Insert ANU logo and running head]

\section{Contact: Dr Liz Curran}

Senior Lecturer, ANU Legal Workshop (Australia-wide Professional Legal Training) \& Assoc. Director International Centre for the Profession, Education and Regulation in Law (PEARL), Australian National University, College of Law.

Mobile 0404106614

Email Liz.Curran@anu.edu.au

Canberra ACT 0200 Australia (Melbourne based)

www.anu.edu.au

CRICOS Provider No. 00120C. ORCID ID 0000-0002-6371-2975

impact \& effectiveness, professional culture (see Chapter Eleven), integration \& collaboration, empowerment, engagement, reduction in stress \& anxiety)

\section{Case Study Seven}

I referred this client to the [HJP] lawyer after a secondary consultation - on the spot. Client is a care and protection matter and parenting client from Snapshot One. She now had concerns over the safety of kids with their dad at the time of our last discussion. Today she is doing much better in her life; the interaction with us all, although brief, has been effective. She feels safe and the dad is now in prison. The HJP lawyer and us working together eased client's mind on what she can do and helps her in her job of parenting her kids. The legal advice from the lawyer gave her validation and yet we could guide her to what was in the best interests of the children - all about trust and not being without true information, which the HJP lawyer can provide. Empathised with her and she is empowered to now do what's in the best interests of the children rather than being so powerless as she once was when she came to us. Now also the client does not feel she's the only one having this experience ... the benefit for this client who was unsafe has been reduced anxiety, reducing her sense of self-contempt, sense of contentment. She couldn't sleep; it's reduced the pressure on her heart, and her wellbeing and the benefit flows onto the kid-no longer keeping the peace and putting up with it but self-aware and realises that the family violence had her protecting the kids all the time and feeling she was walking on eggshells. Now she has a plan or road map and feels she can deal with it. She knows she can call back and get help if she needs it.' (Interview with health/allied health professional, Snapshot Two) (Complexity, also LSC, capacity (enhanced parenting, enhanced decision-making), CiP, engagement, SDH (reduced depression, reduction in heart pressure, can sleep), impact \& effectiveness, integration \& collaboration, empowerment, engagement, hope, reduction in stress \& anxiety)

\section{Case Study Eight}

'With vulnerable clients and disadvantaged families, support work is necessary. For example, many do not know about parenting. They may not have been in the home themselves and institutionalised so where are they going to learn it? If she has 23 warrants outstanding and parenting stuff, the warrants need to be dealt with. If she hits a brick wall, I can in some way help. Having the lawyer on-site is critical. If the lawyer is off-site she has no way of getting there and I would have to drive her and I have other caseloads. If it's all here she can get her medical and legal stuff done all in the one hit. As the ... [de-identified] 
[Insert ANU logo and running head]

\section{Contact: Dr Liz Curran}

Senior Lecturer, ANU Legal Workshop (Australia-wide Professional Legal Training) \& Assoc. Director International Centre for the Profession, Education and Regulation in Law (PEARL), Australian National University, College of Law.

Mobile 0404106614

Email Liz.Curran@anu.edu.au

Canberra ACT 0200 Australia (Melbourne based)

www.anu.edu.au

CRICOS Provider No. 00120C. ORCID ID 0000-0002-6371-2975

worker I was able to get her the access by having the lawyer here - an advantage, as we could do with a similar HJP at our other health centre sites. She would not know the lawyer there whereas helshe might, and even if she doesn't she knows us and as she trusts us she is more likely to see a lawyer as she had a bad experience in the past. Here she is engaging.' (Interview with health/allied health professional, Snapshot Two) (Complexity, also reach, capacity, CiP, engagement, SDH, multiple problems, impact \& effectiveness, professional culture (see Chapter Eleven), integration \& collaboration, empowerment, engagement, reduction in stress \& anxiety)

\section{Case Study Nine}

"My client thought she was going to go to prison and "What would happen to the kids?" She had lost loads of sleep. I had a quick meeting with the lawyer and they told me that they could help and within a matter of minutes I took the client to see the [HJP] lawyer. The woman, it emerged, had had a drug abuse problem at the time of the fines. The lawyer was able to respond to the client in crisis and reassured her she would not go to prison given the circumstances. This woman would have definitely reused drugs if she had not seen the lawyer there and then. It directly impacted on her health and her children and even the grandparents. Her problems were elevated because of previous drug use and it all impacted on the kids, and at that point in time she needed immediate help or who knows what. She may not have gotten food on the table or the kids to school in her panic about going to prison. She definitely was at risk of going back to the drugs. She was about to drop, I would say, 60-80\%, but the intervention with the lawyer averted this and afterwards she [the client] felt she could make sense of what was occurring and the lawyer would immediately put in train some actions and "get the pot off the boil". The lawyer emailed the authorities and got them off the client's case and negotiated with the sheriff. This experience of the lawyer gave me as the ... worker more confidence also to ask the lawyer questions in future, and I felt I could trust her and refer others to her.' (Interview with health/allied health professional, Snapshot Two) (Complexity, also capacity, CiP, engagement, SDH (no drug relapse, increased income security \& income support, increase in nutrition through food, increase in children in school/study, reduced mental health episodes), impact \& effectiveness, professional culture (see Chapter Eleven), integration \& collaboration, empowerment, engagement, reduction in stress \& anxiety)

\section{Case Study Ten}


[Insert ANU logo and running head]

\section{Contact: Dr Liz Curran}

Senior Lecturer, ANU Legal Workshop (Australia-wide Professional Legal Training) \& Assoc. Director International Centre for the Profession, Education and Regulation in Law (PEARL), Australian National University, College of Law.

Mobile 0404106614

Email Liz.Curran@anu.edu.au

Canberra ACT 0200 Australia (Melbourne based)

www.anu.edu.au

CRICOS Provider No. 00120C. ORCID ID 0000-0002-6371-2975

'This lady catastrophised everything and so would not turn up at court to just call and check. The police were set to re-bail her but the [HJP] lawyer intervened after I told her what was going on and asked for help. Lawyer deescalated it and she [client] now realises that a process is not the end of the world and things can be done to avoid disaster, and she now knows she can act earlier. Many of our clients don't know this and so don't respond. She said it brought a lot of relief.' (Interview with health/allied health professional, Snapshot Two) (Complexity, also LSC, capacity, CiP, EI\&P, engagement, SDH (enhanced decision-making), impact \& effectiveness, professional culture (see Chapter Eleven), integration \& collaboration, empowerment, engagement, reduction in stress \& anxiety)

\section{Case Study Eleven}

Client says fits are stressful to her daughter. HJP Lawyer took stuff off her plate but lawyer has helped me to feel like things will be ok legally. Now her daughter is going to school. (Engagement, also reduction in stress, SDH (child in school), Impact and Effectiveness)

\section{Case Study Twelve}

'Client said they would not have known their legal rights. They were referred to the HJP lawyer and she sorted it out-the lease of a car. Pre-approved for a car Loan. Not a lease. Had a Holden. Consumer issue. Lawyer also helping with DHS. Partner's son is autistic and being moved around. Other kids have been in foster care for a while in Sydney. Client's 151/2-year-old daughter lives with father. He remarried and won't let client see her daughter. Went to court - got shared parental parenting plan. Client got contact after four years. Client now hopes to be able to legally get her [daughter] back in her care.' (Complexity, also capacity, engagement, SDH, impact \& effectiveness, hope, engagement, reduction in stress \& anxiety)

\section{Case Study Thirteen}

'A distressed woman had a child custody matter with the father. The legal system had not been good to her and she had help in [another country town]. Her husband was oppressive, just hanging around, and she was so stressed. He worked in the public service and knew all the loopholes and had called around so no lawyer could help her due to "conflict of interest". It had a huge impact on her emotional state and she ended up in a psych centre for two days. The lawyer from the HJP tried to find her another lawyer which was critical and it ended up that she was able to be an intermediary to help this woman.' (Interview with manager, Snapshot Two) (Complexity, also capacity, 
[Insert ANU logo and running head]

\section{Contact: Dr Liz Curran}

Senior Lecturer, ANU Legal Workshop (Australia-wide Professional Legal Training) \& Assoc. Director International Centre for the Profession, Education and Regulation in Law (PEARL), Australian National University, College of Law.

Mobile 0404106614

Email Liz.Curran@anu.edu.au

Canberra ACT 0200 Australia (Melbourne based)

www.anu.edu.au

CRICOS Provider No. 00120C. ORCID ID 0000-0002-6371-2975

engagement, SDH (safety and security, mental health), impact \& effectiveness, hope, engagement, reduction in stress \& anxiety, professional culture (see Chapter Eleven))

\section{Case Study Fourteen}

'I would have lost my car. Really need a car and the thought of not having one stressed me out. Felt trapped. Friends to assist me with travelling around. "When you don't have money everything falls out of place." (Interview with Client) (SDH (mobility), reduction in stress, income support)

\section{Case Study Fifteen}

'A young mother was stressed and had been provided misinformation about her rights in relation to her child. The lawyer was able to correct this misinformation and provide the mum with next steps in a concrete way. This meant for all of us that the mum's decisions were informed and clearer and she was less stressed. She was an intervention order client and so she knew what to be wary of, and not only could she be less stressed but safer.' (In-depth interview with health/allied health professional, Snapshot Two) (Capacity, also engagement, LSC, SDH (safety), impact \& effectiveness, hope, reduction in stress \& anxiety)

\section{Case Study Sixteen}

'We had a matter that resolved favourably in the child protection space. Almost at the contested hearing stage, just before the legislative changes came in. We acted for her and had it not have been for our assistance, she would not have been a primary carer for the child. Supervision order was made prior to legislative changes being made. Significant that she got assistance when she did. It was good that there were still, options otherwise she may have lost hope. Things may have become more chaotic. Child is now with Mum. The legislative changes would have been devastating for her. She just could not get her shit together. The department had moved towards a non-reunification case plan. The department could see that a number of transformative things had happened and she had time to explore that. She was on meth and was able engage in a beauty course.' (In-depth interview with the lawyer) (Complexity, also capacity, engagement, SDH (education facilitated, drug relapse reduced, rehabilitation, connected child and mum), reach, impact \& effectiveness, hope, engagement, reduction in stress \& anxiety) 
[Insert ANU logo and running head]

\section{Contact: Dr Liz Curran}

Senior Lecturer, ANU Legal Workshop (Australia-wide Professional Legal Training) \& Assoc. Director International Centre for the Profession, Education and Regulation in Law (PEARL), Australian National University, College of Law.

Mobile 0404106614

Email Liz.Curran@anu.edu.au

Canberra ACT 0200 Australia (Melbourne based)

www.anu.edu.au

CRICOS Provider No. 00120C. ORCID ID 0000-0002-6371-2975

'Client has mental health issues [adult] with kids. Client brought kids to the paediatrician. Client was told a warrant had been issued and was very bothered. She accessed legal help and was 100\% less stressed. If it hadn't been [for] the HJP she would have self-harmed; when she knew what it really meant she was able to proceed with other arrangements in her life. She is a woman who had very little family or friends and so no reference points. To be able to get access to the lawyer was critical and I have no doubt there would have been a very sad ending to the story if the lawyer had not been easy to access, and she [the client] would not have otherwise known if there had not been an HJP. She thought she would be placed in a police divvy van and was terrified and thought she was going to go to jail, and then with the lawyer's intervention she realised she was not going to jail and had hope. Her elevated levels of distress went right down and her depression and anxiety significantly increased so she could get on with life and her recovery. Having the HJP was hugely significant for this client.' (In-depth interview with health/allied health professional) (Complexity, also capacity, reach, multiple problems, LSC, engagement, SDH (reduced depression, reduction of risk of self-harm, increase in social inclusion), impact \& effectiveness, hope, engagement, empowerment, reduction in stress \& anxiety)

\section{Case Study Eighteen}

'The flow-on effects of sorting out legal issues don't end with the client; they can improve the whole family's lives. A client had an ageing grandfather and problems with her car that she needed for him and her small kids who had health issues too. It was big news in her family that she could get help from the lawyer. What the legal service did through the HJP was increase the client's sense of hope and improved the lives of all the family who could get to where they needed to go because of the lawyer's intervention in getting the car sorted. This service is a huge asset and I value it; if it did not continue, it would be awful.' (In-depth interview with health/allied health professional) (Complexity, also capacity, engagement, SDH (family mobility, could get to support and medical appointments, could support grandfather, could support children, otherwise social isolation, increase in access to health services), impact \& effectiveness, hope, engagement, multiple problems, reach, reduction in stress $\&$ anxiety)

\section{Case Study Nineteen}

'Staff feel supported having a lawyer on-site. They have told me of numbers of cases where the advice has been pivotal in clients not regressing. They know 
[Insert ANU logo and running head]

\section{Contact: Dr Liz Curran}

Senior Lecturer, ANU Legal Workshop (Australia-wide Professional Legal Training) \& Assoc. Director International Centre for the Profession, Education and Regulation in Law (PEARL), Australian National University, College of Law.

Mobile 0404106614

Email Liz.Curran@anu.edu.au

Canberra ACT 0200 Australia (Melbourne based)

www.anu.edu.au

CRICOS Provider No. 00120C. ORCID ID 0000-0002-6371-2975

their clients are deeply affected by the legal system and it impacts on their health. Knowledge of the law and opportunities and entitlements is incredibly empowering for my staff. It's meant better pathways, issue identification, timeliness and changed behaviours, all for better outcomes for our clients.' (Interview with relationship holders - managers) (Capacity, also engagement, LSC, integration \& collaboration, reach, CiP, impact \& effectiveness, empowerment (to better support clients), engagement)

\section{Case Study Twenty}

'The client had a huge range of legal issues and had high anxiety and was very worked up about the issues when I got to see them. I was able to knock off a whole lot of those legal issues - negotiating on their behalf and clarifying things and their legal position. The client had no money and was in a panic. The counsellor linked us in through a secondary consultation and then we were able to advocate. The client had DHHS involvement, a criminal matter, a lot of debt issues and was struggling on a day-to day basis. When the client got worked up they became anxious and issues around their mental illness escalated. Then with letters from the doctor, DHHS backed off and the criminal matter was not going to lead to jail. In terms of the financial matters, the client was judgementproof but was being pursued by debt collectors. Able to reassure them and we tackled each issue one at a time. We worked with her closely and with the D\&A worker and made a difference. After court they said "You're the best. I don't normally trust people but you really showed you care ..." (In-depth interview with legal professional) (Complexity, also capacity, multiple problems, LSC, engagement, SDH (more income - by reducing debt, better mental health, improvement in trust of services whereas previous distrust), impact \& effectiveness, hope, engagement, multiple problems, reach, reduction in stress $\&$ anxiety)

\section{Case Study Twenty-one}

'A client with a severe mental health issue came to us. There were also issues of homelessness and we assisted with an intervention order and crisis accommodation. They were a wreck when the worker from BCHS bought them to us. Now they know what different workers can do and seek help.' (In-depth interview with legal professional) (Complexity, also capacity, engagement, SDH (safety, increase in housing access and housing security, reduction in mental health incidence), impact \& effectiveness, hope, multiple problems, reach, reduction in stress $\&$ anxiety)

\section{Case Study Twenty-two}


[Insert ANU logo and running head]

Contact: Dr Liz Curran

Senior Lecturer, ANU Legal Workshop (Australia-wide Professional Legal Training) \& Assoc. Director International Centre for the Profession, Education and Regulation in Law (PEARL), Australian National University, College of Law.

Mobile 0404106614

Email Liz.Curran@anu.edu.au

Canberra ACT 0200 Australia (Melbourne based)

www.anu.edu.au

CRICOS Provider No. 00120C. ORCID ID 0000-0002-6371-2975

'The client was required to have a regular drug screen as they had a primary relationship with a child. The legal professional raised concerns about the level of protein in the client's tests. We were able to use the screen details in court as we were able to easily get the screen explained by the nurse and it could have made a difference to the client outcome. So HJP works both ways-it's not just about us providing help to the health/allied health professionals but often they help us.' (In-depth interview with legal professional) (Integration \& collaboration, also LSC, capacity, engagement, professional culture (see Chapter Eleven)) 
[Insert ANU logo and running head]

\section{Contact: Dr Liz Curran}

Senior Lecturer, ANU Legal Workshop (Australia-wide Professional Legal Training) \& Assoc. Director International Centre for the Profession, Education and Regulation in Law (PEARL), Australian National University, College of Law.

Mobile 0404106614

Email Liz.Curran@anu.edu.au

Canberra ACT 0200 Australia (Melbourne based)

www.anu.edu.au

CRICOS Provider No. 00120C. ORCID ID 0000-0002-6371-2975

\section{Chapter Eleven - Professional Cultures, Ethics, Collaborative Measurement Tool's Application and Need for Economic Modelling/Costings on Impact}

\section{Professional Culture: An Issue Emerging as Significant in Snapshot Three}

There are a multitude of reasons as to why people do not seek legal help, including not being informed of legal issues, inhibited by costs or giving up due to the 'referral roundabout' - this is reflective in the snapshots as well as advice-seeking behaviour research. ${ }^{80}$ However, an issue that emerged in the data from Snapshot Two, and was more in evidence from the data in Snapshot Three, was that negative experiences of the legal profession or of the law impede clients and even their health/allied health professionals from turning to lawyers for legal help. For a significant majority of the research, participants (including clients and health/allied health professionals, reception and management staff of BCHS) in this HJPRAE during engagement with the Bendigo HJP lawyers overcame this previous reticence. This went to the approachability and style of lawyering according to research participants and is discussed below in more detail. This was as equally evident in client interviews as it was in interviews with health/allied health professionals. The participants reflect on the adversarial nature of the legal system and some of the past experiences with private lawyers. This resonates with some of the analysis of the LCCLC 'Collaborative Survey of Legal and Health/Allied Health Professionals' that the author undertook when performing the ARC Justice Family Violence Evaluation in 2015. ${ }^{81}$

In terms of the author's brief for this HJPRAE to inform replicable models of HJP (Aims 2, 3 and 4 and Objective vi and v), it is clear from a significant number of participants in the Bendigo HJP that they will not refer, nor undertake LSCs for clients or move to build their own legal capacity, if they are concerned the lawyer may not be

\footnotetext{
${ }^{80}$ Balmer, NJ, Pleasence, P, Buck, A \& Walker, HC (2006), 'Worried sick: The experience of debt problems and their relationship with health, illness and disability', Social Policy and Society, vol. 5, no. 1, pp. 39-51; Coumarelos, C, MacCourt, D, People, J, McDonald, HM, Wei, Z, Iriana, R \& Ramsey, S (2012), 'Access to Justice and Legal Needs: Legal Australia-Wide Survey Legal Need in Australia', Law and Justice Foundation of New South Wales, Sydney, available at: http://www.lawfoundation.net.au/ljf/site/templates/LAW_AUS/\$file/LAW_Survey_Australia.pdf; Coumarelos, C \& Wei, Z (2009), 'The legal needs of people with different types of chronic illness or disability', Justice Issues, no. 11, Law and Justice Foundation of NSW, Sydney; and Genn, H (1999), Paths to Justice: What People Do and Think about Going to Law, Hart Publishing, Oxford.

${ }^{81}$ Curran, L (2015a), 'Family Violence Project Evaluation Report', available at: http://lcclc.org.au/wpcontent/uploads/2015/05/Final-Evaluation-Report-LSB-Family-Violence-Curran-14-May-2015.pdf
} 
[Insert ANU logo and running head]

\section{Contact: Dr Liz Curran}

Senior Lecturer, ANU Legal Workshop (Australia-wide Professional Legal Training) \& Assoc. Director International Centre for the Profession, Education and Regulation in Law (PEARL), Australian National University, College of Law.

Mobile 0404106614

Email Liz.Curran@anu.edu.au

Canberra ACT 0200 Australia (Melbourne based)

www.anu.edu.au

CRICOS Provider No. 00120C. ORCID ID 0000-0002-6371-2975

a right fit or might re-traumatise their vulnerable client. This was an area that was also commented upon by the Victorian Royal Commission into Family Violence in September 2015. ${ }^{82}$ This is not only relevant to HJPs in general but has broader implications for clients in general in accessing or feeling able to access legal services. It is also significant for their 'trusted' health and allied health professionals who may be critical, as the Bendigo research results highlight, in them engaging with legal help. Professionals noted that to do so would be problematic as they have a 'client care responsibility' and 'do no harm' framework for their clients that follows certain professional roles. This is a significant finding of this HJPRAE and should inform the future training and professional development of lawyers. Lawyers must be mindful in how they are perceived and what they might need to change so that they use different approaches to lawyering in different client settings. This is especially the case given the significant barriers disadvantaged people experience in seeking legal help in any event or where there are vulnerability or safety concerns.

The Bendigo HJP data suggests that a lawyer who is 'responsive' and 'not arrogant', who 'listens' and 'does not judge', and who is 'collaborative' and 'respectful' is key for trust to occur, which is essential if the referrals are to happen. The Bendigo HJP was effective as these elements were present for clients and the health/allied health professionals according to the data collected.

The other evidence emerging in this HJPRAE is that health/allied health professionals will test a lawyer out through LSC. This is consistent with findings from the Consumer Action Law Centre in a recent report. ${ }^{83}$ These findings, the author suggests, in examining the broader implications of this HJPRAE for future lawyering in MDP in general, challenge the traditional methods of teaching law through case-based learning which does not enhance problem detection and identification skills, as subjects are taught in silos like contracts and torts. This limits the capacity to teach future lawyers about the human dimensions of lawyering and problem-solving where real clients are involved and where clients have multiple issues. Again, this has implications for replicable models of HJP in terms of the education and training of lawyers and their effectiveness.

This is a significant point for others who are intending on embarking on their own HJPs or MDPs and goes to the recruitment and proper support and training of lawyers for

\footnotetext{
${ }^{82}$ State of Victoria (2014-16), Royal Commission into Family Violence: Report and Recommendations, vol. I, Parl. Paper No. 132, pp. 119, 239.

${ }^{83}$ Consumer Action Law Centre (2016) 'Evaluating Consumer Action's Worker Advice Service' http://consumeraction.org.au/evaluating-consumer-actions-worker-advice-service/ accessed 4 September, 2016.
} 
[Insert ANU logo and running head]

\section{Contact: Dr Liz Curran}

Senior Lecturer, ANU Legal Workshop (Australia-wide Professional Legal Training) \& Assoc. Director International Centre for the Profession, Education and Regulation in Law (PEARL), Australian National University, College of Law.

Mobile 0404106614

Email Liz.Curran@anu.edu.au

Canberra ACT 0200 Australia (Melbourne based)

www.anu.edu.au

CRICOS Provider No. 00120C. ORCID ID 0000-0002-6371-2975

working in other MDP roles where they are required to connect with non-legal professionals to assist vulnerable or disadvantaged clients. It may well be that such training may also help the legal professional in engaging with other professionals outside MDP who may also have poor stereotypes or experiences of lawyers, given the rise in therapeutic law practice and conflict resolution and negotiation that require different lawyering to the more combative styles of an adversarial context. An innovation in traditional teaching at law schools and in the professional development of lawyers may better equip lawyers for changing legal practice. Similarly, there are opportunities for non-law students such as nursing, medical, social work and psychology students to learn together in collaborative multi-disciplinary subjects taught across the different disciplines. This may also break down stereotypes and, as has been reflected in the data from the HJPRAE, may enable greater understanding of different roles professionals can play, increase trust and perspectives, and encourage learning skills in collaboration. This may lead to greater effectiveness and efficiency, removing the current blockages in pathways to referral and engagement and breaking down the risk of poor stereotypes discussed by participants in the data extracted below from this HJPRAE.

Extracts from the qualitative data as evidence gathered that are illustrative of the poor perceptions/experiences of lawyers are as follows:

'Because the service is client-focused, we both have had the client's benefit at heart. I've been able to feel confident in discussing the issues with the client and the lawyer. No examples of differences - it has been quite the opposite as it has been positive. The empathy I have seen in practice has been eye-opening. There have been barriers broken down for me from my perspective of a lawyer. Success cannot be measured with the outcome. Sometimes it boils down to the client being willing to be assisted-makes clients more receptive to advice. I am often involved in initial conversations but you can prompt and then the client can take it from there. Private lawyers might "cost you extra"; a private lawyer might say "we've already talked about this"...' (In-depth interview with health/allied health professional, Snapshot Three)

'Clients are responsive. Not always the best experience with lawyers at court. Many have encountered legal issues at a very early age. The experience here would positively challenge the clients' perceptions of the legal system/lawyers. As far as I'm concerned as a professional, I try to use it as much as I can. I try to increase the confidence in the client when engaging the lawyer. The mantra that was bantered around by the lawyer was that the door is always open. Very easy. BCHS is seen as a trusted organisation. We have the holistic view for the clients. It would be disastrous if we lose the service now because we would lose 
[Insert ANU logo and running head]

\section{Contact: Dr Liz Curran}

Senior Lecturer, ANU Legal Workshop (Australia-wide Professional Legal Training) \& Assoc. Director International Centre for the Profession, Education and Regulation in Law (PEARL), Australian National University, College of Law.

Mobile 0404106614

Email Liz.Curran@anu.edu.au

Canberra ACT 0200 Australia (Melbourne based)

www.anu.edu.au

CRICOS Provider No. 00120C. ORCID ID 0000-0002-6371-2975

the goodwill of the clients. Consistency and continuity are very important with this cohort of clients. How else are they going to know if we don't give the clients a voice. Our clients' issues need to be addressed, the sooner the better; it is important as it helps us identify the issue. We have families walking through the door looking for assistance. We are called community health because we are here for our community. Family/parents are relieved that they have connected with the lawyer if they are introduced and encouraged.' (In-depth interview with health/allied health professional, Snapshot Three)

'One thing starting to emerge is the five-minute secondary consultation; workers will use the advice for more than one client. The workers are given knowledge by the lawyer. In lots of cases staff will give a bit of info but they are not the experts, but they can say BTW iffor e.g. you are getting your power cut off you can do this, that and the other, but we can link you up with someone who can assist ... I encourage my staff to have enough little snippets of info to allow them to tell the client to go and speak to the lawyer ... we have identified a number of issues, for example those things under criminal law, what you can keep private and confidential ... Again, it is doing the face-to-face that is important as our workers will have questions. I've been very clear to my staff what their role is. You seek to consult and get advice from others. Each worker has their individual specialist knowledge. You don't need to know it all but you do need to know where to go to get the information. Moreover, if you don't know, you will find out and relay that back to the client. Client-centric focus. What does the client want, not what you think they want!! Be clear about what it is the client wants! Really important - what is it that the client wants? Give them the information then let them make the decision to proceed.' (In-depth interview with health/allied health professional, Snapshot Three)

'To my own practice it is a very different way of practising. It's about reaching clients. Some clients you just know that if asked to call the CLC they wouldn't. We/I am accessible. It is very rewarding to assist the clients at KF. I try to make myself as approachable and supportive as possible. I try to avoid referring clients to other lawyers. I have trust via the worker. The clients come ready to be assisted. You want to do a good job for the worker too. Having the trust of the worker makes you want to assist and get the best outcomes for their clients.' (In-depth interview with health/allied health professional, Snapshot Three)

'Secondary consultations are what provides the pathway of information and on processes. For example, what happens with the filing of documents. They are of immense value to me as otherwise I would be confused. I can check in. I know when I am not sure I can just ask. The beauty is that we are not the experts but 
[Insert ANU logo and running head]

\section{Contact: Dr Liz Curran}

Senior Lecturer, ANU Legal Workshop (Australia-wide Professional Legal Training) \& Assoc. Director International Centre for the Profession, Education and Regulation in Law (PEARL), Australian National University, College of Law.

Mobile 0404106614

Email Liz.Curran@anu.edu.au

Canberra ACT 0200 Australia (Melbourne based)

www.anu.edu.au

CRICOS Provider No. 00120C. ORCID ID 0000-0002-6371-2975

it helps us navigate the system for our clients, especially as many clients may not be ready to see a lawyer right away. You need to understand that many of our clients, if they have even had a lawyer at all, it may not have been a good experience - it might have been a traumatic one. So we use secondary consultations to help clients who would otherwise never see a lawyer and help them ready themselves to see one if they need to by building up the trust. Most lawyers do not do a great job of respecting clients and to be honest I used the secondary consultation to test out the lawyer a number of times myself to see if I would be prepared to hand over my client. You see, if a client is likely to be further harmed, we have a duty of care. I have through the HJP come to see a different type of lawyering which is truly effective. It gives me confidence; I know I can check in quickly which helps me help other clients and it provides a pathway - who is going to refer cold with such vulnerable clients, so you need to know that secondary consultations are heavily linked into whether we will refer or not, and if we don't have a good sense of the lawyer and how they will engage with our client, we may not then refer.' (In-depth Interview with health/allied health professional, Snapshot Three)

'Secondary consultations have helped me to be more confident in lawyers. These ones in the HJP have been timely and responsive - not my previous experience of lawyers - and they are also available and speak plain English. They help us become better at helping our clients with legal issues and also in general build our capacity to also see when perhaps we can be more forceful when we need to be, when we are told things by people that just don't feel right. Often I now know if it doesn't feel right; it's often unlawful what they are trying to get us or the clients to do - especially DHS.' (In-depth interview with health/allied health professional, Snapshot Three)

'The reality for our clients is that without having the smaller things sorted, it means an escalation of stress and anxiety which has risks to their family. With the HJP here they now have had options and they come through the door, disclose to health and allied health and then they get help and then their stress and anxiety goes down. This is a direct effect on their HJP and often means we can work with them in a less anxious and heightened state to address their health and social wellbeing. It's been so great having the HJP, I want it to stay. It's become part of the way we do business.' (Interview with relationship holders - managers, Snapshot Three)

Ethics: an Issue Emerging as Significant from Snapshot Three 
[Insert ANU logo and running head]

\section{Contact: Dr Liz Curran}

Senior Lecturer, ANU Legal Workshop (Australia-wide Professional Legal Training) \& Assoc. Director International Centre for the Profession, Education and Regulation in Law (PEARL), Australian National University, College of Law.

Mobile 0404106614

Email Liz.Curran@anu.edu.au

Canberra ACT 0200 Australia (Melbourne based)

www.anu.edu.au

CRICOS Provider No. 00120C. ORCID ID 0000-0002-6371-2975

As Gyorki ${ }^{84}$ and Tobin-Tyler ${ }^{85}$ have noted, in a HJP ethical conduct rules are not insurmountable. An MDP or HJP can work effectively and keep the professional ethics intact. The extracts below highlight that in the Bendigo HJP it has been possible to be ethical and deliver MDP.

The author delivered a paper at the International Conference on Legal Ethics ${ }^{86}$ in July 2016 and a scholarly article will be available soon. In that paper, the author notes that rules of ethics exist for the protection of the client, rather than for the protection of the profession. The author summarises academic writings on ethics which suggest proscriptive strategies for practitioners which are all predicated on access to numerous lawyers in for-profit contexts and between law firms. This is not suited in the author's submission to MDP with a focus on client care and holistic problem-solving. This conference paper argues this is not the current situation for HJPs which are designed to reach clients who would otherwise not gain legal help, for free, and in its work with health/allied health professionals in a MDP to help the clients through holistic client care. In the paper, the author outlines why the current academic ethics literature is riskaverse. It does not adequately deal with situations where ethical rules, if blindly adhered to when there is little risk, end up obstructing access to justice (a point also noted by the Productivity Commission ${ }^{87}$ ), which is itself unethical.

CLCs have National Service Standards set through the National Association of Community Legal Centres, with frameworks and requirements for ethical practice by CLCs which are actioned in the HJP, and staff have been routinely inducted and trained in ethics. Commentators have argued that HJP and MDP are problematic as they risk

\footnotetext{
${ }^{84}$ Gyorki, L (2013), 'Breaking Down the Silos: Overcoming the Practical and Ethical Barriers of Integrating Legal Assistance into a Healthcare Setting', Inner Melbourne Community Legal Centre and The Churchill Trust Fellowship, available at: https://www.churchilltrust.com.au/media/fellows/Breaking_down_the_silos_L_Gyorki_2013.pdf 85 Tobin-Tyler, E (2008), 'Allies Not Adversaries: Teaching Collaboration to the Next Generation of Doctors and Lawyers to Address Social Inequality', Roger Williams University, School of Law Faculty Papers, Paper 17, p. 249, available at:

http://lsr.nellco.org/cgi/viewcontent.cgi?article=1017\&context=rwu_fp

${ }^{86}$ Curran, L (2016), 'Health-Justice Partnership - Multi-disciplinary Practices: Research

Evidencing Working Ethically to Ensure Reach to Those in Most Need \& Improve Outcomes' (Presentation Slides), July, available at: http://papers.ssrn.com/sol3/cf_dev/AbsByAuth.cfm?per_id=2030109

${ }^{87}$ Australian Government Productivity Commission (2014), 'Access to Justice Arrangements, Final Report', no. 72, September, Australian Government Productivity Commission, Canberra, available at: http://www.pc.gov.au/inquiries/completed/access-justice/report
} 
[Insert ANU logo and running head]

\section{Contact: Dr Liz Curran}

Senior Lecturer, ANU Legal Workshop (Australia-wide Professional Legal Training) \& Assoc. Director International Centre for the Profession, Education and Regulation in Law (PEARL), Australian National University, College of Law.

Mobile 0404106614

Email Liz.Curran@anu.edu.au

Canberra ACT 0200 Australia (Melbourne based)

www.anu.edu.au

CRICOS Provider No. 00120C. ORCID ID 0000-0002-6371-2975

compromising conflict of interest and client confidentiality. ${ }^{88}$ The Bendigo HJP reveals, as did Gyorki's study, that there are many 'work-arounds', including informed client consents, routine check-ins, transparency and clear communication, all of which protect the client's information and fit within the ethical conduct rules.

'Over the life of this project, professional differences, where there were any, have been overcome. It flows onto clients. They see the mutual respect between the professionals and the communication and mutual respect of the agencies the workers for the lawyer and the lawyer for the workers - and this means a lot. It builds the trust for the client in knowing people are working together, when so often their experience is services working in contradiction to each other. The thing is that as professionals we have all been learning about each other's roles, and at times we have contested ideas, but that has led to better outcomes. We question and test each other in a good way and that leads to more nuanced and better responses. It's certainly changed my view of lawyers, which was not so great before the HJP started. The process of sharing and learning and being clear with each other has been well managed and we have all learned. It's a great model.' (In-depth interview with health/allied health professional, Snapshot Three)

'As a worker I had to have a frank discussion with the non-lawyers about client professional privilege and the nature of a client interview. I explained that in the adversarial system the whole idea is that a client should be able to speak freely so that they get full legal advice, and that it is all premised on the importance of the client. The education has had to occur right through the project as it comes up again and again, but it is so important that we all work through the various roles that we have and we can all hear frank discussions and assessments, always mindful of ethics. There are clear understandings and I guess once there is the explanation and as long as it's clear, we can all work through these sorts of issues. If they sit in on a lawyer interview they know about client confidentiality for legal purposes. We also work through what's appropriate and when and where, and consent. We are aware, all of us, of not compromising our clients' rights.' (In-depth interview with health/allied health professional, Snapshot Three)

\section{Collaborative Measurement Tool: Applied over Project Life (Three Years)}

\footnotetext{
${ }^{88}$ Comment of a private practitioner in a panel discussion on ethical issues and MDPs in April 2016 at a Victoria Legal Aid PD session for lawyers in Melbourne.
} 
[Insert ANU logo and running head]

\section{Contact: Dr Liz Curran}

Senior Lecturer, ANU Legal Workshop (Australia-wide Professional Legal Training) \& Assoc. Director International Centre for the Profession, Education and Regulation in Law (PEARL), Australian National University, College of Law.

Mobile 0404106614

Email Liz.Curran@anu.edu.au

Canberra ACT 0200 Australia (Melbourne based)

www.anu.edu.au

CRICOS Provider No. 00120C. ORCID ID 0000-0002-6371-2975

Using the Collaborative Measurement Tool (see Appendix D) to examine the data over the life of the project, the author concludes that the HJP has, in the Snapshot Three phase, moved from silos into the continuum of collaboration. The data relevant to the Collaborative Measurement Tool is extracted in Chapters Nine and Ten and has already been benchmarked against the indicators (namely, the proxies and themes emerging from the literature, CFG and trial Snapshot One) under the proxy 'Collaboration' (which includes integration).

The HJP is no longer merely co-located as the data emerging in Snapshots One and Two indicated, but by Snapshot Three, the data reflected that the Bendigo Project had moved to work seamlessly with many of the staff of BCHS KF. Snapshot Three data reflected substantially more observations such as Snapshots One and Two about the Bendigo HJP being 'trusted' and the 'way we do business', 'seamless', 89 'don't even think about it anymore, they are just part of our team now'. This is also evidenced by the attendance routinely of the lawyer at team meetings and site meetings. The extracts below are illustrative of the evidence that supports this move to collaboration in Snapshot Three. Transition issues have been resolved, and one professional noted that 'it made the relationship stronger for having to work through the issues'.

\section{Collaborative Measurement Tool: Areas for Further Work}

This section makes some recommendations for not only the Bendigo HJP (Project Aim 1) but also has similar relevance for other replicable models of HJP and MDP in general (Project Aim 2-4 and Objectives v, vi, vii and viii).

Areas for further work in the data in relation to the movement to collaboration with community that clients and staff (professional and client services) identified as critical include the role of CLE in empowering and engaging the community. A need for the Bendigo HJP was to do CLE to improve community knowledge of their legal rights as well as developing their own skills in advocacy. Many of the participants in Snapshots One and Two noted this as a gap. The author, however, wishes to note that the Bendigo HJP has a lawyer that takes referrals, LSC and does client casework (except care and protection work. since a project was funded for care and protection work due to an identified need, as discussed earlier in this Full Final Report, in Chapter Two). The ability to also conduct CLE, given the limited resources, is an issue that may be ripe for

\footnotetext{
${ }^{89}$ In the absence of funding for computer software to analyse data, using a 'find and search' function in Word, 178 positive references to 'trust' were found, with the most significant numbers emerging in Snapshot Three. Similarly, this was the case with the term 'seamless', which appeared 24 times, with almost all references to this adjective appearing in Snapshot Three.
} 
[Insert ANU logo and running head]

\section{Contact: Dr Liz Curran}

Senior Lecturer, ANU Legal Workshop (Australia-wide Professional Legal Training) \& Assoc. Director International Centre for the Profession, Education and Regulation in Law (PEARL), Australian National University, College of Law.

Mobile 0404106614

Email Liz.Curran@anu.edu.au

Canberra ACT 0200 Australia (Melbourne based)

www.anu.edu.au

CRICOS Provider No. 00120C. ORCID ID 0000-0002-6371-2975

consideration for a dedicated person who can work with community in a way that will resonate, namely as participants.

Critically, emerging from health/allied health and manager interview data is the use of adult learning approaches, and within a health promotion and community development construct. Nonetheless, relevant to the Collaboration Measurement Tool, by the last Snapshot, it was reported that the HJP lawyer was attending client groups run by BCHS and had 'chats' to them about their legal position. Opportunities such as this, with the lawyer or CLE designated officer going to the places where community are likely to gather (e.g., men's sheds, recovery groups and so on), should be maximised to assist community in awareness of their legal options and what they might do individually and together with others in their community.

Another area for further work emerging from the data is the integration of PD opportunities in the general PD of BCHS so that it is not time-consuming, and to encourage a greater capacity for BCHS staff to participate given their casework commitments. This is especially true of the doctors with their 10-minute slots for patient appointments. For them, use of LSC may be a tool for PD, as is attendance at team meetings. This, however, is a 'two-way street' - while ARC Justice can provide the appropriate responsive PD that is suggested in the data (namely, using adult learning approaches and the expertise of training participants oriented to practice - see data in Chapter Ten), the BCHS staff also can participate, engage and assist in identifying legal issues of the clients, patients or their own practice skills, and identify training needs and take the time to attend. As the data in this HJPRAE suggests, taking such time can actually save time in the longer run by identifying legal problems and referring, utilising template letters prepared by the lawyer as a result of training sessions for the use of health/allied health professionals. This can lead to efficiency and targeted help, and can reach people at critical times, as the data suggest can occur when there is capacity, engagement, collaboration and ultimately empowerment. In the author's own practice experience, ${ }^{90}$ regular attendance at team meetings, which included doctors or nurses or psychologists asking them about issues they had, gave ample opportunity to offer legal support and even template letters that can save time in administration and research. A common lament of health/allied health professionals in other HJPs, in the literature discussed in Chapter Thirteen, is that they did not have time but, when the offerings of a lawyer are clearly valuable and save time and are seen and demonstrated to be effective, this ought to increase engagement.

\footnotetext{
${ }^{90}$ The author worked in various capacities (as Clinical Supervisor and Director) for 10 years at the Banyule Community Health Service (based on a public housing estate) as a community lawyer.
} 
[Insert ANU logo and running head]

\section{Contact: Dr Liz Curran}

Senior Lecturer, ANU Legal Workshop (Australia-wide Professional Legal Training) \& Assoc. Director International Centre for the Profession, Education and Regulation in Law (PEARL), Australian National University, College of Law.

Mobile 0404106614

Email Liz.Curran@anu.edu.au

Canberra ACT 0200 Australia (Melbourne based)

www.anu.edu.au

CRICOS Provider No. 00120C. ORCID ID 0000-0002-6371-2975

A PD pre- and post-training survey was provided to the LCCLC to be administered so as to provide feedback and measure changes in practice. This would have been helpful if it had been administered in terms of the Collaborative Tool, but to the author's knowledge it was not administered in any PD despite its relevance to this evaluation. If so, the aggregated data collected at the time has not been provided to the author. The author did ask but was advised in June that the PD tool had not been administered, but that it was the intention of LCCLC to administer it for future PD.

Participants in Snapshot Three also noted there was room for more collaboration on policy (Project Deliverable, Contract Extract, Chapter Two Full Final Report) between the two agencies and their Board and Executive on systemic issues relevant to their clients. This had started to occur with work on child protection in Snapshot Two and has also occurred in relation to an Office of the Public Advocate Inquiry. The author 's previous research ${ }^{91}$ demonstrates that such joint action takes time and is likely to occur in the future given the readiness of the managers interviewed to embark on such joint initiatives and work more strategically together, as was indicated in interviews with them in Snapshot Three.

Below are some of the extracts from the qualitative data that demonstrate movement towards collaboration:

'Co-localised services de-escalate clients' issues. Clients being able to walk into a community health service takes away from the client's sense of being stigmatised. We are in a very middle-class setting. Our clients are judged by the outside world. The notion of a client being able to walk into a health service and get help, including legal issues which are often very pressing, is great. Not having this option, clients often won't be able to seek the information for themselves. By intervening you are assisting with health issues. Many of our clients in this service are intergenerational, they are used to being treated or not knowing that things can be different, that they don't have to put up with that. That they have legal rights. I've had to talk to child protection and they quote legislation at me and I find it difficult to understand and I'm an educated person. We ask a range of questions about our clients' psycho-social problems which includes legal questions, stock-standard questions plus ongoing assessment. There are often triggers for when a client is not travelling so well. Often parents slip back when their children have been taken to the cop shop, there is a

\footnotetext{
${ }^{91}$ Curran, L (2007c) 'Making the Legal System more Responsive to Community: A Report on the Impact of Victorian Community Legal Centre (CLC) Law Reform Initiatives', Reichstein Foundation, available at: http://www.fclc.org.au/public_resource_details.php?resource_id=1152
} 
[Insert ANU logo and running head]

\section{Contact: Dr Liz Curran}

Senior Lecturer, ANU Legal Workshop (Australia-wide Professional Legal Training) \& Assoc. Director International Centre for the Profession, Education and Regulation in Law (PEARL), Australian National University, College of Law.

Mobile 0404106614

Email Liz.Curran@anu.edu.au

Canberra ACT 0200 Australia (Melbourne based)

www.anu.edu.au

CRICOS Provider No. 00120C. ORCID ID 0000-0002-6371-2975

negative impact all the way down the line.' (Interview with relationship holders - managers, Snapshot Three)

'To my own practice it is a very different way of practising. It's about reaching clients. Some clients you just know that if asked to call the CLC they wouldn't. We/I am accessible. It is very rewarding to assist the clients at KF. I try to make myself as approachable and supportive as possible. I try to avoid referring clients to other lawyers. I have trust via the worker. The clients come ready to be assisted. You want to do a good job for the worker too. Having the trust of the worker makes you want to assist and get the best outcomes for their clients.' (In-depth interview with lawyer, Snapshot Three)

'Well, I know it's a collaboration. We have stopped using the terminology of co-location now. When we started it was all training and legal need identification that still needs to happen, especially with staff turnover and refreshing, but now it's a team approach. The staff are much less guarded, there is trust, relationships have been tested, especially during the transition around the second snapshot, but we have moved forward and are all stronger for it. There is less promoting, it's now more seamless and business as usual that we work together seamlessly. I reflect on when we first started this and really we had no idea we were in siloes, but now the clients are better off, we are better informed and we have changed our practice to a point where it's truly multidisciplinary, inclusive of law and the lawyers. It would not have worked if we had not had the right type of lawyers, as I have said previously, and good staff who are client-centred and who are working through issues for the SDH outcomes for clients. We share a vision and that has been key. I would like to see more reporting along the way to boards and executives of both partners and I guess that's been a learning ... The reality for our clients is that without having the smaller things sorted it means an escalation of stress and anxiety which has risks for their family. With the HJP here they now have had options and they come through the door, disclose to health and allied health, and then they get help and then their stress and anxiety goes down. This is a direct effect on their HJP and often means we can work with them in a less anxious and heightened state to address their health and social wellbeing. It's been so great having the HJP. I want it to stay. It's become part of the way we do business.' (Interview with relationship holders - managers, Snapshot Three)

'Over time ... there has been a change in personnel - we have navigated that pretty successfully. The lawyer has worked hard to integrate at KF and engage staff. I've observed a shift in some of the casework profiles. Some of that may be around skills and experience. We have grown our own practice to 
[Insert ANU logo and running head]

\section{Contact: Dr Liz Curran}

Senior Lecturer, ANU Legal Workshop (Australia-wide Professional Legal Training) \& Assoc. Director International Centre for the Profession, Education and Regulation in Law (PEARL), Australian National University, College of Law.

Mobile 0404106614

Email Liz.Curran@anu.edu.au

Canberra ACT 0200 Australia (Melbourne based)

www.anu.edu.au

CRICOS Provider No. 00120C. ORCID ID 0000-0002-6371-2975

incorporate child-protection matters. The lawyer not undertaking as much of that work is not as much of an issue. Work has moved towards more civil work, consumer, fines, family violence. Any reflection on the life of the project senior and middle management. Lots of energy at the start and the end of the project. Probably been a dip, whilst the project went through its forming stage. Visibility of the program etc. Soliciting referrals and tracking the valuation outcomes.' (Interview with relationship holders - managers, Snapshot Three)

'It felt like there were barriers to my assistance. It felt a little bit lonely. But I started to interact with them at team meetings. It could have been how they perceived lawyers, but now it is very comfortable. I have not had any differences with any of them. They have been managed and overcome.' (In-depth interview with a lawyer, Snapshot Three)

'LSCs have helped me to be more confident in lawyers. These ones in the HJP have been timely and responsive - not my previous experience of lawyers - and they are also available and speak plain English. They help us become better at helping our clients with legal issues and also in general build our capacity to also see when perhaps we can be more forceful when we need to be, when we are told things by people in positions that just don't feel right. Often, I now know if it doesn't feel right, it's often unlawful what they are trying to get us or the clients to do-especially DHHS.' (In-depth INTERVIEW with health/allied health professional, Snapshot Three)

'Inefficiency I perceive is the concern ... we go back to the old way of business. Worst case - we don't have additional funding to continue. How then might we resource the program? How do we realign resources? It may be that some internal design works needs to happen. Not all good ideas will be funded full term. There is some redesign work with health services. Are there big blue sky opportunities that will present themselves to reduce client accessibility problems? Funding applications that offer mutual bonuses; for example, FV in collaboration with BCHS?' (Interview with relationship holders - managers, Snapshot Three)

'I think there could be more visibility to board level with the program and more championing with government. I think we do hold the interest of the board and we need to jointly appeal to government.' (Interview with relationship holders - managers, Snapshot Three)

'Things have grown. It has remained positive and there have not been major partnership anxieties. They have remained supportive of the worker and the program. While there have been some deficiencies, we have been able to work 
[Insert ANU logo and running head]

\section{Contact: Dr Liz Curran}

Senior Lecturer, ANU Legal Workshop (Australia-wide Professional Legal Training) \& Assoc. Director International Centre for the Profession, Education and Regulation in Law (PEARL), Australian National University, College of Law.

Mobile 0404106614

Email Liz.Curran@anu.edu.au

Canberra ACT 0200 Australia (Melbourne based)

www.anu.edu.au

CRICOS Provider No. 00120C. ORCID ID 0000-0002-6371-2975

around those roadblocks and get some results in particular areas.' (Interview with relationship holders - managers, Snapshot Three)

'As a worker I had to have a frank discussion with the non-lawyers about client professional privilege and the nature of a client interview. I explained that in the adversarial system the whole idea is that a client should be able to speak freely so that they get a full legal advice and that it is all premised on the importance of the client. The education has had to occur right through the project as it comes up again and again but it is so important that we all work through the various roles that we have and we can all hear frank discussions and assessments, always mindful of ethics. There are clear understandings, and I guess once there is the explanation and as long as it's clear, we can all work through these sorts of issues. If they sit in on a lawyer interview they know about client confidentiality for legal purposes. We also work through what's appropriate and when and where and consent. We are aware, all of us, of not compromising our client's rights.' (In-depth interview with lawyer, Snapshot Three)

'Assuming the HJP is sustainable. I don't think there have been any gaps. Lawyers have been responsive to legal issues. They have adapted really well to our clients' needs. Even if they don't know, they will find the answer to the issue and get back to us. The journey from co-location to true integration would not occur in 12 months - we need the three-year period to see how this works. We have been talking to Peter regarding funding submissions etc. We need to discuss funding strategies. Common applications between LCCLC and BCHS is a good place to start.' (Interview with relationship holder - manager, Snapshot Three)

'Our staff are now looking at the broader issues. That's not to say they weren't doing this before, but it now includes the legal. There are information sessions and LSCs and these help warm referrals. Something about having the lawyer here, and visible too, it enables a time and place which is important for our clients as sometimes they may not be ready, but when they are it can help so much, especially with the clients that come to KF who have often been so demoralised, and trust is key. This means that when clients are in crisis about an issue they have direct access to the lawyer on-site. This means they can get help, and what it also means is it de-escalates their crisis, and so it's been great to have the HJP here for us and for the clients.' (Interview with relationship holders - managers, Snapshot Three) 
[Insert ANU logo and running head]

\section{Contact: Dr Liz Curran}

Senior Lecturer, ANU Legal Workshop (Australia-wide Professional Legal Training) \& Assoc. Director International Centre for the Profession, Education and Regulation in Law (PEARL), Australian National University, College of Law.

Mobile 0404106614

Email Liz.Curran@anu.edu.au

Canberra ACT 0200 Australia (Melbourne based)

www.anu.edu.au

CRICOS Provider No. 00120C. ORCID ID 0000-0002-6371-2975

'Everything is more and more centralised and people fall through the gaps because of this. The system is becoming less and less responsive, not more, and so a project like the HJP, where people who struggle with multiple needs and health issues that confound and debilitate are lost, so this face-to-face interaction between them, their health professional and a lawyer has a huge impact. Our clients can go into one site and get all their issues attended to. This is a relief not only to clients but has also been a huge relief to our staff who now have a better idea of how the system works and what they can do.' (Interview with relationship holders - managers, Snapshot Three)

'The reality for our clients is that without having the smaller things sorted, it means an escalation of stress and anxiety which has risks to their family. With the HJP here they now have had options and they come through the door, disclose to health and allied health and then they get help and then their stress and anxiety goes down. This is a direct effect on their HJP and often means we can work with them in a less anxious and heightened state to address their health and social wellbeing. It's been so great having the HJP, I want it to stay. It's become part of the way we do business.' (Interview with relationship holders - managers, Snapshot Three)

'Clients were used to not knowing what they did not have to put up with. It's been the same for workers. Now we all know our and the clients' rights better. The clients are learning they can push back a bit, but even more empowering is that the workers also know they can push back and that they can advocate and argue for the clients' rights. So having the HJP has meant a clearer idea of what is and not law and to argue for our and clients' rights not to be trodden on now. Even when you are well educated, sometimes when someone in authority says you have no rights you tend to believe them. Now with the HJP lawyer, we have been able to check in, and even if she has not got the answer she goes away and checks and always gets back to us. We know we can trust her and the advice and it makes us more effective as advocates. You cannot always have the lawyer do all the work, and by building and empowering us and our clients to know where they stand and to be able to speak up as appropriate, it means we can reach and help more clients to navigate the legal system and the HJP has and is helping us do this every day. Due to tenancy and financial circumstances our clients are more and more trapped, and so now we know more of the legal it is enhancing the help we can provide and our confidence and ability to be better at what we do ... secondary consultations have been invaluable - a short, sharp interaction goes a long way and helps 
[Insert ANU logo and running head]

\section{Contact: Dr Liz Curran}

Senior Lecturer, ANU Legal Workshop (Australia-wide Professional Legal Training) \& Assoc. Director International Centre for the Profession, Education and Regulation in Law (PEARL), Australian National University, College of Law.

Mobile 0404106614

Email Liz.Curran@anu.edu.au

Canberra ACT 0200 Australia (Melbourne based)

www.anu.edu.au

CRICOS Provider No. 00120C. ORCID ID 0000-0002-6371-2975

clients further along the chain, thus extending our reach.' (Interview with relationship holders - managers, Snapshot Three)

'Just the other day we had some kids in trouble, and in a meeting which involved a number of clients refereed to us, we talked about the clients' issues. The lawyer had previously done some staff training and LSCs with some of the staff present and they were able to share their information on what to do with the other staff to help the clients. The staff at that meeting told the other staff about the benefits for them of using the HJP and so now other staff are using it too.' (Interview with relationship holders - managers, Snapshot Three)

'Over the life of this project, professional differences, where there were any, have been overcome. It flows onto clients. They see the mutual respect between the professionals and the communication and mutual respect of the agencies the workers for the lawyer and the lawyer for the workers - and this means a lot. It builds the trust for the client in knowing people are working together, when so often their experience is services working in contradiction to each other. The thing is that as professionals we have all been learning about each other's roles, and at times we have contested ideas, but that has led to better outcomes. We question and test each other in a good way and that leads to more nuanced and better responses. It's certainly changed my view of lawyers, which was not so great before the HJP started. The process of sharing and learning and being clear with each other has been well managed and we have all learned. It's a great model.' (In-depth interview with health/allied health professional, Snapshot Three)

'I tell my workers to speak to the lawyer. I think the project has gained momentum/stability. It has been tested and there has been positive feedback. Expectation has been reinforced.' (In-depth interview with health/allied health professional, Snapshot Three)

'I have received LSCs, less so now as I'm now more senior. As part of supervision we tell workers not to forget that the lawyer is here. I've been putting this into place and being more mindful of the need to address legal issues. It's important for workers to remind each other - almost like embedding. At the coalface it is more difficult to remember to do this.' (In-depth interview with health/allied health professional, Snapshot Three)

I have incredible confidence in accessing it. I would be devastated if it were not there ... can't imagine that process being as responsive. It has informed me of the hard data of stuff. The Ivo example is a good one where I can check legal things with the lawyer. Now I have another string to my bow. Legal stuff often 
[Insert ANU logo and running head]

\section{Contact: Dr Liz Curran}

Senior Lecturer, ANU Legal Workshop (Australia-wide Professional Legal Training) \& Assoc. Director International Centre for the Profession, Education and Regulation in Law (PEARL), Australian National University, College of Law.

Mobile 0404106614

Email Liz.Curran@anu.edu.au

Canberra ACT 0200 Australia (Melbourne based)

www.anu.edu.au

CRICOS Provider No. 00120C. ORCID ID 0000-0002-6371-2975

gets tangled up in medico-legal but we have not taken it there. Some lawyers, in my previous opinion, might only be interested when things have escalated. I see this is not the case with the HJP - vulnerabilities. Clients now know that the issue does not have to be huge; there is no benchmark. The client's issues are not trivialised.' (In-depth interview with health/allied health professional, Snapshot Three)

'Type of lawyer is critical. I have noticed a difference between the two lawyers. It took time but the new lawyer does just fit in with us. She just gets on with assisting us. She has the right way of managing clients. You don't want an absolute extravert or an absolute introvert. If she does not know an answer, she tells you and she will get back to you.' (In-depth interview with health/allied health professional, Snapshot Three)

\section{Need for HJP Economic Modelling and Costing in General in Future}

As noted earlier, the author's project brief is to make recommendations and inform replicable models and make suggestions (Project Brief, Aims 2-4, Objectives v-viii, Contract Extract). It is beyond this author's and the project advisers' expertise, and outside this project brief, for costing and economic modelling in terms of measuring the cost savings of interventions for clients and the wider system by the early intervention and prevention benefits to the health, justice and welfare system of HJP and MDP. The evidence in the Bendigo HJP is suggestive that the intervention is reaching people who would otherwise not gain legal help, and reducing later escalation or preventing problems emerging that otherwise might take more resources and activate further processes, such as court or tribunal intervention or ill health, which can have costs imposts on the health, justice and welfare system and services more broadly.

If the lawyers can better reach clients through a HJP, then if a range of legal matters can be navigated, rights explained and matters sorted through negotiation and advocacy, often out of court and with key decision-makers, such as public authorities, this is likely to reduce the impost on other areas of the legal, health and social support system. For example, there was one case the allied health professional reported on that illustrates the point. The client had been so scared of the court proceedings that she intended to not go to court on her court date and hide away. The allied health professional sat in with the HJP lawyer and the client, as the lawyer explained that the court case did not mean the client was going to go to jail. The client was relieved, attended court, and a warrant did not have to be issued for her arrest due to non-attendance, with all the attendant police follow-up, administration, further court hearings and cost that the client's non-attendance at court would have entailed. This client would never have received the legal help at a critical point in time were it not for the allied health 
[Insert ANU logo and running head]

\section{Contact: Dr Liz Curran}

Senior Lecturer, ANU Legal Workshop (Australia-wide Professional Legal Training) \& Assoc. Director International Centre for the Profession, Education and Regulation in Law (PEARL), Australian National University, College of Law.

Mobile 0404106614

Email Liz.Curran@anu.edu.au

Canberra ACT 0200 Australia (Melbourne based)

www.anu.edu.au

CRICOS Provider No. 00120C. ORCID ID 0000-0002-6371-2975

professional identifying the issues, notifying the lawyer, and the opportunistic ability of the lawyer on-site to provide help to the client on the spot.

In another example, a client was alarmed and agitated at legal correspondence. The mental health nurse was able to quickly call on the lawyer who explained the documentation was not as bad as the client believed and was able to ease the client's state of mind from the point where the nurse had concerns that if it were not for the lawyer's intervention, the client's mental health condition would have been triggered and led to a hospital admission. In gathering quantitative data, one area for further exploration, which was beyond the scope of this evaluation and is for future HJPRAEs, would be for the economic savings of this nature to be examined and costed. This would go some way to ascertaining the specific cost savings to the justice, health and social system of an HJP. See further discussion in Chapters Thirteen and Fourteen.

Similarly, to be able to quantify increases in income support caused by interventions where money goes back into the pockets of families who are on or below the poverty line, would also be useful.

This goes directly to the SDH in terms of income security having clear implications on the SDH so families can afford utilities, have income for food, recreation, school excursions, warm clothes and so on. In one reported situation of a participant, a client was a victim of irresponsible lending. As a result of the lawyers' intervention, the client was paid out $\$ 5000$ she never owed in the first place. The client commented she now had extra money to buy food and support her child and pay utilities as a result of having the debt written off. In another case, clarifying a client's income support entitlement meant the client averted debt through having extra income. The client noted otherwise there had been a deficit of income against family expenses. Being able to document the cost benefits of the HJP for both families, who have as a result sufficient income to heat their houses, buy food and so on, it is possible that it improves SDH. Similarly, costing the saving of early legal help, which otherwise would have led to downstream costs, would be useful. Law and accountancy firms might consider this as a new way of providing pro-bono assistance to improve access to justice by assistance in the building of an evidence base. This is also in line with the Productivity Commission's recommendations as to enhanced evidence-based research and a need for costings of early interventions and models that are effective. ${ }^{92}$

\footnotetext{
${ }^{92}$ Australian Government Productivity Commission (2014), 'Access to Justice Arrangements, Final Report', no. 72, September, Australian Government Productivity Commission, Canberra, available at: http://www.pc.gov.au/inquiries/completed/access-justice/report, vol. 1, pp. 171-176, vol. 2, p. 713, and Overview Report, p. 43.

${ }^{92} \mathrm{PC}$ above note xii, 11, 31 and vol. 2, pp. 708-713.
} 
[Insert ANU logo and running head]

\section{Contact: Dr Liz Curran}

Senior Lecturer, ANU Legal Workshop (Australia-wide Professional Legal Training) \& Assoc. Director International Centre for the Profession, Education and Regulation in Law (PEARL), Australian National University, College of Law.

Mobile 0404106614

Email Liz.Curran@anu.edu.au

Canberra ACT 0200 Australia (Melbourne based)

www.anu.edu.au

CRICOS Provider No. 00120C. ORCID ID 0000-0002-6371-2975

It is part of the author's project brief to also make recommendations as to efficiency and measurements for possible replicable models of HJP (Objectives v and vi, and Aims 2, 3 and 4 of the Project Brief, Chapter Two, Full Final Report) more widely than this Bendigo HJP. Given, as noted above, the lack of funds for research evaluations, the author has some suggestions as to how such costings and modelling might occur. The use of pro-bono law and accounting firms, and provision by large firms of interns or funded fellowships, could enable a method of modelling and costings of savings from the HJP interventions. Many law firms now have in-house accounting and commercial expertise that could be offered as a pro-bono contribution. This could provide muchneeded expertise and the evidence base and modelling to inform policy-makers and funders, as clearly the evidence emerging is that HJP and collaborative MDP are ways of reaching clients early who might otherwise be invisible and are effectively targeted.

A further idea is the use of volunteer students with economic or commercial training (many law students have combined law and commerce degrees) who can pull together costings. They could be harnessed to ascertain any costs saving of a HJP which these client matters suggest. This sort of project might also align with the university assignments or could be done on a volunteer basis. Bringing into the research this economic dimension through utilisation of such expertise could inform public policy and funding decisions. The author is aware, for instance, that the Nottingham Law School at Trent University Nottingham's Legal Advice Centre routinely asks its student volunteers to calculate additional income support enabled by the Law Clinic and reports on these costings and savings made by their legal interventions. They do this on an annual and quarterly basis. Costings due to tribunal payouts of clients and debt reductions, such as that the author used in relation to the 'Bulk Debt Negotiation' Project, ${ }^{93}$ are also useful to demonstrate increases in client income, savings and increased client autonomy as a consequence. They can also factor into costings for reductions in imposts on the state. (See Chapter Fourteen, Recommendations.)

\footnotetext{
${ }^{93}$ Curran, L (2013e), 'Solving Problems - A Strategic Approach: Examples, Processes \& Strategies', 13 May, Legal Workshop, Australian National University College of Law, available at: http://law.anu.edu.au/sites/all/files/legalworkshop/final_report_solving_legal_problems_curran_calc_1 3_march_2013.pdf; and Holland, J (2016), 'Negotiating Bulk Debt: Outcomes from the Bulk Debt Negotiation Project', unpublished report for Victoria Legal Aid, West Heidelberg Community Legal Service, Legal Aid NSW, Good Shepherd Australia \& New Zealand. The author thanks Denis Nelthorpe for sharing this report.
} 
[Insert ANU logo and running head]

\section{Contact: Dr Liz Curran}

Senior Lecturer, ANU Legal Workshop (Australia-wide Professional Legal Training) \& Assoc. Director International Centre for the Profession, Education and Regulation in Law (PEARL), Australian National University, College of Law.

Mobile 0404106614

Email Liz.Curran@anu.edu.au

Canberra ACT 0200 Australia (Melbourne based)

www.anu.edu.au

CRICOS Provider No. 00120C. ORCID ID 0000-0002-6371-2975

\section{PART FOUR - Overall Findings, Learnings, Conclusions and Recommendations}

\section{Chapter Twelve - Overall Findings}

Based on the quantitative and qualitative data collected through the field work and aggregated service data, the overall findings for the HJPRAE are summarised as follows.

\section{Specific to the Bendigo HJP}

1. The clients of the HJP are complex and more often than not have more than one legal problem and a multitude of other health and social welfare problems. They often feel judged and lack trust in services. They will seek help when they feel they are not judged, where they are respected and where there is service responsiveness. Appointments are problematic - time and place can be critical to engagement, especially for people who have experiences of trauma or negative previous experiences of the legal system.

2. During the life of the Bendigo Health-Justice Partnership, it has provided a significant amount of legal service to clients on a range of matters and often where one client has a significant number of legal issues. The clients' lives are complicated and building trust takes time. Given the project has only one lawyer co-located at the HJP, the number of clients and client problems tackled is significant in view of the limited staff, funding and resources. The service's CLSIS data totals are as follows:

Totals

- $\quad$ Casework and Advices combined, where clients are only counted once (106 + 141) $=247$

- $\quad$ Casework and Advices combined, where duplicate client casework and advice are included, but only if the open date and close date are different between those duplicates $(122+161)=283$.

Both numbers are reported as the program aims to address a client's multifaceted legal issue. This may require additional casework or advice for a particular client; therefore, instances where the client has returned to the service are counted.

Summary

- $\quad$ Casework - 159 instances of casework over 47 problem types.

- $\quad$ Advice - 160 instances of advice over 50 problem types. 
[Insert ANU logo and running head]

\section{Contact: Dr Liz Curran}

Senior Lecturer, ANU Legal Workshop (Australia-wide Professional Legal Training) \& Assoc. Director International Centre for the Profession, Education and Regulation in Law (PEARL), Australian National University, College of Law.

Mobile 0404106614

Email Liz.Curran@anu.edu.au

Canberra ACT 0200 Australia (Melbourne based)

www.anu.edu.au

CRICOS Provider No. 00120C. ORCID ID 0000-0002-6371-2975

This is a significant amount of work undertaken by the Bendigo HJP, especially given the project is small in that it entails a lawyer based on-site three days a week but doing HJP work off-site in the LCCLC office (e.g. court appearances, court preparation, administration and legal research). There is also recent funding for a child protection team which is also doing some HJP work based on referrals.

1. The Bendigo HJP does not rely on clients to work out if their problem is legal. Due to a trained intermediary (through PD and LSCs), they trust who makes their pathway clearer as the professionals have been trained in identifying legal issues (e.g., debt, Centrelink, housing, family violence, discrimination, fines, child protection, human rights under the Victorian Charter of Human Rights and Responsibilities).

2. Clients are getting help earlier through the Bendigo HJP and the data is suggestive that the Bendigo HJP is having a positive impact (e.g., no drug relapse, reduced stress, reductions in suicidal ideation (see below), and findings in Chapter Ten).

3. The Bendigo HJP is reaching clients who would otherwise not have sought legal help. The role of their trusted health or allied health professional in facilitating that reach has been overwhelmingly critical $-90 \%$ of clients interviewed in the HJPRAE said that without the HJP they would not have sought legal help.

4. Clients who have multiple and complex problems reported they were anxious and frightened as they did not know their rights/position. They reported this impacted on their health and wellbeing. The effectiveness and quality of the HJP service and its impact as reported by health/allied health professionals delivered the following relevant responses:

- confidence in engaging with services in clients to have increased by $90.9 \%$

- $\quad$ knowledge of rights and responsibilities in clients to have increased by $72.7 \%$

- $\quad$ knowledge of options and more skilled over time in clients to have increased by $90.9 \%$.

5. The intervention of the Bendigo HJP is reported for the large proportion of clients interviewed as having a positive impact on their SDH - it is possible that it offers 'hope' as they now have someone to negotiate for them who knows their legal position; they 'now know where they stand'.

6. The capacity of professionals, due to the HJP, to respond to legal issues with confidence has increased; that is, they have become 'empowered'. The capacity of professionals, both lawyers and non-lawyers as well as client service staff, is key/critical to being able to support clients in a timely way, when in crisis or ready for help. The professional staff, in their in-depth interviews, reported that 
[Insert ANU logo and running head]

\section{Contact: Dr Liz Curran}

Senior Lecturer, ANU Legal Workshop (Australia-wide Professional Legal Training) \& Assoc. Director International Centre for the Profession, Education and Regulation in Law (PEARL), Australian National University, College of Law.

Mobile 0404106614

Email Liz.Curran@anu.edu.au

Canberra ACT 0200 Australia (Melbourne based)

www.anu.edu.au

CRICOS Provider No. 00120C. ORCID ID 0000-0002-6371-2975

the personal and professional changes in themselves over the time of the HJP were as follows:

- $\quad$ Stress decreased by $75 \%$.

- $\quad$ Anxiety decreased by $75 \%$.

- $\quad$ Resilience increased by $75 \%$.

- $\quad$ Trust increased by $87.5 \%$.

- Responsiveness increased by $87.5 \%$.

- $\quad$ Engagement increased over time by $87.5 \%$.

- $\quad$ Confidence increased by $75 \%$.

- Knowledge of rights and responsibilities increased by $62.5 \%$.

7. The Bendigo HJP has significantly increased the capacity of staff to be more responsive and to identify problems capable of a legal solution, as well as changing the practice of a significant number of the health/allied health professional staff, who now refer and seek LSCs more routinely, and regard them as the 'way we now do business'. LSCs are critical to the success of an HJP and in reaching clients who would otherwise not seek or get legal help. LSCs are helping workers to help clients and understand the legal system, and professionals can get advice on their own obligations - ethical and legal - which increases confidence. LSC extends the reach of the HJP: it builds on knowledge and corrects misunderstandings. For example, 'when the department ${ }^{94}$ says "no", it might not be'. The data revealed that of the health/allied health professional participants, $81.9 \%$ 'Strongly Agree' and 18.2\% 'Agree' there is 'huge value' to them in LSC ( $100 \%$ positive view on its value).

8. Non legal-professionals reported their own confidence had increased due to the often-used LSC for more than one client and sharing of the knowledge from their LSC with others in their team, thus reaching far more clients than the initial LSC. Therefore, LSC has increased the number of people who receive legal information that the HJP might not otherwise have had the capacity to assist, through the allied and health professionals being able to act as trusted intermediaries.

9. The Bendigo HJP lawyer has integrated and broken down stereotypes - 'we work as a team'. (See Chapter Eleven for a detailed discussion of the barriers

\footnotetext{
${ }^{94}$ Child protection within the Department of Health and Human Services (DHHS)
} 
[Insert ANU logo and running head]

\section{Contact: Dr Liz Curran}

Senior Lecturer, ANU Legal Workshop (Australia-wide Professional Legal Training) \& Assoc. Director International Centre for the Profession, Education and Regulation in Law (PEARL), Australian National University, College of Law.

Mobile 0404106614

Email Liz.Curran@anu.edu.au

Canberra ACT 0200 Australia (Melbourne based)

www.anu.edu.au

CRICOS Provider No. 00120C. ORCID ID 0000-0002-6371-2975

posed by poor experiences/perceptions of lawyers by clients and their support staff in seeking help.)

10. The Bendigo HJP has increased the professional capacity of lawyers and health/allied health professionals through the sharing of skills, knowledge and different approaches and practice. This lifts the level of advice and support that all the HJP participants can help clients with.

11. As a result of the Bendigo HJP, all clients interviewed (as a sample of the broader client group) report improved stress and anxiety, an ability to take the next steps, that they would return to the HJP next time, and that they would seek help earlier with other problems. This is suggestive of the fact that clients are empowered and that there is potential for earlier intervention and prevention.

12. Overall, $60 \%$ of clients stated their stress had been reduced a lot as a result of the intervention, while $40 \%$ noted their stress had been reduced 'a bit'. Fortunately, none reported stress being increased or remaining the same as a result of the intervention of the HJP, even though when you examine the qualitative data taken from clients in each of the three snapshots, their situations and circumstances were often far from ideal and often they had complex legal issues and complicated factors at play in their day-to day lives $-100 \%$ noted it had a positive impact on their levels of stress and anxiety.

13. Of the clients interviewed, $100 \%$ reported that their voice was being heard, which positively indicates that the proxy around empowerment and client voice was in evidence. Similarly, in terms of the capacity proxy, $100 \%$ of clients reported that they 'knew more about the legal rights and where they sit in the legal process'. This is suggestive of the fact that clients are empowered and that there is potential for earlier intervention and prevention.

14. A significant number of the clients (90\%) presenting to the HJP represented by the project sample had between five and eight legal problems, and reported that were it not for the referral and trust in their health/allied health professional through the HJP they would not have sought legal help with their problems.

15. Of the clients interviewed, $40 \%$ reported having previous poor experiences with lawyers, or that the legal system was a deterrent in seeking legal help.

16. The Bendigo HJP has, over the life of the project, moved from services for health and allied health being separate to the legal centre and operating in silos, to becoming an integrated team and a multi-disciplined practice. It is suggested by the data that it has been effective in reducing negative SDH and had a positive impact on clients' lives. The project should, with ongoing funding, 
[Insert ANU logo and running head]

\section{Contact: Dr Liz Curran}

Senior Lecturer, ANU Legal Workshop (Australia-wide Professional Legal Training) \& Assoc. Director International Centre for the Profession, Education and Regulation in Law (PEARL), Australian National University, College of Law.

Mobile 0404106614

Email Liz.Curran@anu.edu.au

Canberra ACT 0200 Australia (Melbourne based)

www.anu.edu.au

CRICOS Provider No. 00120C. ORCID ID 0000-0002-6371-2975

resources and commitment, be able to continue to reach clients who would otherwise not gain legal help.

17. Trust and relationships take time and cannot be driven by a 'top-down' approach. A key strength of the Bendigo HJP project was its organic nature and relationship base. The importance of enabling time, building respect, working through issues together and in partnership and collaboration (with clients, community, professional, client service staff, management, the executive and board), and that the Bendigo HJP project pilot funding was for three years, have all been critical to enabling the Bendigo HJP to be assessed on all the evidence as effective in reaching clients, targeting services effectively, and as an efficient and responsive service.

\section{General Application to other Replicable Models of HJP (Project Brief, Aim 2 and Objective v)}

18. Clients turn to 'trusted' health/allied health professionals but may not turn to lawyers without the facilitation and transferral of trust. Some clients will not turn to a lawyer as they are not emotionally ready (e.g., due to trauma, fragility, fear), and so the health/allied health professional that they trust becomes an important intermediary for them to gain legal help and information at salient times.

19. The physical layout and placement of the lawyer is critical to the success of HJP. Being on-site, visible and accessible and responsive to health/allied health professionals is critical to success as it is the 'opportunistic' moment by the photocopier, or in the lunch room, where the trusted health or allied health professional and receptionist can be reminded of the availability of legal help.

20. A service which is a HJP needs to be 'opportunistic' in taking advantage of the client's health appointments to provide legal assistance - due to complexities of life and confusion, lack of confidence and being overwhelmed etc.

21. The capacity of professionals, both lawyers and non-lawyers as well as client service staff, is key/critical to being able to support clients in a timely way and when in crisis or ready for help.

22. LSCs are often short in duration, which for time-poor professionals with significant caseloads can be key.

23. Health/allied health professionals reported using LSCs to test the lawyer before making a referral and as critical to building trust. They used it to check in and verify facts, for their own personal peace of mind and to reduce their stress. 
[Insert ANU logo and running head]

Contact: Dr Liz Curran

Senior Lecturer, ANU Legal Workshop (Australia-wide Professional Legal Training) \& Assoc. Director International Centre for the Profession, Education and Regulation in Law (PEARL), Australian National University, College of Law.

Mobile 0404106614

Email Liz.Curran@anu.edu.au

Canberra ACT 0200 Australia (Melbourne based)

www.anu.edu.au

CRICOS Provider No. 00120C. ORCID ID 0000-0002-6371-2975

24. HJPs, if they are not already doing so, ought to routinely count and value the time spent by the lawyer/s on LSC as part of its data collection, given LSC are so critical to the HJP's effectiveness and engagement with both clients and legal professionals.

25. The type of lawyer has been critical to the success of the Bendigo HJP and should be considered when hiring and recruiting staff. Lawyers can't 'just sit in their office' but need to interact, integrate, not be 'too stuffy' or 'too hierarchical', 'avoid jargon' and show 'respect'. The type of person in the role is key to the HJP's success.

26. Trust and relationships take time to demonstrate an impact and their effectiveness, as they are predicated on relationships, human experience, confidence and positive interactions and cannot be driven by a 'top-down' approach. 
[Insert ANU logo and running head]

\section{Contact: Dr Liz Curran}

Senior Lecturer, ANU Legal Workshop (Australia-wide Professional Legal Training) \& Assoc. Director International Centre for the Profession, Education and Regulation in Law (PEARL), Australian National University, College of Law.

Mobile 0404106614

Email Liz.Curran@anu.edu.au

Canberra ACT 0200 Australia (Melbourne based)

www.anu.edu.au

CRICOS Provider No. 00120C. ORCID ID 0000-0002-6371-2975

\section{Chapter Thirteen - Lessons Emerging for other HJP and MDP More Broadly: 'Informing Replicable Models'}

\section{Social Determinants of Health}

$\mathrm{SDH}$ are hard to measure but it is not impossible to measure them.

\section{Barriers to Clients Seeking Help}

Barriers are not limited to a lack of information, lack of confidence, a legal system that is hard to navigate, poor public knowledge, the cost of lawyers or a lack of power, that the existing advice-seeking behaviour research suggests. Although all of these factors play a part, the qualitative data from the Bendigo Health-Justice Partnership research and evaluation is suggestive that barriers may also stem from the way in which the legal system has dealt with clients in the past or a negative experience of lawyers that acts as a deterrent to both the client and sometimes health/allied health professionals in seeking legal help. The experience of the Bendigo HJP Project shows that if the lawyer is 'nonjudgemental', 'approachable' and 'responsive', such poor perceptions of lawyers can be countered, leading to more referrals and client engagement and thus enabling further reach.

\section{Partnerships and Collaborations Are Hard and Need Investment and Time}

Working in partnerships towards collaboration is challenging, problematic and hard. It requires significant investments of time and regular contact points from senior management down the tree to service delivery and front-of-office staff. This was stressed by Noone ${ }^{95}$ et al. previously. It has also been stressed in studies from the United States:

'The task of working out a common mission and focus among varying disciplines sometimes generates conflict and frustration and requires a significant expenditure of time. But ... there is a shared belief that coordination and collaboration offer the best hope of an effective response for these families and enables communities to continue providing core services to the neediest families in the face of growing resource constraints. A sense of crisis, the

\footnotetext{
${ }^{95}$ Noone, MA, \& Digney, K (2010), “'It's Hard to Open up to Strangers" - Improving Access to Justice: The Key Features of an Integrated Legal Services Delivery Model', La Trobe University Rights and Justice Program Research Report, available at SSRN: http://ssrn.com/abstract=1799648
} 
[Insert ANU logo and running head]

\section{Contact: Dr Liz Curran}

Senior Lecturer, ANU Legal Workshop (Australia-wide Professional Legal Training) \& Assoc. Director International Centre for the Profession, Education and Regulation in Law (PEARL), Australian National University, College of Law.

Mobile 0404106614

Email Liz.Curran@anu.edu.au

Canberra ACT 0200 Australia (Melbourne based)

www.anu.edu.au

CRICOS Provider No. 00120C. ORCID ID 0000-0002-6371-2975

commitment of the participating individuals, their inter-personal collaborative skills, and the maintenance of clear and open channels of communication are cited as factors critical to the success of collaborative efforts. ${ }^{96}$

And in terms of partnerships between lawyers and non-lawyers:

'The problem presented is an atmosphere of distrust, fear and antagonism - not all of which is unfounded. It is the result of a lack of communication; failure of understanding of basic professional objectives, methods and philosophy of the co-professional; and above all, the mystique built up by ever increasing malpractice insurance rates. ${ }^{97}$

Relevant here, is part of the Family Violence Project of the LCCLC mentioned earlier, which the author evaluated in 2015. As part of the project, LCCLC developed a new survey instrument (the Collaborative Health Survey Tool) to measure experiences and views on effective collaboration between health and legal service providers in family violence matters. Such a survey was a useful way of finding out about what assists collaboration. The survey was conducted from 1 February until 31 March 2015. The survey responses revealed that some lawyers can tend to see themselves as the font of all wisdom, and are perceived as arrogant and unhelpful. This perhaps reflects that often lawyers tend to be task-oriented and consider things with a technical lens and sometimes do not fully appreciate other contexts in which other professionals also operate.

It is so important for clients to gain full help on a range of legal and non-legal issues to be able to realise their human rights. Where only 13-16 per cent of vulnerable clients have been gaining legal help, such professional barriers need to be overcome. ${ }^{98}$ Understandably, consciously or unconsciously, before a health/allied health professional (with their own professional obligations to their client) will be prepared to refer a vulnerable client or patient to a lawyer, it is natural for them to only do so where

\footnotetext{
${ }^{96}$ Barth, RP, Goldberg, S, Pietrzak, J, Price, A \& Parker, T (1995), ‘Abandoned infants programs: Assistance programs providing innovative responses on behalf of infants and young children'.

${ }^{97}$ Norton, M (1971), 'Development of an interdisciplinary program of instruction in medicine and law', Journal of Medical Education, vol. 46, no. 5, p. 405, as cited in Tobin-Tyler, E (2008), 'Allies Not Adversaries: Teaching Collaboration to the Next Generation of Doctors and Lawyers to Address Social Inequality', Roger Williams University, School of Law Faculty Papers, Paper 17, p. 2, available at: http://lsr.nellco.org/cgi/viewcontent.cgi?article=1017\&context=rwu_fp

${ }^{98}$ Coumarelos, C, MacCourt, D, People, J, McDonald, HM, Wei, Z, Iriana, R \& Ramsey, S (2012), 'Access to Justice and Legal Needs: Legal Australia-Wide Survey Legal Need in Australia', Law and Justice Foundation of New South Wales, Sydney, available at: http://www.lawfoundation.net.au/ljf/site/templates/LAW_AUS/\$file/LAW_Survey_Australia.pdf
} 
[Insert ANU logo and running head]

\section{Contact: Dr Liz Curran}

Senior Lecturer, ANU Legal Workshop (Australia-wide Professional Legal Training) \& Assoc. Director International Centre for the Profession, Education and Regulation in Law (PEARL), Australian National University, College of Law.

Mobile 0404106614

Email Liz.Curran@anu.edu.au

Canberra ACT 0200 Australia (Melbourne based)

www.anu.edu.au

CRICOS Provider No. 00120C. ORCID ID 0000-0002-6371-2975

the lawyer is seen as an effective communicator, personable and trustworthy; someone who will not just be concerned with the client's technical legal issues without heeding the client's context and personal circumstances, such as ill health or being overwhelmed. Where the health/allied health professional trusts the lawyer and gains a sense that they will work effectively with a client in a way that is in line with the therapeutic framework, and which will not re-traumatise, then they will be more likely to have a conversation with a client who may, in turn, be more willing to see a lawyer - in other words, what many participants and now this author term a 'transferral of trust' (based on a participant using this terminology in the Bendigo HJP). If the health/allied health professional trusts the lawyer and indicates this to the client, then the client who trusts the existing relationship with the health/allied health professional is likely to be more willing to see the lawyer.

When the HJP lawyer is visible, available and regularly having 'opportunistic' conversations with health/allied health professionals ${ }^{99}$ at photocopiers, in lunch rooms and around board tables, and when people feel they have a relationship of trust, a focus on client care and problem-solving leads to the overcoming of professional and cultural differences and a sharing of common values. It can also build capacity and hence responsiveness:

'... the benefits of providing this service include: building capacity amongst health professionals to identify and respond to legal needs and assisting health professionals to understand when a referral to a lawyer may be necessary. ${ }^{, 100}$

As one research participant put it in Snapshot Two:

'This is a new trial, forging new relationships and working in a new way for all of us. We are trying to break out of silos and traditional oppositions and adversarial settings, especially for lawyers, which is why the type of lawyer is key, as I said in Snapshot One. It's not always comfortable but we need to work through this as it is a better way of getting to the clients who need us.' (Interview with relationship holder - manager, Bendigo HJP)

\footnotetext{
${ }^{99}$ See also Noone, MA, \& Digney, K (2010), “'It's Hard to Open up to Strangers”- Improving Access to Justice: The Key Features of an Integrated Legal Services Delivery Model', La Trobe University Rights and Justice Program Research Report, available at SSRN: http://ssrn.com/abstract=1799648 ${ }^{100}$ Gyorki, L (2013), 'Breaking Down the Silos: Overcoming the Practical and Ethical Barriers of Integrating Legal Assistance into a Healthcare Setting', Inner Melbourne Community Legal Centre and The Churchill Trust Fellowship, available at: https://www.churchilltrust.com.au/media/fellows/Breaking_down_the_silos_L_Gyorki_2013.pdf
} 
[Insert ANU logo and running head]

\section{Contact: Dr Liz Curran}

Senior Lecturer, ANU Legal Workshop (Australia-wide Professional Legal Training) \& Assoc. Director International Centre for the Profession, Education and Regulation in Law (PEARL), Australian National University, College of Law.

Mobile 0404106614

Email Liz.Curran@anu.edu.au

Canberra ACT 0200 Australia (Melbourne based)

www.anu.edu.au

CRICOS Provider No. 00120C. ORCID ID 0000-0002-6371-2975

As the author's brief includes informing replicable models of HJP (Project Brief, Aim 2 and Objective v), the findings from Snapshot Two on the transition in staff in the research are critical for other HJPs that may experience staff transitions and key staff who go on extended leave. This applies to staff in both the legal and health services in the partnership. Gaps in service on-site should be averted as much as possible. New legal staff who fill in need to be steeped in the knowledge that the HJP model is done differently to traditional lawyering, where the lawyer waits in a legal office for others to come to them. This overlooks the body of recent empirical research (see Chapter Three) and more practically the heavy health/allied health professional caseloads, the negative stereotypes of lawyers (see the discussion in Chapter Eleven) that inhibit referrals, and emphasises the importance of trust of health/allied health professionals if they are to make referrals.

Further, as new lawyers enter HJP work, they have a steep learning curve if they come from private practice, legal aid or traditional community legal centre practices. Accordingly, induction must be careful and it must be stressed that the HJP model means they will have to do things very differently and learn about different professionals. As the data from the participants extracted in Chapters Nine, Ten and Eleven evidence, HJP lawyers ought not just be concerned with legal technical skills but should also conquer and spend time on establishing, developing and sustaining interdisciplinary professional relationships, learning to collaborate and understand the different professional roles so they can work respectfully. Similarly, new staff in the health partnership unaccustomed to working with lawyers in a MDP may also need time to adjust and for the trust to build. This is a key learning from Snapshot Two of the Bendigo HJP.

It is not easy for a new lawyer, trained in narrow legal siloes, going from law school into practice, to suddenly feel confident and easy working with new and different professionals when they may be in a new district, and have few ties to the community in which they come to work. It is natural for them to seek comfort among the legal professionals who make up a workplace team in such a new environment. Even where the lawyer is introduced to health/allied health professional staff that they have to work with in co-located service, this may not be enough. There is significant change to adapt to: different professionals, new people, different ways of practice that take you out of the approach you have been trained in and are accustomed to, making the task challenging and daunting for the newcomer who may not have the background in HJP models. In the Chapter Fourteen recommendations, this report will be suggesting that the current training and education of law students and lawyers is problematic in an age when new paradigms of lawyering are required. 
[Insert ANU logo and running head]

\section{Contact: Dr Liz Curran}

Senior Lecturer, ANU Legal Workshop (Australia-wide Professional Legal Training) \& Assoc. Director International Centre for the Profession, Education and Regulation in Law (PEARL), Australian National University, College of Law.

Mobile 0404106614

Email Liz.Curran@anu.edu.au

Canberra ACT 0200 Australia (Melbourne based)

www.anu.edu.au

CRICOS Provider No. 00120C. ORCID ID 0000-0002-6371-2975

If lawyers are to be effective, then it should be acknowledged that the case-based learning of court decisions and traditional teaching of law in subject siloes unrelated to human context and the reality of multi-faceted legal problems, are not equipping students to be lawyers who know about collaborative and relationship skills. This is equally relevant to practical legal training and further PD of more-senior lawyers. In addition, 'student clinics' that provide MDP opportunities for different students in different disciplines to work together would better prepare law students for MDP and holistic client care and break down professional barriers and stereotypes. This should be explored so that emerging professionals can work effectively together to better assist clients and patients.

Given that trust and relationships can so easily be broken down (as is demonstrated in the data extracted in Chapter Eight and in the data extracted and literature discussed in Chapter Eleven), such a transition should be entered into with a supported, planned approach and guided induction, and a clear expectation that the HJP model is not 'business as usual'. Rather, it is an innovative approach that takes a different approach to traditional lawyering models with expectations of being on-site and visible in the community health setting routinely and regularly.

It should be stressed that being interactive and flexible and responsive may reap returns in the longer term for any lawyer (as evidenced in the data extracted from the lawyer in-depth interviews in Chapters Seven through Eleven) and help the HJP in transition and reach clients. The lawyers who work for a time in a HJP model setting (in-depth interview with lawyers, Snapshots One and Three) share the view that relationships and mutual support and learnings of the lawyer in the health setting are conducive to improved client support, early intervention, and proactivity. Lawyers reflecting on the whole project journey in the Bendigo HJP Snapshot Three note that by spending longer in the HJP, they build a strong sense of their own capacity as a lawyer to do more for a client, because of the holistic, client-centred model of the health service professionals noting that the traditional legal model may often let the client down hard or leave them out in the cold. There is a lesson in this for other HJPs and for MDP and legal practice in general from this Bendigo HJPRAE.

\section{Ethical Process Client Complexity and Vulnerability}

When the client group has any possibility of vulnerability or is perceived as having risks, the ethics committees of universities and other agencies (e.g., government departments) will often require step-by-step ethics processes rather than granting overall approval until they are reassured about the potential harm. This requires additional work as often the tools, and information sheets and consent forms, will require modification at each phase. 
[Insert ANU logo and running head]

\section{Contact: Dr Liz Curran}

Senior Lecturer, ANU Legal Workshop (Australia-wide Professional Legal Training) \& Assoc. Director International Centre for the Profession, Education and Regulation in Law (PEARL), Australian National University, College of Law.

Mobile 0404106614

Email Liz.Curran@anu.edu.au

Canberra ACT 0200 Australia (Melbourne based)

www.anu.edu.au

CRICOS Provider No. 00120C. ORCID ID 0000-0002-6371-2975

\section{Value of Qualitative Data that Interprets and Goes behind Reasons for Qualitative Data when Dealing with Human Service}

This research evaluation was about finding out what works and why and what impacts on the SDH. To have a deeper understanding, qualitative data is needed. Much universal research does not collect qualitative data as it is time-consuming to collect, identify themes and analyse. Yet it is this that uncovers the complexities and layers which are so important in research around social exclusion and what works. Quantitative data is often favoured as it is often about adding and aggregating and can utilise computer programs. When combined, it can go deep and find the reasons why something works and does not work and actually assess whether the service is actually having an impact on people's lives. Measurements that look at whether something has been done (e.g., transactional, 'tick a box') do not uncover the quality of the transaction, nor whether it in fact has an impact and is effective. Quantitative data can inform of such factors and unravel complexities of clients, service provision and systemic barriers so that policy can be less blunt and learnings about what is effective practice can be shared.

Quantitative data does little to explain why the patterns exist and this has been the challenge of this project. This is why this research collects quantitative data but really relies on qualitative data to make sense of the figures in the quantitative data and the reasons that lie behind them. This is critical in understanding the 'push and pull' factors behind what makes people engage in getting legal help and understanding adviceseeking behaviour.

The work that HJPs do, as they target some of the most 'at-risk' members of society, is complex, where clients have not one but multiple and cascading legal and other problems which have often gone unnoticed or unassisted. This was particularly in evidence in the 'guided professional journals' which highlighted barriers, service problems in government departments, and the challenges facing professionals on a dayto-day basis, which could have otherwise been overlooked. It is critical to therefore remind participants in HJP and researchers, funders and champions that the work, although effective, is not easily done and takes time and energy and drive - to not only establish relationships but to sustain, nurture, develop and resource them.

\section{Professional Development Training Needs to Be Tailored to Professionals - Practical, Interactive, Accessible and Not in Lecture Format: Scenarios Should Build on Professional's Real Casework and Allow Space and Time for Conversations}

Results from the Bendigo HJPRAE suggest that professional development should avoid legal jargon and might be sequential over time, of a building-block nature and determined by need identified by staff in client work or through numbers of LSCs. If 
[Insert ANU logo and running head]

\section{Contact: Dr Liz Curran}

Senior Lecturer, ANU Legal Workshop (Australia-wide Professional Legal Training) \& Assoc. Director International Centre for the Profession, Education and Regulation in Law (PEARL), Australian National University, College of Law.

Mobile 0404106614

Email Liz.Curran@anu.edu.au

Canberra ACT 0200 Australia (Melbourne based)

www.anu.edu.au

CRICOS Provider No. 00120C. ORCID ID 0000-0002-6371-2975

PD is done well, it is critical to building capacity, empowering and instilling confidence. If not done well, it can set relationships back and trust can be lost. Respect for different professional expertise is key. As one participant describes it:

'You can build on a relationship by email and a phone call but the foundation for a professional relationship is confidence and personal knowledge of the casework; referrals need to come but they don't if you don't trust. Training plays a part as if poorly done you go backwards. It's all connected. You need to keep at it and not take relationships for granted and you also need to help us revisit knowledge, as once-off training does not all get retained - that's why it all works in together. Secondary consultations can reinforce training. If we have secondary consultations, we will want to do the training, but if it's not done in a way that respects us and what we have to do and heavy caseloads and in a sensible way, then we will just see it's a waste of time and that will then impact on your engagement proxy too. We want to help our clients too but we also don't and can't waste our time. Training and PD needs to be thought through not just in terms of content but effective delivery that is meaningful to us in practice.' (Interview with health/allied health professional, Bendigo HJP)

\section{Multi-disciplinary Practice through an HJP is Effective, Targeted and Extends Reach to the Socially Excluded}

So far, the overwhelming majority of evidence gathered in the Bendigo HJPRAE across multiple tools is suggestive that MDP through an HJP is effective, targeted and extends reach to the socially excluded, and can be a complement to traditional models of lawyering that extend the reach of legal services to 'at-risk' and often invisible community members who have little voice and knowledge of their legal position. In the words of one of the client participants:

'People should be able to know their rights like I do. They should know they have choices, not just been told and threatened so they sign away their rights to their child. The lawyer also got DHS off my back which made me more stressed and likely to make more mistakes ... you need to get the word out there about your service, in fact I am going to post how good you are on my Facebook page as there are lots of people in KF who think they have to do what they are told and I want them to know their rights like I do.' (Interview with Client, Bendigo HJP) 
[Insert ANU logo and running head]

\section{Contact: Dr Liz Curran}

Senior Lecturer, ANU Legal Workshop (Australia-wide Professional Legal Training) \& Assoc. Director International Centre for the Profession, Education and Regulation in Law (PEARL), Australian National University, College of Law.

Mobile 0404106614

Email Liz.Curran@anu.edu.au

Canberra ACT 0200 Australia (Melbourne based)

www.anu.edu.au

CRICOS Provider No. 00120C. ORCID ID 0000-0002-6371-2975

\section{Chapter Fourteen - Conclusions and Recommendations}

\section{Conclusions - Specific to the Bendigo HJP \\ Reaching Those Who Would Otherwise Not Gain Legal Help}

The evidence-based research (quantitative and qualitative) proves that this small and modest pilot project which sees a full-time lawyer based at BCHS for three days of the week, in a Bendigo Health-Justice Partnership between ARC Justice Ltd Bendigo and the Bendigo Community Health Services, has been an effective, targeted, efficient model. The Bendigo HJP meets its stated aim of reaching people who would otherwise not gain legal help with their legal problems through working with the trusted health and allied health professionals to whom clients turn at the Kangaroo site of BCHS. The Bendigo HJP data suggests that the project has also had a demonstrable effect on improving the social determinants of health of its clients (see data and discussion Chapters Four through Ten, Full Final Report).

\section{Journey Towards Integration and Collaboration}

The evidence shows the HJP Partners, Bendigo Health-Justice Partnership and ARC Justice, have moved beyond working largely in silos in responding to legal issues of clients, towards collaboration on a range of levels both professionally and organisationally and in terms of physical layout and IT and other systems to enable the HJP model to work. The overwhelming majority of evidence gathered in the Bendigo HJP research and evaluation data across multiple tools is suggestive that multidisciplinary practice through an HJP is effective, targeted and extends reach to the socially excluded, and it can be a complement to traditional models of lawyer that extend the reach of legal services to 'at-risk' and often invisible community members who have little voice and knowledge of their legal position.

The Bendigo HJP has not been easy. Relationships of trust take time to develop and need to be sustained. This takes significant time and effort but reaps rewards for clients and professional staff alike. Through the life of the project, high levels of trust between professionals using the HJP were evidenced and increased, and these are critical if clients are going to be reached.

As the author's brief includes the making of suggestions/recommendation (Project Brief, Objective vi), it might assist in the future if the health/allied health partner and the legal partner both assign a person as a point of contact to enable concerns of any nature to be raised and dealt with in a timely manner. It is fair to say that over the duration of the evaluation, the 'point of contact' was sometimes confusing. This might 
[Insert ANU logo and running head]

\section{Contact: Dr Liz Curran}

Senior Lecturer, ANU Legal Workshop (Australia-wide Professional Legal Training) \& Assoc. Director International Centre for the Profession, Education and Regulation in Law (PEARL), Australian National University, College of Law.

Mobile 0404106614

Email Liz.Curran@anu.edu.au

Canberra ACT 0200 Australia (Melbourne based)

www.anu.edu.au

CRICOS Provider No. 00120C. ORCID ID 0000-0002-6371-2975

also assist in seamless service and PD topics raised in some of the data. Putting clear lines of communication in place is essential.

This multi-disciplinary project, with professionals of different disciplines working together to assist clients with a range of complex needs, has seen a demonstrable increase in engagement of clients and health/allied health professionals. The capacity, confidence and sense of empowerment has improved as a result of the HJPs.

The HJP has seen the lawyers involved move from a traditional mode of lawyering, which waits for people to come to the lawyer, to the lawyers being more holistic, joined up, integrated and collaborative. This at times has been a challenge, but there is a demonstrated shift and evidence that this way of working and the use of Legal Secondary Consultations are 'critical' for clients if they are to be reached and for staff if they are going to be prepared to make referrals to the lawyer.

\section{Social Determinants of Health}

The evidence gathered through the data means it is possible that some social determinants of health for clients have improved as a result of the Bendigo HJP interventions. The data reveals reported decreases in levels of stress and anxiety and enhanced resilience in clients and in the health/allied health professionals who support them as a result of the HJP interventions, all of which go to reducing the risk of poor health outcomes.

As the data demonstrates in Chapters Nine and Ten, clients and their health/allied health professionals report that clients have been able to move forward or focus on their other often significant health and wellbeing issues because they know their legal problems are being handled and because they do not stress over their legal position so much as they 'now know where they stand'. For example, drug-addicted clients' risk of relapse has been reduced, and mentally ill clients have averted triggers to psychosis, by opportunistic access to a lawyer as they were in a heightened state of alarm about their legal matter.

Clients report a clear impact in their lives - and this is relevant to shaping positive impacts on their social determinants of health - of the HJP in the data gathered in the author's research and evaluation and detailed throughout this Full Final Report. This includes the fact that, if not for the Bendigo HJP, they would have lost their child, have no money to feed their child or to live, or would not be alive. There are a large number of examples of why and where the HJPs have impacted positively on the social determinants of health in this Full Final Report (see impact \& effectiveness in Chapter Ten).

\section{Effectiveness}


[Insert ANU logo and running head]

\section{Contact: Dr Liz Curran}

Senior Lecturer, ANU Legal Workshop (Australia-wide Professional Legal Training) \& Assoc. Director International Centre for the Profession, Education and Regulation in Law (PEARL), Australian National University, College of Law.

Mobile 0404106614

Email Liz.Curran@anu.edu.au

Canberra ACT 0200 Australia (Melbourne based)

www.anu.edu.au

CRICOS Provider No. 00120C. ORCID ID 0000-0002-6371-2975

The Bendigo HJP Project has achieved what it set out to do in terms of the impact it has had both for clients and for health/allied health professionals in supporting clients with legal need. This work would not have been possible but for, as the data suggests, the committed way in which the two partners, BCHS and ARC Justice, have worked together to meet many of the challenges presented.

The weight of evidence gathered in this Bendigo Health-Justice Partnership Research and Evaluation demonstrates the care, skill and commitment of the two partner agencies for the clients and community they serve $-90 \%$ of the clients interviewed in this small Bendigo HHJP indicated they would not have sought legal help were it not for the actions of BCHS in linking them into the HJP.

It was reported that $100 \%$ of clients' stress and anxiety had reduced due to the intervention of the Health-Justice Partnership and that the same number had more confidence in engaging with services through the HJP.

\section{Areas for Improvement}

This Full Final Report (see Chapter Eleven) identified that more community legal education and professional development targeted at doctors are areas where there could be improvement and more work undertaken. This is however difficult as noted, given the project's limited resources and personnel. This might be an area for funders into the future, whether government, philanthropy or pro-bono sponsored staff, given the data suggests it is key to reach, capacity and empowerment of community and staff. The reality is that to some extent, legal practitioners can tend to be fairly pragmatic about their role, and often with court dates and deadlines for filing to meet, time out of the office to represent clients in court, and tribunals and duties to the court (see discussion in Chapter Eleven) that extend beyond the individual client, in this regard they may focus on getting on with the business of advice and casework. By contrast, health/allied health workers are possibly less likely to approach the lawyers, in the first instance, to build the relationship because of their perception of what lawyers are like. This is elaborated on in Chapter Eleven, Full Final Report. As a consequence, health/allied health partners all need to be proactive in fostering the relationship. They cannot expect that the legal partner (generally consisting of, for instance, in the Bendigo HJP, one project lawyer) can cover all of the bases with respect to fostering the relationship. At the end of the day, as the data from this research and evaluation demonstrates, a HJP is an effective way of reaching people who would otherwise be invisible; data is suggestive of its improving client SDH outcomes and building engagement, capacity and empowerment for each of the partner agencies and the clients who they aim to assist.

\section{Summary}


[Insert ANU logo and running head]

\section{Contact: Dr Liz Curran}

Senior Lecturer, ANU Legal Workshop (Australia-wide Professional Legal Training) \& Assoc. Director International Centre for the Profession, Education and Regulation in Law (PEARL), Australian National University, College of Law.

Mobile 0404106614

Email Liz.Curran@anu.edu.au

Canberra ACT 0200 Australia (Melbourne based)

www.anu.edu.au

CRICOS Provider No. 00120C. ORCID ID 0000-0002-6371-2975

In summary, the empirical evidence (including substantial quantitative and qualitative data across a number of tools) emerging from the Bendigo Health-Justice Partnership Research and Evaluation is that where there is collaboration through referrals, LSCs, respectful professional development, client follow-up by both legal and health/allied health professionals, clear understanding and transparency, and effective and targeted service, then it can reach clients who would not otherwise gain legal help. The proxies which are indicative benchmarks for the project's impact and positive outcomes for the social determinants of health, namely engagement, capacity, collaboration and empowerment, were all evidenced in the empirical data.

The Bendigo HJP, it is suggested by the data, has made inroads positively, it is possible, into clients' social determinants of health and built the capacity of all their professionals to be able to better support clients to navigate complex systems and problems. The case studies in the report in Chapter Ten emerging from the study are powerful and the author commends them to any reader wishing to understand how the social determinants of health can impact upon the complex lives of the clients of BCHS and ARC Justice in the Health-Justice Partnership in Bendigo.

LSCs were critical to the success of the Bendigo HJP and in reaching clients who would otherwise not seek or get legal help. LSCs are helping workers to help clients, understand the legal system, and allow professionals to get advice on their own obligations, ethical and legal, which increases confidence - these in turn extend the reach of the HJP, build on knowledge and correct misunderstandings. LSCs need to be counted and valued as they are emerging as being just as important as client advices in reaching clients, as some clients may be too traumatised to see a lawyer, or mentally unwell, and so working with their trusted health or allied health professional through LSC is overwhelmingly described by $100 \%$ of participants in this research as of huge value.

The HJP in Bendigo has also demonstrated how innovative and collaborative are its approaches to lawyering which break the traditional mould of the lawyer sitting in an office and waiting for the clients to come. Instead, by going to where the clients are likely to be, alongside the health and allied health professionals that clients are likely to trust, it can reach those otherwise excluded and unknowing of their legal rights. Critical in this is that the lawyer needs to be an approachable, down-to-earth, genuine lawyer who respects clients and non-lawyers and other professionals and the role they all can play to work together for integrated, seamless, holistic client care, as has been achieved in the Bendigo HJP.

The author suggests, based on the quantitative and qualitative data, that is suggestive of effectiveness, quality and impact of the Bendigo HJP that further funding for the HJP be forthcoming in the future from government, council, philanthropy, pro-bono 
[Insert ANU logo and running head]

\section{Contact: Dr Liz Curran}

Senior Lecturer, ANU Legal Workshop (Australia-wide Professional Legal Training) \& Assoc. Director International Centre for the Profession, Education and Regulation in Law (PEARL), Australian National University, College of Law.

Mobile 0404106614

Email Liz.Curran@anu.edu.au

Canberra ACT 0200 Australia (Melbourne based)

www.anu.edu.au

CRICOS Provider No. 00120C. ORCID ID 0000-0002-6371-2975

contributions and other sources, but that it might be expanded to include staff who can assist the HJP lawyer in provision more consistently in professional development for health/allied health staff and for and with and in collaboration with the community. It also should be considered for funding of other HJPs to enable more community members currently excluded or unable to obtain or seek help with legal problems to be reached in a range of other settings, including social welfare service, general practitioner clinics, hospitals, schools and anywhere else people are likely to turn to trusted intermediaries for help with a range of health and social problems.

In the words of a research participant,

'I have incredible confidence in accessing it. I would be devastated if it were not there ... can't imagine that process being as responsive. It has informed me of the hard data of stuff. The Ivo example is a good one where I can check legal things with the lawyer. Now I have another string to my bow. Legal stuff often gets tangled up in medico-legal but we have not taken it there. Some lawyers, in my previous opinion, might only be interested when things have escalated. I see this is not the case with the HJP - vulnerabilities. Clients now know that the issue does not have to be huge; there is no benchmark. The client's issues are not trivialised.' (In-depth interview with health/allied health professional, Snapshot Three)

\section{Recommendations}

The author's specific project brief is also to make recommendations specific to the Bendigo HJP and more broadly. Accordingly, the author makes the following recommendations. The author notes that many of these recommendations flow from the participants in the research. Some have emerged from the overall analysis of all the project data by the author and others are suggestions that the author believes may further enhance replicable or existing models of HJP and its reach and relate to broader areas of funding, education and policy that stem from the literature; practice, research and teaching expertise, and from the data itself.

\section{Specific to the Bendigo HJP}

\section{Sustainability - Funding well beyond the pilot needs to occur to ensure the advances are harnessed and extended.}

The HJP model is effective, efficient and targeted and reaches clients through health and allied health providers. As such it needs sustained and adequate funding from government, council, philanthropy, pro-bono contributions and other sources, and the potential beyond having one HJP lawyer to make even greater inroads in supporting clients. In particular, it would be enhanced by more staff, including health promotion/community development and legal education and empowerment functions. 
[Insert ANU logo and running head]

\section{Contact: Dr Liz Curran}

Senior Lecturer, ANU Legal Workshop (Australia-wide Professional Legal Training) \& Assoc. Director International Centre for the Profession, Education and Regulation in Law (PEARL), Australian National University, College of Law.

Mobile 0404106614

Email Liz.Curran@anu.edu.au

Canberra ACT 0200 Australia (Melbourne based)

www.anu.edu.au

CRICOS Provider No. 00120C. ORCID ID 0000-0002-6371-2975

\section{Professional development for doctors.}

Another area for further work is the integration of PD opportunities for doctors into the general professional development of BCHS so that it is not time-consuming, and to encourage a greater capacity for BCHS staff to participate given their casework commitments. This is especially true of the doctors with high patient numbers and the 10-minute slots for patient appointments. For them, use of LSCs may be a tool for PD, regular attendance at medical and general practitioner/paediatrician team meetings, and assistance with template letters; for example, the special circumstances list.

3. Community legal education and professional development training should include more training on the art of argument and rehearsal of difficult conversations with decision-makers - for health/allied health professionals, it would empower them more in advocacy.

See Chapter Ten data, Full Final Report from BCH health/allied health staff.

4. A simple, plain English, easy to administer 'Legal Health Checklist' should be made available to all BCHS staff across all sites (both professional and client service staff) - one could also be prepared for clients.

This was requested by a number of research participants, including the doctors and reception staff, as something they would find useful (see Chapters Eight and Nine, Full Final Report). It can be based in simple existing tools that are available from the Health-Justice Partnership Tool Kit and the National Centre for Health-Justice Partnerships in Australia.

5. Engagement of the Boards and Executive of both partners in the Bendigo Health-Justice Partnership in joint reporting on the impacts of the HealthJustice Partnership on clients and community and staff, strategic planning and policy work.

Participants in Snapshot Three also noted there was room for more collaboration on policy between the two agencies and their Board and Executive on systemic issues relevant to their clients. This had started to occur with work on child protection in Snapshot Two and has also occurred in relation to an Office of the Public Advocate Inquiry. Such joint action takes time and is likely to occur into the future given the readiness of the managers interviewed to embark on such joint initiatives and work more strategically together, as was indicated in interviews with them in Snapshot Three.

6. Physical placement of the lawyer in the building or any future building in which the Health-Justice Partnership is based.

This will enable Legal Secondary Consultations to be seamless, easy and opportunistic as this helps clients and staff capacity. 
[Insert ANU logo and running head]

\section{Contact: Dr Liz Curran}

Senior Lecturer, ANU Legal Workshop (Australia-wide Professional Legal Training) \& Assoc. Director International Centre for the Profession, Education and Regulation in Law (PEARL), Australian National University, College of Law.

Mobile 0404106614

Email Liz.Curran@anu.edu.au

Canberra ACT 0200 Australia (Melbourne based)

www.anu.edu.au

CRICOS Provider No. 00120C. ORCID ID 0000-0002-6371-2975

7. The Bendigo HJP is a 'two-way street'. Ongoing communication between the legal partner and the health partner is essential for the seamless and collaborative nature of the project. The health/allied health partner and the legal partner both assign a person as a point of contact to enable concerns of any nature to be raised and dealt with in a timely manner.

See discussion, Chapter Thirteen, Full Final Report

8. Proactivity - health/allied health partners all need to be proactive in fostering the relationship. They cannot expect that the legal partner (generally consisting of one project lawyer) can cover all of the bases with respect to fostering the relationship.

See discussion earlier in Chapter Fourteen, Full Final Report.

9. Funding in future research and evaluation of the Bendigo HJP should be sought for the running of a focus group following each snapshot period (if the snapshot methodology is followed).

The focus group task, in a very rich and real way, addresses the SDH. Checking in with the community following each snapshot is a powerful addition and a hugely informative check and balance. It could ensure a continual check-in with the target client group and provide a mechanism to offer ongoing CLE to vulnerable and disadvantaged clients. See the discussion, Chapters One through Four, Full Final Report.

\section{General Recommendations for Replicable/Existing Models of HJP, Funding,} Education and Policy

1A. Research evaluation should not fit into limited available funds but should be funded according to the actual work and the societal and tax payer value of building the evidence-based practice that is required to ensure good and effective service to community.

Having an embedded, routinised evidence base is critical to inform and ensure good practice and replicable models.

2A. Funding in future, if this methodology is favoured in future studies, should be sought for the running of a focus group following each snapshot period (if the snapshot methodology is followed).

The focus group task informs, in a very rich and real way, the SDH. Checking in with the community following each snapshot is a powerful addition and a hugely informative check and balance. It could ensure a continual check-in with the target client group and provide a mechanism to offer ongoing CLE to vulnerable and disadvantaged clients. See the discussion, Chapters One through Four, Full Final Report. 
[Insert ANU logo and running head]

\section{Contact: Dr Liz Curran}

Senior Lecturer, ANU Legal Workshop (Australia-wide Professional Legal Training) \& Assoc. Director International Centre for the Profession, Education and Regulation in Law (PEARL), Australian National University, College of Law.

Mobile 0404106614

Email Liz.Curran@anu.edu.au

Canberra ACT 0200 Australia (Melbourne based)

www.anu.edu.au

CRICOS Provider No. 00120C. ORCID ID 0000-0002-6371-2975

\section{A. Community legal education/community development in a multi- disciplinary way.}

There is a role for the Health-Justice Partnership in empowering community and engaging with community more broadly in the knowledge of their legal rights and developing their own skills in advocacy. This should be done where possible in a multidisciplinary setting in conjunction with community health partners who can also inform legal education with a health promotion perspective to enhance community social and health outcomes. Such sessions could be run jointly, with the health and allied health professional and lawyer using adult learning approaches that respect the participants' experience. In the current project, as there was only one HJP lawyer, it was not possible to conduct as much of this work. Given its importance (see the evidence in the research data) this work should be enabled through funding and a person who is able to undertake this work to build professional and community capacity and engagement.

4A. Education of law students at university in practical legal training and lawyer professional development, in holistic client care and breaking down professional barriers and stereotypes, by skills training in different styles of lawyering.

Current training and education of law students, experienced lawyers and graduate lawyers is problematic in an age when new paradigms of lawyering are required. If lawyers are to be effective, case-based learning alone and the traditional teaching of law in subject silos unrelated to human context and the reality of multi-faceted legal problems will not equip them for real-life legal practice or good practice. Poor perceptions and experiences of lawyers (see the discussion in Chapter Eleven, Full Final Report) will not change until they have improved collaborative and relationship skills. This is equally relevant to Practical Legal Training courses and further professional development of more-senior lawyers. Universities, the Law Institute of Victoria and PLT providers need to be mindful of changing legal practice and the evidence base for quality and effective legal practice.

\section{A. Multi-disciplinary student clinical programs should be taught at university across faculties to promote collaborative practice, and funding made available.}

In view of the shortcomings in legal education and the value for all students in learning to work collaboratively across disciplines, there seems to be an ideal opportunity for universities to introduce some multi-disciplinary student clinics, where law students, nursing students, social work students and counselling students might all undertake a clinical project for credit. Funding opportunities for this should be made available. The opportunities for students to learn about collaboration, other disciplines, and to look at things through a different lens would be a way of making future professionals better 


\section{Contact: Dr Liz Curran}

Senior Lecturer, ANU Legal Workshop (Australia-wide Professional Legal Training) \& Assoc. Director International Centre for the Profession, Education and Regulation in Law (PEARL), Australian National University, College of Law.

Mobile 0404106614

Email Liz.Curran@anu.edu.au

Canberra ACT 0200 Australia (Melbourne based)

www.anu.edu.au

CRICOS Provider No. 00120C. ORCID ID 0000-0002-6371-2975

able to work out of silos and trained to think outside legal categories and more laterally and holistically. They could learn skills of relational lawyering and collaboration by learning in relevant and appropriate settings alongside non-legal students in training to be professionals (e.g., nursing, medicine, psychology, social work). This might lead them to think not only as narrow legal technicians but to see things more laterally, enabling a different type of professional relevant to MDP and HJP but also likely to benefit a range of clients and be useful in corporate settings as well.

6A. Legal Secondary Consultations - DATA CAPTURE to ensure practiceinformed support and valuing of this form of advice and training to support those undertaking legal and non-Legal Secondary Consultation. The Community Legal Centre data-capture systems should count and value Legal Secondary Consultations as a legitimate method of expanding the reach of legal assistance service to professionals and clients who may not be ready to see a lawyer.

Legal Secondary Consultations 'are pivotal' - 'it would not work if we did not have LSCs'. A significant majority of research participants noted that LSC enables quick, efficient and targeted building of knowledge which can 'save time' in the long run. LSCs need to be done well as they are so critical to engaging and reaching vulnerable and disadvantaged clients. Training in good LSC is also critical to ensure they comply with legal professional requirements but are also practical, useful and useable.

7A. Physical placement of the lawyer in the building or any future building in which the Health-Justice Partnership is based.

This will enable Legal Secondary Consultation to be 'seamless', 'easy' and 'opportunistic' and 'reach clients earlier' who are 'in crisis', as this helps clients and staff capacity to respond and make 'informed choices', and 'increases confidence'.

8A. Inclusion in training of client service staff as they are on the front line and could also refer at points in time that are critical.

See Chapter Ten data from $\mathrm{BCH}$ reception staff.

9A. Future research with costing of savings from early legal help, which otherwise would have led to downstream costs to the health, social and legal system and which supplement the basic income for families, would be useful.

Given, as noted above, the lack of funds for research evaluations, the author has some suggestions. The use of pro-bono law and accounting firms and provision by large firms of intern or funded fellowships to do costings of saving from the HJP interventions could be a way of finding the expertise and examining the evidence base and modelling. Another possibility is the use of volunteer students with economic or commercial 
[Insert ANU logo and running head]

Contact: Dr Liz Curran

Senior Lecturer, ANU Legal Workshop (Australia-wide Professional Legal Training) \& Assoc. Director International Centre for the Profession, Education and Regulation in Law (PEARL), Australian National University, College of Law.

Mobile 0404106614

Email Liz.Curran@anu.edu.au

Canberra ACT 0200 Australia (Melbourne based)

www.anu.edu.au

CRICOS Provider No. 00120C. ORCID ID 0000-0002-6371-2975

training (many law students have combined law and commerce degrees) who could model and cost savings for a HJP where these client matters suggest. In the UK, some law centres and student law clinics (Nottingham Trent University) enlist volunteer students to undertake this. (See the discussion in Chapter Eleven, Full Final Report.) Bringing into the research this economic dimension through utilisation of such expertise could inform public policy and funding decisions.

10A. Funding of other HJPs (as a complement to existing general and specialist legal services) should be forthcoming in the future from government, council, philanthropy, pro-bono contributions and other sources, given the growing evidence base for HJPs (including the Bendigo HJPRAE) as an effective innovation.

This will enable more community members currently excluded or unable to obtain or seek help with legal problems to be reached in a range of other settings, including social welfare service, general practitioner clinics, hospitals, schools and anywhere else people are likely to turn to trusted intermediaries for help with a range of health and social problems. 
[Insert ANU logo and running head]

\section{Contact: Dr Liz Curran}

Senior Lecturer, ANU Legal Workshop (Australia-wide Professional Legal Training) \& Assoc. Director International Centre for the Profession, Education and Regulation in Law (PEARL), Australian National University, College of Law.

Mobile 0404106614

Email Liz.Curran@anu.edu.au

Canberra ACT 0200 Australia (Melbourne based)

www.anu.edu.au

CRICOS Provider No. 00120C. ORCID ID 0000-0002-6371-2975

\section{$\underline{\text { References }}$}

Allen Consulting Group (2014), 'Review of the National Partnership Agreement on Legal Assistance Services, Final Report', June, Allen Consulting Group, Melbourne, Australia, available at: http://www.acilallen.com.au/cms_files/NPA\%20Review_LAS\%20report_final.p df

Attorney-General, 'Strategic Framework on Access to Justice in the Federal Civil Justice System', available at:

https://www.ag.gov.au/LegalSystem/Documents/A\%20Strategic\%20Framework $\% 20$ for $\% 20$ Access $\% 20$ to $\% 20 \mathrm{Justice} \% 20 \mathrm{in} \% 20$ the $\% 20 \mathrm{Federal} \% 20 \mathrm{Civil} \% 20 \mathrm{Jus}$ tice\%20System.pdf

Australian Government Productivity Commission (2014), 'Access to Justice Arrangements, Final Report', no. 72, September, Australian Government Productivity Commission, Canberra, available at: http://www.pc.gov.au/inquiries/completed/access-justice/report

Balmer, NJ, Pleasence, P, Buck, A \& Walker, HC (2006), 'Worried sick: The experience of debt problems and their relationship with health, illness and disability', Social Policy and Society, vol. 5, no. 1, pp. 39-51

Barth, RP, Goldberg, S, Pietrzak, J, Price, A \& Parker, T (1995), 'Abandoned infants programs: Assistance programs providing innovative responses on behalf of infants and young children'.

Beeson, T, McCallister, BD, \& Regenstein, M (2013), 'Making the Case for MedicalLegal Partnerships: A Review of Evidence', The National Center for MedicalLegal Partnership, School of Public Health and Health Services, The George Washington University

Biuso, C, Newton, B (2008), 'Supporting quality care in general practice: The collaboratives approach', Australian Journal of Primary Health, vol. 14, no. 2, pp. $46-52$.

Buck, A, Pleasence, P, Balmer, N, O'Grady, A \& Genn, H (2004), 'Lone parents and civil law: Their experience of problems and their advice-seeking behaviour', Social Policy \& Administration, vol. 38, no. 3, pp. 253-69.

Buck, A, Smith, M, Sidaway, J \& Balmer, NJ (2010), 'Community Legal Advice Centres: A Survey of Clients in Reception Areas', Legal Services Commission, London. 
[Insert ANU logo and running head]

\section{Contact: Dr Liz Curran}

Senior Lecturer, ANU Legal Workshop (Australia-wide Professional Legal Training) \& Assoc. Director International Centre for the Profession, Education and Regulation in Law (PEARL), Australian National University, College of Law.

Mobile 0404106614

Email Liz.Curran@anu.edu.au

Canberra ACT 0200 Australia (Melbourne based)

www.anu.edu.au

CRICOS Provider No. 00120C. ORCID ID 0000-0002-6371-2975

Buck, A, Smith, M, Sidaway, J \& Scanlon, L (2010), 'Piecing It Together: Exploring One-stop Shop Legal Service Delivery on Community Legal Advice Centres', Legal Services Commission, London.

Buck, A \& Curran, L (2009), 'Delivery of advice to marginalised and vulnerable groups: The need for innovative approaches', Public Space: The Journal of Law and Social Justice, vol. 3, pp. 1-29.

Burchardt, T, Le Grand, J \& Piachaud, D (2002), 'Degrees of exclusion: Developing a dynamic, multidimensional measure', in J Hills, J Le Grand \& D Piachaud (eds), Understanding Social Exclusion, Oxford University Press, Oxford, pp. 30-43.

Centers for Disease Control and Prevention, 'Social Determinants of Health', available at: http://www.cdc.gov/socialdeterminants/faq.html\#b

'CHART-IT or, Capturing Health - An Attorney Reporting Tool for Impact Tracking: A Framework for Systematically Documenting the Impact of Legal Assistance on the Health of Low Income Individuals and Families', Medical Legal Partnership Illinois, hard copy handed to the author in Canada on 7 July 2016

Clarke, S \& Forell, S (2007), 'Pathways to justice: The role of non-legal services', Justice Issues, no. 1, Law and Justice Foundation of NSW, Sydney.

Colvin JD, Nelson B \& Cronin K (2012), 'Integrating social workers into medicallegal partnerships: Comprehensive problem solving for patients', Soc. Work, vol. 57, no. 4, pp. 333-41.

Conover, CJ \& Whetten-Goldstein, K (2002), 'The impact of ancillary services on primary care use and outcomes for HIV/AIDS patients with public insurance coverage', AIDS Care, vol. 14(sup001), pp. 59-71.

Consumer Action Law Centre (2016), 'Evaluating Consumer Action's Worker Advice Service', available at: http://consumeraction.org.au/evaluatingconsumer-actions-worker-advice-service/

Coumarelos, C, MacCourt, D, People, J, McDonald, HM, Wei, Z, Iriana, R \& Ramsey, S (2012), 'Access to Justice and Legal Needs: Legal Australia-Wide Survey Legal Need in Australia', Law and Justice Foundation of New South Wales, Sydney, available at: http://www.lawfoundation.net.au/ljf/site/templates/LAW_AUS/\$file/LAW_Surv ey_Australia.pdf

Coumarelos, C \& Wei, Z (2009), 'The legal needs of people with different types of chronic illness or disability', Justice Issues, no. 11, Law and Justice Foundation of NSW, Sydney. 
[Insert ANU logo and running head]

\section{Contact: Dr Liz Curran}

Senior Lecturer, ANU Legal Workshop (Australia-wide Professional Legal Training) \& Assoc. Director International Centre for the Profession, Education and Regulation in Law (PEARL), Australian National University, College of Law.

Mobile 0404106614

Email Liz.Curran@anu.edu.au

Canberra ACT 0200 Australia (Melbourne based)

www.anu.edu.au

CRICOS Provider No. 00120C. ORCID ID 0000-0002-6371-2975

Crockett, A \& Curran, L (2013a), 'A Practical Methodology for Measuring the Quality and Outcomes and Legal Assistance Services', University of Tasmania Law Review, vol. 32, no. 1, October

Crockett, A \& Curran, L (2013b), 'A Practical Model for Measuring Effectiveness', Conference Paper, International Legal Aid Group Conference, The Hague, June, available at:

http://papers.ssrn.com/sol3/cf_dev/AbsByAuth.cfm?per_id=2030109

Curran, L (2005), 'Making connections: The benefits of working holistically to resolve people's legal problems', E Law - Murdoch University Electronic Journal of Law, vol. 12.

Curran, L (2007a), 'Ensuring Justice and Enhancing Human Rights: A Report on Improving Legal Aid Service Delivery to Reach Vulnerable and Disadvantaged People', La Trobe University, Melbourne, available at: http://libertyvictoria.org/sites/default/files/Report\%20-\%20Ensuring\%20Justice $\% 20$ and\%20Enhancing\%20Human\%20Rights.pdf

Curran, L (2007b), 'Making the Legal System More Responsive to Community: A Report on the Impact of Victorian Community Legal Centre (CLC) Law Reform Initiatives', West Heidelberg Community Legal Service, West Heidelberg, Vic.

Curran, L (2007c) 'Making the Legal System more Responsive to Community: A Report on the Impact of Victorian Community Legal Centre (CLC) Law Reform Initiatives', Reichstein Foundation, available at: http://www.fclc.org.au/public_resource_details.php?resource_id=1152

Curran, L (2008), 'Relieving some of the legal burdens on clients: Legal aid services working alongside psychologists and other health and social service professionals', The Australian Community Psychologist, vol. 20, no. 1, pp. 4756

Curran, L (2012a), 'A literature review: Examining the literature on how to measure the "successful outcomes": Quality, effectiveness and efficiency of Legal Assistance Services, Australian Attorney General's Department, Canberra, available at: http://www.ag.gov.au/LegalSystem/Legalaidprograms/Documents/ Literature\%20review\%20of\%20legal\%20assistance\%20by\%20Dr\%20Liz\%20[ Author 2 surname].pdf

Curran, L (2012b), "We Can See There's Light at the End of the Tunnel Now": Demonstrating and Ensuring Quality Service to Clients', Legal Aid ACT, Canberra, available at: http://www.legalaidact.org.au/pdf/Light_at_the_end_of_the_Tunnel_Legal_Aid _Services_Quality_and_Outcomes.pdf 
[Insert ANU logo and running head]

\section{Contact: Dr Liz Curran}

Senior Lecturer, ANU Legal Workshop (Australia-wide Professional Legal Training) \& Assoc. Director International Centre for the Profession, Education and Regulation in Law (PEARL), Australian National University, College of Law.

Mobile 0404106614

Email Liz.Curran@anu.edu.au

Canberra ACT 0200 Australia (Melbourne based)

www.anu.edu.au

CRICOS Provider No. 00120C. ORCID ID 0000-0002-6371-2975

Curran, L (2013a), 'A practical model for demonstration and ensuring quality legal aid services: A case study in applied research', International Legal Aid Group Conference paper with Andrew Crockett, CEO of Legal Aid ACT, The Hague, Holland.

Curran, L (2013b), 'Encouraging Good Practice in Measuring Effectiveness in the Legal Service Sector', Legal Workshop, Australian National University College of Law, 21 May, available at:

http://www.plelearningexchange.ca/database/solving-problems-strategicapproach-examples-processes-strategies

Curran, L (2013c), 'Legal Review: Not All in the Statistics', Law Institute Journal, vol. 87, no. 7, July, pp. 36-9

Curran, L (2013d), 'Measuring legal services: A practical methodology for measuring quality and outcomes of legal assistance services', University of Tasmania Law Review, vol. 32, no. 1, pp. 70-95.

Curran, L (2013e), 'Solving Problems - A Strategic Approach: Examples, Processes \& Strategies', 13 May, Legal Workshop, Australian National University College of Law, available at:

http://law.anu.edu.au/sites/all/files/legalworkshop/final_report_solving_legal_pr oblems_curran_calc_13_march_2013.pdf

Curran, L (2013f), 'The Strategic Approach to Legal Problem Solving - Examples, Processes \& Strategies', Legal Workshop, Australian National University College of Law, available at:

http://www.plelearningexchange.ca/database/solving-problems-strategicapproach-examples-processes-strategies/

Curran, L (2015a), 'Family Violence Project Evaluation Report', available at: http://lcclc.org.au/wp-content/uploads/2015/05/Final-Evaluation-Report-LSBFamily-Violence-Curran-14-May-2015.pdf

Curran, L (2015b), 'Holistic approaches to reaching and assisting clients experiencing vulnerability or disadvantage - Health-Justice Partnerships in Australia and beyond, with a focus on the emerging value of LSCs', International Legal Aid Group Conference, Scotland.

Curran, L (2015c), “Why Didn't You Ask?" - Evaluation of the Family Violence Project of Loddon Campaspe Community Legal Community Legal Centre', Loddon- Campaspe Community legal centre and the Legal Service Board.

Curran, L (2016), 'Health-Justice Partnership - Multi-disciplinary Practices: Research Evidencing Working Ethically to Ensure Reach to Those in Most 
[Insert ANU logo and running head]

\section{Contact: Dr Liz Curran}

Senior Lecturer, ANU Legal Workshop (Australia-wide Professional Legal Training) \& Assoc. Director International Centre for the Profession, Education and Regulation in Law (PEARL), Australian National University, College of Law.

Mobile 0404106614

Email Liz.Curran@anu.edu.au

Canberra ACT 0200 Australia (Melbourne based)

www.anu.edu.au

CRICOS Provider No. 00120C. ORCID ID 0000-0002-6371-2975

Need \& Improve Outcomes' (Presentation Slides), July, available at: http://papers.ssrn.com/sol3/cf_dev/AbsByAuth.cfm?per_id=2030109

Curran, L \& Noone, M (2007), 'The challenge of defining unmet legal need', Journal of Law and Social Policy, vol. 21, no. 1, pp. 63-89

Curran, L \& Noone, MA (2008), 'Access to justice: A new approach using human rights standards', International Journal of the Legal Profession, vol. 15, no. 3, pp. 195-229.

Curran, L \& Victorian Legal Services Board and Commissioner (2016), 'HealthJustice Partnership Development Report', available at: http://www.lsbc.vic.gov.au/documents/ReportHealth_Justice_Partnership_Development-2016.PDF

Currie, A (2007a), 'The Legal Problems of Everyday Life', Legal Aid: A New Beginning?, International Legal Aid Group Conference, University of Strathclyde, Antwerp, Belgium.

Currie, A (2007b), 'Civil justice problems and the disability and health status of Canadians', Journal of Law and Social Policy, vol. 21, p. 71.

Dahlgren, G \& Whitehead (2006), 'European Strategies for Tackling Social Inequities in Health: Levelling Up Part 2', WHO Studies on and Economic Determinants of Population, no. 3, p. 20, available at:

http://www.euro.who.int/_data/assets/pdf_file/0018/103824/E89384.pdf

Dal Pont, G (2006), Lawyers' Professional Responsibility, Thomson LawBook Co., Pyrmont, NSW.

Darkenwald, G \& Merriam, S (1982), Adult Education Foundations of Practice, pp. $128-9$.

Dick, B (2016), Action Research and Action Learning for Community and Organisational Change, available at: http://www.aral.com.au

Federation of Community Legal Centres Victoria (2015), Legal Services Agreement Signed Amidst Serious Ongoing Concerns for Community Legal Clients, press release, 6 July, available at:

http://www.fclc.org.au/cb_pages/media_releases.php

Genn, H (1999), Paths to Justice: What People Do and Think about Going to Law, Hart Publishing, Oxford.

Gyorki, L (2013), 'Breaking Down the Silos: Overcoming the Practical and Ethical Barriers of Integrating Legal Assistance into a Healthcare Setting', Inner Melbourne Community Legal Centre and The Churchill Trust Fellowship, available at: 
[Insert ANU logo and running head]

\section{Contact: Dr Liz Curran}

Senior Lecturer, ANU Legal Workshop (Australia-wide Professional Legal Training) \& Assoc. Director International Centre for the Profession, Education and Regulation in Law (PEARL), Australian National University, College of Law.

Mobile 0404106614

Email Liz.Curran@anu.edu.au

Canberra ACT 0200 Australia (Melbourne based)

www.anu.edu.au

CRICOS Provider No. 00120C. ORCID ID 0000-0002-6371-2975

https://www.churchilltrust.com.au/media/fellows/Breaking_down_the_silos_L_ Gyorki_2013.pdf

Harding, R, Sherr, L, Singh, S, Sherr, A \& Moorhead, R (2002), 'Evaluation of welfare rights advice in primary care: The general practice perspective', Health \& Social Care in the Community, vol. 10, no. 6, pp. 417-22.

Healthy Living Network (2012), 'Healthy Communities Initiative Quality Framework Guide', Australian Government Department of Health and Aging, available at: http://www.healthylivingnetwork.com.au

Hegarty, K, Humphreys, C, Forsdike, K, Diemer, K \& Ross, S (2014), 'Acting on the Warning Signs: An Advocacy Health Alliance to Address Family Violence through a Multi-disciplinary Approach', Evaluation Final Report, August, University of Melbourne (copy provided to author).

Himmelman, A (2001), 'On coalitions and the transformation of power relations: Collaborative betterment and collaborative empowerment', American Journal of Community Psychology, vol. 29, no. 2, pp. 277-84.

Holland, J (2016), 'Negotiating Bulk Debt: Outcomes from the Bulk Debt Negotiation Project', unpublished report for Victoria Legal Aid, West Heidelberg Community Legal Service, Legal Aid NSW, Good Shepherd Australia \& New Zealand.

Lawton, E (2007) 'Medical-legal partnerships: From surgery to prevention?', Management Information Exchange Journal, vol. 37, pp. 38-42, 53.

Lawton, E. \& Tobin-Tyler, E (2013), 'Optimizing the health impacts of civil legal aid interventions: The public health framework of medical-legal partnerships', Rhode Island Medical Journal, vol. 96, no. 7, pp. 22-6.

Lee, DM (1994), 'Becoming an expert: Reconsidering the place of wisdom in teaching adults', in Jan D Sinnott (ed.), Interdisciplinary Handbook of Adult Lifespan Learning, p. 243.

Low Commission (2015), 'The Role of Advice Services in Health Outcomes', June, Consilium Research and Consultancy, London, available at: http://asauk.org.uk/wp-content/uploads/2015/06/ASA-report_Web.pdf

Moorhead, R, Robinson, M \& Matrix Research and Consultancy (2006), 'A Trouble Shared: Legal Problems Clusters in Solicitors' and Advice Agencies', DCA research series, no. 8/2006, Department of Constitutional Affairs, London.

Naitove, B (1982), 'Medicolegal education and the crisis of interprofessional relations', American Journal of Law and Medicine, vol. 8, p. 293. 
[Insert ANU logo and running head]

\section{Contact: Dr Liz Curran}

Senior Lecturer, ANU Legal Workshop (Australia-wide Professional Legal Training) \& Assoc. Director International Centre for the Profession, Education and Regulation in Law (PEARL), Australian National University, College of Law.

Mobile 0404106614

Email Liz.Curran@anu.edu.au

Canberra ACT 0200 Australia (Melbourne based)

www.anu.edu.au

CRICOS Provider No. 00120C. ORCID ID 0000-0002-6371-2975

National Association of Community Legal Centres (2015), 'National Census Report', available at:

http://www.naclc.org.au/resources/NACLC\%20Census\%20-\%20National\%20R eport\%202015\%20-\%20FINAL.pdf

National Center for Medical-Legal Partnership (2015), Performance Measures Handbook, August, available at: http://medical-legalpartnership.org/resources/

National Center for Medical-Legal Partnership and Milken Institute School of Public Health, George Washington University (2014), 'Background and Related Information about the MLP Measures Development Process', 9 July, copy provided to the author

Newman, J (2012), 'Miami's medical-legal partnership: Preparing lawyers and physicians for holistic practice', Indiana Health Law Review, University of Miami Law Review, available at: http://ssrn.com/abstract=2014824 or http://dx.doi.org/10.2139/ssrn.2014824

Noble, P (2012), 'Advocacy-Health Alliances - Better Health through Medical-legal Partnership', Loddon Campaspe Community Legal Centre \& The Clayton Utz Foundation, available at:

https://advocacyhealthalliances.files.wordpress.com/2012/08/ahareport_general1.pdf

Noone, M (1992), 'Imperatives for Community Legal Centres', Alternative Law Journal, vol. 17, no. 3, pp. 120-4

Noone, MA (2007), 'They all come in one door: The transformative potential of an integrated service model - A study of the West Heidelberg Community Legal Service, in P Pleasence, A Buck \& N Balmer (eds), Transforming Lives: Law and Social Process, The Stationery Office, London.

Noone, MA (2009), 'Towards an integrated service response to the link between legal and health issues', Australian Journal of Primary Health, vol. 15, pp. 203-11

Noone, MA (2012), 'Integrated legal services: Lessons from West Heidelberg Community Legal Service', Alternative Law Journal, vol. 37, no. 1, p. 26, available at SSRN: http://ssrn.com/abstract=2030556 or http://dx.doi.org/10.2139/ssrn.2030556

Noone, MA \& Curran, L (2008), 'Access to justice: A new approach using human rights standards', International Journal of the Legal Profession, vol. 15, no. 3 , pp. 195-229.

Noone, MA \& Digney, K (2010), “"It's Hard to Open up to Strangers”- Improving Access to Justice: The Key Features of an Integrated Legal Services Delivery 
[Insert ANU logo and running head]

\section{Contact: Dr Liz Curran}

Senior Lecturer, ANU Legal Workshop (Australia-wide Professional Legal Training) \& Assoc. Director International Centre for the Profession, Education and Regulation in Law (PEARL), Australian National University, College of Law.

Mobile 0404106614

Email Liz.Curran@anu.edu.au

Canberra ACT 0200 Australia (Melbourne based)

www.anu.edu.au

CRICOS Provider No. 00120C. ORCID ID 0000-0002-6371-2975

Model', La Trobe University Rights and Justice Program Research Report, available at SSRN: http://ssrn.com/abstract=1799648

Noone, MA \& Tomsen, S. (2006), Lawyers in Conflict: Australian Lawyers and Legal Aid, The Federation Press, New South Wales

Norton, M (1971), 'Development of an interdisciplinary program of instruction in medicine and law', Journal of Medical Education, vol. 46, no. 5, p. 405.

O’Grady A, Pleasence P, Balmer NJ, Buck, A \& Genn, H (2004), 'Disability, social exclusion and the consequential experience of justiciable problems', Disability \& Society, vol. 19, no. 3, pp. 259-72, doi: 10.1080/0968759042000 204158

Pentland, J \& Drosten, P (1996), 'Financial counselling and problem gambling counselling: Exploration of a service model', Australian Journal of Primary Health - Interchange, vol. 2, no. 2, pp. 54-62.

Pleasence, P \& Balmer, NJ (2009), 'Mental health and the experience of social problems involving rights: Findings from the United Kingdom and New Zealand', Psychiatry, Psychology and Law, vol. 16, no. 1, pp. 123-40

Pleasence, P, Balmer, NJ \& Buck, A (2008), 'The health cost of civil-law problems: Further evidence of links between civil-law problems and morbidity, and the consequential use of health services', Journal of Empirical Legal Studies, vol. 5, no. 2, pp. 351-73

Pleasence, P, Balmer, NJ, Buck, A, O’Grady, A \& Genn, H (2004a), 'Civil law problems and morbidity', Journal of Epidemiology and Community Health, vol. 58 , no. 7, pp. 552-7

Pleasence, P, Balmer, NJ, Buck, A, O'Grady, A \& Genn, H (2004b), 'Multiple justiciable problems: Common clusters and their social and demographic indicators', Journal of Empirical Legal Studies, vol. 1, no. 2, pp. 301-29, doi: 10.1111/j.1740-1461.2004.00009.x

Pope, J (2012), 'Making Bendigo a Child Friendly City: A Set of Indicators of Child and Young People's Well-Being to Galvanise Action', Department of Planning and Community, St Luke's, Bendigo, Vic., available at: https://www.stlukes.org.au/File.axd?id=9bea31a7-a4bc-4a03-86e7b28dc69c5a94

Redfern Legal Centre, 'Aboriginal Health-Justice Partnership, Redfern Legal Centre and Sydney Area Health District, Six Month Evaluation', December 2015, available at: www.redfern legalcentre.org.au

Regenstein, M (2014), 'Developing Measures for Medical-Legal Partnership', 10 April, National Center for Medical-Legal Partnership, Milken Institute of Public 
[Insert ANU logo and running head]

\section{Contact: Dr Liz Curran}

Senior Lecturer, ANU Legal Workshop (Australia-wide Professional Legal Training) \& Assoc. Director International Centre for the Profession, Education and Regulation in Law (PEARL), Australian National University, College of Law.

Mobile 0404106614

Email Liz.Curran@anu.edu.au

Canberra ACT 0200 Australia (Melbourne based)

www.anu.edu.au

CRICOS Provider No. 00120C. ORCID ID 0000-0002-6371-2975

Health, The George Washington University (PDF provided to the author in April 2014)

Roberts, T \& Currie, J (2012), 'PBLO at SickKids: A Phase II Evaluation of the Medical-Legal Partnership between Pro Bono Law Ontario and SickKids Hospital Toronto, Final Report', Focus Consultants, Victoria, Canada, available at: http://www.probono.net/va/search/item.451249

Robinson, M \& Cottrell, D (2005), 'Health professionals in multi-disciplinary and multi-agency teams: Changing professional practice', Journal of

Interprofessional Care, vol. 19, no. 6, pp. 547-60, doi:

$10.1080 / 13561820500396960$

Sen, A (2000), Development as Freedom, Anchor Books, New York.

Sherr, L, Sherr A, et al. (2002), 'A Stitch in Time - Accessing and Funding Welfare Rights through Health Service Primary Care', London Department of Primary Care and Population Sciences, Institute of Advanced Legal Studies, School of Medicine, University of London, London.

Shin, P, Byrne, F, Jones, E, Teitelbaum, J, Repasch, L \& Rosenbaum, S (2010), 'Medical-Legal Partnerships: Addressing the Unmet Legal Needs of Health Center Patients'.

Schwarz, M, Allison, F \& Cunneen, C (2013a), 'A Report of the Australian Indigenous Legal Needs Project', James Cook University, Cairns, available at: http://www.jcu.edu.au/ilnp/public/groups/everyone/documents/technical_report/ jcu_131180.pdf

Schwarz, M, Allison, F \& Cunneen, C (2013b), 'The Civil and Family Law Needs of Indigenous People in Victoria', James Cook University, Cairns

State of Victoria (2014-16), Royal Commission into Family Violence: Report and Recommendations, vol. I, Parl. Paper No. 132.

Thoits, PA (2010), 'Stress and health: Major findings and policy implications', vol. 51(S), Journal of Health and Behaviour, pp. 41-53.

Tobin-Tyler, E (2008), 'Allies Not Adversaries: Teaching Collaboration to the Next Generation of Doctors and Lawyers to Address Social Inequality', Roger Williams University, School of Law Faculty Papers, Paper 17, p. 249, available at: http://lsr.nellco.org/cgi/viewcontent.cgi?article $=1017 \&$ context $=$ rwu_fp

Tobin-Tyler, E (2010), 'Teaching social justice and health: Professionalism, ethics, and problem-solving in the medical-legal classroom', Global Health Governance, vol. 38, pp. 701-7. 
[Insert ANU logo and running head]

\section{Contact: Dr Liz Curran}

Senior Lecturer, ANU Legal Workshop (Australia-wide Professional Legal Training) \& Assoc. Director International Centre for the Profession, Education and Regulation in Law (PEARL), Australian National University, College of Law.

Mobile 0404106614

Email Liz.Curran@anu.edu.au

Canberra ACT 0200 Australia (Melbourne based)

www.anu.edu.au

CRICOS Provider No. 00120C. ORCID ID 0000-0002-6371-2975

Tobin-Tyler, E (2011), 'Poverty, Health and Law: Readings and Cases for MedicalLegal Partnership'.

Tobin-Tyler, E (2012), 'Aligning public health, health care, law and policy: Medicallegal partnership as a multilevel response to the social determinants of health', Journal of Health \& Biomedical Law, no. 8, pp. 211-47.

Tobin-Tyler, E (2013), "'Small places close to home": Toward a health and human rights strategy for the U.S.', Health and Human Rights, vol. 15, no. 2, pp. 1-17.

Tobin-Tyler, E, Anderson, L, Rappaport, L, Shah, A, Edberg, D \& Paul, E (2014), 'Medical-legal partnership in medical education: Pathways \& opportunities', Journal of Legal Medicine, vol. 35, no. 1, pp. 149-77.

Triado, T, White, J \& Brown, A (2013), 'Community Health Quality Health Improvement Initiatives', Department of Health, available at: http://www.healthcaregovernance.org.au/docs/forum-1-quality-in-vic.pdf

Trubek, L \& Farnham, J (2000), 'Social Justice Collaboratives: multi-disciplinary practices for people', Clinical Law Review, vol. 7, pp. 227-8.

Victorian Health Care Association (2014), Health Matters, issue 1, May, p. 5 , available at: www.vha.org.au

Wise, M \& Signal, L (2000), 'Health promotion development in Australia and New Zealand', vol. 15, no. 3, Health Promotion International, Oxford University Press.

World Health Organization (WHO) and Commission on Social Determinants of Health (2008), 'Closing the Gap in a Generation: Health Equity through Action on Social Determinants of Health', available at: http://whqlibdoc.who.int/publications/2008/9789241563703_eng.pdf?ua=1

\section{Web References}

http://www.plelearningexchange.ca/resources/needs_evaluations/

http://canadianepc.org/files/CBA-Access-to-Justice-Metrics.pdf

www.internationallegalaidgroup.org/index ... /5-edinburgh-2015-conference-papers

http://www.fordham.edu/info/25023/interdisciplinary_approaches_to_the_legal_profe ssion/8067/exploring_access_to_justice_from_a_variety_of_perspectives_progr am

http://ohrh.law.ox.ac.uk/realizing-the-right-to-health-for-the-most-disadvantaged/ 
[Insert ANU logo and running head]

\section{Contact: Dr Liz Curran}

Senior Lecturer, ANU Legal Workshop (Australia-wide Professional Legal Training) \& Assoc. Director International Centre for the Profession, Education and Regulation in Law (PEARL), Australian National University, College of Law.

Mobile 0404106614

Email Liz.Curran@anu.edu.au

Canberra ACT 0200 Australia (Melbourne based)

www.anu.edu.au

CRICOS Provider No. 00120C. ORCID ID 0000-0002-6371-2975

\section{Appendix A - Bendigo Community Health Services}

With a strong connection to our community and over 40 years of local health experience, Bendigo Community Health Services understands local health issues and responds to our consumers through a range of services and partnerships.

Bendigo Community Health Services is a not-for-profit community organisation funded through various government health programs, community donations and sponsorships.

With over 200 staff and more than 50 programs, Bendigo Community Health Services works closely with our consumers and local organisations to contribute to the health and wellbeing of our community.

We:

- $\quad$ champion equity and work to make a fundamental change for the disadvantaged

- $\quad$ promote healthy lifestyles and preventative practices that lead to improvements in the health and wellness of the community

- $\quad$ provide services which enable improved individual and community health and wellbeing

- $\quad$ lead and coordinate an extensive range of primary and community health services and activities, including those provided in cooperation with other agencies and providers

- $\quad$ commit to safety, quality and continuous improvement for all stakeholders.

\section{We are effective in and respected for:}

- client relationships and service responsiveness

- commitment to quality services and appropriateness of care

- $\quad$ leadership in planning, service provision, governance and consumer advocacy

- $\quad$ reputation as an employer, a provider and a partner of choice

- $\quad$ contribution to building healthier communities by looking forward and working towards positive change.

\section{Our Structure}

Bendigo Community Health Services includes four branches organised around key areas of expected outcomes for our service to our community:

- Corporate services

- $\quad$ Community engagement and support

- Healthy communities 
[Insert ANU logo and running head]

\section{Contact: Dr Liz Curran}

Senior Lecturer, ANU Legal Workshop (Australia-wide Professional Legal Training) \& Assoc. Director International Centre for the Profession, Education and Regulation in Law (PEARL), Australian National University, College of Law.

Mobile 0404106614

Email Liz.Curran@anu.edu.au

Canberra ACT 0200 Australia (Melbourne based)

www.anu.edu.au

CRICOS Provider No. 00120C. ORCID ID 0000-0002-6371-2975

- $\quad$ Primary health and integrated care.

Each of the program levels within these branches is represented in our organisational flowchart, which can be accessed by visiting http://www.bendigohealth.org.au/Content/Docs/42014\%200rganisational\%20Chart_2 015_v4.pdf

\section{Vision}

Better health and wellbeing across generations.

\section{Mission}

Working hand in hand with our community to achieve healthier lives.

\section{Values}

\section{Respect}

We build respectful relationships through trust, empathy and collaboration.

\section{Inclusive}

We recognise and promote accessible, safe and holistic health care as a basic human right.

\section{Integrity}

We are authentic and accountable and we honour our obligations.

\section{Innovation}

Through continuous learning, we ensure an agile, responsive and sustainable service.

\section{Programs}

Bendigo Community Health Services has over 200 staff delivering a wide range of programs and services for Bendigo and surrounding areas.

Services include children and youth, counselling, alcohol and other drugs, medical and chronic disease management.

\section{Services at a Glance}

\section{ADVOCACY HEALTH ALLIANCE}

Works with families to directly address their unresolved legal needs, working with health professionals and advocates.

ALCOHOL AND OTHER DRUGS COUNSELLING SERVICES (ADULT \& YOUTH) 
[Insert ANU logo and running head]

Contact: Dr Liz Curran

Senior Lecturer, ANU Legal Workshop (Australia-wide Professional Legal Training) \& Assoc. Director International Centre for the Profession, Education and Regulation in Law (PEARL), Australian National University, College of Law.

Mobile 0404106614

Email Liz.Curran@anu.edu.au

Canberra ACT 0200 Australia (Melbourne based)

www.anu.edu.au

CRICOS Provider No. 00120C. ORCID ID 0000-0002-6371-2975

Psychological support for individuals or families affected by alcohol and other drug use. Youth counselling provides psychological support for young people 25 years and under.

\section{ALCOHOL AND OTHER DRUG GROUP PROGRAMS}

Provides a variety of group programs such as relapse prevention, skills for life and collaborative therapy.

\section{ALCOHOL AND OTHER DRUG SUPPORT}

Provides outreach support, advocacy and linkage for individuals and families in AOD treatment programs to health, welfare, education and employment services.

\section{BLOOD-BORNE VIRUS AND SEXUALLY TRANSMITTABLE INFECTION CLINIC}

Provides testing for blood-borne viruses and sexually transmittable infections. Offers specific information and health advice.

\section{CARER WELLBEING PROGRAM}

Supports the health and wellbeing needs of mental health carers and assists mental health carers to access a broad range of services to improve their health and wellbeing.

\section{CHILD HEALTH INVEST (kidzspace)}

Medical assessments and interventions program offering paediatric health clinic and counselling support. Referral from a general practitioner is required.

\section{CHILDRENS' ADVOCATE WORKER}

Advocates for children and ensures their best interests are understood in any planning.

\section{CHRONIC DISEASE MANAGEMENT}

Works with you and your doctor to help you manage your diabetes or respiratory condition.

\section{COMMUNITY EDUCATION}

Alcohol and other drugs, sexual health, chronic disease management. Specialist infectious diseases program. School and workplace education and information sessions available. Guest speakers are available to address groups on health and wellbeing issues. Workplace health and wellbeing programs are available.

\section{COMMUNITY SOUP KITCHEN}

Provides free meals and bread each Thursday between 4 p.m. and 5 p.m. in a safe, social and friendly environment with access to services. Café de Mill arcade, 171 Hargreaves Street, Bendigo. We thank sponsors Beck Legal, Strath Village IGA, Strath Hill Hot Bake, JL King and Co and Café de Mill.

\section{CULTURALLY SENSITIVE COUNSELLING}


[Insert ANU logo and running head]

Contact: Dr Liz Curran

Senior Lecturer, ANU Legal Workshop (Australia-wide Professional Legal Training) \& Assoc. Director International Centre for the Profession, Education and Regulation in Law (PEARL), Australian National University, College of Law.

Mobile 0404106614

Email Liz.Curran@anu.edu.au

Canberra ACT 0200 Australia (Melbourne based)

www.anu.edu.au

CRICOS Provider No. 00120C. ORCID ID 0000-0002-6371-2975

A service available to people of a refugee background. Talk in a relaxed, private space about your worries and start to find ways to cope with them. You will receive acceptance, support and respect in a safe, neutral and non-judgemental environment.

\section{COUNSELLING AND MENTAL HEALTH}

Brief and ongoing counselling, assessment, referral for individuals, families, children and groups working towards better health and wellbeing - depression, anxiety, addictive behaviours, relationship and family difficulties, grief and loss.

\section{DIABETES EDUCATION SERVICE}

Education and information programs on the management of diabetes for individuals, families or groups.

\section{EARLY CHILDHOOD INTERVENTION}

Provides a family-based program for children (0-6 years) with a developmental delay or disability.

\section{ELMORE PLANNED ACTIVITY GROUP}

Offers support to frail, aged or disabled men and women to assist to maintain independence in the Elmore community.

\section{FAMILY DAY CARE}

Provides quality care for children up to 12 years of age in the homes of approved educators.

\section{FAMILY SERVICES}

Assist and support families to develop, maintain and strengthen their independence, skills and wellbeing and promote positive parenting skills.

\section{FAMILY SUPPORT PARENTING PROGRAMS}

These parenting programs assist families to strengthen their practical skills for family living and communication, promotes healthy and harmonious relationships, supports families to build on positive strategies to manage the challenges facing families today.

\section{HEADSPACE BENDIGO}

Supports young people aged 12-25 years who are experiencing difficulties. Call (03) 54345345 for more information or an appointment.

\section{HELPING CHILDREN WITH AUTISM \& BETTER START SERVICES}

Please contact the Early Childhood Intervention team for further information.

INNOVATIVE HEALTH SERVICES FOR HOMELESS YOUTH PROGRAM 
[Insert ANU logo and running head]

Contact: Dr Liz Curran

Senior Lecturer, ANU Legal Workshop (Australia-wide Professional Legal Training) \& Assoc. Director International Centre for the Profession, Education and Regulation in Law (PEARL), Australian National University, College of Law.

Mobile 0404106614

Email Liz.Curran@anu.edu.au

Canberra ACT 0200 Australia (Melbourne based)

www.anu.edu.au

CRICOS Provider No. 00120C. ORCID ID 0000-0002-6371-2975

Provides access to services that improve health outcomes for homeless or at-risk young people and their dependents.

\section{MEDICAL PRACTICE}

A range of medical practitioners offering general practice services based in three locations.

\section{MEN'S HEALTH CLINIC}

Offers a range of male-friendly services, including health assessments, information, referral and annual check-ups.

\section{NEEDLE SYRINGE PROGRAM (NSP) MOBILE OUTREACH TEAM}

Provides clean injecting equipment, safe sex, health information, education, support and referral to health and welfare services. To access the program call 1800636514 between 7.30 p.m. and 10.45 p.m. Tuesday to Saturday. The NSP is also available during business hours at our Bendigo central site at 171 Hargreaves Street, Eaglehawk site at 3 Seymoure Street, and Kangaroo Flat site at 13 Helm Street.

\section{NON-RESIDENTIAL WITHDRAWAL SERVICE}

Provides non-residential withdrawal treatment and support services in conjunction with a client's general practitioner. Services are delivered by different modalities such as outreach, home-based, outpatient, in-hospital supported withdrawal.

\section{OPTIONS CLINIC}

Sexual health and family planning services for men and women.

\section{PHYSIOTHERAPY}

Offers advice and treatment for treating injuries, pain and stiffness in joints and/or muscles, and adult and paediatric physiotherapy services.

\section{PODIATRY}

Foot health for clients who are older or have a disability or a chronic illness. Diabetes foot health assessments and community education sessions available.

\section{QUIT SMOKING PROGRAM}

Advice and programs for smokers seeking to quit.

\section{REFUGEE ACTION PROGRAM}

A dedicated service in community development to build capacity of target communities.

\section{REFUGEE HEALTH NURSE}

Supports individuals, families and refugee communities to improve their health and wellbeing. 
[Insert ANU logo and running head]

Contact: Dr Liz Curran

Senior Lecturer, ANU Legal Workshop (Australia-wide Professional Legal Training) \& Assoc. Director International Centre for the Profession, Education and Regulation in Law (PEARL), Australian National University, College of Law.

Mobile 0404106614

Email Liz.Curran@anu.edu.au

Canberra ACT 0200 Australia (Melbourne based)

www.anu.edu.au

CRICOS Provider No. 00120C. ORCID ID 0000-0002-6371-2975

\section{RESPIRATORY MANAGEMENT}

This service is designed for individuals and families to learn more about lung health, asthma management and smoking cessation.

\section{RESIDENTIAL WITHDRAWAL SERVICE (NOVA HOUSE)}

Nova House is an adult residential program for people undertaking alcohol and drug withdrawal. The program is offered to people aged 21 and over who live in Victoria.

\section{SCHOOL-FOCUSED YOUTH SERVICES}

Fostering links between schools and community organisations to support at-risk young people who require prevention or early intervention strategies to assist their learning, development, health and wellbeing.

\section{SETTLEMENT SERVICES}

Provides services for migrants and people of refugee backgrounds through Humanitarian Settlement Services, Settlement Grants Program and Complex Case Services.

\section{SEXUAL HEALTH AND FAMILY PLANNING SERVICE}

An informal and confidential setting to assist both men and women in making informed choices and decisions on their sexual and reproductive health issues.

\section{SPECIALIST PHARMACOTHERAPY SERVICES}

Specialist alcohol and drug medical practitioner to provide methadone and buprenorphine (pharmacotherapy) treatment.

\section{STANDBY}

24-hour coordinated response to support the needs of families, friends and associates, schools, workplaces and community groups who have been bereaved through suicide. Call 0439173310 (24 hours, 7 days a week).

\section{STRENGTH TRAINING AND WALKING PROGRAMS}

Conducted at various Bendigo and Elmore locations to increase physical activity and provide social opportunities for older people.

\section{STRONG PEOPLE STAY YOUNG}

Designed for people aged 50+ to increase strength through weight training.

\section{WOMEN'S HEALTH CLINIC}

Provides pap smears, breast health checks, advice and information on women's health issues such as sexual and contraceptive health.

\section{WORKPLACE AND EMPLOYMENT HEALTH PROMOTION}


[Insert ANU logo and running head]

Contact: Dr Liz Curran

Senior Lecturer, ANU Legal Workshop (Australia-wide Professional Legal Training) \& Assoc. Director International Centre for the Profession, Education and Regulation in Law (PEARL), Australian National University, College of Law.

Mobile 0404106614

Email Liz.Curran@anu.edu.au

Canberra ACT 0200 Australia (Melbourne based)

www.anu.edu.au

CRICOS Provider No. 00120C. ORCID ID 0000-0002-6371-2975

Assists businesses, organisations and job seekers to address employee health needs.

\section{YOUTH COUNSELLING SERVICE}

For young people under 25 years, individual sessions and support available. Includes alcohol and drug counselling.

\section{YOUTH HEALTH SERVICES}

Provide a youth-friendly health service, including GPs, nurses and counsellors.

\section{YOUNG PREGNANT AND PARENTING PROGRAM}

For young people aged 25 or younger who are pregnant or parenting their first child under the age of four years. Provides specific health information, assistance and education about pregnancy, birthing, parenting and life issues.

\section{WAY OUT PROGRAM}

Provides physical and mental health promotion and suicide-prevention strategies targeted at improving the health outcomes of young people who are same-sex-attracted or sex and gender diverse.

For further information, see https://bchs.com.au/ 
[Insert ANU logo and running head]

\section{Contact: Dr Liz Curran}

Senior Lecturer, ANU Legal Workshop (Australia-wide Professional Legal Training) \& Assoc. Director International Centre for the Profession, Education and Regulation in Law (PEARL), Australian National University, College of Law.

Mobile 0404106614

Email Liz.Curran@anu.edu.au

Canberra ACT 0200 Australia (Melbourne based)

www.anu.edu.au

CRICOS Provider No. 00120C. ORCID ID 0000-0002-6371-2975

\section{Appendix B - ARC Justice}

ARC Justice works within a community development framework. Empowerment, participation and human rights are hallmarks of this framework. Its mission is to promote and support services that protect and enhance the rights and interests of those who are disadvantaged due to structural, social, economic or cultural inequalities. It acknowledges the Aboriginal people as the traditional owners of the land.

\section{Board}

Its Board provides oversight and governance to ensure that our programs work towards an inclusive community built on a foundation of human rights and equality before the law. The Board meets monthly to evaluate the organisation's operations and to ensure that appropriate policies and procedures are in place to minimise risks.

\section{Programs}

\section{Loddon Campaspe Community Legal Centre}

Loddon Campaspe CLC provides free legal information and advice to Central Victorians who can't afford a lawyer or who are ineligible for legal aid. We also promote social justice and individual empowerment through our community legal education and law reform. It is based in Bendigo. The lawyers provide legal outreach to Echuca, and court assistance at Castlemaine, Echuca, Kerang, Kyneton, Maryborough and Swan Hill courts. It also delivers community legal education and professional development, and promotes justice through its law reform program. Information, advice, representation, legal education and law reform are all an integrated part of its core service delivery as is the case with community legal centres in Australia. A direct referral to access services is not required. ARC Justice is a non-profit community organisation dedicated to human rights and social justice.

The office is open 9 a.m. to 5 p.m., Monday to Friday. It offers appointments outside these office hours but you will need to make such an appointment during office hours.

Quality public engagement around justice issues is critical. Our understanding of what is meant by 'justice' has real and immediate impacts on our lives and the health of our community. Loddon Campaspe CLC believes that an open dialogue around issues of justice is essential to the success of its work. With this in mind, in 2014 we created Talking Justice: a space for Central Victorians to come together to share and discuss social justice concerns in a stimulating and respectful environment.

\section{Goulburn Valley Community Legal Centre}

Goulburn Valley CLC provides free legal information and advice to Goulburn Valley residents who can't afford a lawyer or who are ineligible for legal aid. It also promotes 
[Insert ANU logo and running head]

Contact: Dr Liz Curran

Senior Lecturer, ANU Legal Workshop (Australia-wide Professional Legal Training) \& Assoc. Director International Centre for the Profession, Education and Regulation in Law (PEARL), Australian National University, College of Law.

Mobile 0404106614

Email Liz.Curran@anu.edu.au

Canberra ACT 0200 Australia (Melbourne based)

www.anu.edu.au

CRICOS Provider No. 00120C. ORCID ID 0000-0002-6371-2975

social justice and individual empowerment through our community legal education and law reform programs. This service is based in Shepparton.

\section{Housing Justice}

Housing Justice provides advice, information and assistance to tenants about their rights and responsibilities, the Victorian Civil and Administration Tribunal (VCAT), and negotiating with landlords and real estate agents. This service is based in Bendigo.

For more information, see http://arcjustice.org.au/about-us/ 
[Insert ANU logo and running head]

Contact: Dr Liz Curran

Senior Lecturer, ANU Legal Workshop (Australia-wide Professional Legal Training) \& Assoc. Director International Centre for the Profession, Education and Regulation in Law (PEARL), Australian National University, College of Law.

Mobile 0404106614

Email Liz.Curran@anu.edu.au

Canberra ACT 0200 Australia (Melbourne based)

www.anu.edu.au

CRICOS Provider No. 00120C. ORCID ID 0000-0002-6371-2975

\section{Appendix C - Community Focus Group Summary}

Taken from authors' contemporaneous notes - comments are from a range of the 26 participants and just listed as noted, in no particular order.

\section{Scenario Responses}

\section{Scenario}

Mary and David have three children: Alex, who is six years of age, attends school and has mild autism; Eric, who is three years of age; and Lily, who is 20 months old. They live in a two-bedroom public housing house which is poorly maintained and crowded. They are on Centrelink. They have a $\$ 5000$ credit card debt, used to pay bills and school expenses and a recent pay day loan. They have been getting demands from debt collectors. David was laid off from his factory job two years ago and has been unable to find work. He gets depressed and is withdrawn, finding it hard to leave the house. Sometimes there is family conflict and Mary often feels stressed. Alex needs extra support in school. Their electricity has been disconnected recently and it is winter.

Source: material is based on the Bendigo Community Health Annual Reports 2011-12 \& 2012-13.

\section{Questions for Participants}

1. What practical, realistic things do you think would improve things for:

- Mary

- $\quad$ David

- Alex

- $\quad$ Eric

- Lily.

Consider: their physical health, mental health, social supports, legal help, education, income support, debt, housing.

The kids come first and what can you do when you don't know what to do and everything is so hard to work out. Kids are hard enough and then you add illness and I'm not well; Mum tries to help but she has not been well. Credit cards and owe lots to lots, tried to get help from one of those financial companies that said it could consolidate debt, now they charge and so in worse; no-one gets that when you are down you can't just shake yourself out of it mate. Kids, they are sick, and without the health centre I would not have been able to get the assessment I needed to get help for her; challenging kids' behaviours put on so much stress so to have workers there even to get ideas from is a godsend. 
[Insert ANU logo and running head]

\section{Contact: Dr Liz Curran}

Senior Lecturer, ANU Legal Workshop (Australia-wide Professional Legal Training) \& Assoc. Director International Centre for the Profession, Education and Regulation in Law (PEARL), Australian National University, College of Law.

Mobile 0404106614

Email Liz.Curran@anu.edu.au

Canberra ACT 0200 Australia (Melbourne based)

www.anu.edu.au

CRICOS Provider No. 00120C. ORCID ID 0000-0002-6371-2975

Not enough to live on even for day-to-day costs so you end up borrowing and then bugger, you're in trouble.

2. What are some of the barriers?

Not enough money, services work in silos, no-one wants to help, lack of safe housing, stupid decision-making; e.g., 'sleep in a tent' - we have kids. Going round in circles, tiring, too many hurdles.

Me mental illness doesn't make it easy. So many rules and have no idea; no-one to help when you need it, sometimes it's just someone as a sounding board. The health centre does this when I am desperate, it calms me down; yeah, like it seems like what's the point and they give you some ideas. Yeah, I would not have gotten my kid help if the worker hadn't talked to other workers who advocated.

If they feel stable then not likely to always feel stressed under siege; e.g., what happens if they are disconnected from gas, electricity, if they can't pay their bills? Other?

No hot meals, kids get sick, can't do homework as no light, get behind in schools, get colds as no heater, get disconnected often. No money to pay. No, I didn't know about hardship cases - never have this sort of information and wouldn't know where to go to look for it.

Kids get behind in school if no light and also we have no space for them to study.

Always telling you what to do but get them to try to live with depression and a lack of stability.

3. What in your view would help lead to healthy outcomes and promote and improve their wellbeing?

Decent home that's secure; run away from violence and kids and me live in a tent.

Can't pay bills and so kids get sick - disconnection, no warmth, a blanket not enough, kids get colds and get sick.

We don't know what to do: don't know you can take action; don't know legal rights; don't lawyers cost money; don't like lawyers they are too remote. How can they help us?

You know, housing if you have it might not be good for kids' health and you're not allowed to fix it and it takes the housing people forever; well they ignore you; that's if you're lucky enough to have a house!

With depression you have to learn how to live all over again, yeah, step by step. Some days OK, sometimes it's minute by minute, it can turn. This is frightening for you; you also think about when you were higher and so it's even harder to get out of it then. 
[Insert ANU logo and running head]

\section{Contact: Dr Liz Curran}

Senior Lecturer, ANU Legal Workshop (Australia-wide Professional Legal Training) \& Assoc. Director International Centre for the Profession, Education and Regulation in Law (PEARL), Australian National University, College of Law.

Mobile 0404106614

Email Liz.Curran@anu.edu.au

Canberra ACT 0200 Australia (Melbourne based)

www.anu.edu.au

CRICOS Provider No. 00120C. ORCID ID 0000-0002-6371-2975

Family support worker helps when you are overwhelmed; they can help you list problems and work through one by one otherwise too much; yeah, they know questions to ask and when you answer them you go, 'Oh geez, no wonder it's all too much sometimes'.

Not what you know but who you know, yeah.

'Deaths can impact.'

Steps between school and workplace really hard, disconnect. No face to put on someone. Governments don't fund services anymore that you know people under one roof like this one and it just gets hard, yeah - trust and relationships, that's important if you are going to get help.

Too much responsibility sometimes when you have so many issues and kids have poor health too. You try to do your best but you worry.

Being in school's not enough, need learning support, and what about when you miss due to health of kid?

I might know my rights but even if I do and feel threatened I fold; yeah, you won't speak up even if you know it's wrong.

Small things: no heat, being harassed by debt collectors, they all add up, yeah, then you get depressed - no power, need an advocate. It's the small things: bills and not being able to pay - no money but you feel bad and then disconnection, that means problems with food, light, cold - kids are the first priority but then poor health.

4. What role do you think Bendigo Community Health working with the legal service as part of this Advocacy Health Alliance program might have in the lives of people like David and Mary and their kids?

Well at the moment it's a safe place and we trust them. They have other activities that draw you in and when you're down it's undignifying to ask for help; integrated services make it easier as if I have to go elsewhere I may not be able to get there. You don't have the energy for all the problems to go all over the place to get help and it costs; one place all under one roof makes sense and if there's a lawyer, needs to be a nice approachable one. Cam is great - he gets us out of pickles as he has common sense; yeah, treat us with common sense and not big words and with dignity.

5. What things make a difference for people like Mary and David in your view?

Being able to get help all in one go; simple steps and take some issues out of their basket. Too stressful for them, all their problems, pathways for him to get work. For me, I could not get out of bed, only coming to the health centre made a difference; yeah, you're in a dark place, can't just shake out of it - losing your job is devastating; yeah, 
[Insert ANU logo and running head]

\section{Contact: Dr Liz Curran}

Senior Lecturer, ANU Legal Workshop (Australia-wide Professional Legal Training) \& Assoc. Director International Centre for the Profession, Education and Regulation in Law (PEARL), Australian National University, College of Law.

Mobile 0404106614

Email Liz.Curran@anu.edu.au

Canberra ACT 0200 Australia (Melbourne based)

www.anu.edu.au

CRICOS Provider No. 00120C. ORCID ID 0000-0002-6371-2975

for me I could not get out of bed and it's hard to engage, and this affects the wife and kids who got more stressed and I got angry.

Help us get community back; it's all about being connected and that would lead to a better outcome for the whole family.

Someone to advocate for them and if they knew what to do more like as you said, hardship and who to talk to, yeah, but sometimes it's overwhelming so you need someone who can speak their language to arc up for you; yeah, power won't listen but when you have a degree they sometimes listen. Not always, they can be buggers; yeah, and so you lose your temper - not many would keep their cool - and then it's harder to get help as they put you down the bottom of the list, yeah.

Someone to stay in touch, see you're OK.

Community to community support but need space to make it happen - the connections.

Yeah, like a payment plan, help with that.

Empowerment - need a sounding board to practise on in case not getting it right.

'If one thing goes wrong when you're doing OK then it can set you right back and it is hard to get back up and it all can come tumbling down. I have one setback and it becomes so tough'; yeah, like a death.

More rational discussions around housing and assessments as they don't listen/want to know.

Waiting lists in housing, three kids and three adults and another seven people in a tiny house so not suited - homework an issue.

Give people an opportunity to fix their own house as too long otherwise.

Library.

Look, if a lawyer was here at the health service, geez that would help; I didn't know lawyers could help with debts and housing and discrimination and things like that until today. Need more knowledge about legal rights; we just get trodden on all the time, yeah. Here here.

'Hey, show of hands - who thinks having a lawyer at the health centre would rock?'

Need advocate can connect with.

Have a debriefer, like they rang me after the death to see if I was OK, that was unexpected but a big help, yeah, that sort of follow-up to see if you're OK; yeah, twins' best friend suicided, that was tough. 
[Insert ANU logo and running head]

\section{Contact: Dr Liz Curran}

Senior Lecturer, ANU Legal Workshop (Australia-wide Professional Legal Training) \& Assoc. Director International Centre for the Profession, Education and Regulation in Law (PEARL), Australian National University, College of Law.

Mobile 0404106614

Email Liz.Curran@anu.edu.au

Canberra ACT 0200 Australia (Melbourne based)

www.anu.edu.au

CRICOS Provider No. 00120C. ORCID ID 0000-0002-6371-2975

Many thanks for your participation and expressing your views. It will be very helpful in ensuring the project is grounded and informing how the AHA might try to assist people in the future.

Geez we shared a lot here; good to be asked. Can we have more of these? Helpful to me, not just you, as learned something about my rights and hardship claim to stop disconnections; more training on legal stuff so we are not taken for a ride. Yeah, would like to be empowered; knowledge is power and we need help, back against the wall, so help with a lawyer working with other under one roof, that would be great. We don't often get asked; yeah, good to have more chances to have a voice. We never get asked about things like you have that affect us - more of that. 'Thanks so much for LISTENING.'

Action: 'Keep us posted'.

\section{Summary}

The community stated in the Community Focus Group that they never felt heard and that they wanted to have a voice as many decisions affected them but they were never asked. They advised that they often did not know their legal rights and how to speak to decision-makers. They also observed that they had lived experience of policies but that they felt they had no voice. They identified a need for training that might give them information and confidence so they could be 'empowered'.

Simple things help with engagement: relationships trust, support, step-by-step solutions, overwhelmed.

Concrete, timely interventions 'under one roof' around housing, information about debt and solutions, accessible services and dignity and respect. Disconnections: huge flow-on effect. Education. poor health, impacts by debt, illness, depression and not knowing solutions.

The CFG went for the full two hours. We expected 15 people but 26 people attended. Some (17 people) voluntarily indicated the money was attractive but now having done the CFG it would have been worthwhile even without the money. Seven people indicated they would have attended even without the contribution for their time.

February 2015 
[Insert ANU logo and running head]

\section{Contact: Dr Liz Curran}

Senior Lecturer, ANU Legal Workshop (Australia-wide Professional Legal Training) \& Assoc. Director International Centre for the Profession, Education and Regulation in Law (PEARL), Australian National University, College of Law.

Mobile 0404106614

Email Liz.Curran@anu.edu.au

Canberra ACT 0200 Australia (Melbourne based)

www.anu.edu.au

CRICOS Provider No. 00120C. ORCID ID 0000-0002-6371-2975

\section{Appendix D - Curran Collaborative Measurement Tool}

\section{Draft Curran HJP Evaluation - COLLABORATION MEASUREMENT OF PROGRESS TOOL (ECMoPT)}

Project Title: Health-Justice Partnership, Bendigo - Measuring impact of legal interventions to improve patient health

Based on VicHealth and LSB Evaluation Workshop facilitations by Dr Curran feedback

\section{Continuum}

\section{Networking - Coordinating - Cooperation - Collaboration}

Networking Involves the exchange of information for mutual benefit. This requires little time but trust between partners. For example, youth services within a local government area may meet monthly to provide an update on their work and discuss issues that affect clients.

Coordinating Involves exchanging information and altering activities for a common purpose. For example, the youth services may meet and plan a coordinated campaign to lobby the council for more youth-specific services.

Cooperation Involves exchanging information, altering activities and sharing resources. It requires a significant amount of time, a high level of trust between partners, and the ability of agencies to share turf.

Collaboration Includes enhancing the health promotion capacity of the other partner for mutual benefit and a common purpose. Collaborating requires the partner to give up a part of their turf to another agency to create a better or more seamless service system. ${ }^{101}$

\section{TABLE D.1}

[Designer: Please extract the text from the file titled Table D.1 and create an appropriately designed table, complete with title and source line.]

\section{TABLE D.2}

\footnotetext{
${ }^{101}$ Vic Health Partnerships Analysis Tool (https://www.vichealth.vic.gov.au/media-andresources/publications/the-partnerships-analysis-tool), adapted from Himmelman, A (2001), 'On coalitions and the transformation of power relations: Collaborative betterment and collaborative empowerment', American Journal of Community Psychology, vol. 29, no. 2, pp. 277-84.
} 
[Insert ANU logo and running head]

\section{Contact: Dr Liz Curran}

Senior Lecturer, ANU Legal Workshop (Australia-wide Professional Legal Training) \& Assoc. Director International Centre for the Profession, Education and Regulation in Law (PEARL), Australian National University, College of Law.

Mobile 0404106614

Email Liz.Curran@anu.edu.au

Canberra ACT 0200 Australia (Melbourne based)

www.anu.edu.au

CRICOS Provider No. 00120C. ORCID ID 0000-0002-6371-2975

[Designer: Please extract the text from the file titled Table D.2 and create an appropriately designed table, complete with title and source line.]

ECMoPT - Measuring Progress of Collaboration between the HJP and Legal and Health Services

Stage One: Silos - Passive (no active engagement)

1. Agencies working independently of each other

1.1. Agencies deliver services within their own service guidelines in isolation from each other

1.2. Meeting infrequently; e.g., once per annum

1.3. Minimal sharing of work practices or experiences

Stage Two: Networking - Informing (one-way engagement, organisation to stakeholder)

2. Take up of inter-program activities

2.1. Clinician attendances at legal PDs

2.2. Agreement to join together for one or two activities per annum

Stage Three: Stakeholders Coordinating - Involving (two-way or multi-way engagement, and stakeholders act independently)

3. Some take up of inter-program activities; e.g., twice per annum

3.1. Referrals to the other service

3.2. Agreement to work on services or projects together from time to time

3.3. Briefing of one agency by another concerning its activities

3.4. Awareness that working together might be of benefit to agencies/clients/community

Stage Four: Partnerships - Cooperation

4.1. Agencies agree through a written project proposal or memorandum of understanding to work in partnership

4.2. The agencies making up the partnership commit and provide either inkind or financial support to work in partnership

4.3. Referral system developed

4.4. Implementation of a legal screening tool in existing or new screening tool, jointly adopted 
[Insert ANU logo and running head]

\section{Contact: Dr Liz Curran}

Senior Lecturer, ANU Legal Workshop (Australia-wide Professional Legal Training) \& Assoc. Director International Centre for the Profession, Education and Regulation in Law (PEARL), Australian National University, College of Law.

Mobile 0404106614

Email Liz.Curran@anu.edu.au

Canberra ACT 0200 Australia (Melbourne based)

www.anu.edu.au

CRICOS Provider No. 00120C. ORCID ID 0000-0002-6371-2975

4.5. Partners working together to support clients through sharing resources and interacting with and referring clients

4.6. Partners run a few joint forums per annum, raising awareness

Stage Five: Collaboration (two-way or multi-way engagement: joint learning, decision-making and actions)

5.1. Increased understanding of the different professional roles in each partner organisation is demonstrated

5.2. Management support, often in the form of resources, along with professional development and coaching

5.3. 'Workarounds' / reflective practice changes to service informed by research evaluation or practice enhancements or PD

5.4. Active referrals to and from services, not just from one to the other

5.5. Referral system refined to enable seamlessness

5.6. Operationalisation and regular use of legal screening tool at health service

5.7. Increasing seamlessness demonstrated by referrals; reported levels of trust and confidence between the partners

5.8. Knowledge of HJP staff by other health service staff, and knowledge of facts relevant to partner agency by HJP staff

5.9. Lunchroom/corridor conversations

5.10. LSCs between partners

5.11. Clinician attendances at PDs and vice versa (reciprocity demonstrated between professionals)

5.12. Seamless referrals to the HJP; e.g., from the health service to the lawyer and to the health service by the lawyer

5.13. Communicate to stakeholders where you are as an organisation, what the next step is, and how everybody's efforts are contributing to the ultimate goal

5.14. Management buy-in from health service; e.g., sending information to staff / championing project

5.15. Working together on systemic reforms; e.g., joint submissions to inquiries or joint actions to bring about change in practice, administration, laws or policy (e.g., changing sheriff practice, preventing asbestos or mould and hence asthma) 
[Insert ANU logo and running head]

\section{Contact: Dr Liz Curran}

Senior Lecturer, ANU Legal Workshop (Australia-wide Professional Legal Training) \& Assoc. Director International Centre for the Profession, Education and Regulation in Law (PEARL), Australian National University, College of Law.

Mobile 0404106614

Email Liz.Curran@anu.edu.au

Canberra ACT 0200 Australia (Melbourne based)

www.anu.edu.au

CRICOS Provider No. 00120C. ORCID ID 0000-0002-6371-2975

5.16. Joint presentations at seminars/PD/conference of different disciplines

\section{Stage Six: Integration}

6.1. Joint learning and decision-making

6.2. Empowering (new forms of accountability: decisions delegated to partners, partners play a role in governance of each other)

6.3. Referrals to/from are part of operationalised practice and occur due to capacity, raised awareness, and clear and appropriate problem identification

6.4. Enhanced capacity of legal and health/allied health professionals who work seamlessly to identify and assist clients within and respect professional roles and ethical considerations

6.5. Adjust plans on the basis of feedback and changed circumstances

6.6. Implementation of learnings from reflection and evaluation into operations of the service

6.7. Senior management and the Board have an understanding of partnerships and are committed to them at every level, from policies to individual interactions

\section{TABLE D.3}

\begin{tabular}{|l|l|l|l|}
\hline Measurable & \multicolumn{1}{|c|}{ Indicators } & \multicolumn{1}{|c|}{ Tool to Measure } & Year \\
\hline $\begin{array}{l}\text { 1. Take up of } \\
\text { inter-program } \\
\text { activities }\end{array}$ & $\begin{array}{l}\text { 1.1. Use of legal } \\
\text { screening tool at } \\
\text { health service }\end{array}$ & $\begin{array}{l}\text { Adoption of tool and its } \\
\text { integration and usage, } \\
\text { professional journals, } \\
\text { professional interviews, } \\
\text { referral practice, referral } \\
\text { increases, interviews with } \\
\text { staff }\end{array}$ & \\
\cline { 2 - 5 } & $\begin{array}{l}\text { Clinician attendances } \\
\text { at legal PDs and } \\
\text { lawyer attendances at } \\
\text { health service PDS }\end{array}$ & $\begin{array}{l}\text { Data collected on attendance, } \\
\text { PD evaluations, interviews } \\
\text { with staff }\end{array}$ & \\
\cline { 2 - 5 } & $\begin{array}{l}\text { Management buy-in } \\
\text { evidenced by sending } \\
\text { information to and } \\
\text { between staff, inviting } \\
\text { staff to events as }\end{array}$ & $\begin{array}{l}\text { Professional journals, } \\
\text { professional interviews, focus } \\
\text { groups, PD evaluations }\end{array}$ & \\
\hline
\end{tabular}


[Insert ANU logo and running head]

\section{Contact: Dr Liz Curran}

Senior Lecturer, ANU Legal Workshop (Australia-wide Professional Legal Training) \& Assoc. Director International Centre for the Profession, Education and Regulation in Law (PEARL), Australian National University, College of Law.

Mobile 0404106614

Email Liz.Curran@anu.edu.au

Canberra ACT 0200 Australia (Melbourne based)

www.anu.edu.au

CRICOS Provider No. 00120C. ORCID ID 0000-0002-6371-2975

\begin{tabular}{|c|c|c|}
\hline & $\begin{array}{l}\text { routine practice, } \\
\text { seamless IT and } \\
\text { management } \\
\text { workarounds, } \\
\text { championing of } \\
\text { project across the } \\
\text { services }\end{array}$ & \\
\hline \multirow[t]{5}{*}{$\begin{array}{l}\text { 2. Moving } \\
\text { from silos to } \\
\text { collaboration } \\
\text { and } \\
\text { integration }\end{array}$} & $\begin{array}{l}\text { 2.1. Knowledge of } \\
\text { HJP staff by other } \\
\text { health service staff }\end{array}$ & $\begin{array}{l}\text { Surveys, PD evaluations, } \\
\text { professional journals, } \\
\text { interviews with staff } \\
\text { Increase in referrals, feedback } \\
\text { on LSCs and data collection } \\
\text { on LSCs which capture } \\
\text { downstream impacts }\end{array}$ \\
\hline & $\begin{array}{l}2.2 . \\
\text { Lunchroom/corridor } \\
\text { conversations }\end{array}$ & $\begin{array}{l}\text { Professional journals, } \\
\text { interviews with staff }\end{array}$ \\
\hline & 2.3. LSCs & $\begin{array}{l}\text { Data on numbers of SC } \\
\text { collected, professional } \\
\text { journals, interviews with staff }\end{array}$ \\
\hline & $\begin{array}{l}\text { 2.4. Clinician } \\
\text { attendances at PDs } \\
\text { and lawyer } \\
\text { attendances at health } \\
\text { service PDS }\end{array}$ & $\begin{array}{l}\text { Surveys, PD evaluations, } \\
\text { professional journals, } \\
\text { interviews with staff }\end{array}$ \\
\hline & $\begin{array}{l}\text { 2.5. Seamless referrals } \\
\text { to the HJP from the } \\
\text { health service } \\
\text { 2.6. Demonstrated } \\
\text { improvement in } \\
\text { knowledge of what } \\
\text { each other does that } \\
\text { builds capacity to } \\
\text { identify and respond } \\
\text { to issues }\end{array}$ & $\begin{array}{l}\text { Referral numbers increasing, } \\
\text { surveys, PD evaluations, } \\
\text { professional journals, } \\
\text { interviews with staff } \\
\text { Documentations of meetings } \\
\text { and joint actions between } \\
\text { partners and outcomes } \\
\text { Submissions or letters on } \\
\text { policy matters undertaken by } \\
\text { HJP jointly }\end{array}$ \\
\hline
\end{tabular}


[Insert ANU logo and running head]

\section{Contact: Dr Liz Curran}

Senior Lecturer, ANU Legal Workshop (Australia-wide Professional Legal Training) \& Assoc. Director International Centre for the Profession, Education and Regulation in Law (PEARL), Australian National University, College of Law.

Mobile 0404106614

Email Liz.Curran@anu.edu.au

Canberra ACT 0200 Australia (Melbourne based)

www.anu.edu.au

CRICOS Provider No. 00120C. ORCID ID 0000-0002-6371-2975

\begin{tabular}{|c|c|c|}
\hline & $\begin{array}{l}\text { 2.7. Joint } \\
\text { collaborations on } \\
\text { systemic issues } \\
2.8 \text {. Enhanced skills } \\
\text { of partnering } \\
\text { professionals to both } \\
\text { identify legal } \\
\text { problems and to } \\
\text { advocate as } \\
\text { appropriate } \\
\text { 2.9. Adjust plans on } \\
\text { the basis of feedback } \\
\text { and changed } \\
\text { circumstances }\end{array}$ & $\begin{array}{l}\text { Joint actions or campaigns on } \\
\text { client issues or trends taken } \\
\text { between partner agencies to } \\
\text { make systemic change or } \\
\text { raise awareness } \\
\text { Media coverage } \\
\text { Implementation of reforms } \\
\text { suggested or references to } \\
\text { work undertaken by the HJP } \\
\text { on the specific issue; e.g., } \\
\text { Hansard, listed and referred to } \\
\text { in reports }\end{array}$ \\
\hline \multirow[t]{2}{*}{$\begin{array}{l}\text { 3. Increasing } \\
\text { seamlessness }\end{array}$} & $\begin{array}{l}\text { 3.1. 'Workarounds' / } \\
\text { action research } \\
\text { changes to service }\end{array}$ & $\begin{array}{l}\text { Professional journal, } \\
\text { interviews with staff }\end{array}$ \\
\hline & $\begin{array}{l}\text { 3.2. Referral system } \\
\text { developed and refined } \\
\text { 3.3. Regular referrals } \\
\text { 3.4. Improved } \\
\text { problem identification } \\
\text { and responsiveness } \\
\text { 3.5. Reports of non- } \\
\text { legal professional } \\
\text { staff enhanced } \\
\text { capacity } \\
\text { 3.6. Reports of non- } \\
\text { legal professional } \\
\text { staff use of } \\
\text { information provided } \\
\text { by legal partner } \\
\text { 3.7. Reports of } \\
\text { intention to change } \\
\text { practice }\end{array}$ & $\begin{array}{l}\text { Surveys, PD evaluations, } \\
\text { professional journals, } \\
\text { interviews with staff } \\
\text { Case studies from clients and } \\
\text { service providers } \\
\text { Interviews with management } \\
\text { Management support for } \\
\text { changes needed to support } \\
\text { services operation and } \\
\text { partnership. }\end{array}$ \\
\hline
\end{tabular}


[Insert ANU logo and running head]

\section{Contact: Dr Liz Curran}

Senior Lecturer, ANU Legal Workshop (Australia-wide Professional Legal Training) \& Assoc. Director International Centre for the Profession, Education and Regulation in Law (PEARL), Australian National University, College of Law.

Mobile 0404106614

Email Liz.Curran@anu.edu.au

Canberra ACT 0200 Australia (Melbourne based)

www.anu.edu.au

CRICOS Provider No. 00120C. ORCID ID 0000-0002-6371-2975

\begin{tabular}{|l|l|l|l|}
\hline & $\begin{array}{l}\text { 3.8. Reports of } \\
\text { changes in practice }\end{array}$ & & \\
\hline $\begin{array}{l}\text { 4. Senior } \\
\text { management } \\
\text { and the Board } \\
\text { have an } \\
\text { understanding } \\
\text { of }\end{array}$ & & $\begin{array}{l}\text { Interviews with relationship } \\
\text { holders and staff }\end{array}$ & \\
partnerships & & & \\
and are & & & \\
committed to \\
them at every & & & \\
level, from & & & \\
policies to & & & \\
individual & & & \\
interactions. & & & \\
\hline
\end{tabular}


[Insert ANU logo and running head]

Contact: Dr Liz Curran

Senior Lecturer, ANU Legal Workshop (Australia-wide Professional Legal Training) $\&$ Assoc. Director International Centre for the Profession, Education and Regulation in Law (PEARL), Australian National University, College of Law.

Mobile 0404106614

Email Liz.Curran@anu.edu.au

Canberra ACT 0200 Australia (Melbourne based)

www.anu.edu.au

CRICOS Provider No. 00120C. ORCID ID 0000-0002-6371-2975

\section{Appendix E - Tools and Questions}

[Designer: Please insert the PDF titled Appendix E.] 